Thiago Rubio

Phosphate glasses containing silver nanoparticles for applications in plasmonics

São Carlos, SP

July, 2021 

Thiago Rubio

\title{
Phosphate glasses containing silver nanoparticles for applications in plasmonics
}

\author{
Dissertation presented to the Graduate Pro- \\ gram in Chemistry at São Carlos Insti- \\ tute of Chemistry, University of São Paulo \\ (IQSC/USP) to obtain the degree of Master \\ of Science. \\ Concentration area: Analytical and Inorganic \\ Chemistry
}

University of São Paulo

São Carlos Institute of Chemistry

Advisor: Prof. Dr. Danilo Manzani

Exemplar revisado

O exemplar original encontra-se em

São Carlos, SP

July, 2021 
Rubio, Thiago

Phosphate glasses containing silver nanoparticles for applications in plasmonics / Thiago Rubio. - São Carlos, 2021.

$148 \mathrm{f}$.

Dissertação (Mestrado em Química Analítica e Inorgânica) - Instituto de Química de São Carlos / Universidade de São Paulo, 2021.

Edição revisada

Orientador: Prof. Dr. Danilo Manzani

1. Vidro. 2. Nanopartículas. 3. Espectroscopia Raman. 4. SERS. 5. Fotocatálise. I. Título. 
This work is dedicated to every black and LGBTQIA+ individual who did not have the opportunities to chase their dreams. 



\section{Acknowledgements}

Throughout my Masters course, I have received so much support and assistance, and I would like to acknowledge them.

I would like to thank my mother, Auxi, for all the support during my journey up to this moment. Mom, during all my ups and downs, you have been my lifeline. You are a strong, courageous woman, and every time I need a lighthouse to keep sailing towards my dream, I turn to you. My achievements are in gratitude for all your efforts.

I would also like to thank my sisters and my brother. Pamela, my eldest sister, you are brave. Your job put you in the frontlines of the battle against COVID-19. You have been through so much, but you keep battling because you love what you do, and you make your passion your mission. Samantha, my younger sister, you are fierce. You have not yet discovered what is your big dream, but you have an entire life ahead of you. This journey may seem a little scary sometimes, but I know that, when you find the path you truly want to follow, you will do it with utter determination and disposition. Thierry, my big brother, it has been a while since we last saw each other, but I know that, like me, you are bravely following your dreams with all your heart. You all inspire me, and I am very thankful for having you in my life.

In addition, I would like to thank Prof. Danilo Manzani, my advisor. Ever since I met you, I could see that you have this burning passion for Science and teaching. You truly love what you do. You welcomed me as your student, and thanks to you, I developed a strong passion for Inorganic Chemistry and Materials Science too.

I am thankful for my life Mentor, Daisaku Ikeda, and for my friends from Soka Gakkai (Society for Value Creation, SGI) Ikeda conveyed the teachings of Nichiren Buddhism to Brazil and the whole world, building a Humanism network that seeks the expansion of peace and friendship bonds among all humanity. Without the solid philosophical foundations that I obtained through the Buddhist practice and the unconditional support from my great friends from Youth Division and Taiyo Ongakutai (music ensemble), the hardship moments would be much harder.

I have so many people in my life who I can call friends. Every single one of you is special. The majority of my Masters was conducted during the COVID-19 pandemics, 
and even though sometimes I felt lonely or sad, I knew I was never alone. I can always reach you whenever I need to talk or to know that you are all bravely living through these times. Simply listing your names in this paragraph would not be enough to thank you all for being my friends. But I want you all to know I am very grateful, and you can count on me always.

I would like to thank the University of São Paulo (USP) and São Carlos Institute of Chemistry (IQSC) for the infrastructure offered, and all my colleagues from LaMIV (Laboratory of Inorganic and Vitreous Materials) for putting up with me and for helping me with many parts of my research. I am also thankful for all the collaborators that helped me to obtain and interpret the results acquired.

Lastly, I would like to acknowledge CNPq (Research grant 130645/2019-2), Fapesp (Research grant 2019/16230-1), and CAPES for the financial support. Those agencies are extremely vital for the progress of our country. Without funding, there is no science. 
"Não faz mal que seja pouco, o que importa é que o avanço de hoje seja maior que o de ontem. Que nossos passos de amanhã sejam mais largos que os de hoje.

Que sejam humanistas de braços fortes em luta solidária com as pessoas deserdadas.

Atuem agora e vivam o presente com a certeza de que neste exato instante está se erguendo o futuro." 



\section{Abstract}

Silver nanoparticles (Ag-NPs) are species that exhibit the surface plasmon resonance (SPR) effect. In this work, such plasmons were utilized in two different applications: the enhancement of Raman spectra via surface-enhanced Raman scattering (SERS), and the degradation of organic molecules using photocatalysis. To achieve these purposes, two novel glass compositions were synthesized, one using lead phosphate (PBTN), and other using sodium phosphate (NBTN). Both contain titanium oxide in their compositions, and the effect of the insertion of this compound on the thermal properties and chemical structure of the glasses was investigated through thermal analysis, Raman spectroscopy, X-ray diffraction, and photoluminescence spectroscopy. Silver nanoparticles were, then, synthesized on the surface of NBTN glasses using $\mathrm{Na}^{+} / \mathrm{Ag}^{+}$ion exchange followed by controlled thermal treatment, and electron microscopy techniques, alongside UV-visible spectroscopy were employed to confirm the synthesis. SERS experiments were conducted using crystal violet as analyte, and it was possible to detect it on the glass surface up to a lower limit of $10^{-6} \mathrm{~mol} / \mathrm{L}$ using NBTN-Ag120 sample. Photocatalysis tests were run using the glass samples in powder and bulk forms. The photodegradation of methylene blue was assessed. While in the former, $57.8 \%$ of degradation was obtained, in the latter, an even greater amount of dye was degraded, $77 \%$. In both cases, tests using no glass sample and using NBTN glass containing no Ag-NPs were conducted. It was proven that the vitreous substrate acts as a photocatalyst on its own. Moreover, the degradation percentage was greater when the nanoparticles were present in the material, showing that plasmonic mechanisms were responsible for the enhancement in the overall process. The solid materials developed during this work and herein presented are good candidates for devices in both fields of sensing and photocatalysis.

Keywords: phosphate glass, ion exchange, silver nanoparticles, plasmonics, SERS, photocatalysis. 



\section{Resumo}

Nanopartículas de prata (Ag-NPs) são espécies que exibem o efeito de ressonância plasmônica de superfície (SPR). No presente trabalho, estes plasmons foram utilizados em duas diferentes aplicações: a amplificação de sinais de espectros Raman por meio de espalhamento intensificado por superfície (SERS) e a degradação de moléculas orgânicas usando fotocatálise. Para alcançar esses objetivos, duas novas composições vítreas foram sintetizadas, uma usando fosfato de chumbo (PBTN), e outra usando fosfato de sódio (NBTN). Ambas contêm óxido de titânio em suas composições, e o efeito da inserção deste composto nas propriedades térmicas e na estrutura química dos vidros foi investigado por meio de análise térmica, espectroscopia Raman, difração de raios-X e espectroscopia de fotoluminescência. Nanopartículas de prata foram, então, sintetizadas na superfície dos vidros NBTN usando-se a troca iônica $\mathrm{Na}^{+} / \mathrm{Ag}^{+}$seguida de tratamento térmico controlado, e técnicas de microscopia eletrônica, junto à espectroscopia no UV/Visível, foram empregadas para confirmar tal síntese. Os experimentos de SERS foram conduzidos usando cristal violeta como analito, e foi possível detectá-lo na superfície dos vidros a um limite inferior de $10^{-6} \mathrm{~mol} / \mathrm{L}$ usando a amostra NBTN-Ag120. Os testes de fotocatálise foram realizados usando amostras de vidro na forma de pó e de monólito. A fotodegradação do azul de metileno foi avaliada. Enquanto na primeira forma, 57,8\% de degradação foi alcançada, na segunda, uma quantidade ainda maior de corante foi degradada, 77\%. Em ambos os casos, testes sem amostra vítrea e usando amostras de vidro sem Ag-NPs foram conduzidos. Foi constatado que o substrato vítreo atua sozinho como fotocatalisador. Além disso, foi mostrado que a porcentagem de degradação foi maior quando as nanopartículas estavam presentes no material, demonstrando que mecanismos plasmônicos foram responsáveis pela intensificação do processo de fotocatálise. Os materiais desenvolvidos durante este trabalho e aqui apresentados são bons candidatos a dispositivos em ambos os campos de sensores e fotocatálise.

Palavras-chaves: vidros fosfatos, troca iônica, nanopartículas de prata, plasmônica, SERS, fotocatálise. 



\section{List of Figures}

Figure 1 - Theoretical temperature-enthalpy plot emphasizing the glass transition phenomenon and its temperature.

Figure $2-$ (a) 2D Representation of a crystal of $\mathrm{Al}_{2} \mathrm{O}_{3}$; (b) 2D representation of a glass of the same composition. . . . . . . . . . . . . 34

Figure 3 - Plots of nucleation and crystal growth against temperature. Three

\begin{tabular}{|c|}
\hline different regions can be identified: (I) The nuclei are formed but do not \\
\hline
\end{tabular}
grow, (II) crystallization happens and (III) there is no nucleation, so there is no growth, even though it is possible. . . . . . . . . . . . 36

Figure 4 - Time-temperature-transformation curve for a generic glass-forming melt. 37

Figure 5 - Schemes showing the connectivity patterns in phosphate compounds and glasses. . . . . . . . . . . . . . . . . . . . . . . . . . . 38

Figure 6 - Lycurgus cup, depicting the death of King Lycurgus. The cup is a piece

\begin{tabular}{|c|}
\hline from 4th Century Roman Empire. The glass exhibits the dichroism \\
\hline effect due to silver and gold nanoparticles dispersed in it. In reflected \\
\hline light, it exhibits the color green, whilst in transmitted light, the color \\
\hline red. It is currently displayed at the British Museum in London. CBritish \\
\hline
\end{tabular}

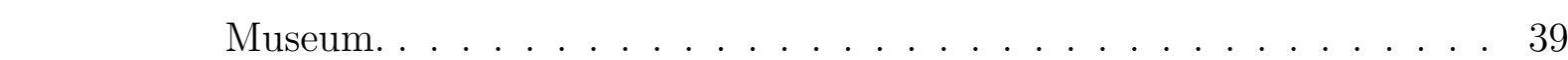

Figure 7 - Set of cups from the German Bohemian era made of cranberry glass. CC BY-SA 3.0, https://commons.wikimedia.org/w/index.php?curid=8946999. 40

Figure 8 - Localized surface plasmon illustration. . . . . . . . . . . . . . . . . 41

Figure 9 - UV-Vis absorption spectra of a solution of tetrachloroaurate ions and

\begin{tabular}{|c|}
\hline a suspension of gold nanoparticles. In the first case, the absorption is \\
\hline consequence of electronic transitions, while in the second, it is due to \\
\hline surface plasmon resonance.
\end{tabular}
surface plasmon resonance. . . . . . . . . . . . . . . . 42

Figure 10 - Illustration of the photocatalysis process. . . . . . . . . . . . . . . . 46

Figure 11 - Band gap energy values for some semiconductors employed as photocatalysts. . . . . . . . . . . . . . . . . . . 46

Figure 12 - Plasmonic photocatalysis mechanism. . . . . . . . . . . . . . . 47

Figure 13 - Solar radiation spectrum. The blue line shows the intensity of the incoming rays before entering Earth's atmosphere. Its gases absorb a great portion of the photons in the ultraviolet and infrared regions, therefore not reaching Earth's surface, and resulting in the red spectrum. 48

Figure 14 - (a) Fipronil and (b) Thiamethoxam structures. . . . . . . . . . . . . . 49

Figure 15 - Schematic of a heat flow calorimeter. . . . . . . . . . . . . . 53

Figure $16-$ General aspect of a DSC curve or thermogram. . . . . . . . . . . . . 54 
Figure 17 - General shape of the potential well of a molecule, considering the anharmonicity, and containing the vibrational energy levels. . . . . . . 56

Figure 18 - Energy diagrams showing the processes involved in Rayleigh, Stokes, and anti-Stokes scattering. . . . . . . . . . . . . . . 58 58

Figure 19 - Interaction volume between the electron beam and the sample, showing different results of the interaction. CC BY-SA 4.0. . . . . . . . . . 63

Figure 20 - Enhancement of the detection of Rhodamine $6 \mathrm{G}$ via SERS. The bottom spectrum is from an aqueous solution of rhodamine $6 \mathrm{G}$, and the top spectrum is from rhodamine in Ag colloidal suspension medium. . . . . 66

Figure 21 - DSC curves for lead phosphate systems. There is an increase in the characteristic temperatures with increasing amount of $\mathrm{B}_{2} \mathrm{O}_{3} . \ldots . .71$

Figure 22 - Raman spectra of PBTN glasses with $633 \mathrm{~nm}$ laser excitation. . . . . . 73

Figure 23 - Close-up views from PBTN Raman spectra comparing the normalized intensities of samples containing 10, 20 and $30 \mathrm{~mol} \%$ of $\mathrm{B}_{2} \mathrm{O}_{3}$. . . . . 73

Figure 24 - Diffractograms obtained from PBTN15 samples after heat treatments at the three crystallization temperatures identified in its DSC curve. . . 75

Figure 25 - Phase search results for the crystallized PBTN15 glass. . . . . . . . . . 75

Figure 26 - Difference in coloration of NBTN15 glass with $\mathrm{TiO}_{2}$ amount, mold/annealing

\begin{tabular}{|c|}
\hline temperature, melting temperature, and time of melting. In each set of \\
\hline
\end{tabular}
samples, the conditions that were not varied are fixed as $15 \mathrm{~mol} \% \mathrm{TiO}_{2}$, $450{ }^{\circ} \mathrm{C}, 1100^{\circ}$, and $30 \mathrm{~min}$. . . . . . . . . . . . . 77

Figure 27 - Photoluminescence spectra of NBTN15 sample melted at $1100{ }^{\circ} \mathrm{C}$ for 30 min and annealed at $450{ }^{\circ} \mathrm{C}$. . . . . . . . . . . . . . 78

Figure 28 - X-ray photoelectron spectra of the NBTN glass samples annealed at 350,400, and $450{ }^{\circ} \mathrm{C}$. . . . . . . . . . . . . . . . . . 79

Figure 29 - EPR spectra of the NBTN glass samples annealed at 350, 400, and 450

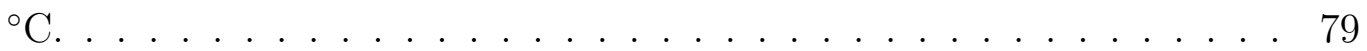

Figure 30 - DSC curves for sodium phosphate systems. Increasing titanium amounts yield higher crystallization temperatures in relation to lead phosphate glasses. . . . . . . . . . . . . . . . 80

Figure 31 - Raman spectra of NBTN glasses with $633 \mathrm{~nm}$ excitation laser. . . . . . 81

Figure 32 - Close-up views from NBTN Raman spectra comparing the normalized intensities of samples containing 10, 15 and $20 \mathrm{~mol}_{\%}$ of $\mathrm{TiO}_{2}$. . . . . . 82

Figure 33 - NBTN15 glass samples after ion exchange and thermal treatment. . . . 83

Figure 34 - NBTN20 glass samples before and after ion exchange and thermal treatment. . . . . . . . . . . . . . . . . . . . 8 84

Figure 35 - UVVis-NIR absorption spectra for ion exchanged and thermally treated NBTN15 sample. . . . . . . . . . . . . . . . 85 
Figure 36 - Backscattered electrons images, EDX mappings and line scans of Ag on the cross section of the samples. The values in the bottom are the calculated layer depths of silver on the surface of the samples. . . . . . 86

Figure 37 - Transmitted electrons images of NBTN15 bulk samples containing AgNPs on the surface treated with (a) 30min ion exchange, (b) 60min ion exchange, and (c) 120min ion exchange. . . . . . . . . . . . . . . . 88

$\begin{array}{r}\hline \text { exchange, and (c) } 120 \text { min ion exchange. } \\ \hline\end{array}$

Figure 38 - Glass powders obtained after ion exchange (above) and thermal treat-

\begin{tabular}{|l|}
\hline ment processes (below). The first sample corresponds to the original \\
\hline
\end{tabular}

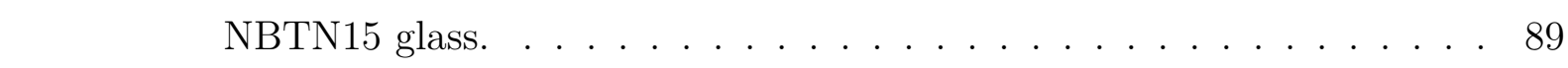

Figure 39 - UV/Vis diffuse reflectance spectra of NBTN-Ag samples (a) after ion exchange only and (b) after ion exchange and thermal treatment. . . . 90

Figure 40 - Transmitted electrons images of powdered glass samples containing Ag-NPs (a) 120IE and (b) 120TT. . . . . . . . . . . . . . . . . . . 91

Figure 41 - Raman spectra of NBTN-Ag120 sample before and after contact with droplets of fipronil 1000ppm in acetone. The spectrum of fipronil standard is shown as reference (in black). . . . . . . . . . . . . . . . . 94

Figure 42 - Raman spectra of NBTN-Ag120 sample before and after contact with droplets of thiamethoxam 1000ppm in acetonitrile. The spectrum of thiamethoxam standard is shown as reference (in black). . . . . . . . . 95

Figure 43 - Raman spectra of NBTN-Ag120 sample before and after contact with \begin{tabular}{|c|}
\hline droplets of 2,2'-bipiridine 900ppm in ethanol. The spectrum of $2,2^{\prime}-$ \\
\hline bipiridine standard is shown as reference (in blue). . . . . . . . . . . 96
\end{tabular}

Figure 44 -Crystal violet structure. . . . . . . . . . . . . . . . . . . 97

Figure 45 - SERS detection of crystal violet in concentrations $10^{-3}, 10^{-4}, 10^{-5}$, and $10^{-6} \mathrm{~mol} \mathrm{~L}^{-1}$ on the surface of glass samples decorated with $\mathrm{Ag}-\mathrm{NPs}$ \begin{tabular}{|r}
\hline with ion exchange bath times of 30,60 , and $120 \mathrm{~min}$. \\
\hline
\end{tabular}

Figure 46 - Non-scaled spectra for comparison of the effect of surface interaction with the glass samples on the intensity of the signals of $\mathrm{CV} 10^{-4} \mathrm{~mol}$ $\mathrm{L}^{-1}$. Appendix $\mathrm{C}$ contains this comparison for the other concentrations

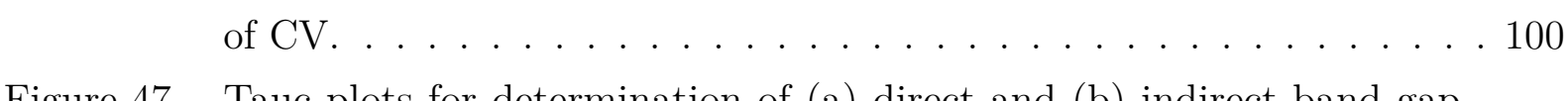

Figure 47 - Tauc plots for determination of (a) direct and (b) indirect band gap energies of NBTN-Ag bulk samples. . . . . . . . . . . . . . . 102

Figure 48 - Tauc plots for determination of direct (a and c) and indirect (b and d) band gap energies of powder glass samples after ion exchange only (a and b) and after ion exchange and thermal treatment (c and d). . . . . 103

Figure 49 - Methylene blue structure. . . . . . . . . . . . . . . . . . . . . . 104

Figure 50 - Adsorption curve for 60IE sample suspended in an aqueous solution of

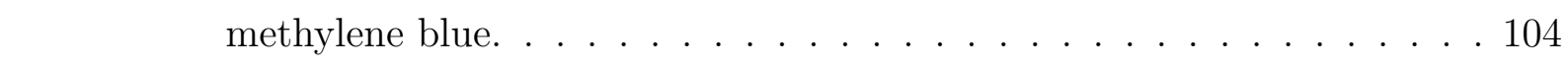

Figure 51 - Experimental setup of the photocatalysis tests in dispersion. . . . . . . 105 
Figure 52 - Photodegradation curves of methylene blue. From top to bottom, each plot shows the experiments with the samples of 30, 60, 90, and 120 min ion exchange baths, with and without thermal treatment. The photodegradation curves using no glass and a blank sample (glass with no Ag-NPs) are showed as control. . . . . . . . . . . . . . . 106

Figure 53 - Photodegradation curves of methylene blue. Each curve refers to the experiments using no glass sample (only the degradation by light is observed), using NBTN15 without Ag-NPs, and the NBTN-Ag120 sample.108

Figure 54 - Photodegradation curves of methylene blue. Each curve refers to the experiments using no glass sample (only the degradation by light is observed), using NBTN15 without Ag-NPs, NBTN-Ag90, and NBTNAg120. . . . . . . . . . . . . . . . . . 109

Figure 55 - 30 min ion exchanged sample back-scattered electrons image, 150x magnification. . . . . . . . . . . . . . . . . . . . 121

Figure 56 - 30 min ion exchanged sample back-scattered electrons image, 1000x magnification. . . . . . . . . . . . . . . . 122

Figure 57 - 30 min ion exchanged sample back-scattered electrons image, 10000x magnification. . . . . . . . . . . . . . . . . . . 122

Figure 58 - EDX line scans for oxygen, sodium, phosphorus, titanium, and silver for the $30 \mathrm{~min}$ ion exchanged sample. Line width: $351 \mu \mathrm{m}$. . . . . . . . . 123

Figure 59 - 60 min ion exchanged sample back-scattered electrons image, 150x magnification. . . . . . . . . . . . . . . . . . . . 123

Figure 60 - 60 min ion exchanged sample back-scattered electrons image, 1000x magnification. . . . . . . . . . . . . . . . 124

Figure $61-60$ min ion exchanged sample back-scattered electrons image, 10000x magnification. . . . . . . . . . . . . . . . 124

Figure 62 - EDX line scans for oxygen, sodium, phosphorus, titanium, and silver for the 60 min ion exchanged sample. Line width: $363 \mu \mathrm{m}$. . . . . . . . . 125

Figure 63-90 min ion exchanged sample back-scattered electrons image, 150x magnification. . . . . . . . . . . . . . . 125

Figure 64 - 90 min ion exchanged sample back-scattered electrons image, 1000x magnification. . . . . . . . . . . . . . . 126

Figure 65 - 90 min ion exchanged sample back-scattered electrons image, 10000x magnification. . . . . . . . . . . . . . 126

Figure 66 - EDX line scans for oxygen, sodium, phosphorus, titanium, and silver for the 90 min ion exchanged sample. Line width: $351 \mu \mathrm{m}$. . . . . . . . . 127

Figure 67 - 120 min ion exchanged sample back-scattered electrons image, 150x magnification. . . . . . . . . . . . . . . 127 
Figure 68 - 120 min ion exchanged sample back-scattered electrons image, 1000x magnification. . . . . . . . . . . . . . . . . . . . 128

Figure 69 - 120 min ion exchanged sample back-scattered electrons image, 10000x magnification. . . . . . . . . . . . . . . . . . 128

Figure 70 - EDX line scans for oxygen, sodium, phosphorus, titanium, and silver for the 120 min ion exchanged sample. Line width: $341 \mu \mathrm{m}$. . . . . . . . 129

Figure 71 - 30 min ion exchanged sample transmitted electrons image. . . . . . . . 131

Figure 72 - 30 min ion exchanged sample transmitted electrons image. . . . . . . . 132

Figure 73 - 30 min ion exchanged sample transmitted electrons image. . . . . . . . 132

Figure 74 - EDX maps of NBTN-Ag30 sample for oxygen, sodium, phosphorus, titanium, and silver. . . . . . . . . . . . . . . . . . . 133

Figure 75 - 60 min ion exchanged sample transmitted electrons image. . . . . . . . 133

Figure 76 - 60 min ion exchanged sample transmitted electrons image. . . . . . . . 134

Figure 77 - 60 min ion exchanged sample transmitted electrons image. . . . . . . . 134

Figure 78 - 60 min ion exchanged sample transmitted electrons image. . . . . . . . 135

Figure 79 - EDX maps of NBTN-Ag60 sample for oxygen, sodium, phosphorus, titanium, and silver. . . . . . . . . . . . . . . 135

Figure 80 - 120 min ion exchanged sample transmitted electrons image. . . . . . . 136

Figure 81 - 120 min ion exchanged sample transmitted electrons image. . . . . . . 136

Figure 82 - 120 min ion exchanged sample transmitted electrons image. . . . . . . 137

Figure 83 - 120 min ion exchanged sample transmitted electrons image. . . . . . . 137

Figure $84-120$ min ion exchanged sample transmitted electrons image. . . . . . . 138

Figure 85 - EDX maps of NBTN-Ag120 sample for oxygen, sodium, phosphorus, titanium, and silver. . . . . . . . . . . . . . . . . . 138

Figure 86 - Transmitted electrons image of powdered glass sample with 120 min of ion exchange bath. . . . . . . . . . . . . . . . . . . . . . 139

Figure 87 - Transmitted electrons image of powdered glass sample with 120 min of ion exchange bath. . . . . . . . . . . . . . . . . . 139

Figure 88 - Transmitted electrons image of powdered glass sample with 120 min of ion exchange bath. . . . . . . . . . . . . . . . . . 140

Figure 89 - Transmitted electrons image of powdered glass sample with 120 min of ion exchange bath. . . . . . . . . . . . . . . . 140

Figure 90 - EDX maps of powdered glass sample with 120 min of ion exchange bath for oxygen, sodium, phosphorus, titanium, and silver. . . . . . . . . . 141

Figure 91 - Transmitted electrons image of powdered glass sample with $120 \mathrm{~min}$ of ion exchange bath and 10 min of thermal treatment at $T_{g}+10^{\circ} \mathrm{C}$. . . . 141

Figure 92 - Transmitted electrons image of powdered glass sample with 120 min of ion exchange bath and 10 min of thermal treatment at $T_{g}+10^{\circ} \mathrm{C}$. . . 142 
Figure 93 - Transmitted electrons image of powdered glass sample with 120 min of ion exchange bath and $10 \mathrm{~min}$ of thermal treatment at $T_{g}+10^{\circ} \mathrm{C}$. . . . 142

Figure 94 - EDX maps of powdered glass sample with 120 min of ion exchange bath and 10 min of thermal treatment at $T_{g}+10^{\circ} \mathrm{C}$ for oxygen, sodium, phosphorus, titanium, and silver. . . . . . . . . . . . . . 143

Figure 95 - Raw data of SERS experiments on NBTN-Ag30 sample. . . . . . . . 145

Figure 96 - Raw data of SERS experiments on NBTN-Ag60 sample. . . . . . . . 146

Figure 97 - Raw data of SERS experiments on NBTN-Ag120 sample. . . . . . . . 146

Figure 98 - Raw data of Raman experiments on NBTN sample that does not contain Ag-NPs. . . . . . . . . . . . . . . . . . . . . . 147

Figure 99 - Non-scaled spectra for comparison of the effect of surface interaction with the glass samples on the intensity of the signals of CV $10^{-3} \mathrm{~mol} \mathrm{~L}^{-1}$. 147

Figure 100-Non-scaled spectra for comparison of the effect of surface interaction with the glass samples on the intensity of the signals of CV $10^{-5} \mathrm{~mol} \mathrm{~L}^{-1}$. 148 


\section{List of Tables}

Table 1 - Lead phosphate glass compositions, densities, and appearance . . . . . . 70

Table 2 - Characteristic temperatures for PBTN glasses . . . . . . . . . . . . . . 71

Table 3 - Assignment of bands for PBTN Raman spectra . . . . . . . . . . . . . . 72

Table 4 - Sodium phosphate glass compositions, densities, and appearance . . . . 76

Table 5 - Characteristic temperatures for NBTN glasses . . . . . . . . . . . . 80

Table 6 - Assignment of bands for NBTN Raman spectra . . . . . . . . . . . . . . 82

Table 7 - Band assignment for solid fipronil Raman spectrum . . . . . . . . . . . 94

Table 8 - Band assignment for solid thiamethoxam Raman spectrum . . . . . . . 95

Table 9 - Band assignment for solid 2,2'-bipyridine Raman spectrum . . . . . . . 96

Table 10 - Band assignment for solid crystal violet Raman spectrum . . . . . . . . 99

Table 11 - Optical band gap energies for NBTN-Ag bulk samples . . . . . . . . . . 102

Table 12 - Optical band gap energies for NBTN-Ag powdered samples . . . . . . . 103

Table 13 - Percentage of degradation of methylene blue in solution using NBTN glass powders after $1 \mathrm{~h}$ of irradiation with light . . . . . . . . . . . 107 



\section{List of abbreviations and acronyms}

Ag-NP Silver nanoparticle

bipy 2,2'-Bipyridine

CV Crystal violet

DSC Differential scanning calorimetry

EDX Energy-dispersive X-ray spectroscopy

EPR Electron paramagnetic resonance spectroscopy

fpn Fipronil

FTIR Fourier transform infrared absorption spectroscopy

LSP Localized surface plasmon

MB Methylene blue

NMR Nuclear magnetic resonance spectroscopy

NP Nanoparticle

SEM Scanning electron microscopy

SERS Surface-enhanced Raman scattering

SPR Surface plasmon resonance

TEM Transmission electron microscopy

tmx Thiamethoxam

XPS X-ray photoelectron spectroscopy

XRD X-ray diffractometry 



\section{Contents}

Glass and photocatalysis: introduction . . . . . . . . . . . . . . 27

1 GLASS AS A TECHNOLOGY . . . . . . . . . . . . . . . . . . . . 29

1.1 Glass: the first material . . . . . . . . . . . . . . . . . . . . . 29

$1.2 \quad$ Glass and optical devices . . . . . . . . . . . . . . . . . . 29

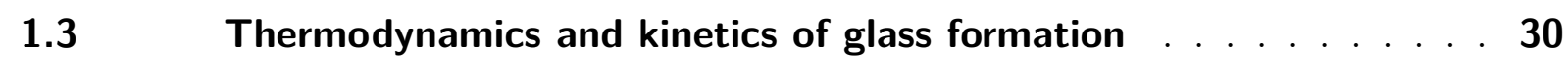

$1.4 \quad$ Glass structure and glass forming theories . . . . . . . . . . . . . 33

$1.5 \quad$ Structural connectivity in phosphate glasses . . . . . . . . . . . . . 37

2 METAL NANOPARTICLES . . . . . . . . . . . . . . . . . 39

$2.1 \quad$ Nanotechnology . . . . . . . . . . . . . . . . . . . . . . 39

$2.2 \quad$ Synthesis of metallic nanoparticles . . . . . . . . . . . . . . . . . 40

$2.3 \quad$ Surface plasmon resonance . . . . . . . . . . . . . . . . . 41

$2.4 \quad$ Nanoparticles in glasses . . . . . . . . . . . . . . . . . . . 42

3 PHOTOCATALYSIS . . . . . . . . . . . . . . . . 45

$3.1 \quad$ Photocatalysis principles . . . . . . . . . . . . . . . 45

$3.2 \quad$ Glasses as photocatalysts . . . . . . . . . . . . . . . . 45

3.3 Plasmonics: going further . . . . . . . . . . . . . . . . 47

4 MOTIVATION AND OBJECTIVES . . . . . . . . . . . . . . . . . . 49

$4.1 \quad$ Emerging pollutants . . . . . . . . . . . . . . . . 49

$4.2 \quad$ General objectives . . . . . . . . . . . . . . . . . . . . . . 50

5 CHARACTERIZATION TECHNIQUES . . . . . . . . . . . . . 53

$5.1 \quad$ Differential Scanning Calorimetry . . . . . . . . . . . . . 53

$5.2 \quad$ Spectroscopy . . . . . . . . . . . . . . . . . 54

$5.2 .1 \quad$ Infrared absorption spectroscopy (vibrational spectroscopy) . . . . . . . . . 55

$5.2 .2 \quad$ Raman scattering spectroscopy . . . . . . . . . . . . . . . . . . 56

$5.2 .3 \quad$ Ultraviolet/visible absorption and photoluminescence spectroscopy (elec-

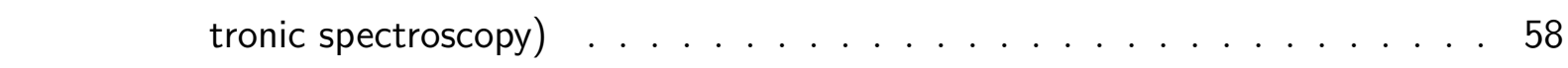

$5.2 .4 \quad$ X-ray photoelectron spectroscopy . . . . . . . . . . . . . . . . 60

$5.2 .5 \quad$ Resonance spectroscopy (nuclear magnetic resonance and electron paramagnetic resonance $) \ldots \ldots \ldots$. . . . . . . . . . . . 60

$5.2 .6 \quad$ Experimental setups . . . . . . . . . . . . . . . . 61

$5.3 \quad$ X-ray diffraction $\ldots \ldots \ldots \ldots \ldots \ldots$

$5.4 \quad$ Electron microscopy $\ldots \ldots \ldots$. . . . . . . . . . . . 63 
$5.4 .1 \quad$ Scanning electron microscopy $\ldots \ldots \ldots \ldots 64 \ldots \ldots \ldots$

$5.4 .2 \quad$ Transmission electron microscopy $\ldots \ldots \ldots \ldots 64 \ldots \ldots$

$5.4 .3 \quad$ Energy-dispersive X-ray spectroscopy. . . . . . . . . . . . . . . . . . . 64

$5.5 \quad$ Surface-enhanced Raman scattering . . . . . . . . . . . . . 65

$5.5 .1 \quad$ Enhancement factors $\ldots \ldots \ldots 6 . \ldots \ldots 6$

5.5 .2 Determination of signals enhanced by SERS . . . . . . . . . . . . 67

6 GLASS SYNTHESIS AND CHARACTERIZATION . . . . . . 69

$6.1 \quad$ Lead phosphate glass system $\ldots \ldots \ldots$. . . . . . . . 69

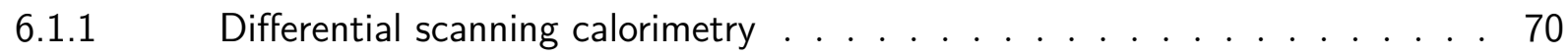

$6.1 .2 \quad$ Raman spectroscopy $\ldots \ldots \ldots$. . . . . . . . . . . . . . . 72

$6.1 .3 \quad$ Crystallization essays and X-ray diffractometry $\ldots \ldots \ldots \ldots$

$6.2 \quad$ Sodium phosphate glass system $\ldots \ldots \ldots \ldots$

$6.2 .1 \quad$ Photoluminescence spectroscopy . . . . . . . . . . . . . . . . . . . 77

$6.2 .2 \quad$ X-ray photoelectron spectroscopy and electron paramagnetic resonance

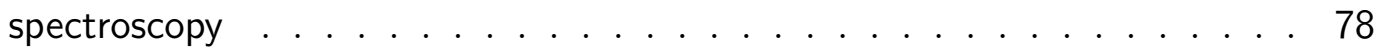

6.2 .3 Differential scanning calorimetry . . . . . . . . . . . . . . . 80

$6.2 .4 \quad$ Raman spectroscopy $\ldots \ldots \ldots \ldots 1$

$6.3 \quad$ lon exchange $\ldots \ldots \ldots . \ldots \ldots$

$6.3 .1 \quad$ Appearance and UV-Vis spectroscopy $\ldots \ldots \ldots$. . . . . . . . . 84

$6.3 .2 \quad$ Scanning electron microscopy and energy-dispersive $X$-ray analysis . . . . 85

$6.3 .3 \quad$ Transmission electron microscopy $\ldots \ldots$. . . . . . . . . . 87

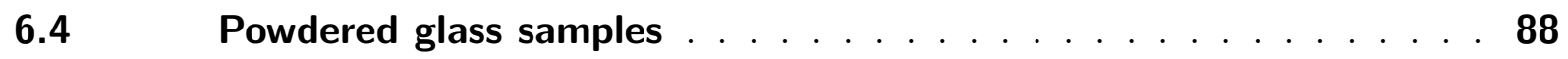

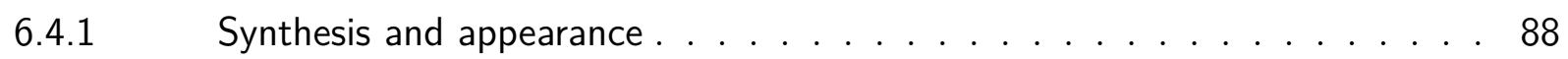

$6.4 .2 \quad$ UV-Vis spectroscopy $\ldots \ldots \ldots 9$

$6.4 .3 \quad$ Transmission electron microscopy $\ldots \ldots \ldots$. . . . . . . . . . 90

7 SERS AND PHOTOCATALYTIC ACTIVITY . . . . . . . . . 93

7.1 SERS detection of fipronil, thiamethoxam, and 2,2'-bipyridine: pre-

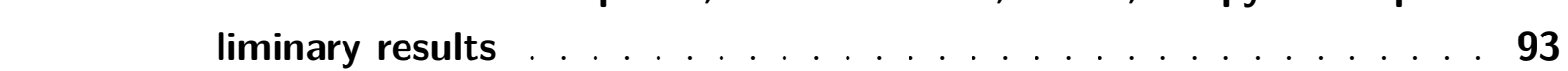

$7.2 \quad$ SERS detection of crystal violet $\ldots \ldots \ldots 7$

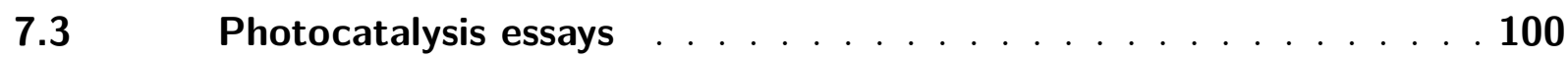

$7.3 .1 \quad$ Optical band gap . . . . . . . . . . . . . . . . . . . . . . . . 101

7.3.2 Photodegradation study of methylene blue: dispersion method . . . . . . 104

$7.3 .3 \quad$ Photodegradation study of methylene blue: bulk method . . . . . . . . 107

8 CONCLUSION $\ldots \ldots \ldots \ldots \ldots \ldots \ldots \ldots \ldots \ldots$

REFERENCES $\ldots \ldots \ldots \ldots \ldots \ldots \ldots \ldots \ldots \ldots$ 
APPENDIX A SEM IMAGES AND EDX RESULTS . . . . . . . 121

APPENDIX B TEM IMAGES AND EDX RESULTS . . . . . . . 131

APPENDIX C CRYSTAL VIOLET SERS RAW DATA . . . . . . 145 



\section{Glass and plasmonics: introduction}

In the same sense that photonics corresponds to the study of manipulation of photons and their interaction with matter, plasmonics refers to the study of plasmons, the collective oscillation of outer shell electrons in metallic structures, and their applications. Metals are the most common type of material in which plasmons are studied, and there are two different effects that arise from the interaction between electromagnetic radiation and plasmons: surface plasmon polaritons (SPP) and localized surface plasmons (LSP). SPPs are the propagation of an electromagnetic wave in the metal-dielectric medium interface and occur on flat surfaces of macroscopic metals. On the other hand, LSPs occur on the surface of nanoparticles and are non-propagating due to the dimensions of these materials. When the interacting radiation wavelength is resonant with the LSP of the nanoparticles in study, the former is absorbed, and the result is an increase in the amplitude of the oscillation of the surface electron density [1].

Plasmonics, albeit not being recent, is currently a rapidly growing research field, due to the simplicity and ready availability of methods of material synthesis and to its wide range of applications, such as solar cells [2, 3], plasmonic waveguides [4], and imaging [5]. Sensing is one of the main areas where plasmonics is employed. The localized surface plasmons of metal nanoparticles are responsible for the enhancement of signals in Raman scattering and luminescence spectra. Hence, SERS is a very powerful tool in the detection of compounds in small concentrations.

Glass is a strong candidate for active substrate for both SERS and photocatalysis due to its facile synthesis and easy shaping and large-scale production. Nanoparticles must be synthesized inside the glass, so it can be employed in SERS experiments. This imposes another advantage: the nanoparticles need not be stabilized as they are in liquid suspensions. When they are on the glass surface, they can be in direct contact with the analyte, and the interaction may happen without competition with stabilizing agents.

Nanoparticles are used in glasses since Antiquity. Gold nanoparticles, for example, were used to give glass a red tint for decorative purposes. However, there are much broader applications in technology currently being studied. Quantum dots doped glass systems are largely studied due to their promising full emissions in the visible spectrum for application in light-emitting devices [6, 7]. Metallic nanoparticles, in turn, can be inserted 
into glasses for many optics-related uses, ranging from simple mirrors, solar concentrators, and photovoltaic devices for energy generation [8] to nonlinear optical properties studies of glass systems [9], SPR based sensors [10], and enhancement of luminescence of rare earth ions [11].

In the photocatalysis context, metal nanoparticles can be used to harvest visible radiation via their localized surface electron resonance and then excite charge carriers (electron-hole pairs) to drive chemical reactions. It is an interesting approach because the excitation wavelengths can be tuned by controlling the size, shape, species of nanoparticles, and the medium they are inserted [12]. Plasmonic photocatalysis is researched in either suspension or semiconducting media [13, looking to increase performance of water-splitting reactions as a potential solution to the global energy crisis [14].

Moreover, the target molecules of this project are organic compounds classified as emerging pollutants. These chemicals are a nuisance for entire ecosystems when they reach water streams, and they cannot be treated by wastewater treatments currently in use. Some examples of emerging pollutants include pesticides and dyes.

Attempting to perform plasmonic photocatalysis on the surface of glasses is a daring challenge, but if such attempt is proven successful, it will be a major step towards green solutions for clean energy generation and emerging pollutants, great problems that the world is currently facing. 


\section{CHAPTER 1}

\section{Glass as a technology}

\subsection{Glass: the first material}

Glass is widely known for its transparency, shine, and durability. These properties make glass one of the first materials to be exploited by early civilizations millennia ago. It can be found in nature in the form of obsidian, tektites, and fulgurites, for example. But it started to be fabricated by humans very early in history. Ancient Egyptians are known to melt raw materials to produce glass for decoration pieces [15].

Domestic utensils, such as plates and cups, windows, chandeliers, and many other decoration objects are present in the daily lives of many people. From greenhouses to lightbulbs, glass found other applications beyond decoration based on its properties [16].

Most glass objects and instruments have silica or sand $\left(\mathrm{SiO}_{2}\right)$ as raw material. Some other compounds may be added to the composition to reach some desired properties, as is the case with lead glass, which has high refractive index and brilliance; due to this, glassware made of lead glass was erroneously called "crystal". Other types of silica-based glass include the borosilicate glass used in laboratory glassware due to its higher chemical resistance, and the aluminosilicate glass used in halogen lamps [17].

\subsection{Glass and optical devices}

One of the main technological applications of glass is in optical devices. Ranging from mirrors and reflective surfaces to telescope and microscope lenses and optical fibers, different glass compositions have been developed and studied to adjust their properties according to the desired application.

Its wide use in optical devices made glass less of a decorative use material to become a subject of study and research in science and technology. Besides mirrors and lenses, glass 
can be used as a waveguide or as part of optical probes, in solid-state lasers, luminescent screens and the widely known optical fibers used in telecommunications systems.

These applications expanded the research in glass science beyond the well-known silicate glass to other classes such as tellurite $\left(\mathrm{TeO}_{2}\right.$-based $)$, phosphate $\left(\mathrm{P}_{2} \mathrm{O}_{5}\right.$-based $)$, vanadate $\left(\mathrm{V}_{2} \mathrm{O}_{5}\right.$-based), chalcogenide (sulfide and selenide-based, for example), halide ( $\mathrm{F}^{-}$-based, for example) and even metallic glass [17].

\subsection{Thermodynamics and kinetics of glass formation}

Glass can be defined in many ways depending on the approach and concepts adopted by each author. A more archaic concept is to say that glass is a transparent solid obtained by fast-cooling a melt. This concept, however, does not suffice to define what glass really is. Among all definitions of glass found in literature, two will be highlighted:

- "Glass is a non-crystalline solid that exhibits the glass transition phenomenon" (J. Zarzycki) [18]

- "Glass is a solid having a non-crystalline structure, which continuously converts to a liquid upon heating" (A. Varshneya) [17]

The first one, even though being succinct, requires a further explanation of the term "glass transition". Albeit a fundamental phenomenon in glass science studies, it can be withdrawn from glass definition, as it is done, in an elegant fashion, by Varshneya.

A more complete definition is given by Zanotto, which explores all its fundamental characteristics: "Glass is a nonequilibrium, non-crystalline condensed state of matter that exhibits the glass transition phenomenon, whose structure is similar to its parent supercooled liquid, and whose fate is to spontaneously relax towards this state and, in the limit of infinite time, to crystallize." [19]

In all these definitions, a clear distinction is made between glass and crystalline solids, in a manner that the word "solid" is avoided in the last statement in order to structurally oppose crystals and glasses. The main characteristic of a crystal is the longrange order of atoms in symmetrically repeated structures called lattices [20]. Although maintaining a short-range order, glasses lack symmetry and lattice arrangement.

To understand the definition of glass transition, it is necessary to observe the behavior of the enthalpy of a substance with temperature: the lower the temperature, the lower its enthalpy; when a phase transition occurs, there is a break in the continuity of the curve (in order for the transition to happen); when it is a solid-liquid transition, the break corresponds to $T_{m}$, the melting temperature of the substance. This can be seen in 
Figure 1: when the temperature is decreased from A to B, the substance crystallizes at $T m$, and its enthalpy drops from B to C; lower temperatures yield lower enthalpies (C to D). When crystallization is prevented after the material reaches $T m$, the substance goes to a state known as supercooled liquid (SCL). This is not a phase transition since there is no discontinuity, and is represented in Figure 1 by the line going from B to E. Decreasing the temperature in the SCL state yields an increasing viscosity, to an extent that the atoms "freeze" and there is a change in the rate of enthalpy variation (point E in the graph). This is the so-called vitreous state: the supercooled liquid turned into a glass (line from $\mathrm{E}$ to $\mathrm{F}$ ).

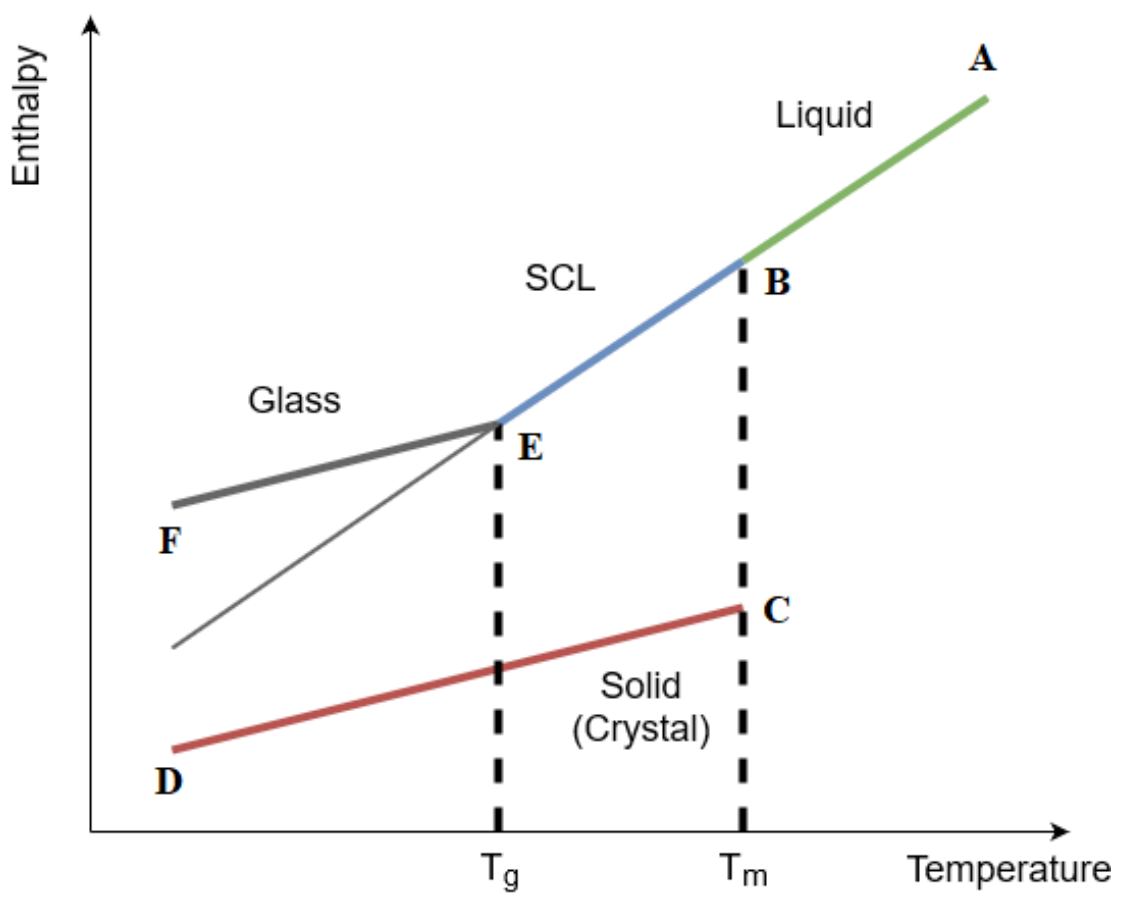

Figure 1 - Theoretical temperature-enthalpy plot emphasizing the glass transition phenomenon and its temperature.

Glass transition is the phenomenon through which the viscosity of a material in the supercooled liquid state increases to an extent that its particles cannot rearrange themselves and there is a change in the rate of enthalpy variation (in fact, this is true for any state function dependent on temperature: volume, entropy, Gibbs energy). It is not a phase transition.

The glass transition is defined based on the rate of change of a property (enthalpy, for example). Hence, it can be better explained in kinetic terms. Furthermore, it cannot be defined by an exact temperature value. It is rather a temperature range, and its value changes according to the rate of temperature decrease: the faster the supercooled liquid is cooled, the higher will be the glass transition temperature.

The viscosity $\eta$ of a fluid (a glass-forming melt, for example) is described by the 
equation

$$
F=\eta A \frac{d v}{d x}
$$

in a situation where the fluid flows in layers in the x-direction. $F$ is the force acting between the layers, $A$ is the surface area of the layers and $v$ is the velocity of the fluid. The temperature dependence of viscosity follows the equation

$$
\eta=\eta_{0} \exp \left(\frac{U_{0}}{k_{B} T}\right)
$$

where $\eta_{0}$ is a constant and $U_{0}$ is the enthalpy of activation of the viscous flow [16]. This equation shows that a lower temperature yields a higher viscosity. Hence, decreasing the temperature of a supercooled liquid will invariantly increase its viscosity. If this decrease is performed to avoid the crystallization, the viscosity will tend to infinity, $\eta \rightarrow \infty$.

Phase transitions happen at fixed temperature-pressure pairs, with its phases in equilibrium. Therefore, the chemical potentials across the transition must equal, $\mu_{j, L}=\mu_{j, M}$. The chemical potential dependences with temperature and pressure are derived from the fundamental equation of chemical thermodynamics $(d \mu=V d P-S d T)$ and correspond to, respectively

$$
\begin{gathered}
\frac{\partial \mu}{\partial T}=-S \\
\frac{\partial \mu}{\partial P}=V
\end{gathered}
$$

From these relationships arises the Clausius-Clapeyron equation,

$$
\frac{d P}{d T}=\frac{\Delta S_{t r}}{\Delta V_{t r}}=\frac{\Delta H_{t r}}{T \Delta V_{t r}}
$$

that defines a phase transition in a temperature-pressure plot (phase diagram).

A transition $L \rightarrow M$ can be called a phase transition if the first or second derivative of the equation $\mu_{j, L}=\mu_{j, M}$ is not continuous. From the equations 1.3 and 1.4 , the following equations can be derived

$$
\begin{gathered}
\frac{\partial \mu_{L}}{\partial P}-\frac{\partial \mu_{M}}{\partial P}=\Delta V_{t r} \\
\frac{\partial \mu_{L}}{\partial T}-\frac{\partial \mu_{M}}{\partial T}=-\frac{\Delta H_{t r}}{T_{t r}} .
\end{gathered}
$$

For first-order phase transitions (crystallization, vaporization), $\Delta V_{t r}$ and $\Delta H_{t r}$ are nonzero, meaning that the slopes of the curve at each side of the transition are different, and the curve is, therefore, discontinuous. The same approach can be verified for second-order phase transitions (crystal phase transition), where the second derivatives are non-zero [21].

Even though the glass transition shown in Figure 1 may seem discontinuous, it is just a simplification. In reality, the curve in the temperature-enthalpy plot is smooth, 
making the curve from SCL to glass continuous [22, 17]. This fact can be used to explain the use of the expression "nonequilibrium state" in the definition of glass. The glass transition is not a phase transition, and therefore, involves states that are not in equilibrium.

Being in a nonequilibrium state means that glasses will be converted to their most stable form. In other words, the glass will relax towards the supercooled liquid and the crystalline solid, respectively, at a given temperature, after an interval of time. That said, the structural relaxation time $\tau$ is defined as

$$
\tau=\frac{\eta(T)}{G_{0}}
$$

in which $G_{0}$ is the shear modulus (measurement of the response of a material to shear stress, the force applied in the same plane of its cross section).

The glass transition can be more precisely defined as the phenomenon at which the observed time of cooling of a supercooled liquid, $t_{\exp }$ (time of observation of the cooling experiment), is in the same order of magnitude as the structural relaxation time, $\tau$ [19]. Furthermore, in order to induce glass forming, $t_{\exp }<<\tau$, in a manner that the cooling rate must be high enough to "freeze" the particles in the liquid state. Otherwise, if $t_{\text {exp }}>>\tau$ the material will follow the path of crystallization.

The structural relaxation time is a function of viscosity, which, in turn, is a function of temperature. Depending on the initial temperature of a glass-forming melt, its $\tau$ will be different. Hence, the glass transition does not happen at a fixed temperature, but it varies according to that initial temperature and the cooling rate. A larger cooling rate yields a higher value for the glass transition temperature $T_{g}$.

\subsection{Glass structure and glass forming theories}

The glass structure differs from its analogous crystal structure in the fact that it lacks long-range order and repetition of a defined lattice. Zachariasen was one of the first to describe the structure of glass [23]. Figure 2 shows his representation of a crystal and a glass of same composition. Clearly, there is a short-range order in both cases, but in the second one, such order is lost due to differences in bond lengths and angles.

Zachariasen then proposed in his paper four rules for glass formation in oxides (with composition $\mathrm{A}_{m} \mathrm{O}_{n}$ ) [23]:

- An oxygen atom is linked to no more than two atoms of type A;

- The coordination number of $\mathrm{A}$ is small;

- The formed polyhedra have shared vertices, not edges nor faces; 
- At least three vertices are shared.

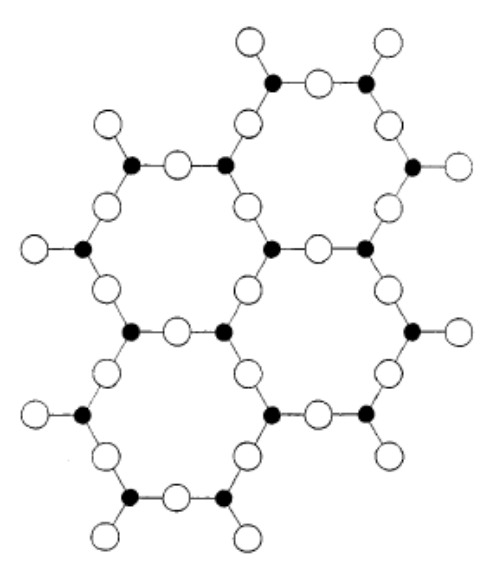

(a)

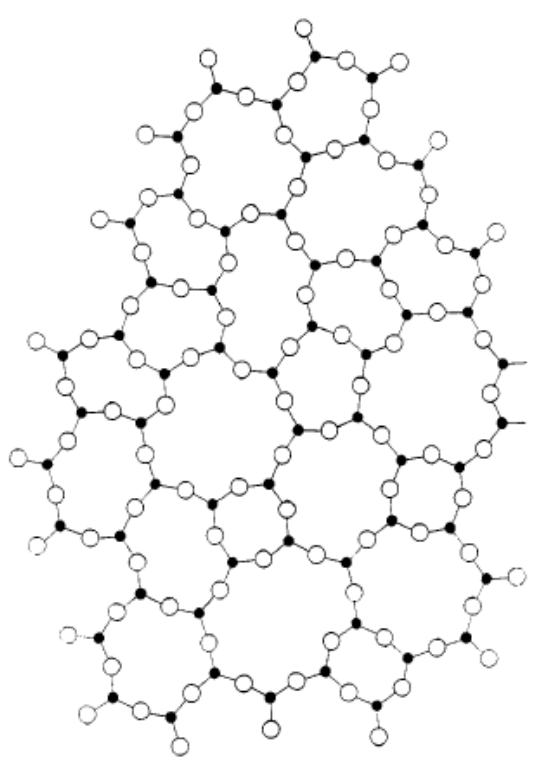

(b)

Figure 2 - (a) 2D Representation of a crystal of $\mathrm{Al}_{2} \mathrm{O}_{3}$; (b) 2D representation of a glass of the same composition. Extracted from [23].

However, these rules only considered oxide glasses. Other theories were developed to include all types of glasses. Stanworth used the electronegativity criterion to assess the capacity of a compound to form a glass [24]; Sun used the bond strength criterion [25]; and Dietzel used a quantity called field strength for a cation [26, 17]. Based on all these criteria, the many compounds used to form glasses can be divided in three categories:

- Glass formers: usually more covalent character, high atom connectivity, capacity to form a network;

- Glass modifiers: usually more ionic character, capacity to break the glass network;

- Glass intermediates: depending on the experiment conditions, can act as either a glass former or modifier.

It is currently known that any substance can form a glass: inorganic and organic compounds, ionic salts and metals (even water can form a glass). The experiment conditions to make this happen (mainly the cooling rate), though, cannot always be achieved with ordinary laboratory equipment. Thus, the above categories are considered to produce glasses using feasible conditions.

The cooling rate is a fundamental condition in glass forming experiments, since it is the factor that determines whether a glass or a crystal is formed from a liquid. 
Crystallization is a phase transition that happens in two steps: nucleation and growth. If one can prevent one or both steps from occurring, then glass forming is favored.

Nucleation is the process of formation of particles aggregates, precursors of crystals. These nuclei are periodic and symmetric like crystals, but they do not have a preferred growth direction (crystal habit). The nuclei formation is governed by two processes: diffusion of particles between the nucleus and the liquid matrix and the energy generated for the nucleus formation. These impose two barriers in nucleation: a kinetic and a thermodynamic, respectively (otherwise, the simple vibration of atoms within the liquid would promote crystal nucleation) [17]. The nucleation rate is expressed by

$$
I=n \nu \exp \left(\frac{-N W^{*}}{R T}\right) \exp \left(\frac{-\Delta G_{D}}{R T}\right)
$$

in which $n$ is the number of atoms, $\nu$ is the atomic vibration frequency, $N$ is the Avogadro constant, $W^{*}$ is the work of nucleation (thermodynamic barrier) and $\Delta G_{D}$ is the activation energy to cross the liquid-crystal interface (kinetic barrier). $W^{*}$ is the maximum value of $W$, the change in energy due to phase transition, which equals

$$
W=\frac{4}{3} \pi r^{3} \Delta G_{c}+4 \pi r^{2} \sigma
$$

where the first term is due to the formation of a phase with lower energy and volume $\left(\Delta G_{c}\right.$ is the energy of crystallization, and $\left.\Delta G_{c}<0\right)$ and the second term corresponds to the formation of a crystal-liquid interface ( $\sigma$ is the interface energy). This equation considers the formation of spherical nuclei with radius $r$. When the first term dominates (for large values of $r$ ), stable nuclei are formed, and when the second dominates (small values of $r$ ), they are dissolved again in the matrix. Therefore, $W^{*}$ corresponds to a critical value of $r$. Equation 1.9 can be converted to

$$
I=I_{0} \exp \left(-\frac{W^{*}+\Delta G_{D}}{k_{B} T}\right)=\frac{A}{\eta} \exp \left(-\frac{16}{3} \frac{\pi \sigma^{3}}{\Delta G_{c}^{2}}\right)
$$

where $A$ is constant. The viscosity comes from the activation energy $\Delta G_{D}$, which is proportional to $\eta$ [15]. Finally, the crystallization energy can be related to the enthalpy of fusion, $\Delta H_{f}$, and the melting temperature, $T_{m}$ of the substance considered, and $\Delta G_{c}$ (considered for a temperature change $\Delta T$ from melting) can be replaced in Equation 1.11 to give

$$
I=\frac{A}{\eta} \exp \left(-\frac{16}{3} \frac{\pi \sigma^{3}}{\Delta H_{f}^{2}}\left(\frac{T_{m}}{\Delta T}\right)^{2}\right)
$$

Crystal growth occurs by deposition of atomic layers on nuclei of critical size. It is driven by the rate of diffusion of atoms from the liquid matrix to the interface with the nuclei, and the energy changes when the substance goes from liquid to crystal phase [22]. The crystal growth rate can, then, be expressed by

$$
U=a \nu^{\prime} \exp \left(-\frac{\Delta G_{D}}{k_{B} T}\right)\left[1-\exp \left(\frac{\Delta G_{c}}{k_{B} T}\right)\right]
$$


where $a$ is the jump from the liquid matrix to the nucleus surface and $\nu^{\prime}$ is the atomic vibration frequency of this jump. Inserting the diffusion coefficient $D$ in this formula (which is related to $a, \nu^{\prime}$ and the kinetic exponential), and then inserting the matrix viscosity (related to $D$ ) gives

$$
U=\frac{D}{a}\left[1-\exp \left(\frac{\Delta G_{c}}{k_{B} T}\right)\right]=f \frac{k_{B} T}{3 \pi a^{2} \eta}\left[1-\exp \left(\frac{\Delta G_{c}}{k_{B} T}\right)\right]
$$

where $f$ is the fraction of the surface available for crystal growth (again in this case $\Delta G_{c}$ can be converted to $\Delta H_{f}$ and $\left.T_{m}\right)[17]$.

Equations 1.11 and 1.14 are both dependent on temperature. Figure 3 shows both rates plotted against temperature. To evaluate the crystallization process in a glass-forming melt and thus avoid it, these can be combined, describing the volume fraction of crystals formed, according to the following equation

$$
\frac{V_{x}}{V}=1-\exp \left[-\int_{0}^{t} I_{v}\left(\int_{t^{\prime}}^{t} U d \tau\right)^{3} d t^{\prime}\right]
$$

in which $I_{v}$ is the nucleation rate per unit volume [15]. Integrating over time gives

$$
\frac{V_{x}}{V}=1-\exp \left(-\frac{\pi}{3} I_{v} U^{3} t^{4}\right)
$$

This formula gives rise to the time-temperature-transformation (TTT) curve, shown in Figure 4. With known $I_{v}$ and $U$ at a specific temperature (below $T_{m}$ ), the time $t$ to generate the desired volume fraction of crystals can be calculated.

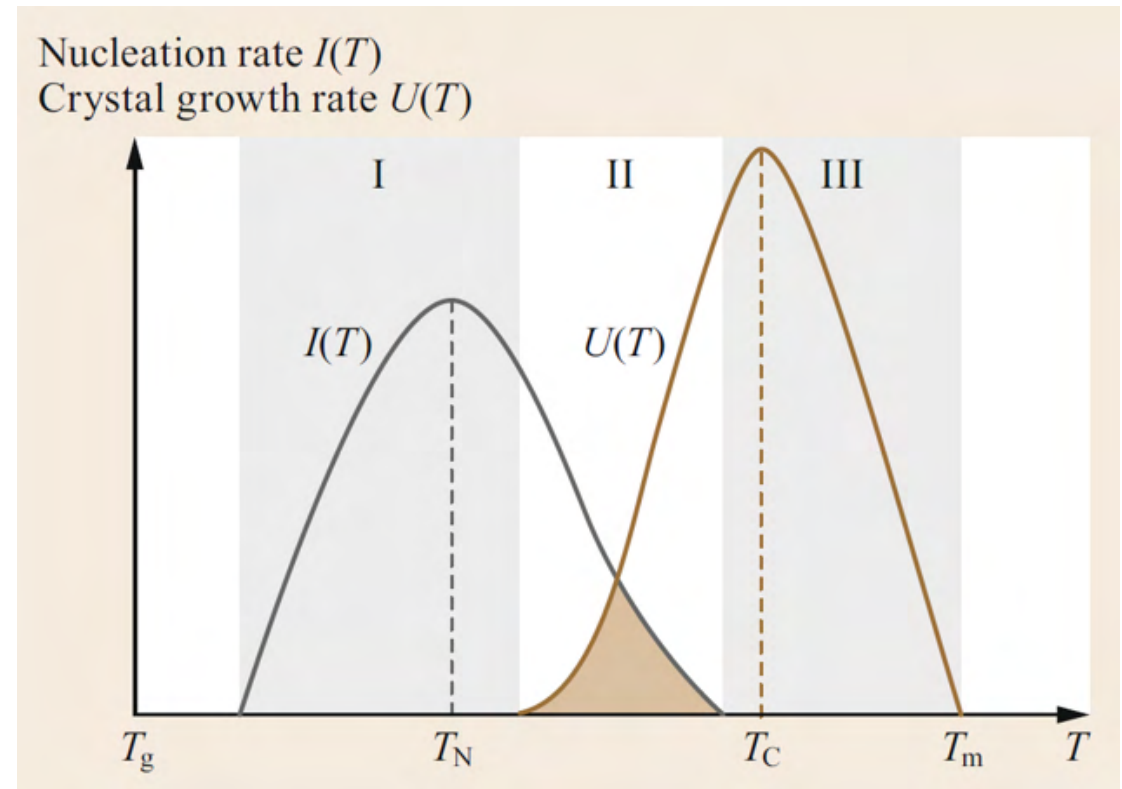

Figure 3 - Plots of nucleation and crystal growth against temperature. Three different regions can be identified: (I) The nuclei are formed but do not grow, (II) crystallization happens and (III) there is no nucleation, so there is no growth, even though it is possible (extracted from [22]). 


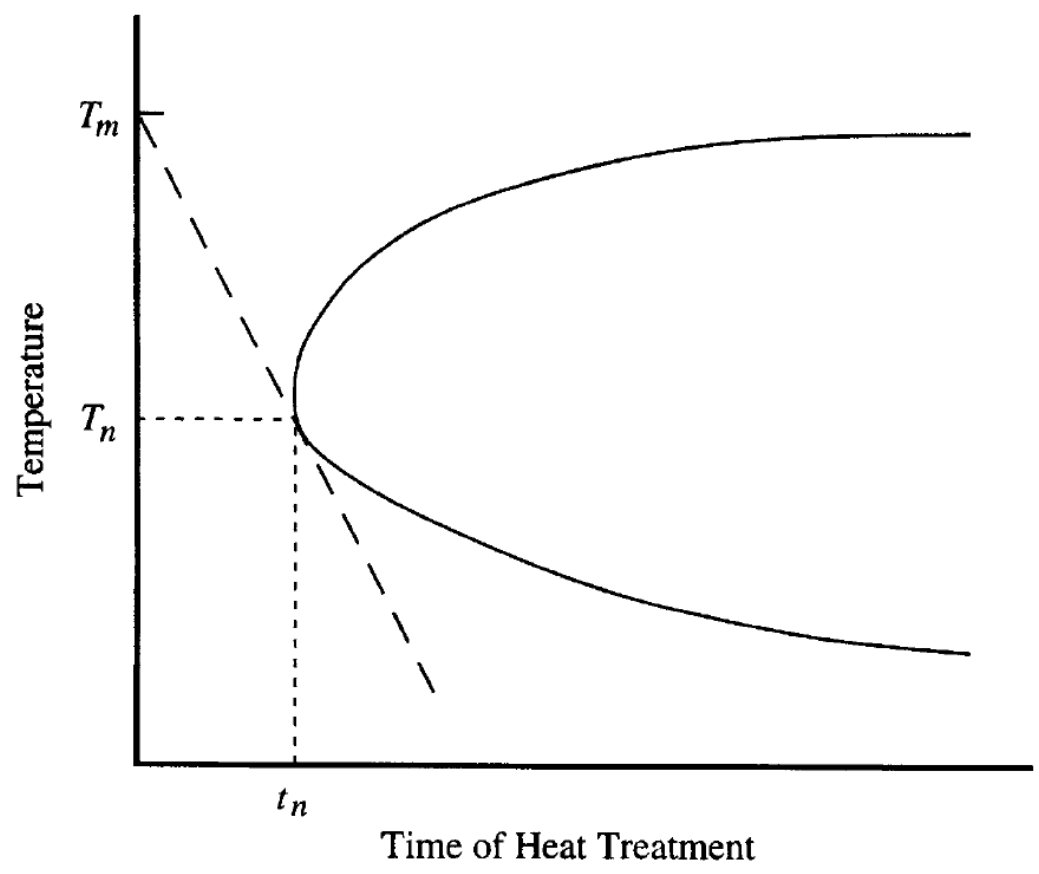

Figure 4 - Time-temperature-transformation curve for a generic glass-forming melt (extracted from [15])

Plotting this curve for a particular glass composition is a laborious task, since the nucleation and growth rates must be known for several values of temperature. But once it is done, the cooling rate necessary to synthesize a glass sample can be easily extracted from it. First, a threshold value for volume fraction of crystals in the glass must be defined (the glass sample to be synthesized must contain less than that fraction of crystals). Then, the critical cooling rate (minimum rate required to produce the desired glass sample) can be calculated via the expression [15]

$$
\frac{d T}{d t}=\frac{T_{m}-T_{n}}{t_{n}}
$$

\subsection{Structural connectivity in phosphate glasses}

The structure in phosphate glasses is composed by tetrahedra in which the central phosphorus atom is coordinated to four oxygen atoms. These $\left[\mathrm{PO}_{4}\right]$ units are connected to each other through either three, two or one bridging oxygen to establish the glass network [27]. Such patterns, listed below, can be named using the symbol $\mathrm{Q}^{n}$, where $n$ denotes the number of bridging oxygens.

- $\mathrm{Q}^{0}$ The four oxygen atoms in the tetrahedra are terminal (non-bridging), and the glass structure is composed by isolated $\left[\mathrm{PO}_{4}\right]$ units. Compounds that possess this 
type of connectivity are called orthophosphates.

- $\mathrm{Q}^{1}$ There is one bridging oxygen connecting two $\left[\mathrm{PO}_{4}\right]$ units, and the remaining bonds in the central phosphorus are with terminal oxygen atoms. Compounds with such structure are called pyrophosphates.

- $\mathrm{Q}^{2}$ The phosphate tetrahedra are composed by two bridging oxygens and two terminal oxygens. Compounds with this connectivity pattern are denominated metaphosphates.

- $\mathrm{Q}^{3}$ Only one oxygen is terminal, while the other three are bridging, connecting neighboring tetrahedra. Compounds with this type of structure are known as ultraphosphates.

A structure where all four oxygen atoms connect two phosphate atoms is not possible, because one oxygen is necessarily double-bonded to the central phosphorus. Furthermore, when there is more than one terminal P-O bond, there is resonance between the double-bonded oxygen and the single-bonded, negatively charged oxygens within the structure. That way, all terminal P-O bonds are essentially equal. All types of phosphate network structure are illustrated in Figure 5.

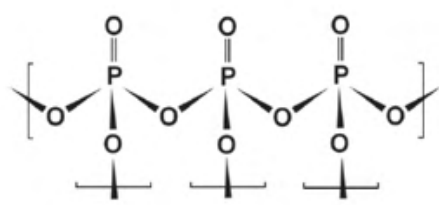

Q3, ultraphosphate

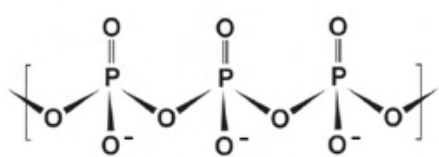

$\mathrm{Q}^{2}$, metaphosphate

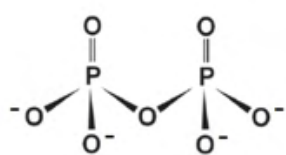

$Q^{1}$, pyrophosphate

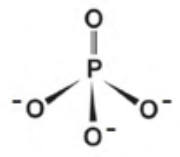

$\mathrm{Q}^{\circ}$, orthophosphate

Figure 5 - Schemes showing the connectivity patterns in phosphate compounds and glasses.

In comparison to silicate glasses, phosphate-based compositions have lower characteristic temperatures (glass transition, crystallization, and melting), which enables for glass synthesis at milder conditions. Other advantages of phosphate glasses include high transparency (transmittance) from ultraviolet to near infrared region (300-3000 nm) and capacity to incorporate large amounts of lanthanide ions, transition metal ions, and nanoparticles. They find a wide range of applications, from photonics to biomedicine [28].

One disadvantage of this class of oxide glasses is its low chemical stability, meaning that phosphate glasses are very susceptible to reaction with water (due to its double-bonded oxygen atom), followed by breakage of the network and degradation. However, this can be contoured by addition of compounds that promote a higher connectivity of the structure, such as transition metals [29]. 


\section{CHAPTER 2}

\section{Metal nanoparticles}

\subsection{Nanotechnology}

Nanoparticles have been observed in human history much before they were given that name. One famous example is the Lycurgus cup, shown in Figure6, in which depending on the illumination it exhibits either a green or red color. This effect is due to the presence of silver and gold nanoparticles in the glass composition. Cups and other decoration utensils such as the ones depicted in Figure 7, were made with what was called "cranberry glass" in the British Victorian Era by adding gold salts to the glass melt. The reason for this exquisite red tint, though, was not known then.

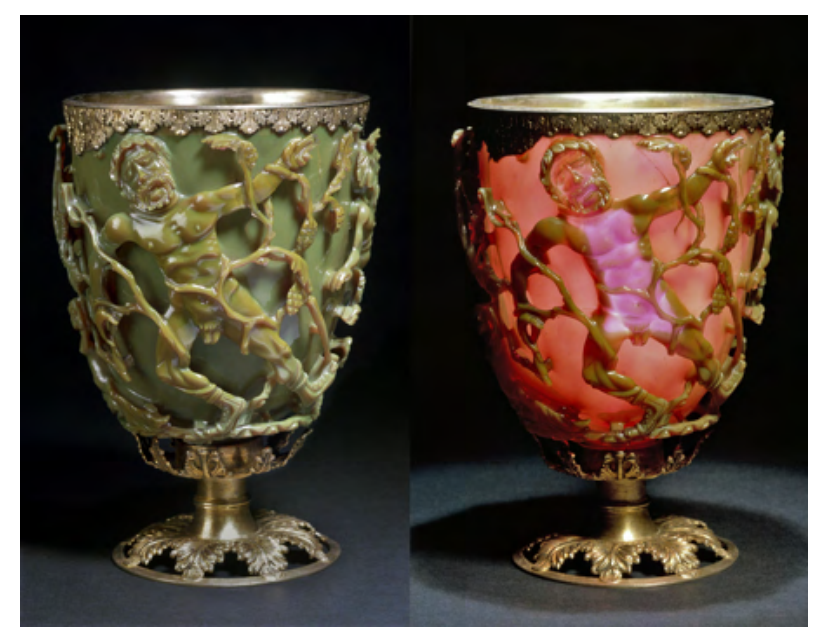

Figure 6 - Lycurgus cup, depicting the death of King Lycurgus. The cup is a piece from 4th Century Roman Empire. The glass exhibits the dichroism effect due to silver and gold nanoparticles dispersed in it. In reflected light, it exhibits the color green, whilst in transmitted light, the color red. It is currently displayed at the British Museum in London. CBritish Museum. 


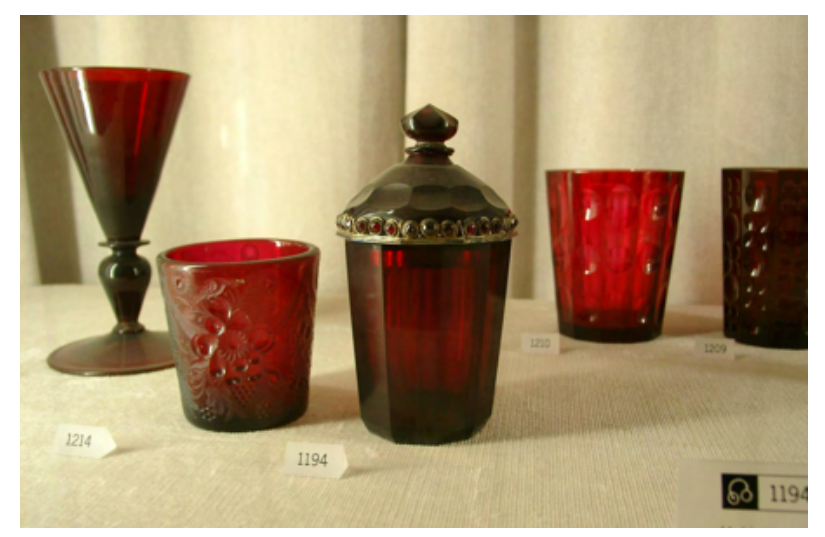

Figure 7 - Set of cups from the German Bohemian era made of cranberry glass. CC BY-SA 3.0, https://commons.wikimedia.org/w/index.php?curid=8946999.

The effective study of colloidal metal particles and their properties started in the 19th Century. Michael Faraday synthesized gold nanoparticles in suspension and studied the dispersion of light in this medium [30], pioneering in the optical investigations of colloidal suspensions. Richard Feynman is considered the father of nanotechnology due to his ideas of manipulating matter at the atomic scale [31].

Nanoscience and nanotechnology, the study of properties and applications of materials with dimensions in the nanometers scale, are very broad fields, encompassing chemistry, physics, biology, computer science and many other areas of knowledge. The size and shape dependence of the physical and chemical properties of nanomaterials makes them a central topic of interest in current research.

\subsection{Synthesis of metallic nanoparticles}

There are two main approaches for controlled synthesis of nanoparticles: top-down and bottom-up. In the first class, the NPs are "broken down" from macroscopic materials. The techniques are mainly physical methods, such as lithography or laser ablation [32, 33. The second class involves chemical processes, and the NPs are built up from atomic units. Chemical vapor deposition (CVD), plasma spray, electrochemical, thermal reduction are some methods of synthesizing nanoparticles in suspension or in a solid substrate [32]. Chemical processes all involve the nucleation and crystal growth steps previously described [34.

The solution-phase synthesis is one of the most common methods to generate metal nanoparticles. A reducing agent and a stabilizing agent are both necessary to promote the reduction of the metallic species and to control its size and shape. Stabilization happens via binding on the nanoparticle surface, which can be either physical adsorption or a chemical bond. However, the access of the surface for some applications, such as catalysis, 
is hindered by these stabilizing agents. Hence, in this project, an in situ generation of $\mathrm{Ag}-\mathrm{NPs}$ on the surface of the vitreous matrix was proposed.

\subsection{Surface plasmon resonance}

The colors of metal nanoparticles, among other properties, are highly dependent on their size, and the difference in relation to their macroscopic counterparts is due to surface plasmons. Plasmon is the collective oscillation of the electron density within a material. In very small particles, these plasmons are localized and generate an oscillating electric field, as depicted in Figure 8, which can interact with incoming electromagnetic radiation.

Localized surface plasmons (LSP) have a natural frequency of oscillation, which is different for each metal species. Metal nanoparticles absorb electromagnetic radiation to excite the LSPs when the wavelength of the former approaches that of the latter, and in the resonance region this absorption reaches its maximum; as a result, the oscillation amplitude increases [34].

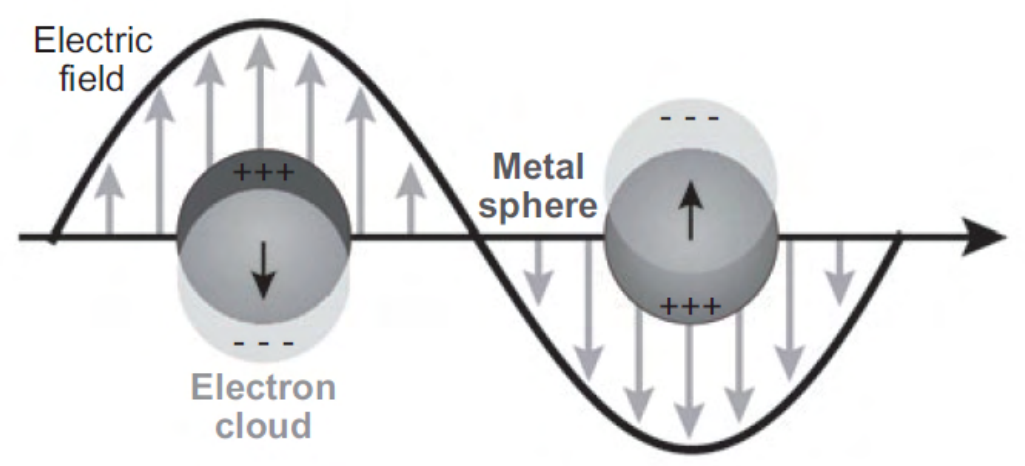

Figure 8 - Localized surface plasmon illustration. Adapted from [35]

The results of the localized surface plasmon resonance (LSPR) effect can be seen in Figure 9. In tetrachloroaurate aqueous solution (yellow, to the left), absorption in the visible region is due to electronic transitions between orbitals with d character. In the gold nanoparticles suspension (red, to the right), absorption happens because of the SPR effect. The wavelength of the SPR absorption band depends not only on the size and shape of the nanoparticles, but also on the dielectric medium in which they are contained and the temperature. Hence, this band can be tuned according to the desired application. 


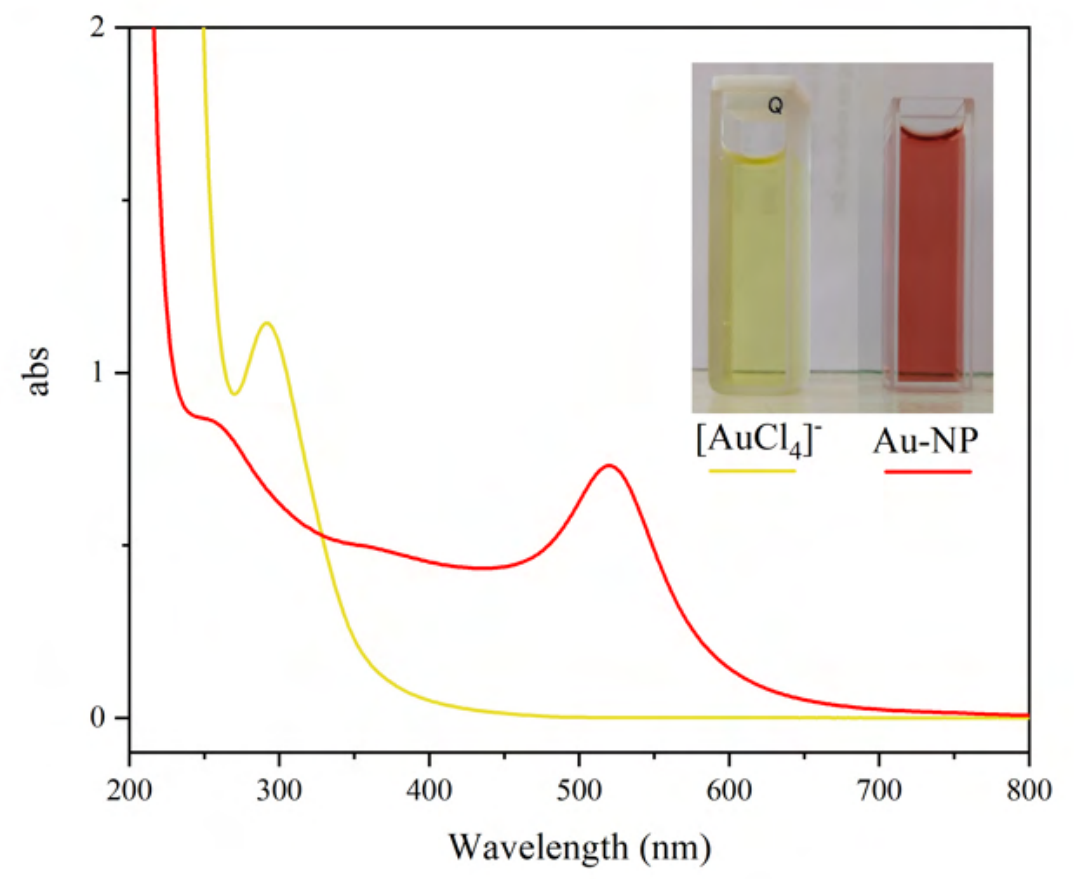

Figure 9 - UV-Vis absorption spectra of a solution of tetrachloroaurate ions and a suspension of gold nanoparticles. In the first case, the absorption is consequence of electronic transitions, while in the second, it is due to surface plasmon resonance.

\subsection{Nanoparticles in glasses}

Besides the aforementioned Lycurgus cup and cranberry glass, metal nanoparticles can be incorporated in glasses for applications that go beyond decoration. Copper, silver, gold, platinum or palladium nanoparticles can be included in glasses via traditional melting-quenching process, ion implantation, sol-gel techniques, laser irradiation and ion exchange.

A widely studied role of metal nanoparticles inside glasses is the enhancement of luminescence from lanthanides in doped glasses, having in mind applications in the telecommunications field [36] and white light emission [37].

This project explored the utilization of nanoparticle-doped glasses as surfaceenhanced Raman scattering (SERS) sensors. SERS is one of the most sensitive methods for detection of compounds adsorbed to the NPs surface [38].

Metal nanoparticles can be synthesized in any glass system. Silicate glasses are the most common. However, systems with lower characteristic temperatures were preferred in this project, which can be achieved more easily.

The ion exchange process (which was employed in the experimental part of this 
project) is applied to glass with the purpose to modify its surface composition, with new physical and chemical properties arising from these modifications. A very famous example is the increase of mechanical resistance of Gorilla ${ }^{\circledR}$ Glass, developed by Corning Inc and used in screens of smartphones and other electronic devices [39, 40]. 



\section{CHAPTER 3}

\section{Photocatalysis}

\subsection{Photocatalysis principles}

Many of the challenges the world is currently facing involve chemicals: air pollution, global warming due to aggravation of greenhouse effect, contamination of water with pesticides and drugs, energy shortage, search for fossil fuels alternatives. All these are problems that the photocatalysis field tries to address.

The use of catalysts to promote reactions is one of the principles of Green Chemistry. The main goals in photocatalysis research is to find novel materials that are safer, minimize residue generation, and are also of facile synthesis. Photocatalysts are mainly used in two applications, water splitting and degradation of organic compounds via oxidation-reduction, visualizing solution for the challenges aforementioned [41, 42].

Semiconductors (metal oxides and sulfides, for example) are commonly used as photocatalysts. Figure 10 depicts how they are used to promote oxidation-reduction reactions mediated by light. The incoming radiation is used to promote the semiconductor electrons to the conduction band, generating electron-hole pairs. As illustrated, these pairs aid redox processes such as water decomposition into molecular hydrogen and oxygen and oxidation/reduction of hazardous organic compounds. Depending on the photocatalyst band gap, there can be activity in the ultraviolet and visible regions of the electromagnetic spectrum [43, 44]. The band gap energies for some common semiconductors are shown in Figure 11 .

\subsection{Glasses as photocatalysts}

Attempting photocatalysis using glasses and glass-ceramics as active substrates has been a growing field of study. Glass can be easily molded in different shapes and sizes 
and produced on large scales. For that reason, vitreous materials are preferred over other types of materials, such as powders and thin films, and one common type of application of glasses with photocatalytic properties is as self-cleaning surfaces [45, 46].

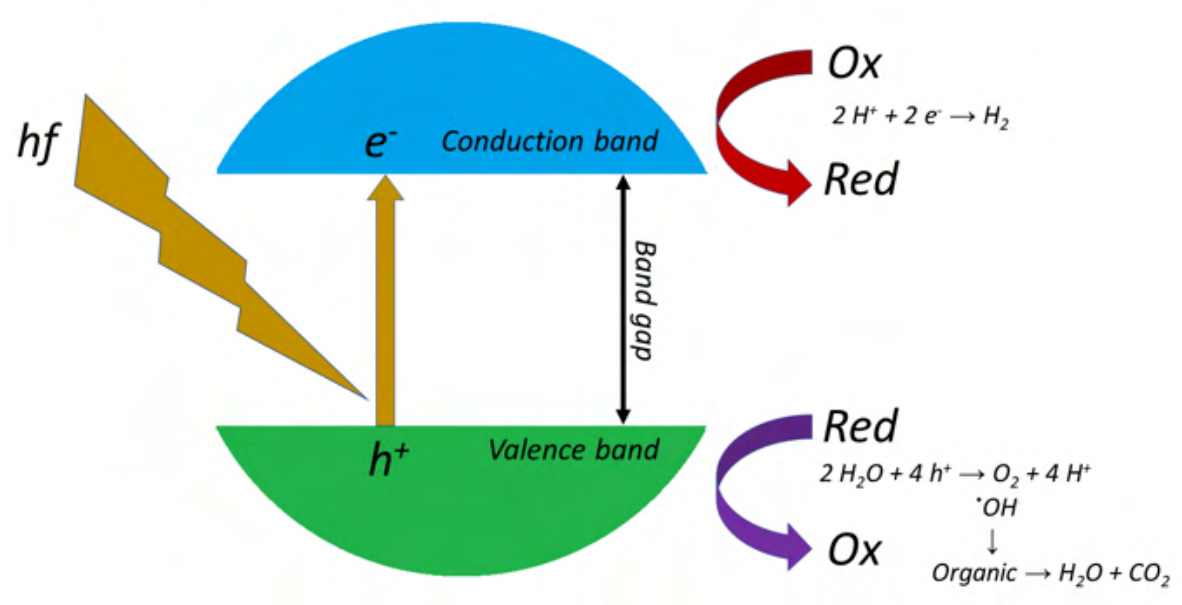

Figure 10 - Illustration of the photocatalysis process.

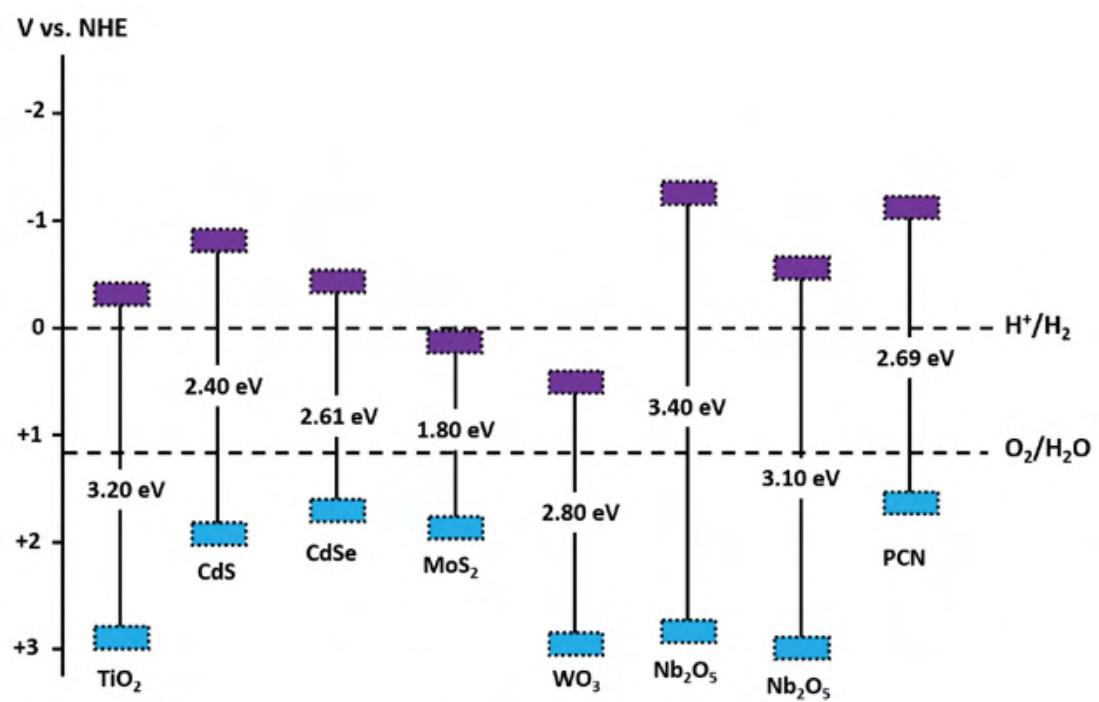

Figure 11 - Band gap energy values for some semiconductors employed as photocatalysts. Extracted from [44].

Glass-ceramics, glasses in which one or more crystalline phase was grown without changing the amorphous character of the overall material, are quite common in studies of photocatalysis in vitreous substrates. Borate [45, 46, 47, 48], phosphate [49], and borosilicate [50, 51] networks were reported as recurrent types of glass networks studied.

Additives are added to the glass composition to promote the photocatalytic activity. A thermal treatment takes place to nucleate crystals within the glass, thus forming the glass-ceramics. Common additives include the semiconductors titanium oxide [49] and zinc 
oxide [50, 51], bismuth oxide to form semiconducting compounds [48, 52], or a combination of oxides that will crystallize as perovskites, such as barium titanate [46].

The targets of the photodegradation processes are organic compounds, usually drugs [45, 46] or dyes [47, 48, 49, 50, 52, but not restricted to those.

The glass synthesis may include additional processes or compounds to enhance the photocatalytic activity, such as acid etching to with HF [47], crystallization of a ferromagnetic phase $\left(\mathrm{BiFeO}_{3}\right)$ in the glass-ceramics [52, 53], or yet, as proposed here, synthesis of plasmonic nanoparticles.

\subsection{Plasmonics: going further}

Plasmonic photocatalysis has been reported many times in literature over the past years. It is a growing subject of interest due to its enormous potential to harvest sunlight and apply it to many uses. This process can be achieved by coupling a substrate with photocatalytic activity with the SPR from metal nanoparticles. A full description of the mechanism of catalytic processes aided by plasmonics is not entirely clear [54, 55]. However, Figure 12 shows that one possible mechanism involves the transfer of electrons from the nanoparticles to the conduction band of the photocatalyst species, allowing for the oxidation-reduction process to happen [41].

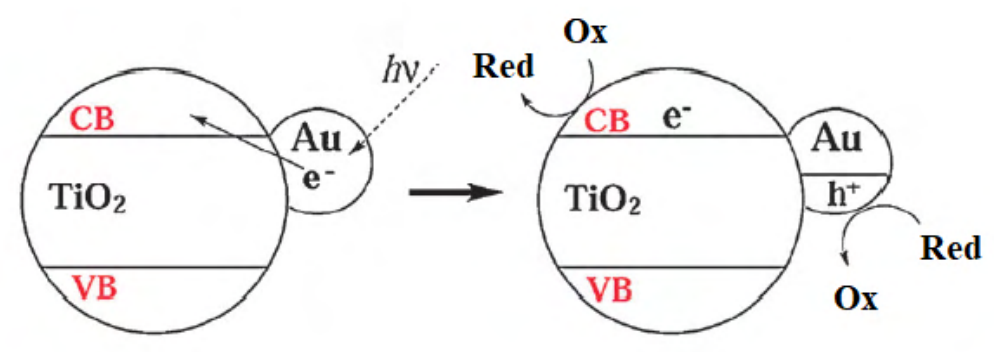

Figure 12 - Plasmonic photocatalysis mechanism. Adapted from [41].

$\mathrm{TiO}_{2}$ is a very common photocatalyst, with a band gap energy that makes it active under UV excitation [44]. Coupling it with metal nanoparticles makes it possible the utilization of the visible region of the electromagnetic spectrum, where the plasmons are excited, in the photocatalysis process. The wavelength used can then be tuned according to the LSPR wavelength [56].

An advantage of using visible light to activate a photocatalytic material is that solar radiation can be used for that purpose. Sun is the primary source of energy for all activity on Earth. Most of the radiation that hits Earth's surface falls on the visible region, 
as can be seen in Figure 13. Hence, harvesting this energy should be a primary goal of any new technology that visualizes a minimum generation of waste or residues.

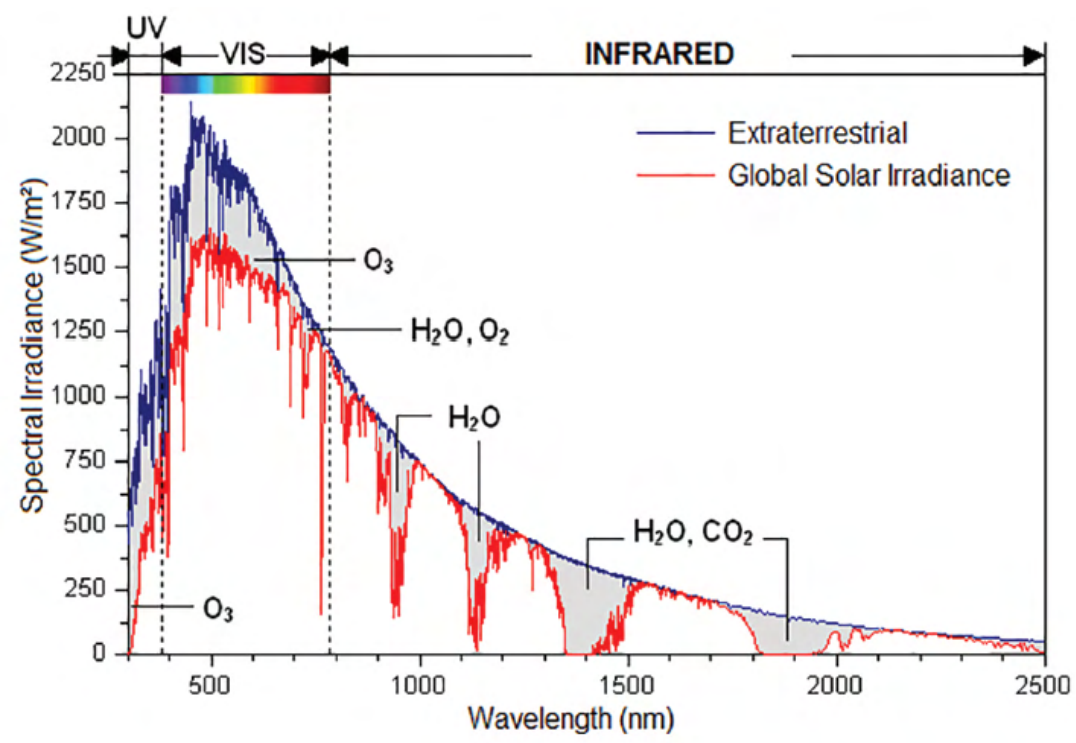

Figure 13 - Solar radiation spectrum. The blue line shows the intensity of the incoming rays before entering Earth's atmosphere. Its gases absorb a great portion of the photons in the ultraviolet and infrared regions, therefore not reaching Earth's surface, and resulting in the red spectrum. Extracted from [44].

Gold and silver nanoparticles are quite common in photocatalysis, but bismuth, platinum and palladium are also utilized in applications such as removal of greenhouse gases from the atmosphere [57] and mineralization of antibiotics [58. Since the catalysis of an organic reaction via plasmonic mechanisms was first reported [59, 60], the field has grown, but it is still a little studied phenomenon.

Common methods for preparing plasmonic photocatalysts include depositionprecipitation, where the semiconductor is added to a solution of the metal ion that generates the NPs followed by calcination of the recovered suspension, photoreduction, where the metal ions are deposited on the semiconductor surface and then reduced by the latter after irradiation with light, and generation of nanocomposites or core-shell structures [58, 61, 62].

Glasses have not yet been reported as active substrates for plasmonic photocatalysis. This is the central challenge proposed by this research project: attempting to promote photodegradation of organic compounds aided by plasmons using a non-crystalline matrix. 


\section{CHAPTER 4}

\section{Motivation and objectives}

\subsection{Emerging pollutants}

Pesticides are among many chemicals that cannot be monitored in fresh water and ground water sources and in the soil due to their very low concentrations. These are collectively called emerging pollutants, and include pesticides, drugs, hormones, microplastics. Emerging pollutants cannot be removed by current used methods of wastewater treatment, thus being able to cause risks to both natural ecosystems and humans [63].

With that context in mind, this project has as one of its goals to provide a method for detecting compounds in very low concentrations (such as pesticides) using glass as the matrix for detection via SERS (due to its low limit of detection) and posterior degradation via plasmonic photocatalysis.

Two organic compounds were initially chosen to assess the SERS and photocatalytic activity of the synthesized glass samples, fipronil and thiamethoxam (Figure 14).
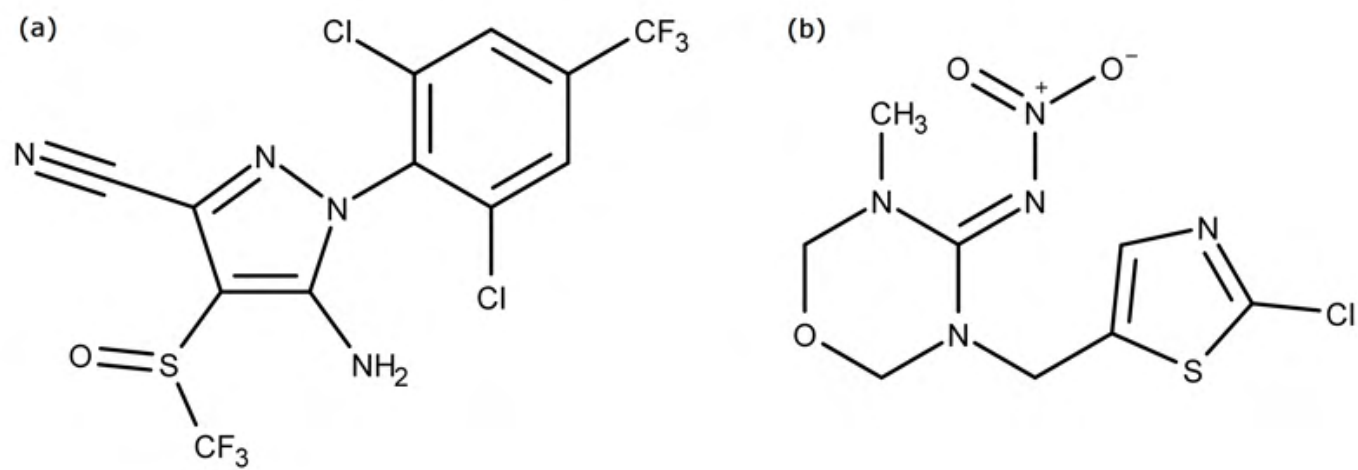

Figure 14 - (a) Fipronil and (b) Thiamethoxam structures.

Fipronil is a phenylpyrazole class pesticide widely used in agriculture and for 
residential use in low concentrations. It is an endocrine disruptor and can cause several problems in humans. Concerns regarding it raised significantly after the 2017 fipronil contamination incident, where chicken eggs for human consumption were found with excessive levels of this pesticide in more than 15 European Union and Asia countries [64, 65].

Thiamethoxam is a neonicotinoid class, broad-spectrum pesticide. Therefore, it not only affects undesired insects, posing a serious threat to species that are vital for the maintenance of any ecosystem, such as bees [66].

Besides the concerns over the serious risks these compounds pose to the environment, they were chosen because they contain atoms (nitrogen, sulfur) and groups (amine, cyano, sulfoxide) the might coordinate to metallic silver atoms from the nanoparticles [67, 68, 69].

Dyes comprise another class of emerging pollutants, which are frequently discarded by textile, leather, plastic, printing, and many other industry branches in the soil and bodies of water [70]. For that reason, they were used here as body of proof for the two proposed applications of the materials. Furthermore, organic dyes are often utilized as models for organic pollutants in general in photocatalysis trials due to their easy recognition by color and analysis by electronic spectroscopy.

\subsection{General objectives}

This Scientific Master's Research project had as one of its main objectives the development and characterization of novel glass substrates containing silver nanoparticles for two distinct applications in plasmonics: effective SERS activity towards low concentrations of organic molecules and degradation of organic compounds using the synthesized glass as photocatalyst, with the Ag-NPs acting as enhancers in that application, known as plasmonic photocatalysis. Both processes would be achieved using the SPR effect from nanoparticles deposited on the glass surface via ion exchange and heat treatment.

The following steps were set as goals to be reached:

- Synthesis and characterization of oxide glasses containing $\mathrm{TiO}_{2}$, a compound that presents good photocatalytic activity, and $\mathrm{Na}_{2} \mathrm{O}$ to allow for the ion exchange of $\mathrm{Na}^{+}$by $\mathrm{Ag}^{+}$;

- Silver nanoparticles (Ag-NPs) growth on the surface of the glass samples via ion exchange in a molten salt mixture bath followed by heat treatment above $T_{g}$ to promote reduction and growth of the NPs;

- Analysis via Surface-Enhanced Raman Spectroscopy of organic molecules anchored 
on the glass surface; the molecules to be tested are pesticides, commonly found as water pollutants in very low concentrations;

- Photocatalytic study of the glass substrates (of both as quenched and containing NPs samples) using an organic dye as body of proof. That way, the photocatalysis experiments can be monitored via electronic spectroscopy. Ultimately, the SPR would aid in the photodegradation, in a very ambitious attempt to develop a plasmonic photocatalyst. 



\section{CHAPTER 5}

\section{Characterization techniques}

\subsection{Differential Scanning Calorimetry}

Differential scanning calorimetry is the thermal analysis method where the heat flow within a sample is measured in comparison to a reference (usually an empty pan). A heating program is set, and the amount of heat (energy) necessary to maintain the sample pan at the same temperature as the reference pan is measured. Figure 15 shows the scheme of a heat flow calorimeter. In this type of equipment, energy is provided to both the sample and reference pans, in a way that the sample temperature changes according to the program set. The heat flow in both pans is monitored by thermocouples.

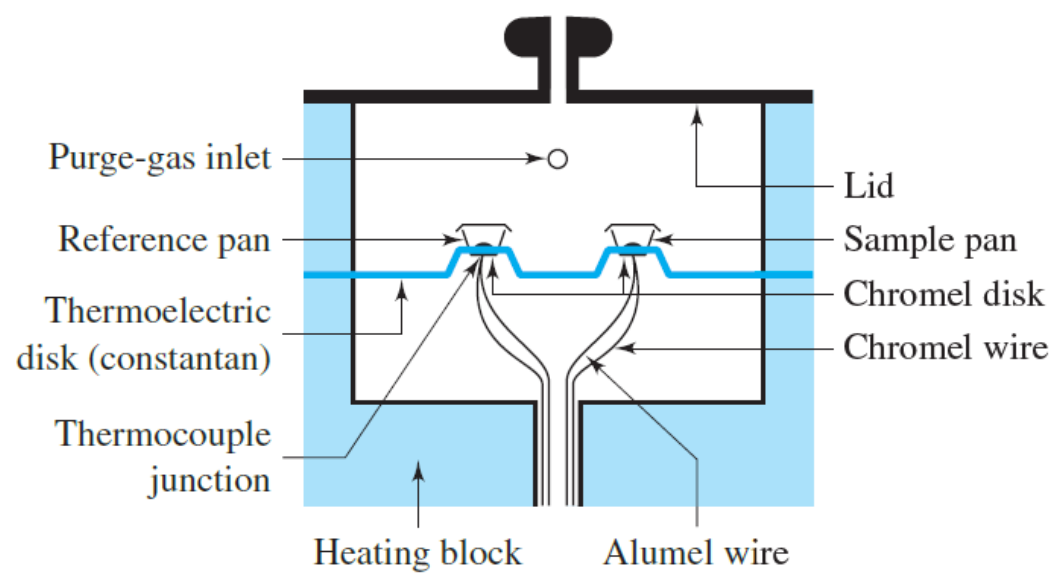

Figure 15 - Schematic of a heat flow calorimeter. Extracted from [71].

During the experiment, the heat flow will vary if the energy is used to promote other events besides the temperature increase, such as phase transitions, which can be identified by peaks (either negative or positive) and glass transition (where there is a 
change in the heat capacity of the material), identified by a change in the baseline. A typical DSC thermogram or curve is shown in Figure 16 [71].

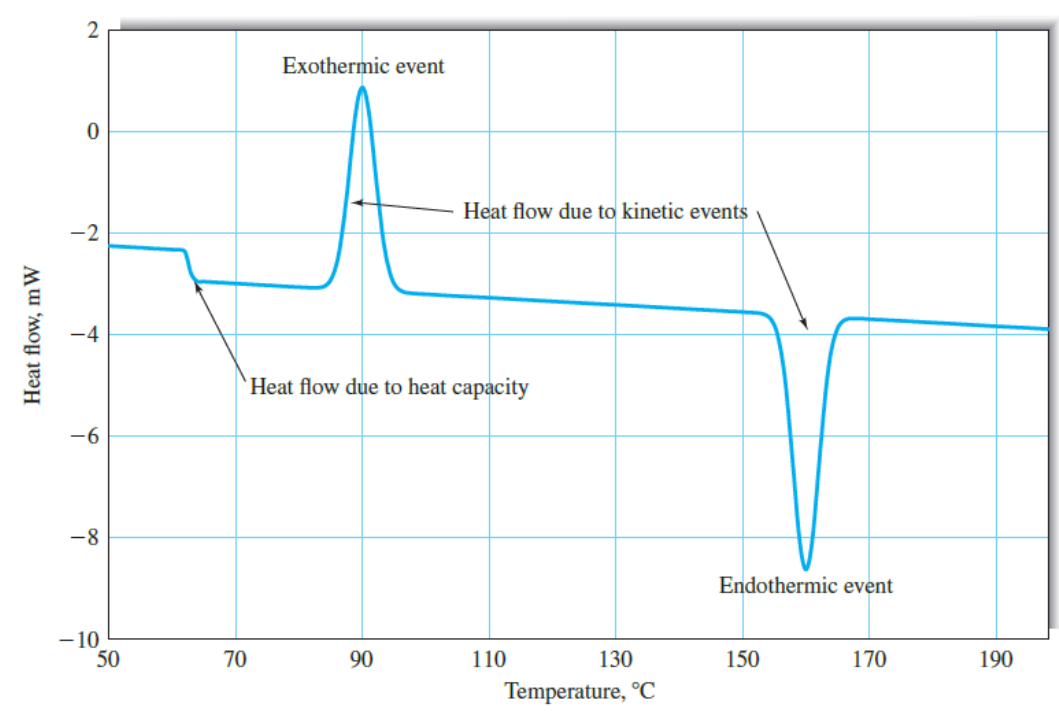

Figure 16 - General aspect of a DSC curve or thermogram. Extracted from [71]

DSC was used here to determine the characteristic temperatures of the synthesized glasses; these are temperatures at which the thermal events, such as crystallization, melting or glass transition, occur. The analyses were performed using a TA Instruments DSC 2910 Calorimeter, under $\mathrm{N}_{2}$ atmosphere from 300 to $600^{\circ} \mathrm{C}$ and a heating rate of $10^{\circ} \mathrm{C} \mathrm{min}{ }^{-1}$.

\subsection{Spectroscopy}

Electromagnetic radiation has a dual nature: it can behave as either waves or particles, depending on how it is studied. Visible light comprises only a small portion of the electromagnetic spectrum. When the interaction with matter involves the exchange of discrete values of energy, light can be described as quantized energy packets called photons. Such change happens in order for energy and momentum to be conserved.

Atoms and molecules obey the principles of Quantum Mechanics. One of these principles states that the energy levels are quantized, meaning that such particles are only allowed to possess discrete values of energy. A transition happens in the atom or molecule when they gain or lose energy. Quantization leads to the fact that the energy gained or lost comes in "packets". And, in the case of a light-matter interaction, these are equivalent to the energy of the interacting photons.

The photon energy is directly related to the frequency $\nu$ of the electromagnetic 
radiation by Planck's constant, $h$, via

$$
E=h \nu=\frac{h c}{\lambda}
$$

There are many ways light can interact with matter. Spectroscopy is the study of each type of interaction between electromagnetic radiation and matter. Absorption, emission, scattering, and resonance are some examples of such interactions. Each of these can be used to analyze the chemical features of an irradiated sample.

The structure of molecules gives rise to energy levels corresponding to their rotational and vibrational motions, as well as to how their electrons are distributed, and the transitions related to each type of level, with their corresponding energies, can be associated with a specific range of wavelengths in the electromagnetic spectrum [21].

Not all transitions between any two energy levels of an atom or molecule are allowed. For a transition to occur, the general rule is that the electric dipole moment of said atom or molecule must oscillate (at least in the moment of the transition) in the same frequency of the interacting photon. This statement, called selection rule, can be translated into the equation

$$
\boldsymbol{\mu}_{f i}=\int \Psi_{f}^{*} \hat{\mu} \Psi_{i} d \tau
$$

where $\boldsymbol{\mu}_{f i}$ is the transition electric dipole vector.

Absorption happens when one or more photons are used to promote the species from a lower to a higher energy level. Likewise, the emission of a photon happens when the species goes from a higher to a lower energy level [20, 21, 72].

\subsubsection{Infrared absorption spectroscopy (vibrational spectroscopy)}

Transitions between vibrational states of a species happen when photons belonging to the mid-infrared region of the electromagnetic spectrum interact with matter.

The vibrational energy levels in a molecule are derived from the application of Schrödinger equation to the harmonic oscillator model. These are written as

$$
\begin{array}{r}
E_{\nu}=\left(\nu+\frac{1}{2}\right) \hbar \omega \\
\omega=\left(\frac{k_{f}}{\mu}\right)^{\frac{1}{2}} \\
\nu=0,1,2, \ldots
\end{array}
$$

where $k_{f}$ is the force constant of a bond, and $\mu$ is the effective mass of the oscillator.

To consider the dissociation of bonds in molecules, the harmonic oscillator is corrected using the anharmonic motion. The consequence is that the vibrational levels are no longer equally separated, as illustrated in Figure 17. 
The transitions between vibrational energy levels are described in terms of normal modes (vibrations of the molecule in which the center of mass remains fixed). The number of normal modes can be found deducting the number of translational and rotational modes. Being $N$ the number of atoms in a given molecule, $3 N$ is the total number of coordinates needed to describe it. That way, the number of normal modes is $3 N-5$ for a linear molecule or $3 N-6$ for a nonlinear molecule.

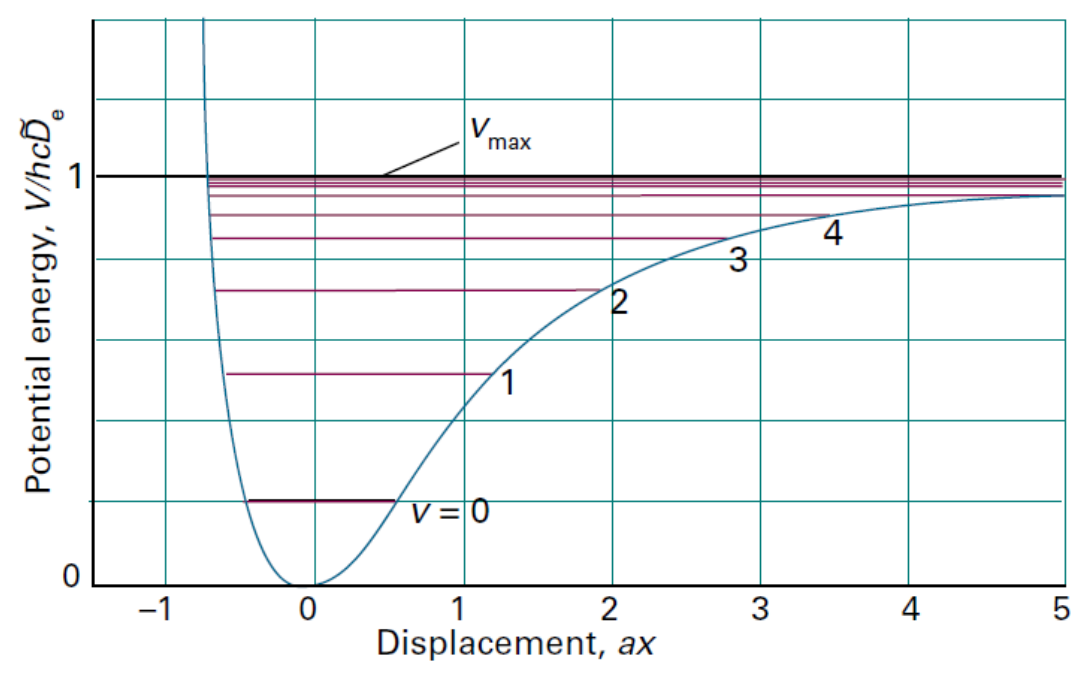

Figure 17 - General shape of the potential well of a molecule, considering the anharmonicity, and containing the vibrational energy levels. Extracted from [21]

Applying the gross selection rule (the transition electron dipole moment must be nonzero) to vibrational transitions, the specific selection rule for the absorption or emission of infrared photons can be deduced. Equation 5.2 can be rewritten as

$$
\boldsymbol{\mu}_{f i}=\left(\frac{d \mu_{0}}{d x}\right)_{0} \int \Psi_{f}^{*} x \Psi_{i} d \tau
$$

Therefore, a vibrational mode will be infrared active if it accompanies a change in the electric dipole moment of the molecule (the derivative in Equation 5.4 must be nonzero). Applying this to a transition between two energy levels $\nu_{n}$ and $\nu_{m}$, it is found that allowed transitions are those where $\Delta \nu= \pm 1$ (only one active mode is allowed to change during a transition). However, anharmonicity relaxes this rule, and overtones (transitions between non-consecutive energy levels) and combination bands (simultaneous excitation of more than one vibration) are commonly found in infrared absorption spectra [20, 21, 72 .

\subsubsection{Raman scattering spectroscopy}

Scattering is the type of interaction with matter where the direction of the incoming photons changes. This is due to absorption and re-emission of light, but differently from 
the ordinary absorption phenomenon, scattering does not happen involving real rotational, vibrational, and electronic states. Therefore, the interacting photons do not have energy equivalent to the difference between the quantized states of matter. The incoming photons cause the promotion of the species to a virtual state, and it very rapidly returns to a real state (either fundamental or excited), re-emitting the now called scattered photons. Scattering happens in all directions.

There are many ways photons can be scattered. They are classified in elastic scattering, where there is no energy transfer with the involved particles, and the scattered photons have the same wavelength as the incident photons, and inelastic scattering, where the energy transfer generates scattered photons with different wavelength than the incident photons.

One example of elastic scattering important in spectroscopy is the Rayleigh scattering, where the size of the particles is smaller than the wavelength of incoming photons. Here, the intensity of scattered radiation is proportional to its wavelength $\left(\lambda^{-4}\right)$, being this the reason why the sky is blue.

Raman scattering is the type of inelastic scattering where the energy difference between the incoming and scattered radiation lies in the infrared region of the electromagnetic region. It can be originated by two processes: Stokes scattering, where the incident photon has a smaller wavelength than the scattered photon, and anti-Stokes scattering, where the incident photon has a larger wavelength than the scattered photon. In both cases the species is found in different states because of difference in its vibrational modes.

Anti-Stokes scattered radiation is less intense than Stokes scattered radiation, because for the first to happen, the interacting molecule has to be in a higher vibrational energy (excited) state, less populated than the fundamental. In its turn, Rayleigh scattered radiation is much more intense than Raman scattered.

Since it involves virtual states (prohibited, because they mostly do not correspond to quantized energy states), scattering is an event very unlikely to happen: around 0.1 $\%$ of incident photons are elastically scattered, while only 1 every 10 million photons are inelastically scattered. For that reason, laser beams are utilized: the high intensity (high photon flux) makes for an appreciable count of inelastically scattered radiation to be generated and subsequently detected. Figure 18 shows the different types of scattering in terms of energy states.

Raman spectroscopy is the technique that uses these inelastically scattered photons to obtain chemical information. Since it involves the vibrational modes of a species, it is used to analyze the bonding in molecules. It is complementary to infrared absorption spectroscopy (FTIR). 

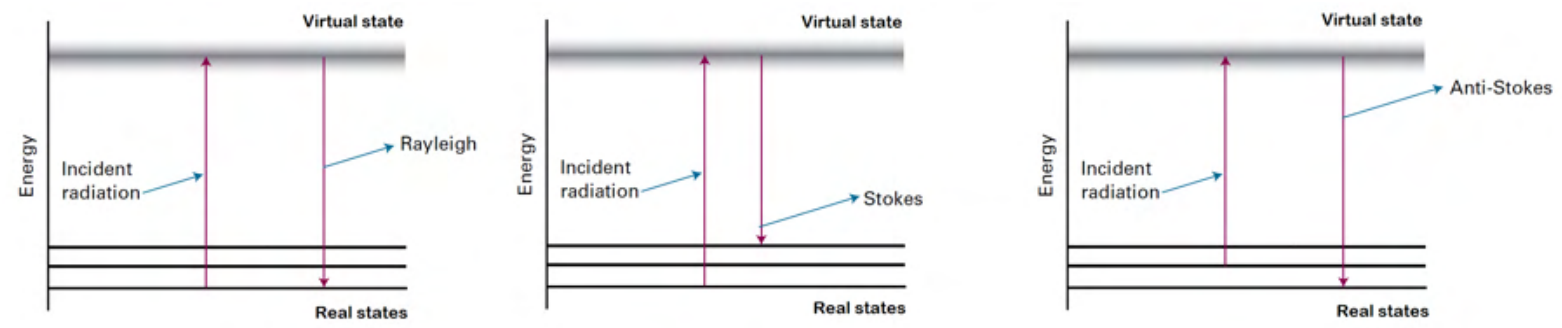

Figure 18 - Energy diagrams showing the processes involved in Rayleigh, Stokes, and anti-Stokes scattering. Adapted from [21]

Such complementarity arises from the selection rules that dictate the activity of a vibrational transition in each type of interaction. Some modes are only infrared active, while others are only Raman active, and will only be shown in the respective spectra.

The interaction of a molecule with electromagnetic radiation causes a distortion of its electron cloud. This is determined by the polarizability tensor, $\alpha$, given by

$$
\boldsymbol{\mu}=\alpha \boldsymbol{E}
$$

where $\boldsymbol{E}$ is the electric field component of the incoming radiation.

For a Raman active mode, Equation 5.2 is rewritten as

$$
\boldsymbol{\mu}_{f i}=\boldsymbol{E}\left(\frac{d \alpha}{d x}\right) \int \Psi_{f}^{*} x \Psi_{i} d \tau
$$

For Equation 5.6 to be nonzero, the derivative must be non-zero. Therefore, a vibrational mode will be Raman active if it accompanies a change in the polarizability of the molecule [20, 21, 72].

\subsubsection{Ultraviolet/visible absorption and photoluminescence spectroscopy (elec- tronic spectroscopy)}

When photons of visible and ultraviolet radiation interact with an atom or molecule, the external electrons of the species change their energy level (electronic states) [73].

When solving the Schrödinger equation to determine the electronic structure of atoms and molecules (analytically for the hydrogen atom, using approximations and computational processes for the other atoms and any molecule), each wavefunction-energy pair that is found as solution corresponds to the (atomic or molecular) orbitals, the regions of probability where the electron may be in the structure, and their respective energy values. Orbitals are defined in terms of the quantum numbers $n, l$ and $m_{l}$. Filling up 
the orbitals with electrons, from the lowest to the highest in energy, gives the electronic configuration of the species. A more complete description of how the electrons are arranged in the orbitals is given by the electronic states, which take in consideration not only the distribution of electrons in the different orbitals, but also their spins (described by the quantum number $m_{s}$ ).

A singular arrangement of electrons in a set of orbitals configures one microstate. Different microstates that arise from one single electron configuration often possess different values of energy, because electron-electron repulsions are considered. The microstates with same energy are grouped together in electronic states, or, in spectroscopy notation, terms. These, in turn, correspond to the electronic states of a species. Finally, the electronic transitions that happen when photons interact with such energy levels correspond to the change in the arrangement of electrons due to a gain or loss of energy (which does not necessarily involve a change in the electronic configuration)

The lowest-energy electronic state is called ground (or fundamental) state, while the higher-energy states are called excited states. In electronic absorption spectroscopy, the absorbed photons are usually involved in transitions from the ground state to an excited state, because the first is statistically the most populated one.

The specific selection rules for electronic transitions can be derived from the symmetry properties of the molecule. The spin selection rule enunciates that transitions accompanied by a change in the total spin are forbidden. The Laporte selection rule states that, in centrosymmetric molecules, there must be a change in the parity of the term in order for a transition to be allowed. Vibrational and rotational transitions often accompany the electronic transitions, which can be also called vibronic for that reason. Laporte rule is often relaxed because of asymmetric vibrations that result in a loss of the center of symmetry of the molecule, causing weaker vibronic transitions to happen.

Electronic excited molecules (if they are not dissociated) return to the ground state via many processes. The excess energy can be transferred to neighboring molecules and used to promote vibrational, rotational, and translational motion. This dissipation of energy throughout the material and to its surroundings (in the form of heat) is called non-radiative decay. On the other hand, radiative decay is when the molecule loses the excess energy through emission of photons, or luminescence.

In photoluminescence spectroscopy, the excited states are reached by means of absorption of photons. The emitted photons are collected, and the results can be presented in two ways:

- Emission spectra measure the intensity of luminescence as a function of the wavelength of the emitted photons when the wavelength of the incident photons is fixed; 
- Excitation spectra measure the intensity of luminescence in a fixed wavelength as the wavelength of the incident photons is scanned.

Combined, these two spectra provide information regarding the electronic states involved in the absorption and emission processes. Jablonski diagrams are graphical representations of the absorption, radiative, and non-radiative decays of a given species [20, 21, 72$]$.

\subsubsection{X-ray photoelectron spectroscopy}

X-rays interact in many different ways with matter. They can be absorbed by atoms, and transitions involving internal electrons may occur. In X-ray photoelectron spectroscopy (XPS), a monochromatic X-ray beam promotes the emission of photoelectrons from a certain orbital in an atom. The photoemission process happens when the energy of the incoming X-ray photons is at least equal to the binding energy of the electron $\left(E_{B}\right)$. The excess energy of the photon is converted to kinetic energy of the ejected electrons $\left(E_{K}\right)$. In that sense, the term $E_{K}$ can be written as

$$
E_{K}=h \nu-E_{B}
$$

A spectrum of the count of photoelectrons ejected from the sample per unit time as function of the kinetic energy is generated, which can then be converted to a spectrum in terms of the binding energy, since the energy of the X-rays employed in the analysis is known. Information regarding the atomic components and their oxidation states can then be obtained.

Experimental data can be compared to reference binding energies, according to the atomic species and chemical state being investigated. One factor that must be considered in the analysis of XPS spectra is the splitting of $\mathrm{p}, \mathrm{d}$, and $\mathrm{f}$ orbitals due to the spin-orbit coupling of electrons, which is reflected in the assignment of peaks in the spectra [74].

\subsubsection{Resonance spectroscopy (nuclear magnetic resonance and electron para- magnetic resonance)}

Resonance happens when the oscillation frequency of the interacting species is of the same order than the electromagnetic radiation, and the result is the increase in the oscillation amplitude. The transference of energy between two entities in resonance is maximum. Two techniques that utilize the resonance phenomenon to obtain chemical information are nuclear magnetic resonance (NMR) spectroscopy and electron paramagnetic resonance (EPR) spectroscopy. In both cases, the spin orientations of a particle (an atomic 
nucleus or an unpaired electron, respectively) lose degeneracy due to an applied external magnetic field. When the energy gap between these two orientations is close to the energy of incoming electromagnetic radiation, the resonance condition is met, and the electromagnetic field generated by the unbalance in particle distribution among the different spin orientations can be detected, giving information about the magnetic entities, such as chemical environment and electronic distribution. In NMR, the resonance frequency happens in radiofrequency region of electromagnetic spectrum, while in EPR, it happens in the microwave region, with magnetic fields normally employed in each technique [21].

\subsubsection{Experimental setups}

Raman spectroscopy data were collected in a Horiba LabRAM HR Evolution spectrometer, with a $1800 \mathrm{~g} \mathrm{~mm}^{-1}$ diffraction grating. The instrument has four laser sources: 325, 473, 633, and $785 \mathrm{~nm}$. All measurements were conducted using the $633 \mathrm{~nm}$ laser beam, except for the SERS experiments with crystal violet, where the $473 \mathrm{~nm}$ laser was employed.

UV-Vis spectra were collected in a Shimadzu UV-3600 UV-Visible-NIR spectrophotometer equipped with a tungsten and a deuterium lamp as radiation sources and a PMT (photomultiplier tube) and $\mathrm{PbS}$ as detectors, in both transmittance and diffuse reflectance modes. They were used to verify the presence of a plasmon band that confirms the synthesis of Ag-NPs in the materials. The photocatalytic activity was also assessed using electronic spectroscopy, and an Ocean Optics USB4000 UV-Visible spectrophotometer was used for that purpose.

Photoluminescence spectra were collected in a Horiba Fluorolog spectrofluorometer equipped with an Xe arc lamp as excitation source and a PMT as detector positioned at a 90-degree angle to the incident beam. Excitation and emission spectra were utilized to determine the species responsible for the color of NBTN glasses.

X-Ray photoelectron spectra were collected on a Scientia Omicron ESCA+ spectrometer, using AlK $\alpha$ radiation $(1486.7 \mathrm{eV})$, in order to confirm the discussion presented on the photoluminescence spectroscopy.

\subsection{X-ray diffraction}

Diffraction is a phenomenon understood using the wave-like behavior of light. It is a consequence of the way waves propagate in space. When a wavefront encounters an object or opening with the dimensions of its wavelength, it is diffracted through it, meaning that the object or opening becomes a secondary source of propagation of that wave. 
Crystals can be understood as symmetric and ordered arrays of atoms. The length of the separation between planes of atoms (lattice, or crystallographic planes) is in the order of angstroms $\left(\AA, 10^{-10} \mathrm{~m}\right)$, the same as the wavelength of X-rays. Hence, X-rays are susceptible to diffraction when directed towards a crystal.

When an X-ray beam is focused on a crystalline sample, it is diffracted by the many crystallographic planes in the structure. Each set of planes constitutes a diffraction grating, and the diffracted waves interfere. The result of this interference is that there it is constructive in a particular angle with respect to the planes (situation where all the waves are in phase), and the diffracted beam, denoted reflection, is very intense in that particular angle. This observation gave rise to Bragg's law, which states that, for constructive interference to exist when X-rays are focused on a crystal, the path difference between two crystallographic planes of the same set must equal an integer multiple of the wavelength. In mathematical notation, this is written as

$$
n \lambda=2 d \sin \theta
$$

where $d$ is the interplanar spacing, and $2 \theta$ is the angle between the incoming and diffracted beams.

The experiment of X-ray diffraction (or diffractometry, XRD) can be performed in powdered samples (where many crystallites will be in the correct direction for a reflection to occur), where it will generate a diffractogram, or in a single crystal, where many diffraction patterns are generated and collected.

In powder XRD, the detector is rotated, and the intensity of the X-ray is recorded as a function of the angle $2 \theta$ with the beam source. In single crystal XRD, the patterns are obtained using a set of four rotations of the sample holder.

The intensity of the reflected beams depends not only on the atomic positions within the crystal lattice, but also on the types of atoms (because the scattering of X-rays is dependent on the electron density). Therefore, XRD is a powerful technique to obtain information regarding the structure of the samples, from interplanar spacing and crystal composition to a full description of how the atoms are arranged in the crystal lattice [20, 21, 72$]$.

Powder XRD data were collected in a Bruker D8 Advance diffractometer, using $\mathrm{CuK} \alpha$ radiation $(1.54 \AA)$ to identify the crystal phases formed after a heat treatment above $T_{g}$ was performed on the synthesized glass. 


\subsection{Electron microscopy}

Optical microscopy uses visible light photons and a set of lenses to obtain images in a shorter scale than the resolution power of the human eye. That is also the main goal of electron microscopy; however, it uses highly energetic electrons instead of photons to produce the images, as its name implies. Accelerated electrons are generated in a vacuum chamber, and a set of electric and magnetic fields works as lenses, to focus the electron beam on the sample and amplify the signals obtained to form the image on the detector.

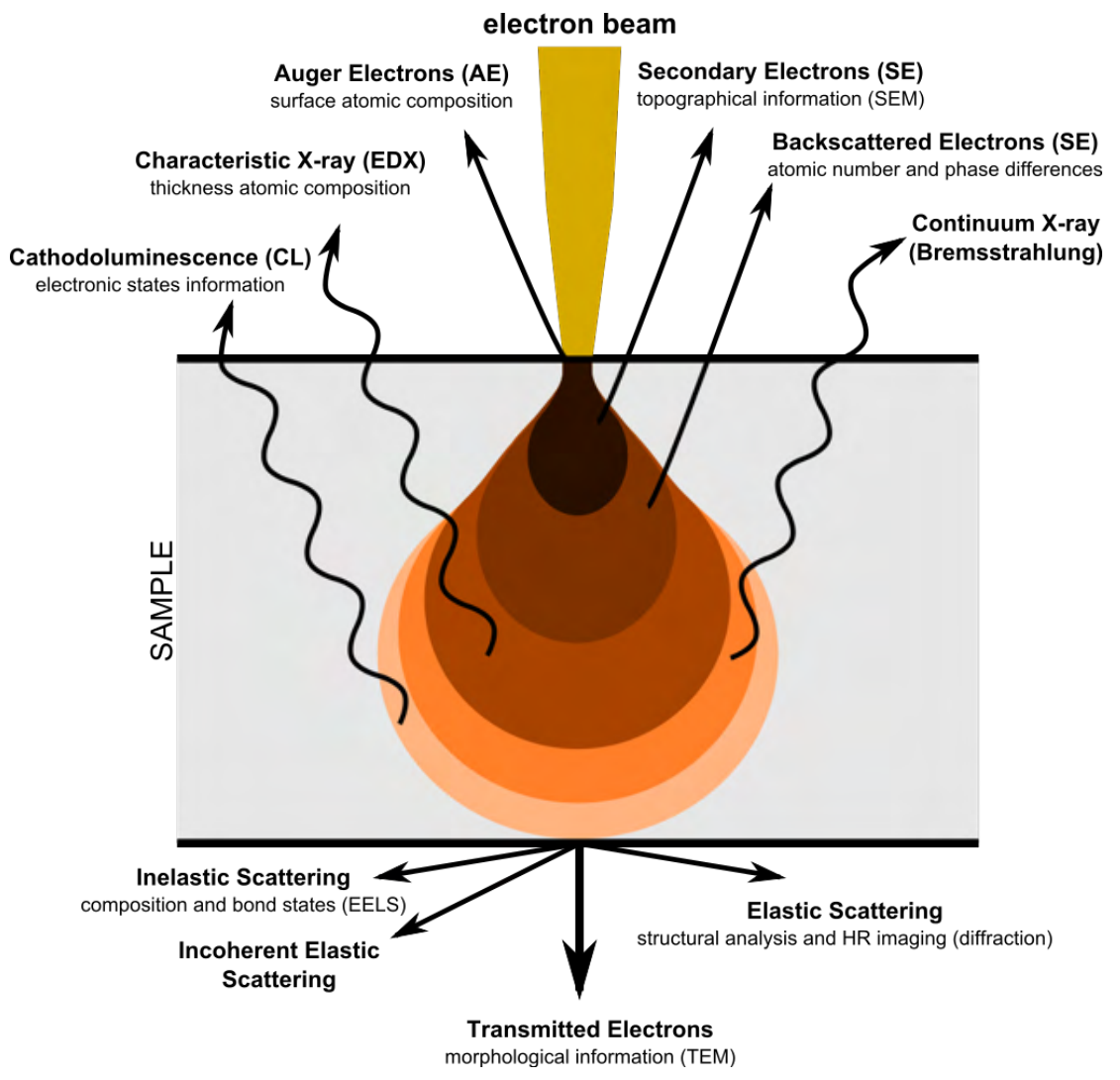

Figure 19 - Interaction volume between the electron beam and the sample, showing different results of the interaction. CC BY-SA 4.0.

When the electron beam hits the sample, they interact via different mechanisms, with many different outcomes, which are displayed in Figure 19. Depending on the energy of the electron beam and the species that are detected (electrons or X-rays, for example), a distinct technique arises [74].

Scanning electron microscopy images were obtained on a LEO-440 electron microscope using a $15 \mathrm{kV}$ accelerating voltage. Transmission electron microscopy images were collected on a JEOL JEM2100 LaB6 200 kV electron microscope. Energy-dispersive X-ray spectroscopy maps were collected in both techniques. 


\subsubsection{Scanning electron microscopy}

Scanning electron microscopy (SEM) uses an electron beam with moderately high energy. The information obtained with this imaging technique are mostly related to topography and phase distribution. One of the main features of SEM is the high depth of field that can be achieved, giving to the generated images a 3D look. Images can be formed by detection of the electrons that escape the sample. The most common types are the backscattered and the secondary electrons.

Backscattered electrons (BSEs) are those that interact elastically with the sample (no loss of energy). Heavier elements produce more BSEs and generate a brighter image than lighter elements. That is a good way to perform compositional analysis in materials.

Secondary electrons (SEs) are those emitted from the atoms that compose the sample and result from inelastic interactions. They are much less energetic than the incident electrons. Images generated with SEs provide good topographical information, due to their generation being mostly on the surface of the material [74].

\subsubsection{Transmission electron microscopy}

Transmission electron microscopy (TEM) utilizes a high energy electron beam (100 to $400 \mathrm{keV}$ ) One of the main features of TEM is its very high magnification power, to acquire images with a few nanometers of dimension. However, it requires thin samples, in order for the electron beam to cross the material. Thus, one limitation of this technique is sample preparation, which usually involves grinding, dispersion in a volatile solvent and mounting on a grid.

The images in TEM are formed by contrast, according to the amount of electrons that reach the detector. They are generated using transmitted electrons, those that pass through the sample without being deflected, and diffracted electrons, those that are scattered (with no loss of energy) after passing through the sample. Moreover, diffraction patterns can be obtained from small regions, because electrons also behave as waves, in the technique known as selected-area electron diffraction (SAED). Hence, information about morphology and structure can be obtained from TEM images and diffraction patterns [74.

\subsubsection{Energy-dispersive X-ray spectroscopy}

When bombarding a sample with high-energy electrons, X-rays are generated as result of the interaction with atoms. In energy-dispersive X-ray spectroscopy (EDX), the wavelengths and intensities of the emitted photons are measured in order to identify the atomic contents in the region of the material being analyzed. 
X-rays are generated in two different ways when the electron beam hits the sample:

- Continuum X-rays, or Bremsstrahlung, a continuous range of wavelengths that is produced as a consequence of the deceleration of the incoming electrons (due to the growing electric repulsion when approaching atomic nuclei) as they penetrate the structure (deceleration causes a loss of energy, that is converted to X-ray photons);

- Characteristic X-rays, which are generated when the electron probe transfers energy to an inner-shell electron, causing its ejection from the atom. The whole that is left is then filled by an electron from an higher energy shell, and the excess energy is then emitted in the form of an X-ray photon. Its wavelength is dependent on the atomic species and on the inner and outer shells involved in the emission process.

In EDX spectroscopy, the intensity of each characteristic X-ray line is proportional to the amount of the corresponding element in the area. It is, therefore, a technique to acquire information regarding atomic composition of samples (qualitatively and quantitatively) [74].

\subsection{Surface-enhanced Raman scattering}

Raman spectroscopy is a very sensible technique. But the intensity of signals can be enhanced in a $10^{6}$ factor with the aid of metal nanoparticles [35]. Surface-enhanced Raman scattering (SERS) corresponds to this enormous increase in intensity of inelastically scattered photons due to the surface plasmon resonance effect.

If a molecule is adsorbed on the surface of the nanoparticle (either physically or chemically), the Raman scattered radiation can be greatly intensified, and much smaller concentrations of analyte can be detected. Figure 20 shows the example of the enhancement of rhodamine $6 \mathrm{G}$ signals when it is in the presence of Ag-NPs. Development of substrates for such a powerful technique as SERS is in steady growth, because detection of compounds in trace amounts is of great importance in areas such as environmental and biochemistry. SERS is being investigated as a tool for single molecule detection, due to the large enhancements that can be achieved [75, 76, 777].

The enhancement of signals via SERS depends on several variables, in a way that not all bands are equally intensified. Such complexity makes the SERS activity of a substrate vary widely with different target molecules[78]. 


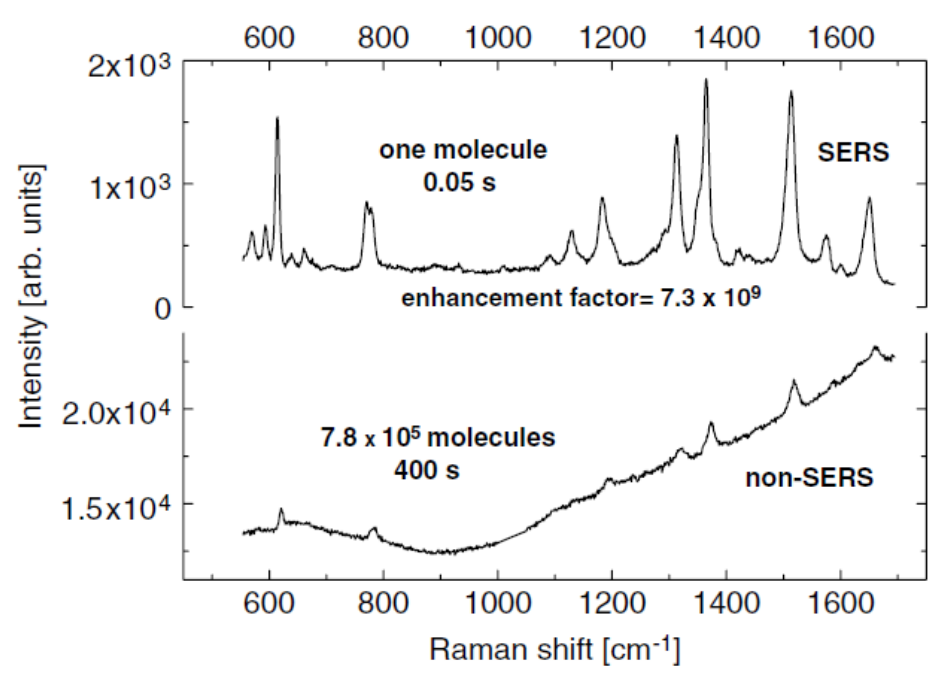

Figure 20 - Enhancement of the detection of Rhodamine 6G via SERS. The bottom spectrum is from an aqueous solution of rhodamine $6 \mathrm{G}$, and the top spectrum is from rhodamine in Ag colloidal suspension medium. Extracted from [79].

\subsubsection{Enhancement factors}

Two mechanisms are responsible for the origin of enhancement in SERS:

- Electromagnetic enhancement Accounts for most of the enhancement. It is a result of the coupling of both the incident and scattered electromagnetic fields with the LSPs of the nanoparticles. In order for it to happen, the molecules must be close to the NPs;

- Chemical enhancement Corresponds to a modification in the polarizability of the molecule probe, that might induce the enhanced resonant Raman scattering. This type of enhancement happens when the molecule is coordinated to the metal atoms that constitute the NPs, and involves charge transfers between the metal and the ligand.

Enhancement factor (EF) is defined as a quantitative measure of the amplification of Raman signals of an analyte on a given substrate. There are multiple ways an EF can be calculated. Most of the times, two different substrates cannot be compared in terms of their EFs, because of the multitude of types and classes of substrates that induce differences in the nature of the enhancement.

Among the many parameters that influence enhancement of Raman signals via SERS are characteristics of the laser source (wavelength and angle of incidence), detection setup, substrate characteristics (NP species and geometry, composition of the material 
that holds the NPs), intrinsic properties of the analyte (polarizability), adsorption of the analyte, and many others.

The simplest way to calculate the enhancement factor based on experimental evidence is the analytical EF: given the parameters $c_{R S}$, the concentration of analyte, $I_{R S}$, the Raman signal, $c_{S E R S}$, the concentration in the SERS experiment (which may or may not be equal to $c_{R S}$ ), and $I_{S E R S}$, the SERS signal, the AEF is calculated by

$$
A E F=\left(\frac{I_{S E R S}}{c_{S E R S}}\right)\left(\frac{c_{R S}}{I_{R S}}\right)
$$

It must be noted that the conditions of both Raman and SERS measurement (preparation, analyte) are required to be the same. Furthermore, this definition implies the assumption that both the intensities vary linearly with concentration of analyte. There is, however, this fact depends strongly on the adosption of the substrate.

Another definition is the SERS substrate enhancement factor (SSEF), which considers adsorption, and is defined as

$$
S S E F=\left(\frac{I_{S E R S}}{N_{\text {surf }}}\right)\left(\frac{N_{\text {vol }}}{I_{R S}}\right)
$$

where $N_{v o l}$ is the average number of molecules in the scattering volume for the Raman measurement, and $N_{\text {surf }}$ is the average number of adsorbed molecules for the SERS experiment (considering the same scattering volume). The difficulty of application of this equation lies in the determination of these two parameters [79].

\subsubsection{Determination of signals enhanced by SERS}

Using a rigorous quantum mechanical treatment of the electronic and vibrational transitions of the molecule, both when bonded and not-bonded to the metal atom in the $\mathrm{NP}$, it is possible to predict which Raman active modes are going to be enhanced in SERS experiments.

In basic terms, the polarizability tensor of the probe molecule, when bonded to the NP metal atom, can be written as

$$
\alpha=A+B+C
$$

where $A$ is the Frank-Condon term, related to when the condition of resonance between an electronic transition (from the ground to an excited state) and the laser radiation is met, $B$ is related to molecule-to-metal transitions, and $C$ is related to metal-to-molecule transitions (there are the Herzberg-Teller terms) [80].

The development of these terms leads to the conclusion that totally symmetric vibrational modes are the ones enhanced in SERS experiments, dominating the spectra, 
while non-totally symmetric modes may also be enhanced, a fact that depends on chargetransfer mechanisms, therefore indicating the presence of ligand-metal bonds between the analyte and the metallic NPs [81]. 


\section{CHAPTER 6}

\section{Glass synthesis and characterization}

All glass samples were synthesized via the traditional melt-quenching process. Two families of phosphate samples were produced: lead phosphate glasses (PBTN) and sodium phosphate glasses (NBTN). A third family of glasses was also proposed in the scope of this project, VGBN glasses, with composition $\mathrm{V}_{2} \mathrm{O}_{5}-\mathrm{GeO}_{2}-\mathrm{Bi}_{2} \mathrm{O}_{3}-\mathrm{Na}_{2} \mathrm{O}$. However, after many attempts, a vitreous sample could not be obtained.

\subsection{Lead phosphate glass system}

PBTN glasses have composition $(85-x) \mathbf{P b}_{2} \mathbf{P}_{2} \mathbf{O}_{7}-x \mathbf{B}_{2} \mathbf{O}_{3}-10 \mathbf{T i O}_{2}-5 \mathrm{Na}_{2} \mathrm{O}$. The amount of boron oxide was varied from 10 to $35 \mathrm{~mol} \%$ (Table 1) and the amount of lead pyrophosphate was respectively reduced (the samples were labeled PBTN10 to PBTN35).

Lead pyrophosphate $\left(\mathrm{Pb}_{2} \mathrm{P}_{2} \mathrm{O}_{7}\right)$ was prepared by reaction of lead acetate $\left(\mathrm{Pb}\left(\mathrm{CH}_{3} \mathrm{COO}\right)_{2}\right)$ with phosphoric acid $\left(\mathrm{H}_{3} \mathrm{PO}_{4}\right)$ at room temperature, producing a white powder insoluble in water [82]. It was then mixed with the remaining reagents in a mortar and then added to a $\mathrm{Pt} / \mathrm{Au}$ crucible. The melting was performed at $1100{ }^{\circ} \mathrm{C}$ for $30 \mathrm{~min}$, followed by casting into a preheated mold at $350{ }^{\circ} \mathrm{C}$ and annealing at this same temperature.

The densities of the samples were measured using the classical Archimedes principle: the solids were weighed in air $\left(m_{a}\right)$ and then again in water $\left(m_{w}\right)$; the density $\rho$ can be calculated using equation 6.1, where $\rho_{w}$ and $\rho_{a}$ are the densities of water and air, respectively.

$$
\rho=\frac{m_{a}}{m_{a}-m_{w}}\left(\rho_{w}-\rho_{a}\right)+\rho_{a}
$$

The results are presented in Table 1. PBTN glasses have an increasing amount of $\mathrm{B}_{2} \mathrm{O}_{3}$ and a decreasing amount of $\mathrm{Pb}_{2} \mathrm{P}_{2} \mathrm{O}_{7}$, accounting for the drop in the density values. 
Table 1 - Lead phosphate glass compositions, densities, and appearance

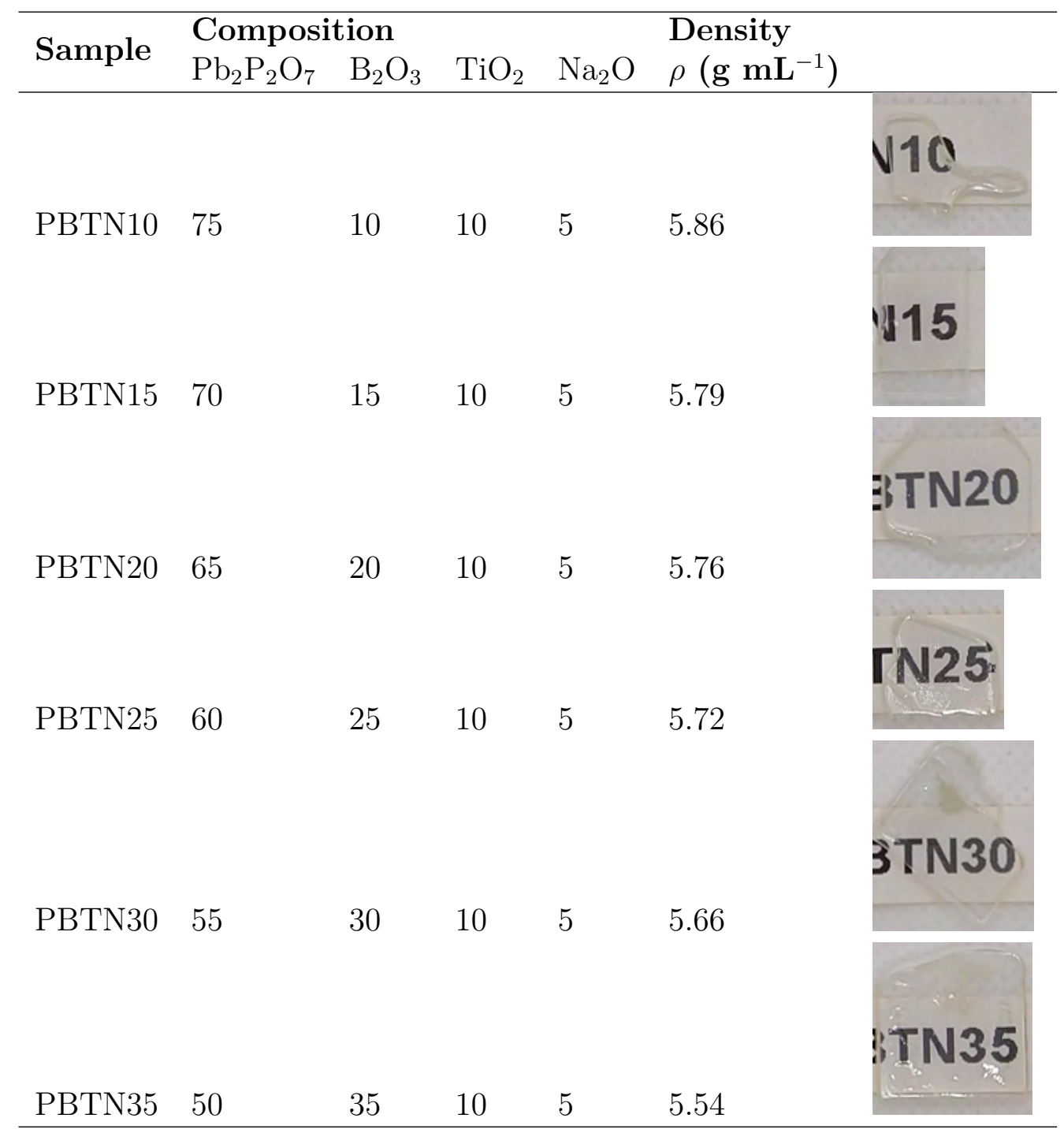

\subsubsection{Differential scanning calorimetry}

The DSC curves of PBTN glasses are shown in Figure 21, while the characteristic temperatures are presented in Table 2.

The PBTN glass family was synthesized with an increasing amount of $\mathrm{B}_{2} \mathrm{O}_{3}$. The effect of these changes is the increase in the characteristic temperatures of the glasses, according to Figure 21. $\mathrm{B}_{2} \mathrm{O}_{3}$ is a glass former, with all oxygen atoms in its network being bridging oxygens (connecting two boron atoms), whilst in phosphate, formed by $\left[\mathrm{PO}_{4}\right]$ units, at least one of the oxygens is a non-bridging oxygen. The glass transition temperature for all glasses were between 430 and $460{ }^{\circ} \mathrm{C}$, and the crystallization peaks for all samples could be identified, happening between 470 and $520^{\circ} \mathrm{C}$. 


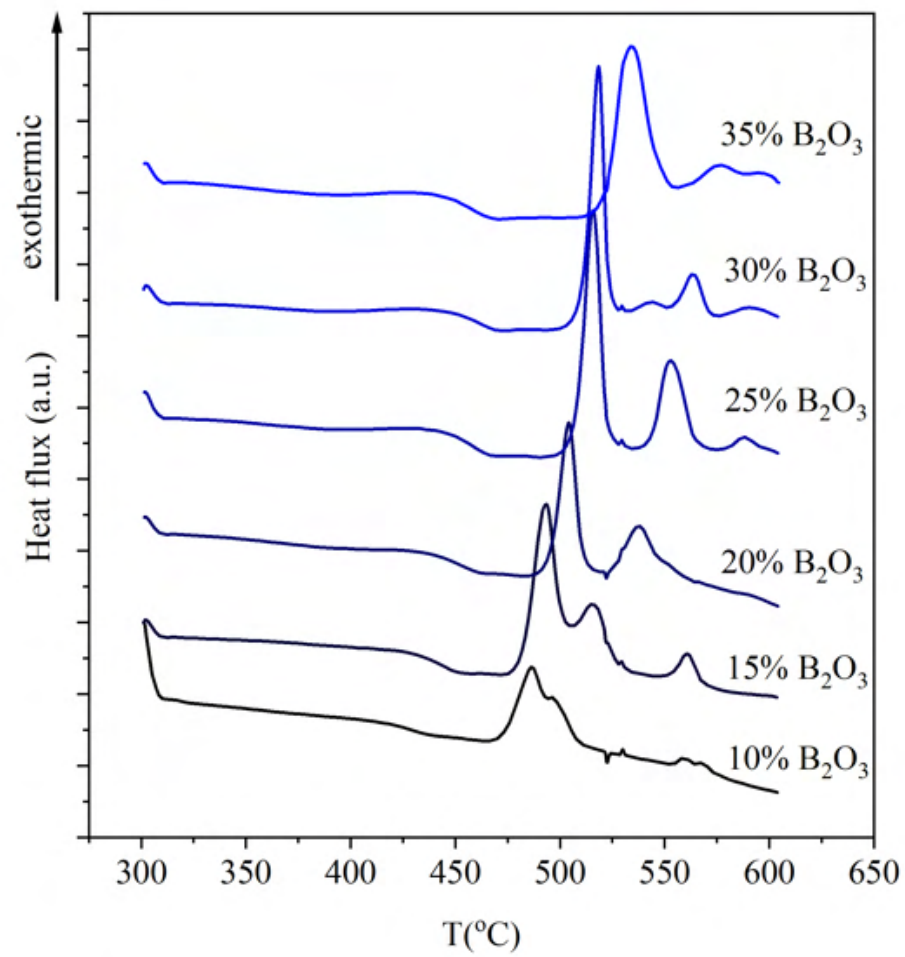

Figure 21 - DSC curves for lead phosphate systems. There is an increase in the characteristic temperatures with increasing amount of $\mathrm{B}_{2} \mathrm{O}_{3}$.

Table 2 - Characteristic temperatures for PBTN glasses

\begin{tabular}{llll}
\hline & \multicolumn{3}{l}{ Characteristic temperatures $\left({ }^{\circ} \mathbf{C}\right)$} \\
\cline { 2 - 4 } Samples & $T_{g}$ & $T_{x}$ & $\Delta T$ \\
\hline PBTN-10 & 436.20 & 470.67 & 34.47 \\
PBTN-15 & 442.99 & 478.13 & 35.14 \\
PBTN-20 & 453.02 & 491.35 & 38.33 \\
PBTN-25 & 458.54 & 502.95 & 44.41 \\
PBTN-30 & 460.62 & 506.26 & 45.64 \\
PBTN-35 & 458.51 & 518.24 & 59.73 \\
\hline
\end{tabular}

Three crystallization peaks can be observed. An increasing amount of boron oxide yields higher temperatures observed for those peaks. Also, the first two peaks, which were initially conjoined, separate, with the second approaching the third peak. These peaks indicate the glass system crystallizes in different ways and phases, an effect that can be attributed to the presence of titanium oxide, a compound that is known to be polymorphic (the three main phases being rutile, anatase - in the tetragonal crystal system - and brookite - in the orthorhombic crystal system). That compound might have formed different polycrystalline phases in association with sodium and phosphate. 
The addition of $\mathrm{B}_{2} \mathrm{O}_{3}$ promotes an increasing thermal stability of the system, with a more pronounced increase in the crystallization temperature onset $\left(T_{x}\right)$ in relation to $T_{g}$. That means that boron oxide has a greater stabilization effect of the non-bridging oxygens than lead ions, with the advantage of increasing the network connectivity.

The temperature range between the glass transition and the crystallization onset gives the thermal stability of the samples. Between these temperatures, the glass is in a viscoelastic regimen (where both larger bond stretching and diffusion of atoms can be experienced) [83]. That range is where the ion exchange experiments can be performed, precisely because such viscoelastic regimen allows for a greater mobility of silver atoms within the glass structure, consequently forming the nanoparticles.

\subsubsection{Raman spectroscopy}

The Raman spectra from PBTN glasses are presented in Figure 22, The assignment of bands is presented in Table 3 .

Phosphate-based glasses present two main regions on their Raman spectra: around $700 \mathrm{~cm}^{-1}$, corresponding to stretching of bonds related to bridging oxygens, P-O-P, and around $1200 \mathrm{~cm}^{-1}$, corresponding to terminal P-O stretching modes [27]. These regions are studied to understand the connectivity patterns of phosphate tetrahedra within the glass network. In other words, Raman spectroscopy is a good tool to analyze whether a $\mathrm{Q}^{0}, \mathrm{Q}^{1}, \mathrm{Q}^{2}$, or $\mathrm{Q}^{3}$ pattern prevails in the glass structure.

Table 3 - Assignment of bands for PBTN Raman spectra

\begin{tabular}{lll}
\hline Raman shift $\left.\mathbf{( c m}^{-1}\right)$ & Assignment & Reference \\
\hline 1315 & B-O stretching & {$[84]$} \\
1150 & $\mathrm{Q}^{2}$ P-O stretching & {$[85]$} \\
1015 & $\mathrm{Q}^{1}$ P-O stretching + B-O diborate stretching & {$[85$,} \\
930 & $\mathrm{Q}^{0}$ P-O stretching + Ti-O stretching & {$[85,[87,88]$} \\
805 & B-O stretching (boroxol ring) & {$[86]$} \\
735 & Symmetric P-O-P stretching & {$[27,85]$} \\
418 & O-P-O bending & {$[27,85]$} \\
\hline
\end{tabular}

To understand the behavior of the phosphate network with addition of $\mathrm{B}_{2} \mathrm{O}_{3}$, each set of bands must be analyzed separately. The increase in the thermal stability, extracted from DSC data, indicates that such addition promotes a polymerization effect in the phosphate glass network. 


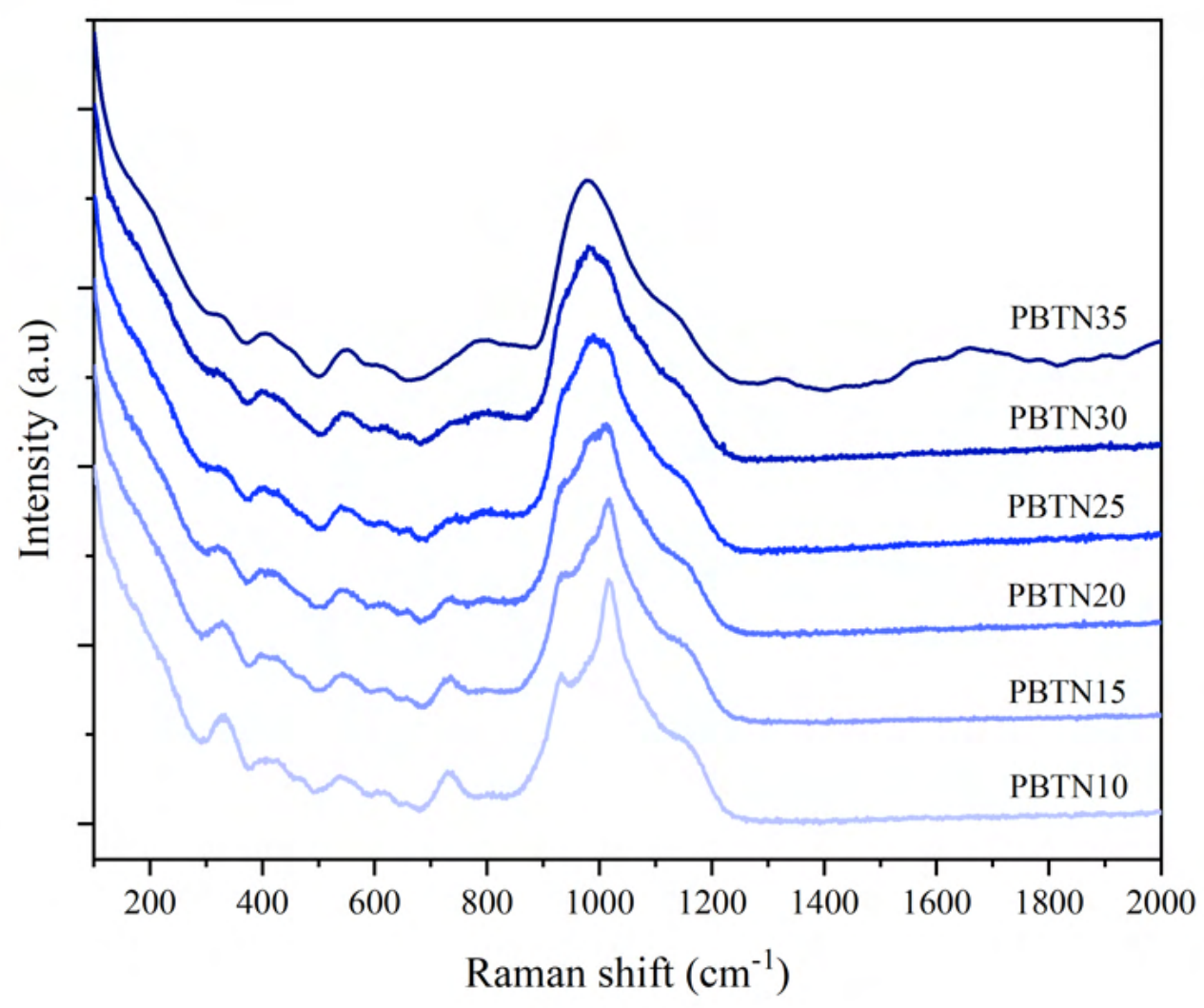

Figure 22 - Raman spectra of PBTN glasses with 633 nm laser excitation.
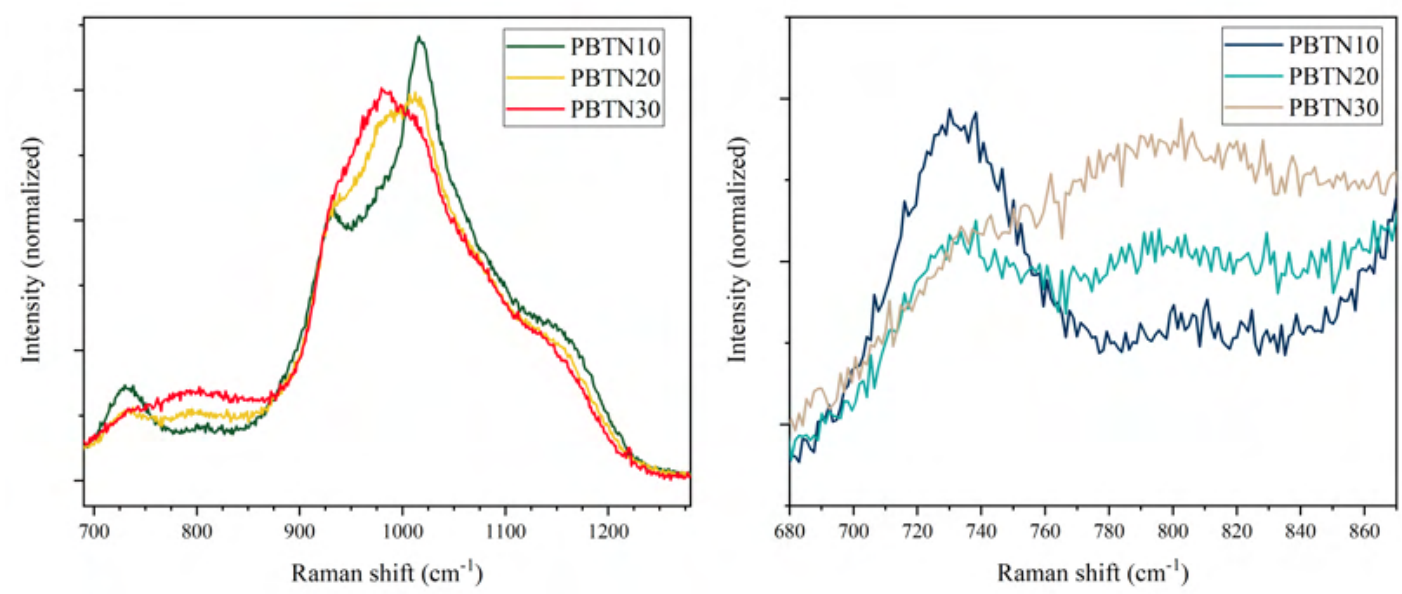

Figure 23 - Close-up views from PBTN Raman spectra comparing the normalized intensities of samples containing 10, 20 and $30 \mathrm{~mol} \%$ of $\mathrm{B}_{2} \mathrm{O}_{3}$.

Lead pyrophosphate is a $\mathrm{Q}^{1}$ phosphate precursor. Therefore, the main band seen in the spectra is expected to be the one corresponding to $\mathrm{Q}^{1}$ connectivity. As shown In Figure 23, the band at $1015 \mathrm{~cm}^{-1}$ seen in the first close-up is indeed originated from 
$\mathrm{Q}^{1} \mathrm{P}-\mathrm{O}$ stretching. This intensity decreases as the amount of pyrophosphate across the samples also decreases. According to Table 3, a B-O stretching from diborate structures can be identified around $1000 \mathrm{~cm}^{-1}$ Raman shift, accounting for the signal appearance in that region of the spectra with higher content of boron. There is also a band at $930 \mathrm{~cm}^{-1}$ corresponding to Ti-O stretching; since the amount of $\mathrm{TiO}_{2}$ in the compositions stays the same, that band does not have its intensity changed. Hence, the decreasing P-O $\mathrm{Q}^{1}$ and the Ti-O bands create an overall broadening effect of the region.

The second close-up in Figure 23 shows a stretching from P-O-P bridging oxygen at $735 \mathrm{~cm}^{-1}$ besides a B-O stretching from boroxol rings centered at $805 \mathrm{~cm}^{-1}$. As expected, the intensity of the first signal decreases as the intensity of the second increases.

The conclusion that can be drawn about the increasing thermal stability in PBTN glasses is that it can be accredited to the higher connectivity of the glass network imposed by the addition of boron oxide in opposition to the lower connectivity if it was purely composed of pyrophosphate. Higher glass transition temperature is directly related to a glass network with more linkages (more bonding oxygens), and the insertion of boron and titanium oxides and their $\left[\mathrm{BO}_{3}\right],\left[\mathrm{BO}_{4}\right]$ and $\left[\mathrm{TiO}_{6}\right]$ polyhedra to the composition promotes such increase in the connectivity.

\subsubsection{Crystallization essays and X-ray diffractometry}

To identify the crystal phases that form with heating, the sample PBTN15 was subject to thermal treatment at three different temperatures, corresponding to the three crystallization peaks in the DSC curve, for 4h. Powder X-ray diffraction was then utilized in the identification. The data were collected in a Bruker D8 Advance diffractometer, using $\mathrm{CuK} \alpha$ radiation $(1.54 \AA)$. Figure 24 shows the results obtained.

As can be seen, the same crystal phases were obtained for all three heat treatments. Furthermore, the relative intensities of the diffraction peaks are the same for all three data set. This means that all phases were equally obtained in all treatments.

A phase search was performed in ICSD (Inorganic Crystal Structure Database) to identify which were formed during the thermal treatment. Figure 25 shows those phases in comparison to the diffractogram obtained.

It was expected that different crystal phases would be formed at each crystallization temperature obtained from the DSC curve. An explanation for what happened instead is that the phases formed are intermediates toward a final crystalline structure, and the $4 \mathrm{~h}$ of heat treatment were not enough to complete the crystallization process. That way, in order to better investigate this, a longer treatment would be necessary. 


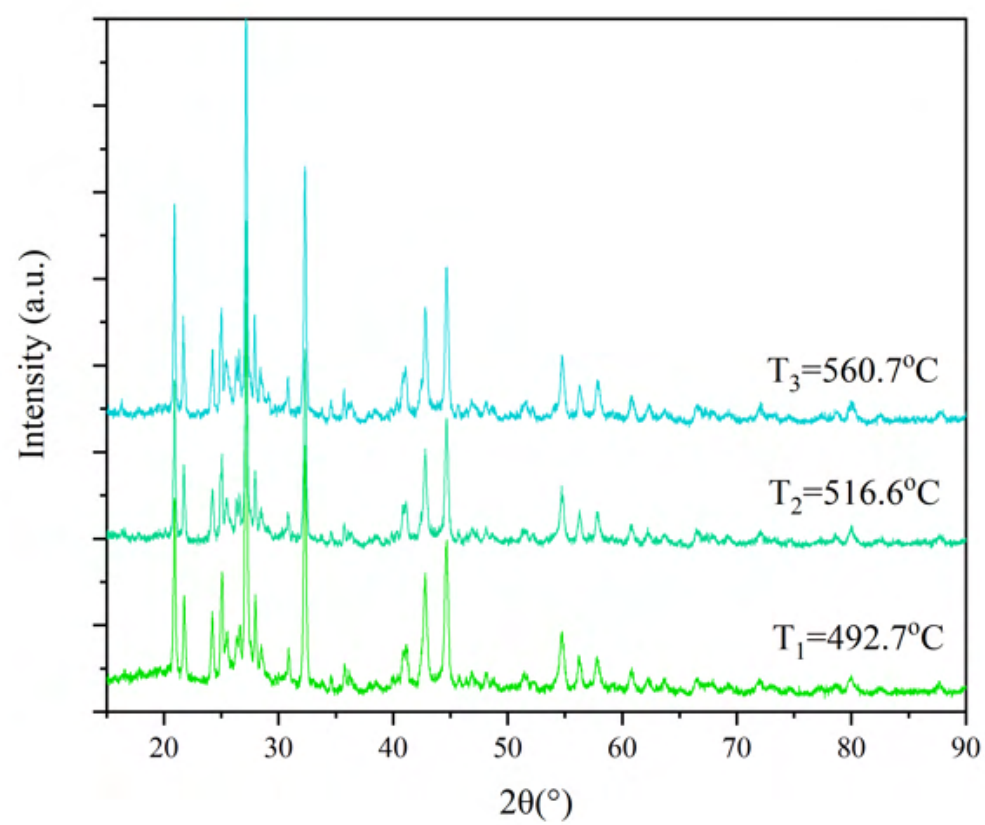

Figure 24 - Diffractograms obtained from PBTN15 samples after heat treatments at the three crystallization temperatures identified in its DSC curve.

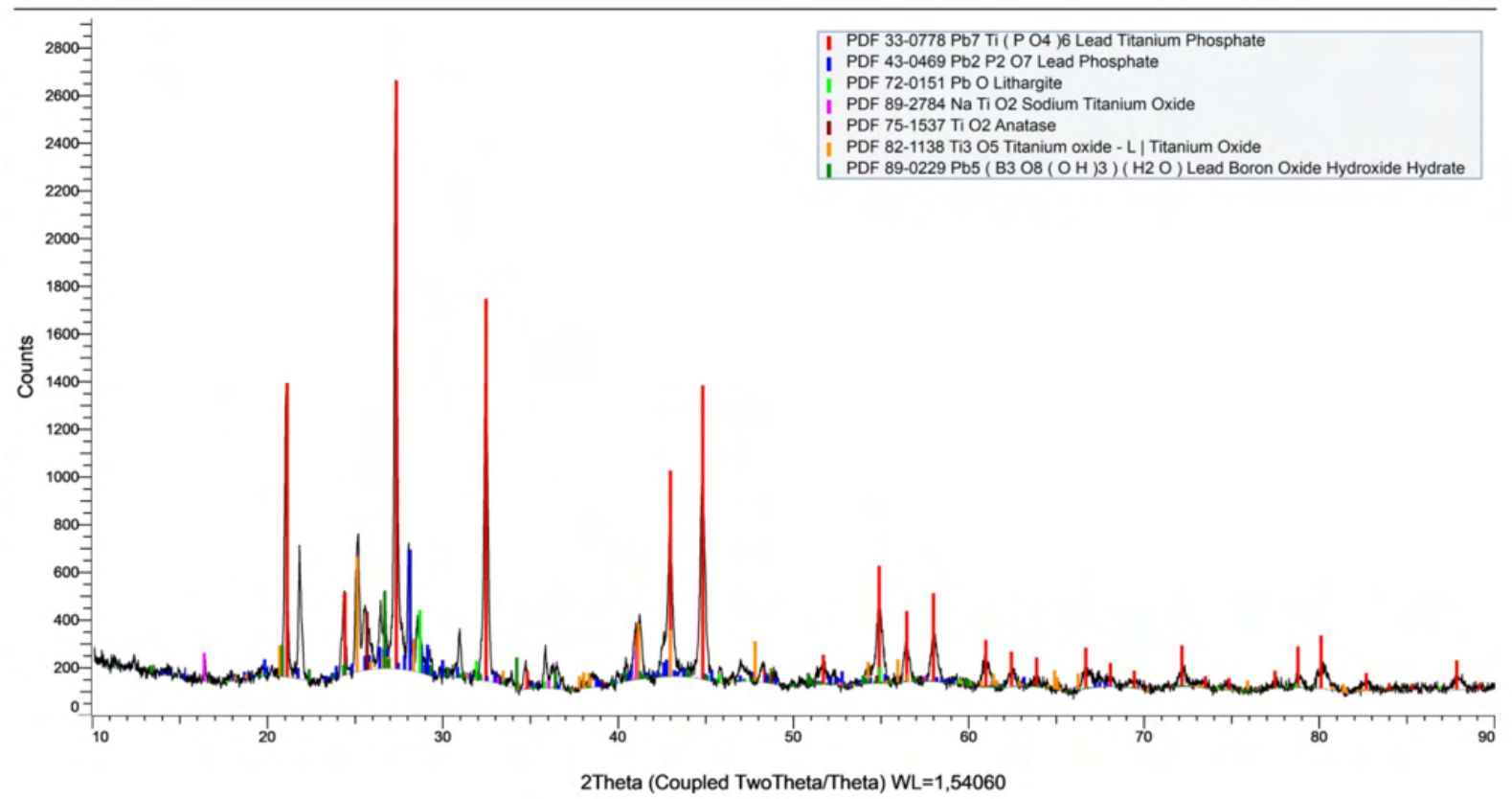

Figure 25 - Phase search results for the crystallized PBTN15 glass. 


\subsection{Sodium phosphate glass system}

NBTN glasses have composition $(65-y) \mathrm{NaPO}_{\mathbf{3}}-\mathbf{3 0 B}_{\mathbf{2}} \mathrm{O}_{\mathbf{3}}-y \mathbf{T i O}_{\mathbf{2}}-\mathbf{5} \mathrm{Na}_{\mathbf{2}} \mathrm{O}$. In this system, the amount of $\mathrm{B}_{2} \mathrm{O}_{3}$ was fixed and then the amount of titanium oxide was increased from 10 to $20 \mathrm{~mol} \%$ (Table 4 ) to evaluate the amount of $\mathrm{TiO}_{2}$ that can be incorporated into the glass without crystallization. The amount of sodium phosphate was respectively reduced. It was not possible to obtain a glass sample with more than $20 \mathrm{~mol} \%$ of $\mathrm{TiO}_{2}$ without crystallization (the samples were labeled NBTN10 to NBTN20).

Ion exchange was later carried out on NBTN glasses. They were chosen over PBTN family in order to avoid the use of lead, a well-known toxic element. Also, it was not necessary to synthesize any of the components of NBTN glass. Thus, the glass synthesis could be reduced by one step. Last, as can be verified comparing thermal stabilities shown in Tables 2 and 5, NBTN glasses are thermally more stable than PBTN glasses.

The densities of the samples are shown in Table 4. PBTN glasses are denser than NBTN glasses due to the presence of lead atoms in the former.

One interesting fact to be noted about the NBTN glasses is that their color changes according to many conditions, such as melting temperature and time, annealing temperature, and concentration of $\mathrm{TiO}_{2}$ used in the composition, as can be noted in Figure 26 (in Table 4, the samples were cast at $350{ }^{\circ} \mathrm{C}$ ). The samples melted at $1100{ }^{\circ} \mathrm{C}$ with annealing at $400{ }^{\circ} \mathrm{C}$ were used for the ion exchange.

Table 4 - Sodium phosphate glass compositions, densities, and appearance

\begin{tabular}{|c|c|c|c|c|c|c|}
\hline \multirow{2}{*}{ Sample } & \multicolumn{2}{|c|}{ Composition } & \multicolumn{4}{|c|}{ Density } \\
\hline & $\mathrm{NaPO}_{3}$ & $\mathrm{~B}_{2} \mathrm{O}_{3}$ & $\mathrm{TiO}_{2}$ & $\mathrm{Na}_{2} \mathrm{O}$ & $\rho\left(\mathbf{g ~ m L}^{-1}\right)$ & \\
\hline NBTN10 & 55 & 30 & 10 & 5 & 2.62 & \\
\hline NBTN15 & 50 & 30 & 15 & 5 & 2.67 & \\
\hline NBTN20 & 45 & 30 & 20 & 5 & 2.71 & 120 \\
\hline
\end{tabular}


Amount of $\mathrm{TiO}_{2}$

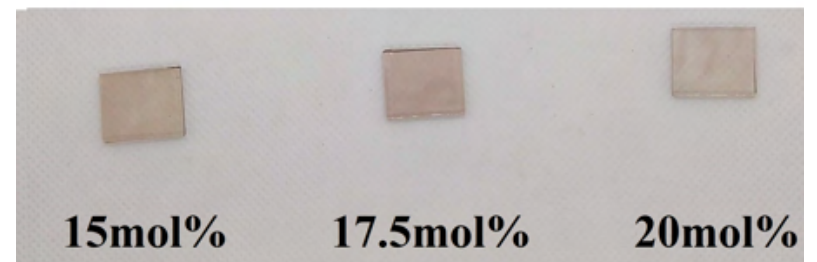

\section{Mold/annealing temperature}

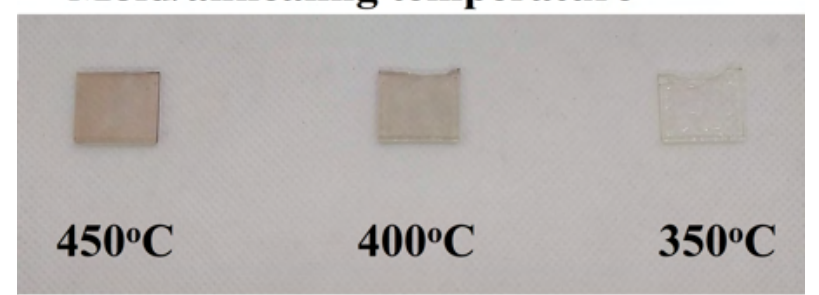

Melting temperature

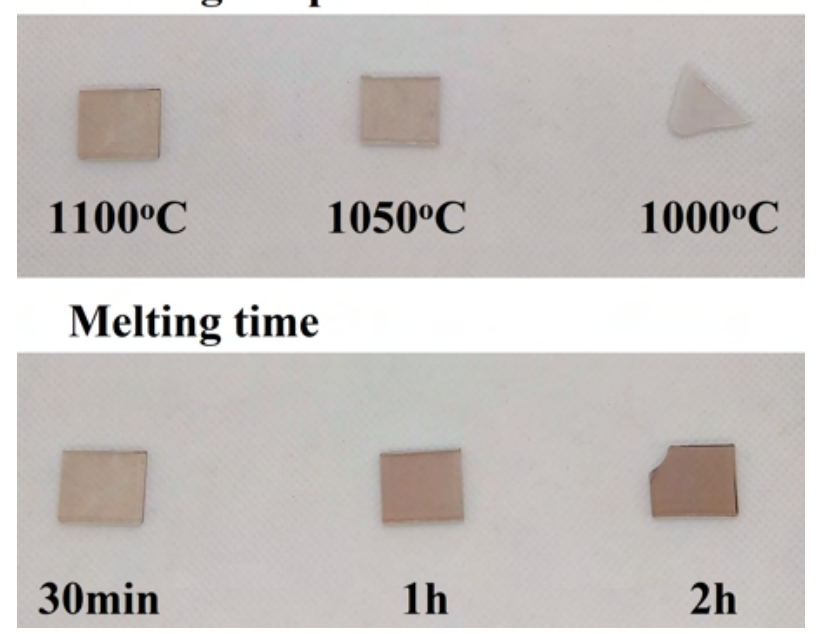

Figure 26 - Difference in coloration of NBTN15 glass with $\mathrm{TiO}_{2}$ amount, mold/annealing temperature, melting temperature, and time of melting. In each set of samples, the conditions that were not varied are fixed as $15 \mathrm{~mol} \% \mathrm{TiO}_{2}, 450{ }^{\circ} \mathrm{C}, 1100{ }^{\circ}$, and $30 \mathrm{~min}$.

Another interesting observation (which is also true for PBTN glasses) is that the NBTN samples are chemically stable: contrary to many phosphate glass compositions, the synthesized glasses are highly resistant to degradation due to ambient humidity. The may be a clue of the inclusion of titanium in the glass network.

\subsubsection{Photoluminescence spectroscopy}

To investigate the reason why NBTN samples are brownish, with the intensity of the color varying according to the conditions of the synthesis, photoluminescence studies were performed on NBTN15 with $30 \mathrm{~min}$ of fusion at $1100{ }^{\circ} \mathrm{C}$ and annealing at $450{ }^{\circ} \mathrm{C}$. The hypothesis was that the color is due to the reduction of $\mathrm{Ti}^{4+}$ in the matrix to $\mathrm{Ti}^{3+}$. Figure 27 presents the excitation and emission spectra taken from the bulk sample aforementioned. 
Titanium is a transition metal, and its d-d electronic transitions strongly depend on the ligand field. Its trivalent cation has a $3 \mathrm{~d}^{1}$ electron configuration, so its free ion electronic state ${ }^{2} \mathrm{D}$ splits into ${ }^{2} \mathrm{E}$ and ${ }^{2} \mathrm{~T}_{2}$ when coordinated (in either octahedral or tetrahedral geometries). The tetravalent cation, on the other hand, is a $3 \mathrm{~d}^{0}$ species.

$\mathrm{Ti}^{4+}$ exhibits a broad band luminescence, that spreads over the visible spectrum, centered in the blue region $(480 \mathrm{~nm})$. This is due to the charge transfer from $\mathrm{O}^{2-}$ ligands to $\mathrm{Ti}^{4+}$ [89]. $\mathrm{Ti}^{3+}$ also display a broad band, but this time centered in the orange region. The transition involved here is between the states ${ }^{2} \mathrm{E}$ and ${ }^{2} \mathrm{~T}_{2}$ of titanium.

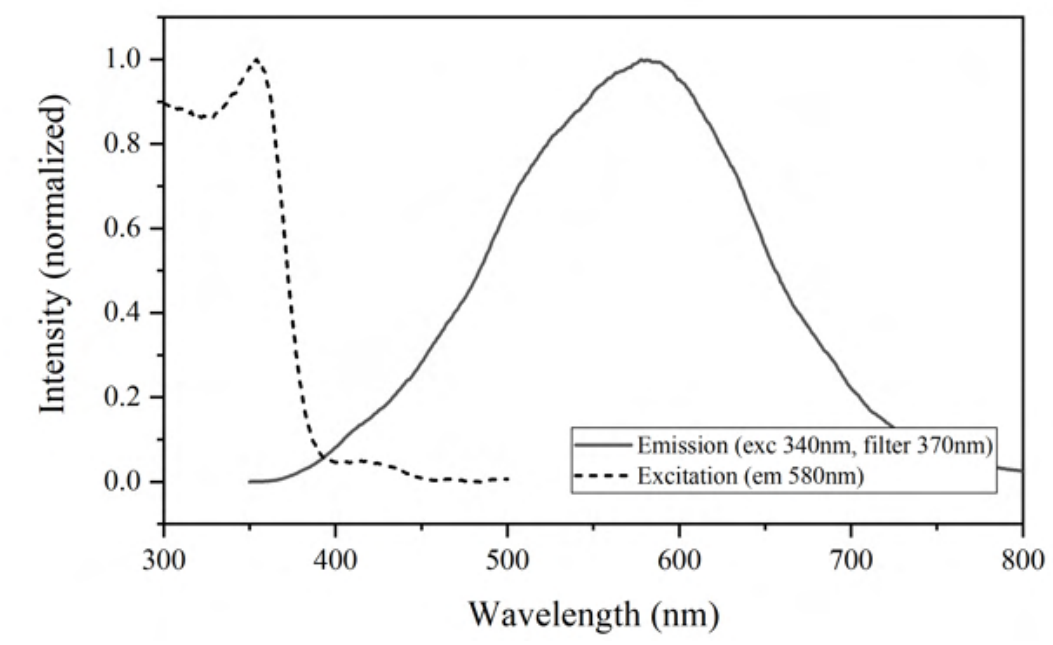

Figure 27 - Photoluminescence spectra of NBTN15 sample melted at $1100{ }^{\circ} \mathrm{C}$ for $30 \mathrm{~min}$ and annealed at $450{ }^{\circ} \mathrm{C}$.

The excitation of the glass sample in the UV, at $354 \mathrm{~nm}$, gives an emission at 583 $\mathrm{nm}$. This is, therefore, evidence of formation of $\mathrm{Ti}^{3+}$ ions in NBTN glass samples. There is a blue shift in the band when compared to literature results [89, 90, which can be attributed to differences in the ligand field and in the surroundings of the metal center.

\subsubsection{X-ray photoelectron spectroscopy and electron paramagnetic resonance spectroscopy}

To confirm that $\mathrm{Ti}^{3+}$ are indeed present in the NBTN samples, XPS experiments were conducted on the samples which the annealing temperature was varied. Figure 28 shows the fitting for Ti2p binding energies. The components that appear at 459 and $465 \mathrm{eV}$ correspond to the $2 \mathrm{p}_{3 / 2}$ and $2 \mathrm{p}_{1 / 2}$, respectively. The symmetric shape of the peaks, along with a spin-orbit splitting of $6 \mathrm{eV}$ are indicative that the sample only contains titanium in the +4 oxidation state. 
Since XPS is a surface-sensitive technique, and the Ti may have been oxidized due to exposure to the atmosphere, EPR spectra were also collected to verify and possibly quantify the amount of $\mathrm{Ti}^{3+}$ in the glass samples.
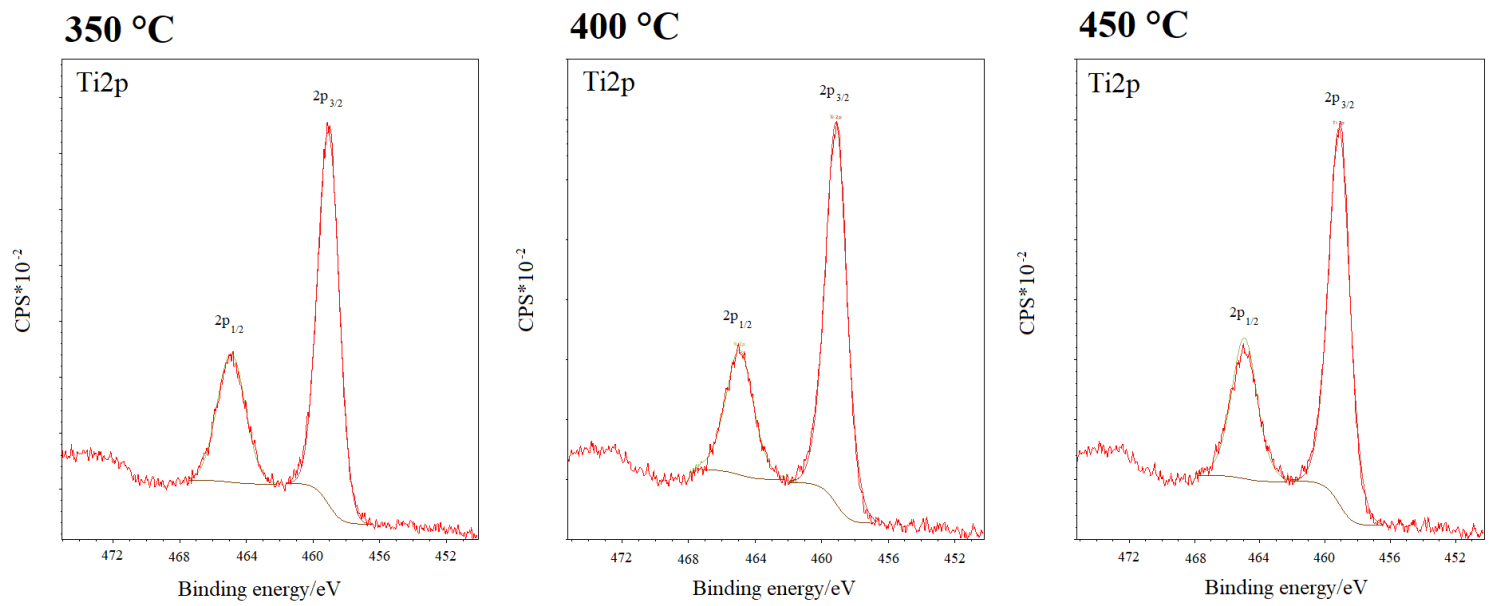

Figure 28 - X-ray photoelectron spectra of the NBTN glass samples annealed at 350, 400, and $450{ }^{\circ} \mathrm{C}$.

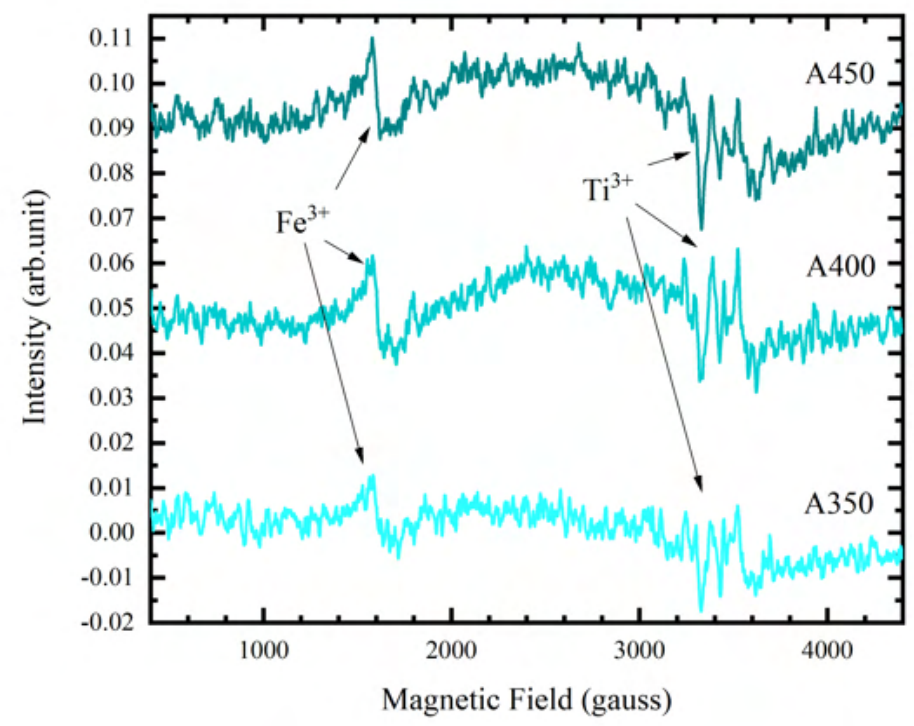

Figure 29 - EPR spectra of the NBTN glass samples annealed at 350,400 , and $450{ }^{\circ} \mathrm{C}$.

The results, displayed in Figure 29, show a very low signal-to-noise ratio, meaning that the amount of paramagnetic species detected was very low. Furthermore, the $\mathrm{Fe}^{3+}$ identified in the spectra corresponds to impurity; that way, the amount of $\mathrm{Ti}^{3+}$ present in the samples is so low that it can also be considered impurity. 
Hence, the color of the NBTN samples could not be attributed to the presence of $\mathrm{Ti}^{3+}$, reduced from $\mathrm{Ti}^{4+}$. The wavelength shift observed in the PL spectra are due to the ligand field, and the broad emission is due to $\mathrm{Ti}^{4+}$. What can be done to find the cause of the glass color is removing one of the starting materials from the composition and synthesizing the ternary glasses, and verify whether any of these compositions is colored, and the one that is colorless will reveal which species is responsible for the color.

\subsubsection{Differential scanning calorimetry}

NBTN DSC thermograms are shown in Figure 30. The characteristic temperatures are tabulated in Table 5 .

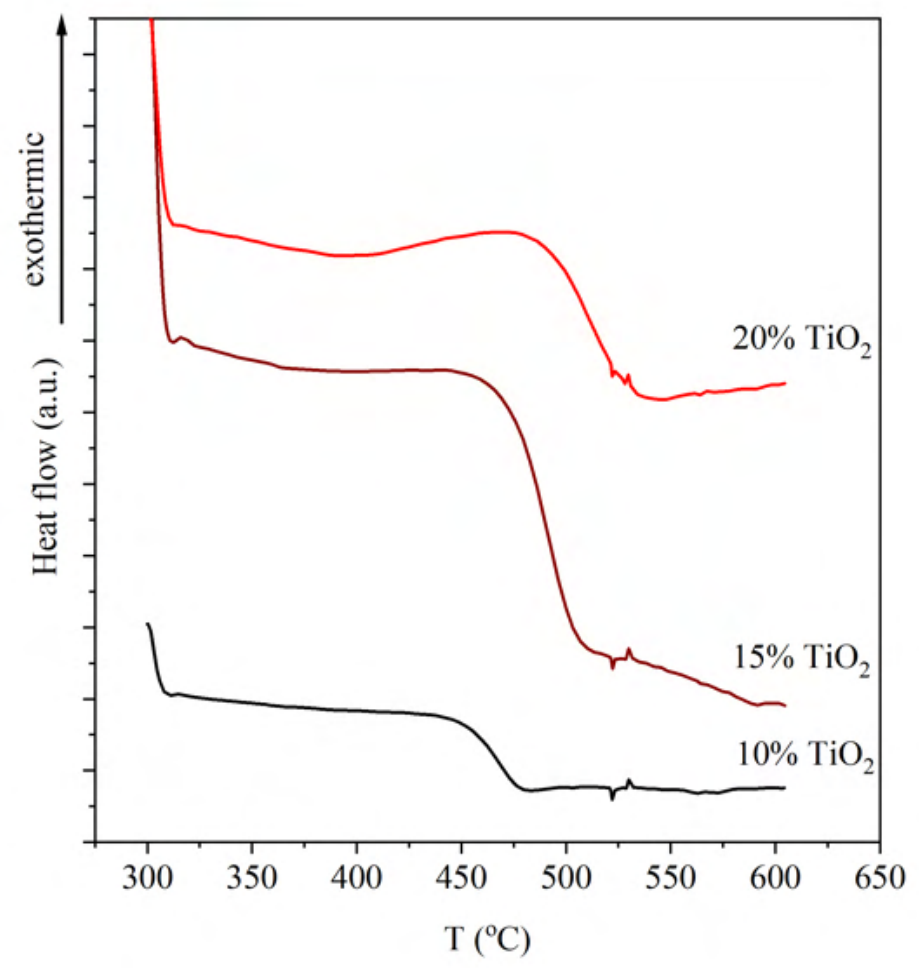

Figure 30 - DSC curves for sodium phosphate systems. Increasing titanium amounts yield higher crystallization temperatures in relation to lead phosphate glasses.

Table 5 - Characteristic temperatures for NBTN glasses

\begin{tabular}{llll}
\hline & \multicolumn{3}{l}{ Characteristic temperatures $\left({ }^{\circ} \mathbf{C}\right)$} \\
\cline { 2 - 4 } Samples & $T_{g}$ & $T_{x}$ & $\Delta T$ \\
\hline NBTN-10 & 467.63 & $>600$ & $>132.37$ \\
NBTN-15 & 491.36 & $>600$ & $>108.64$ \\
NBTN-20 & 508.13 & $>600$ & $>91.87$ \\
\hline
\end{tabular}


Substitution of lead pyrophosphate for sodium phosphate in NBTN glasses yield slightly higher glass transition temperature, when the samples with the same amounts of boron and titanium oxides are compared (PBTN30 and NBTN10). This effect can be attributed to the higher connectivity of the phosphate network in the latter (further details are discussed in the Raman spectroscopy session). When the amount of $\mathrm{TiO}_{2}$ is increased, all the characteristic temperatures increase significantly (the crystallization peaks cannot be observed in the temperature range analyzed), meaning that titanium enters the glass network contributing to increases in both stabilization face to crystallization and connectivity.

\subsubsection{Raman spectroscopy}

Raman spectra for NBTN glasses are shown in Figure 31, and the band assingment, in Table 6. As can be seen, the spectra exhibit luminescence starting at $1400 \mathrm{~cm}^{-1}$. Such effect is probably due to the presence of $\mathrm{Ti}^{3+}$ species, whose luminescence was already verified and discussed [90, 91].

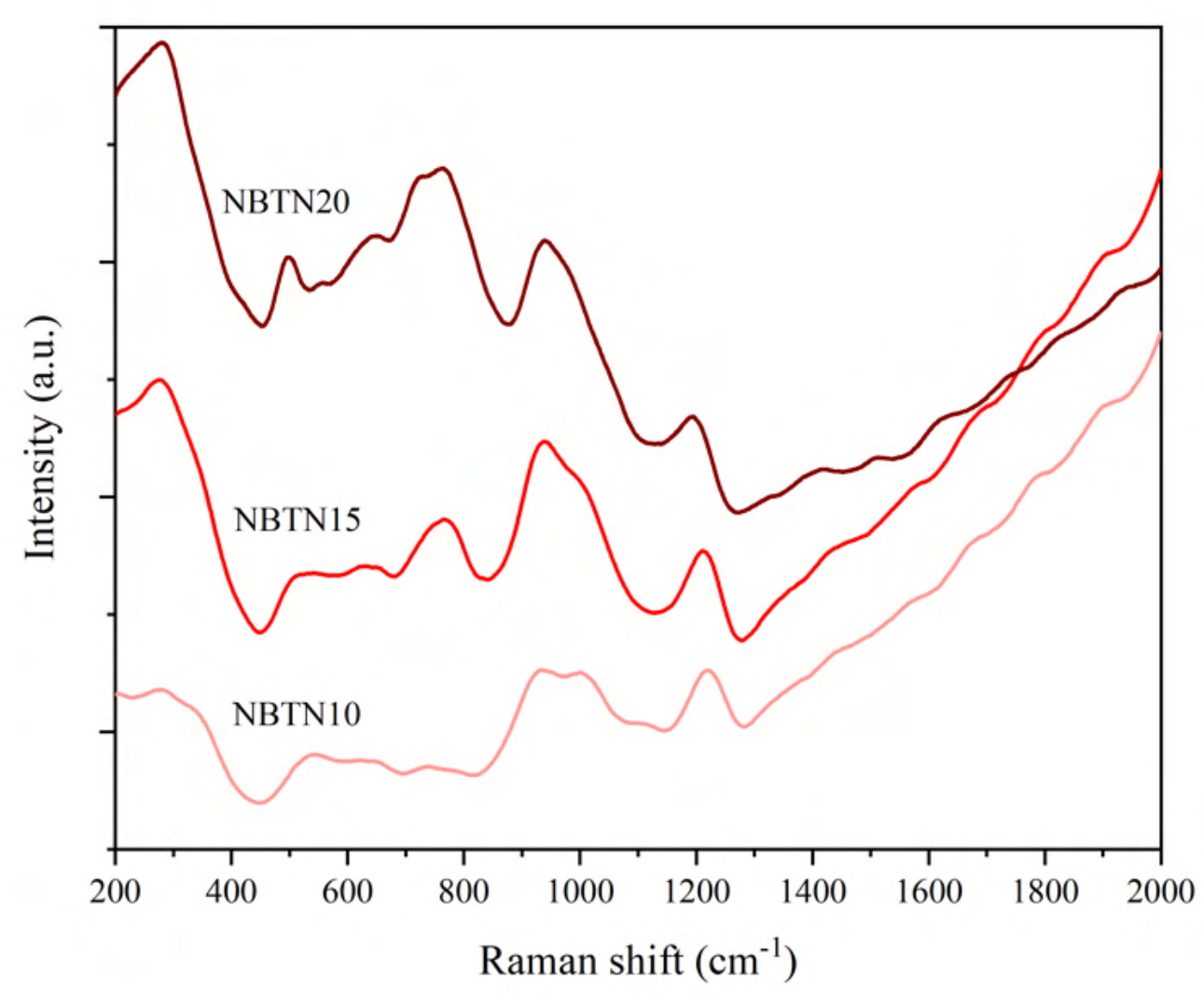

Figure 31 - Raman spectra of NBTN glasses with $633 \mathrm{~nm}$ excitation laser. 
The phosphate source in these glasses was sodium hexametaphosphate, formed mainly by cyclic structures where each phosphorus atom is linked to two bridging oxygen atoms. The synthesized glasses are expected to possess $\mathrm{Q}^{2}$ connectivity. However, no band can be identified that corresponds to such behavior. Instead, two strong bands associated with P-O stretching from $\mathrm{Q}^{1}$ and $\mathrm{Q}^{0}$ connectivities appear (1000 and 935 $\mathrm{cm}^{-1}$, respectively, shown in the first close-up of Figure 32, indicating that titanium oxide promotes a depolymerization of the network. Still, this information is not consistent with the increasing characteristic temperatures of the network, which indicate a highly connected glass network.

Table 6 - Assignment of bands for NBTN Raman spectra

\begin{tabular}{lll}
\hline Raman shift $\left(\mathbf{c m}^{-1}\right)$ & Assignment & Reference \\
\hline 1215 & B-O stretching + Asymmetric O-P-O stretching & {$[84$, 88] } \\
1000 & $\mathrm{Q}^{1}$ P-O stretching + B-O diborate stretching & {$[85, ~ 86]$} \\
935 & $\mathrm{Q}^{0}$ P-O stretching + Ti-O stretching & {$[85$, 87, 88] } \\
772 & Symmetric P-O-P stretching & {$[27,85]$} \\
500 & O-P-O bending & {$[27,85]$} \\
\hline
\end{tabular}
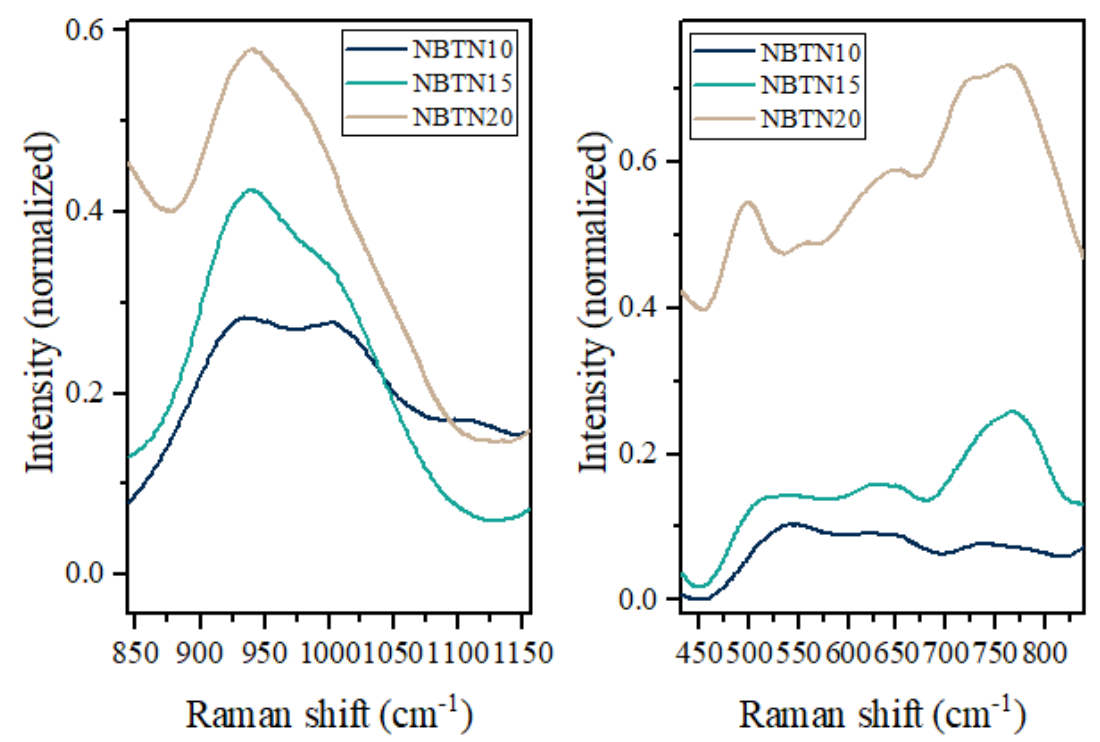

Figure 32 - Close-up views from NBTN Raman spectra comparing the normalized intensities of samples containing 10, 15 and $20 \mathrm{~mol} \%$ of $\mathrm{TiO}_{2}$.

The band at $935 \mathrm{~cm}^{-1}$ can also be attributed to a Ti-O stretching mode, what can account for the increasing intensity when higher amounts of $\mathrm{TiO}_{2}$ is added to the composition. Hence, what might be happening is the insertion of Ti to the glass network, instead of depolymerization. According to the literature [88, 87, P-O-Ti linkages might 
occur across the network, conferring to it a 3D structure due to the octahedral nature of Ti. This might also account for the narrow NBTN glass domain [92]: it was not possible to synthesize glasses with more than $20 \mathrm{~mol} \%$ of $\mathrm{TiO}_{2}$ without crystallizing the sample.

Based on the evidence exposed above, an increasing amount of $\mathrm{TiO}_{2}$ causes an increase in the $T_{g}$ of the glass samples because octahedral Ti are inserted into the phosphate network. A P-O-Ti connectivity prevails over a $\mathrm{Q}^{2}$ phosphate connectivity.

\section{3 lon exchange}

The ion exchange process is a very laborious experiment to carry out manually. Opposite to the totally automated fabrication of Gorilla Glass, here, it was performed with the aid of tweezers in a laboratory furnace.

The species exchanged are $\mathrm{Na}^{+}$, present in the glass composition, and $\mathrm{Ag}^{+}$, that diffuses into the glass surface. The thermal treatment that follows the bath promotes reduction, nucleation, and growth of silver nanoparticles.

It is important to note that there are several variables that affect the nanoparticles size, shape and distribution: molten salt bath temperature, composition, bath time, thermal treatment temperature and time, oven shape (heat distribution).

The ion exchange was carried out in a $\mathrm{NaNO}_{3}-\mathrm{AgNO}_{3}$ molten salt bath, in approximately $4: 1$ proportion (in mol), at $380^{\circ} \mathrm{C}$. The bath time varied from 10 to $120 \mathrm{~min}$. The thermal treatment was carried out in a tubular oven at $T_{g}+10{ }^{\circ} \mathrm{C}$. The samples used in the experiments were NBTN15 (Figure 33) and NBTN20 (Figure 34).

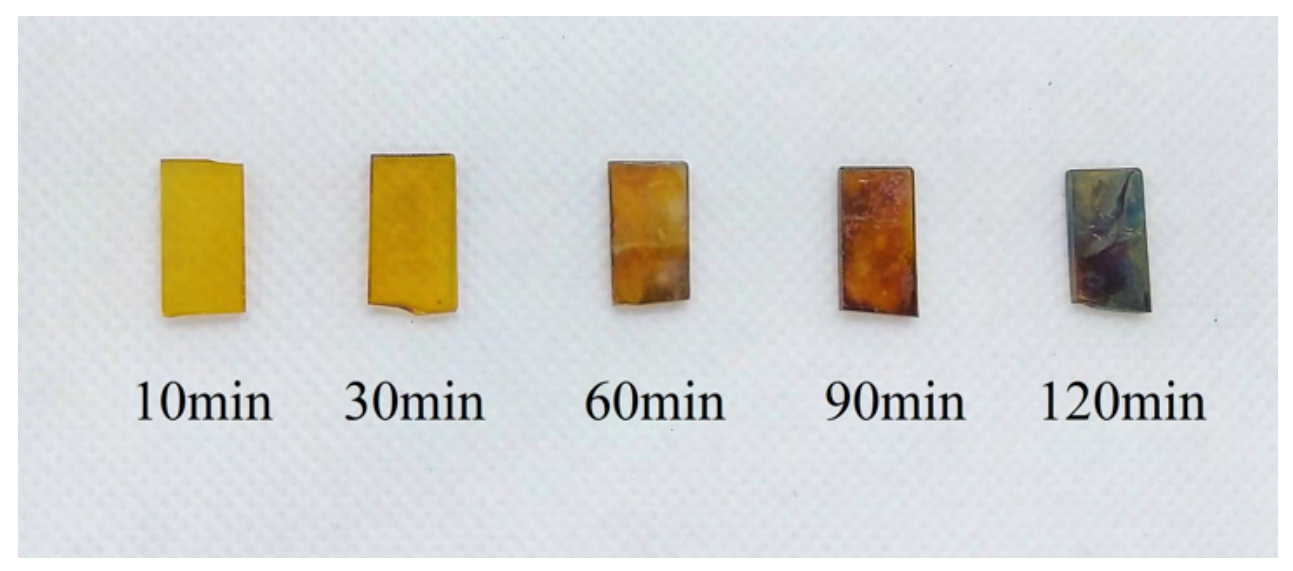

Figure 33 - NBTN15 glass samples after ion exchange and thermal treatment.

SERS and photocatalysis experiments were carried out using NBTN15 samples containing Ag-NPs. From now on, such samples, when in their bulk form (because powdered samples were also synthesized) will be labeled according to the ion exchange bath time 
(since this was the variable that was changed): NBTN-Ag10, NBTN-Ag30, NBTN-Ag60, NBTN-Ag90, and NBTN-Ag120.

(a)

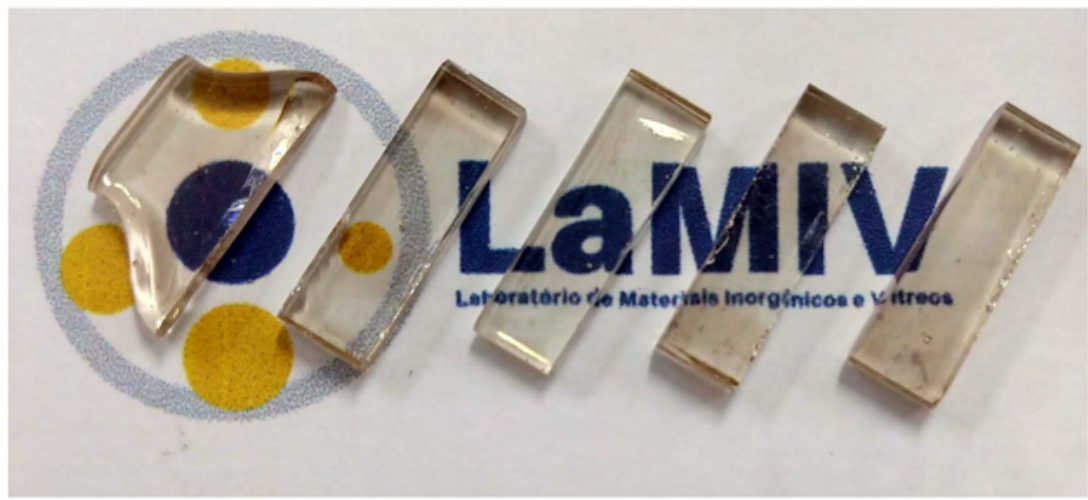

(b)

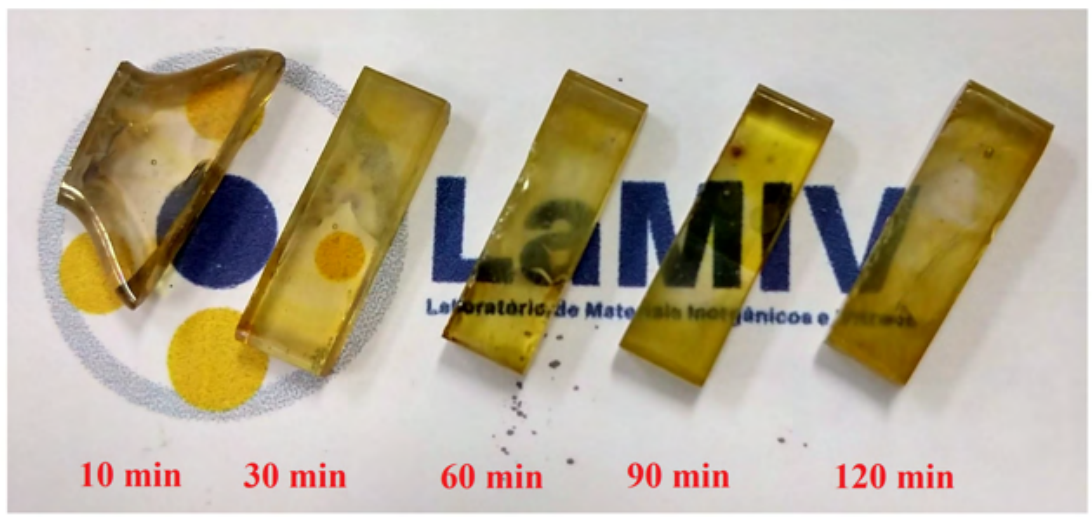

Figure 34 - NBTN20 glass samples before and after ion exchange and thermal treatment.

\subsubsection{Appearance and UV-Vis spectroscopy}

After the ion exchange bath, no apparent change in the sample's appearance was detected. After the thermal treatment in the tubular oven, however, the samples acquired an intense yellow color, as can be seen in Figures 34(b) and 33 . This is evidence of silver nanoparticles growth on the glass surface. The absorption spectra of the samples after thermal treatment were collected, and Figure 35 shows the evolution of the plasmon band of the glass samples with increasing ion exchange bath time.

The growth of a plasmon band at $440 \mathrm{~nm}$ is evidence for silver nanoparticle formation. The geometry and size of the particles affect the absorption wavelength [93]. In the spectra obtained for the glass samples, there was no change in the wavelength of plasmon band. This is a strong indicative that neither the shape nor the size of the Ag-NPs suffered changes with modification of ion exchange bath time. The increasing intensity of the absorption band at $440 \mathrm{~nm}$ indicates, therefore, an increasing concentration of 
nanoparticles within the samples.

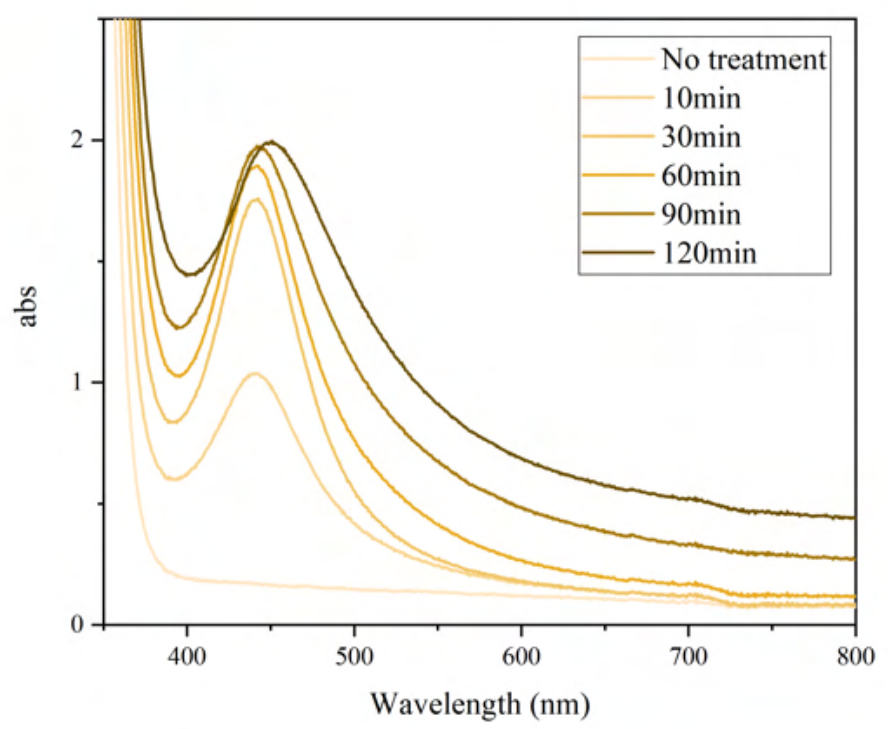

Figure 35 - UVVis-NIR absorption spectra for ion exchanged and thermally treated NBTN15 sample.

The last sample, NBTN-Ag120, however, shows a deviation from the observed trend: there is no further intensity increase in the SPR band, and there is a small shift in its wavelength. This might be happening because of nanoparticles clustering. The concentration of NPs becomes higher to a point that their borders start to touch. Consequences of such contact are changes in the geometry of the overall structure and weakening of the LSPs due to the larger dimensions. These, in turn, promote the observed distortion.

The absorption border at $380 \mathrm{~nm}$ is red-shifted with increasing time of heat treatment. Hence, the samples lose transparency in the ultraviolet region of the spectrum due to the surface plasmon absorption originated from Ag-NPs.

\subsubsection{Scanning electron microscopy and energy-dispersive $\mathrm{X}$-ray analysis}

Prior to the analysis, the samples were coated with carbon, in order for the surface to be conductive. The backscattered electrons images of the cross-section of the samples with 30, 60, 90, and 120 min ion exchange were taken and are presented in Figure 36, as well as EDX maps and line scans for silver. Appendix A contains more detailed images, along with line scan plots for oxygen, sodium, phosphorus, and titanium. The analysis on the cross-section of the samples allowed for identification of the maximum depth the silver ions reached into the glass. 

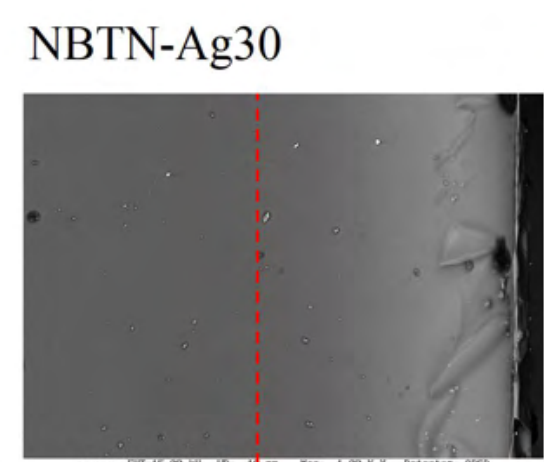

AgLa1, 6
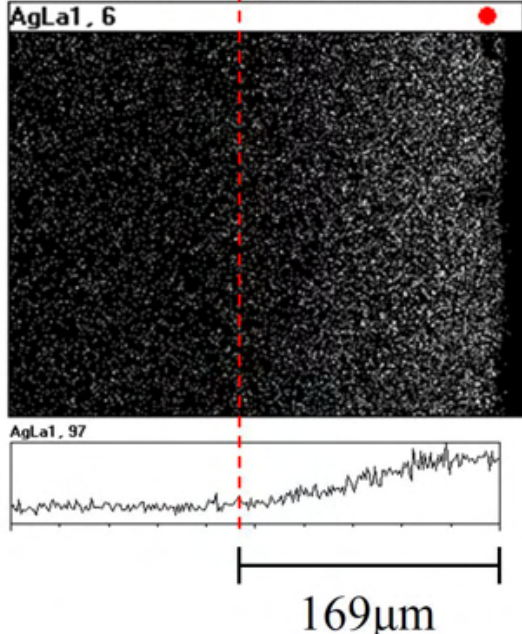

NBTN-Ag60
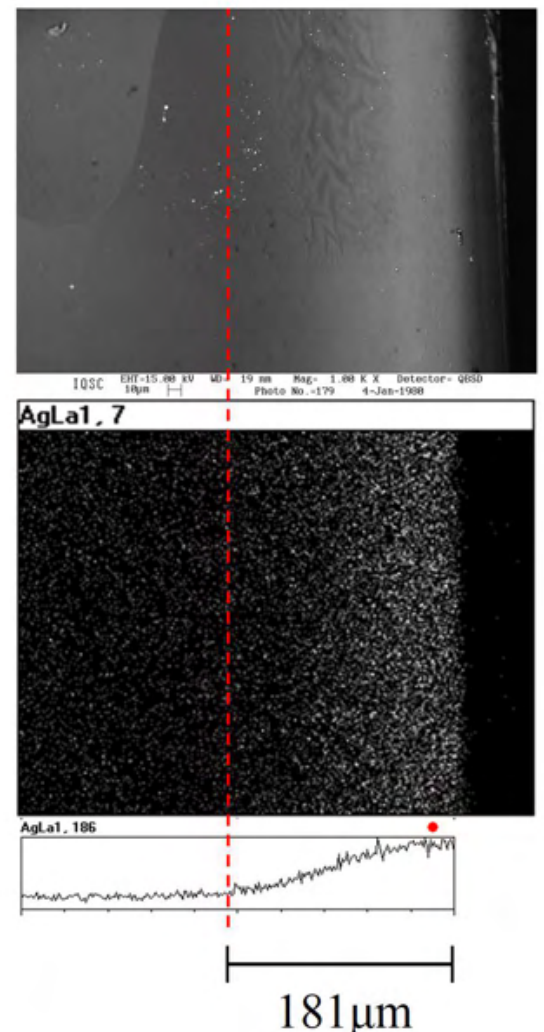

NBTN-Ag90

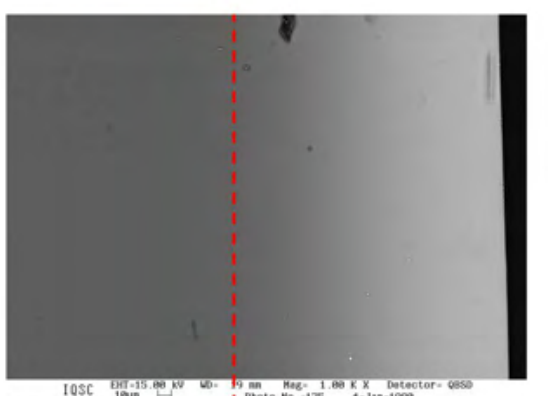

AgLa1, 7
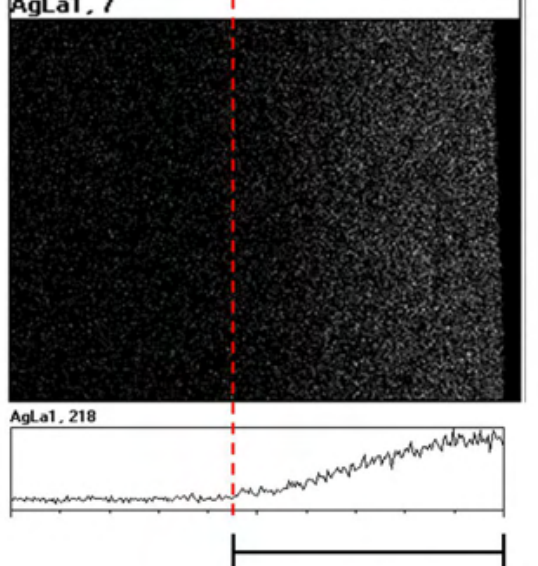

NBTN-Ag120

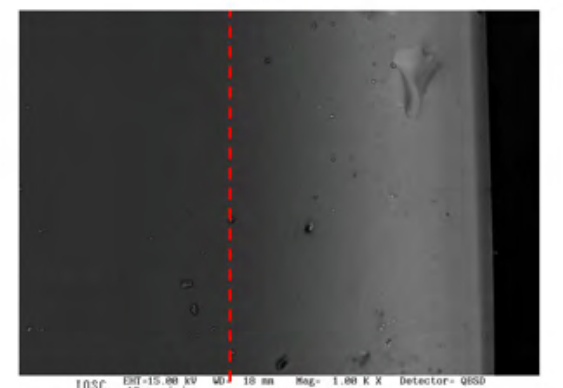

AgLa1, 9

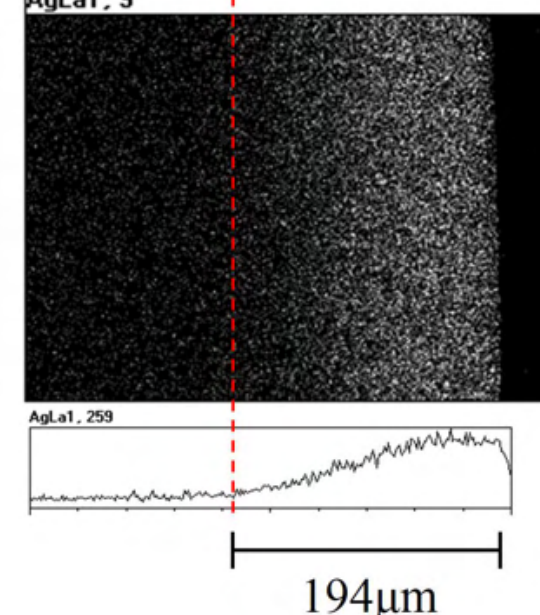

Figure 36 - Backscattered electrons images, EDX mappings and line scans of Ag on the cross section of the samples. The values in the bottom are the calculated layer depths of silver on the surface of the samples. 
The EDX maps and line scans show that silver diffused into the glass up to a depth of $194 \mu \mathrm{m}$. The sodium ions that are exchanged are present in large amounts in the samples, because both the glass former and the glass modifier $\left(\mathrm{NaPO}_{3}\right.$ and $\mathrm{Na}_{2} \mathrm{O}$, respectively) are sources of $\mathrm{Na}^{+}$. Such a high concentration enabled $\mathrm{Ag}^{+}$ions to permeate hundreds of micrometers into the glass surface, even with diffusion times as low as $30 \mathrm{~min}$. It can be noted, however, that there is not a linearity in the depths of the silver layer as a function of diffusion time.

Gorilla Glass manufacturing process is totally automated, with the ion exchange occurring homogeneously throughout the entire glass sheet. Here,even though the process was manually performed, a trend can be observed: the longer the ion exchange treatment, the deeper the silver diffuses into the glass.

\subsubsection{Transmission electron microscopy}

To prepare the bulk samples for TEM analysis, they had their core removed with the aid of a sandpaper, since the surface is the part of the samples where the nanoparticles are located. Then, they were ground in a mortar until a very fine powder was obtained. The powders were suspended in ethanol and dropped on copper grids, which were then allowed to dry. Figure 37 shows the TEM images of the bulk samples. Appendix B contains more detailed images and EDX maps of all samples.

The observed nanoparticles are highly regular in shape. All samples contain mostly spheroidal NPs. A high regularity in the sizes of the synthesized NPs can also be observed in both bulk and powdered samples. Diameters between 5 and $15 \mathrm{~nm}$ were obtained for all the analyzed samples. This is reflected in the UV-Vis spectra, where the plasmon band across the samples did not shift to higher or lower wavelengths. Therefore, as expected, the higher intensity corresponds to a higher amount of Ag-NPs in the glass.

In bulk samples, the longer the ion exchange bath time, the larger the silver layer on the surface of the glass sample (as seen in the EDX line scans, Figure 36). Hence, the absorption due to the SPR of the nanoparticles increases. At $2 \mathrm{~h}$ of ion exchange, they start to aggregate, and, as consequences, the sample starts to lose transparency, and the plasmon band intensity decreases, as evidenced by both the UV-Vis spectra and the appearance of the glass. 
(a)

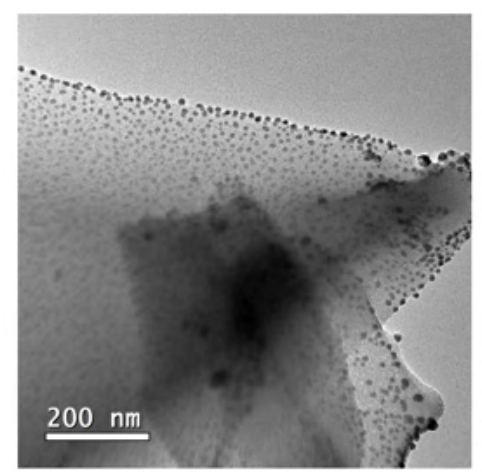

(b)

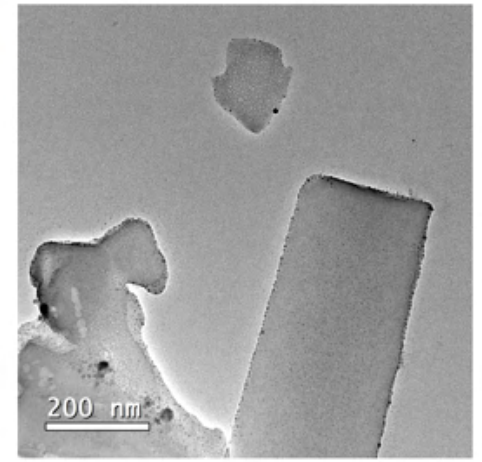

(c)

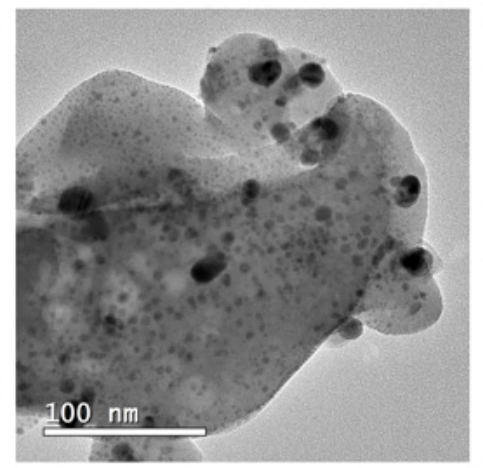

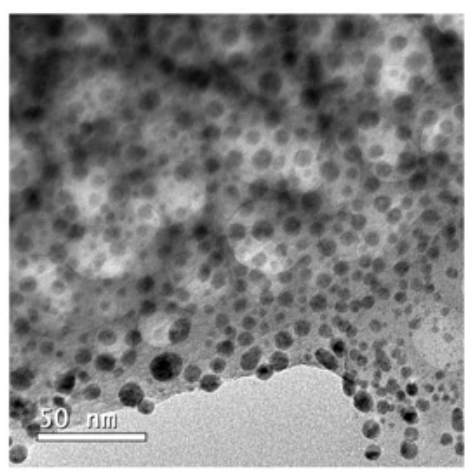
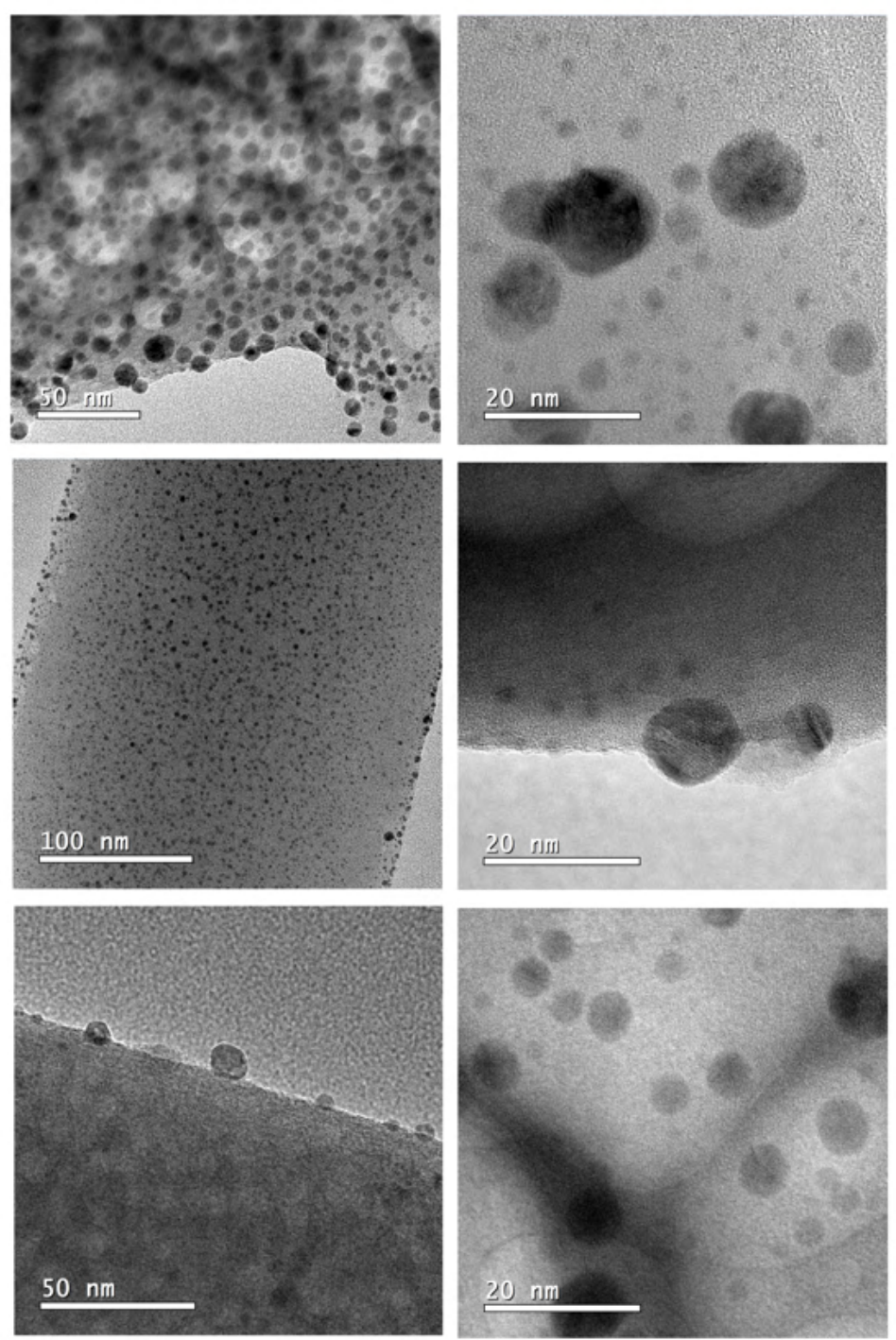

Figure 37 - Transmitted electrons images of NBTN15 bulk samples containing Ag-NPs on the surface treated with (a) 30min ion exchange, (b) 60min ion exchange, and (c) 120min ion exchange.

\subsection{Powdered glass samples}

\subsubsection{Synthesis and appearance}

In addition to the bulk samples, the photocatalysis essays present in Chapter 7 were performed using powdered samples in suspension. Each has an advantage towards the photodegradation experiments: while the bulk samples are more easily synthesized, for having one less step in their preparation, the powders have a greater surface area, which can allow for a more effective activity. 
The powdered NBTN-Ag glass samples were prepared via the following route: melting of the precursors at $1100^{\circ} \mathrm{C}$ in a Pt-Au crucible, and then melt-quenching at 400 ${ }^{\circ} \mathrm{C}$ in a steel mold; milling of the glass in a mortar; ion-exchange in the $\mathrm{NaNO}_{3}-\mathrm{AgNO}_{3}$ 4:1 molten salt bath at $380{ }^{\circ} \mathrm{C}$, followed by washing of the salt excess; thermal treatment at $T_{g}+10^{\circ} \mathrm{C}$; second milling step; granulometry control using a set of sieves. A sample without ion-exchange/thermal treatment was saved for comparative purposes. The ion exchange bath times were 30,60, 90, and $120 \mathrm{~min}$, and the thermal treatment was fixed at 10 min for all samples.

It was observed that, after the ion exchange bath, the samples acquired a yellowish hue, indicating the formation of Ag-NPs. Half of each prepared batch was saved for further analysis, and the thermal treatment was proceeded on the remaining half. A darker yellow hue was obtained. Figure 38 shows all the samples, where these differences in color can be noted. From now on, samples that have been only through ion exchange bath are labeled with the suffix IE, and samples that have been through both ion exchange bath and thermal treatment are labeled with the suffix TT.

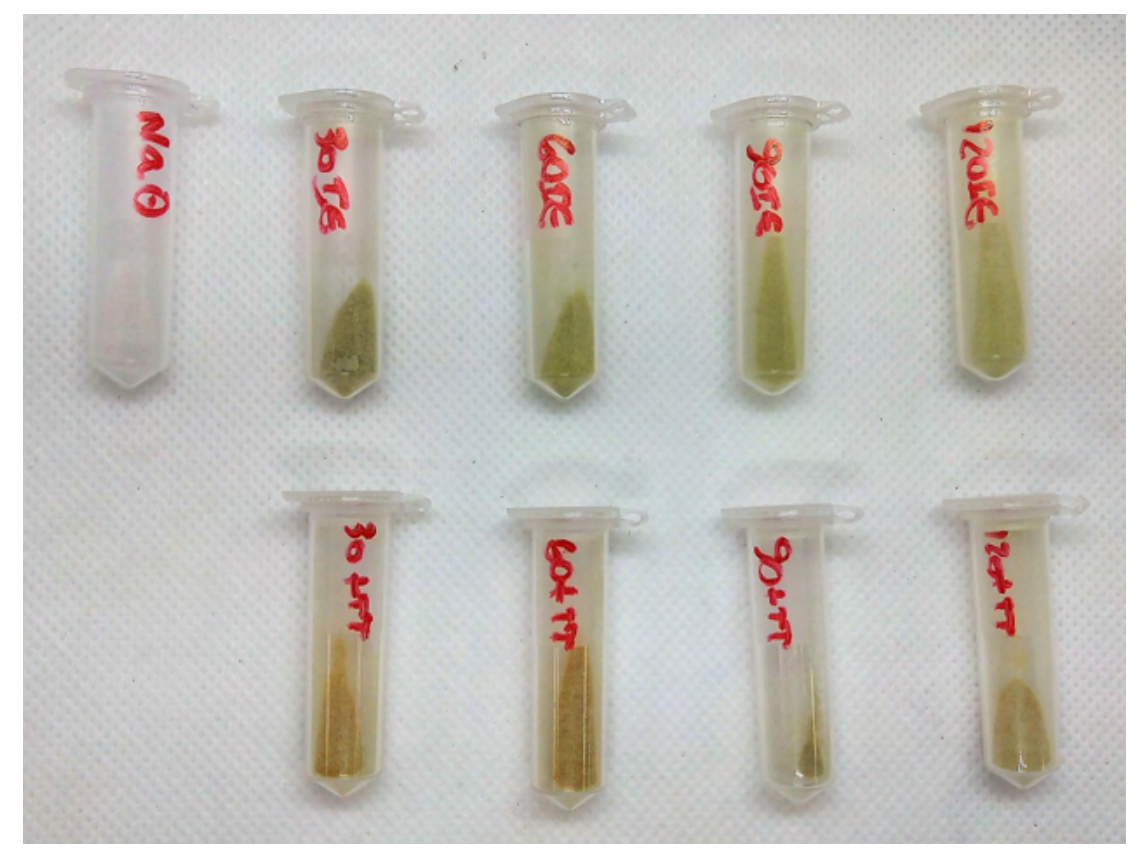

Figure 38 - Glass powders obtained after ion exchange (above) and thermal treatment processes (below). The first sample corresponds to the original NBTN15 glass.

\subsubsection{UV-Vis spectroscopy}

The UV/Vis spectra of these samples, presented in Figure 39, were taken in the diffuse reflectance mode, using the Shimadzu UV-3600 UV-Visible-NIR spectrophotometer. The results of both IE and TT samples show the same trend: the growth of a band centered in $450 \mathrm{~nm}$ with increasing ion exchange time. That band corresponds to the SPR 
absorption of Ag-NPs. Other trend that can be observed is the growth of the plasmon band when comparing the spectra in the left (yellow) with the spectra in the right (orange), meaning that the heat treatment promoted the formation of more nanoparticles in the glass samples.

Slight differences can be noticed between UV-Vis spectra taken via transmittance/absorbance method (bulk samples, Figure 35) and those taken via reflectance method (powder samples, Figure 39). Two reasons are accountable for such distinctions: the different dimensions of both types of samples that were subject to treatment and the measurement method. Even though the ion exchange and thermal treatment conditions were the same for both cases, a greater surface area and smaller grain volume in the powdered materials when compared to a whole piece of glass promote a different outcome in the synthesis process, in aspects such as depth of the Ag-NP layer and total amount of silver incorporated in the substrate.

Revisiting the many ways light interacts with matter, it can be absorbed, scattered or transmitted through the sample. Diffuse reflection refers to the light that is scattered in all directions. Due to the different geometries and particle size of the samples, variations in the intensity of scattered radiation arise. Those are the reasons why the two types of generated spectra are not directly complementary.
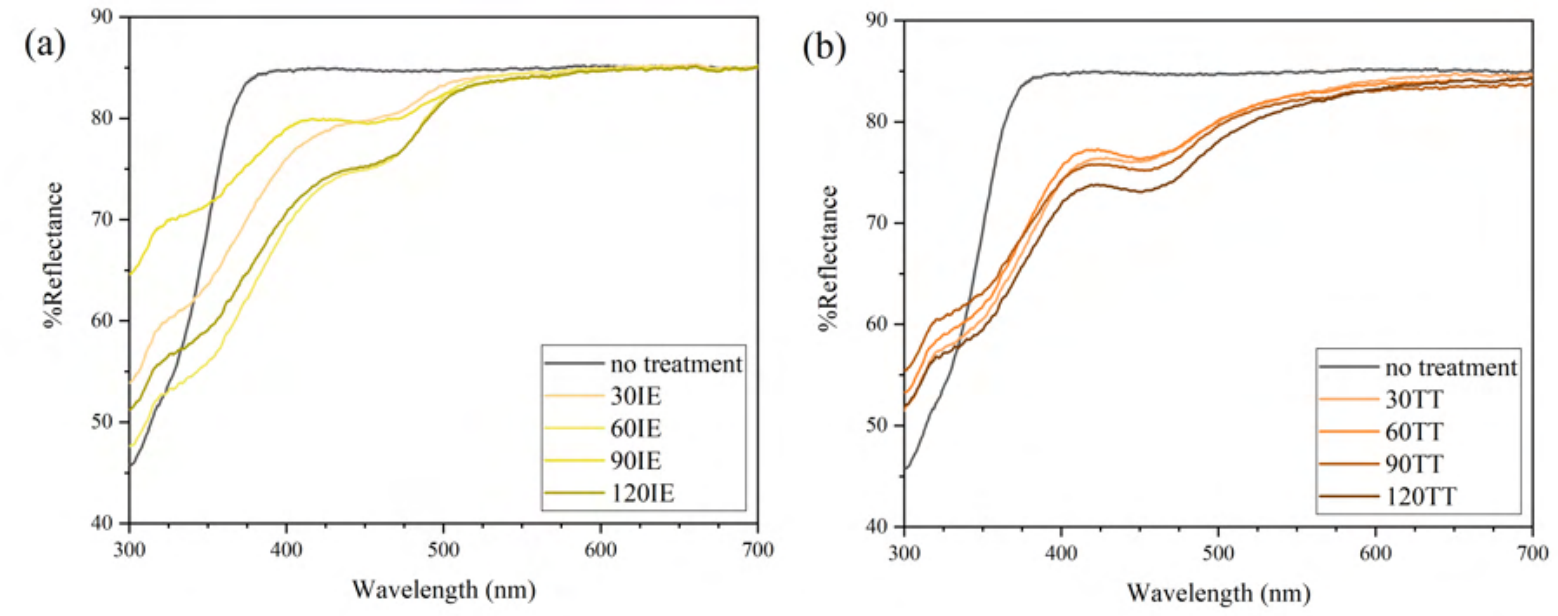

Figure 39 - UV/Vis diffuse reflectance spectra of NBTN-Ag samples (a) after ion exchange only and (b) after ion exchange and thermal treatment.

\subsubsection{Transmission electron microscopy}

TEM images were also obtained for these samples. They were further crushed to obtain a very fine powder and then subjected to the same preparation method than the 
bulk samples.

(a)

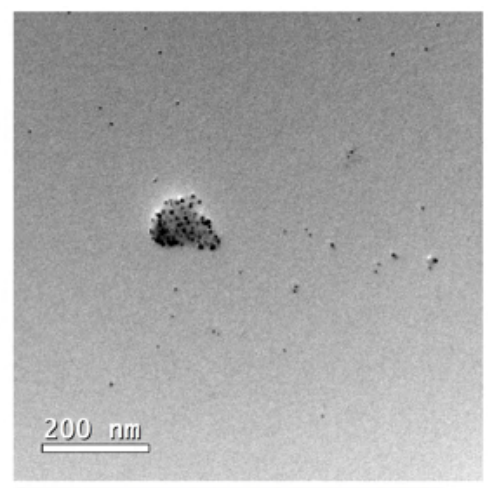

(b)

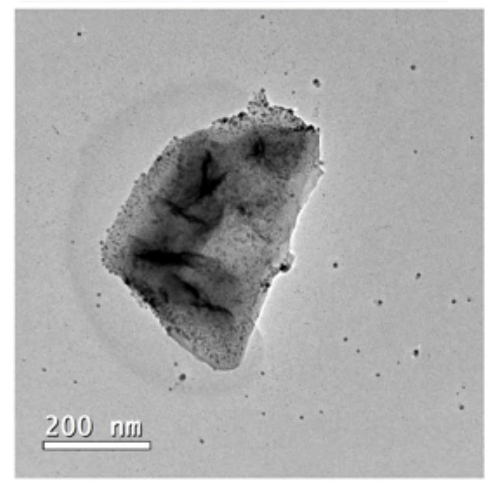

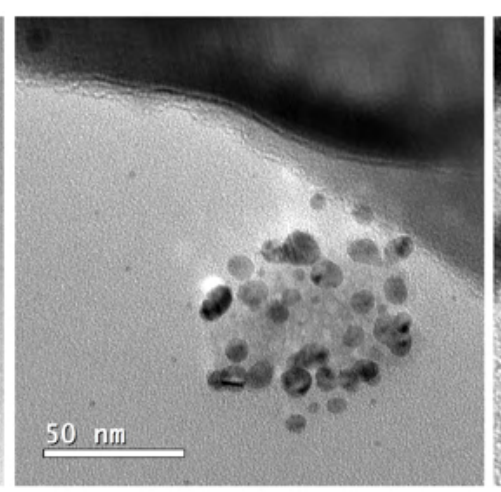
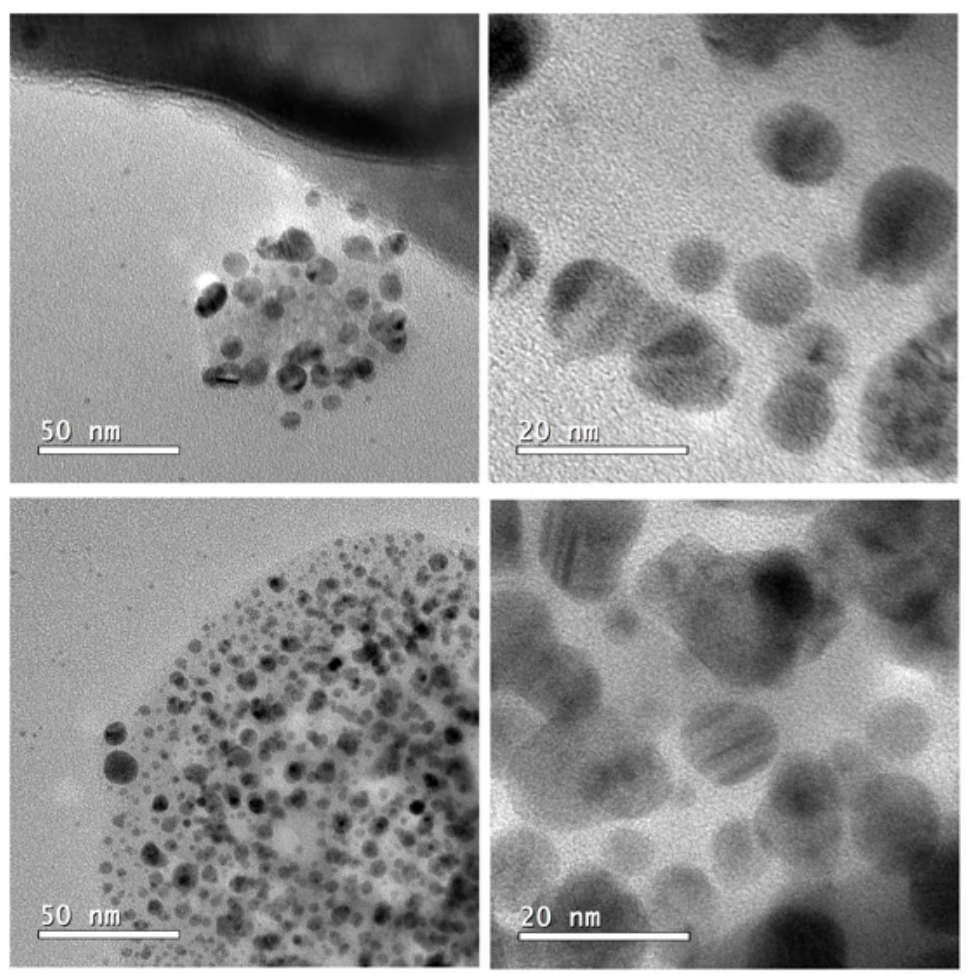

Figure 40 - Transmitted electrons images of powdered glass samples containing Ag-NPs (a) 120IE and (b) 120TT.

In powdered glasses, Figure 40 shows that some NP synthesis was observed after the ion exchange. The observed nanoparticles were again highly regular in shape and size, being spheroidal with diameter around 10-15 $\mathrm{nm}$. After thermal treatment, the amount of Ag-NPs significantly increased. This accounts for the change in color of the samples. Opposite to the bulk samples, there were nanoparticles already present in the powdered glasses right after the ion exchange bath. This happened because of differences in the dimensions of the samples, as mentioned earlier. Smaller grain sizes lead to a higher surface area, which then leads to a different heat and energy distribution. 



\section{CHAPTER 7}

\section{SERS and photocatalytic activity}

\subsection{SERS detection of fipronil, thiamethoxam, and 2,2'-bipyridine: preliminary results}

Density functional theory (DFT) calculations show that fipronil possibly can bind to the Ag-NPs surface via its cyano group [65], whilst for thiamethoxam, DFT shows that such attachment can happen via its nitro group [94].

Fipronil (fpn) and thiamethoxam (tmx) are the analytes that were initially intended to be used to evaluate the SERS activity of the NTBN glasses containing Ag-NPS on their surface. To do that, a Raman spectrum of solid fipronil and thiamethoxam (Aldrich standard) were taken as standards. Then, they were diluted in appropriate solvents (the former in acetone, the latter in acetonitrile) until a $1000 \mathrm{mg} \mathrm{L}^{-1}$ solution was obtained (2.29mmol L $\mathrm{L}^{-1}$ for fipronil, $3.43 \mathrm{mmol} \mathrm{L} \mathrm{L}^{-1}$ for thiamethoxam). The solutions were then poured onto the NBTN-Ag120 sample dropwise. A spectrum was taken after the solvent dried.

For each analyte, different spectra were collected from several regions in the glass sample. For discussion purposes, only the ones containing some information are displayed (some spectra only showed the bands related to the glass structure). SERS substrates contain hot spots, regions where the Raman signals of the analytes are more effectively intensified due to stronger near-field effects, which, in turn, are caused by the characteristics of the nanoparticles present in said region. For that reason, the surface of the glass sample was explored in search of such spots.

Figure 41 shows the spectra of the solid fipronil standard and fipronil solution on the surface of NBTN-Ag120 glass. Table 7 shows the bands assignment.

The bands corresponding to the vibrational modes of chemical bonds containing a nitrogen atom, namely 2251 ( $\mathrm{C} \equiv \mathrm{N}$ stretching), $1608\left(\mathrm{H}_{2} \mathrm{~N}-\mathrm{C}(\mathrm{prz})\right.$ stretching $)$, and and 
$1560 \mathrm{~cm}^{-1}$ (CN-C stretching), either were not identified in the glass spectra or appeared in the form of several weak peaks very close to each other. Such bands were supposed to appear in the SERS spectra because, based on the theoretical evidence aforementioned, their signal is amplified due to the formation of an fpn-Ag-NP structure.

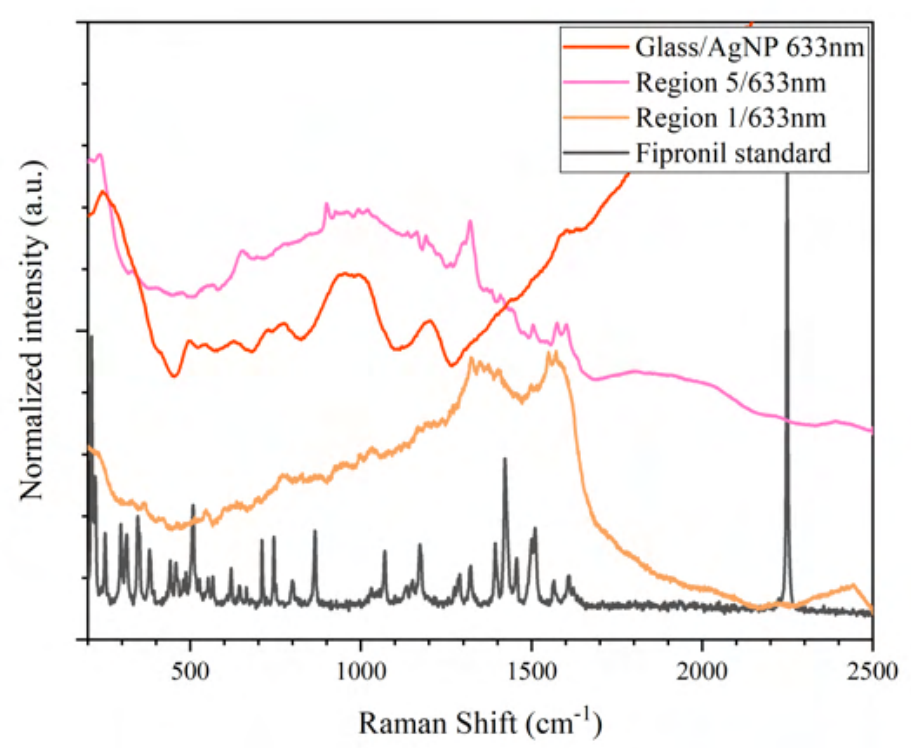

Figure 41 - Raman spectra of NBTN-Ag120 sample before and after contact with droplets of fipronil 1000ppm in acetone. The spectrum of fipronil standard is shown as reference (in black).

Table 7 - Band assignment for solid fipronil Raman spectrum 65]

\begin{tabular}{ll}
\hline Raman shift $\left(\mathbf{c m}^{-1}\right)$ & ${ }^{a}$ Assignment \\
\hline 2251 & $\nu(\mathrm{N} \equiv \mathrm{C})$ \\
1608 & $\nu\left(\mathrm{H}_{2} \mathrm{~N}-\mathrm{C}(\right.$ prz $\left.)\right)$ \\
1509 & $\nu($ pyrazole ring $)$ \\
1421 & $\nu($ phenyl ring $)$ \\
1171 & $\nu(\mathrm{C}($ prz $)-\mathrm{C}($ prz $))$ \\
1068 & $\nu(\mathrm{NC}-\mathrm{C}($ prz $))$ \\
866 & $\beta($ phenyl ring $)$ \\
508 & $\beta($ pyrazole ring $)$ \\
\hline
\end{tabular}

$\bar{a}$ Abbreviations: $\nu$, stretching, $\beta$, bending

Thiamethoxam experiment results are shown in Figure 42, and the band assignment is presented in Table 8. Again, instead of bands that may be amplified due to the formation of a tmx-Ag-NP structure, such as at 1416 (N-O nitro stretching) and $980 \mathrm{~cm}^{-1}$ (O-N-O nitro strecthing), no bands appeared, or only a series of faint peaks can be seen in the spectra. 


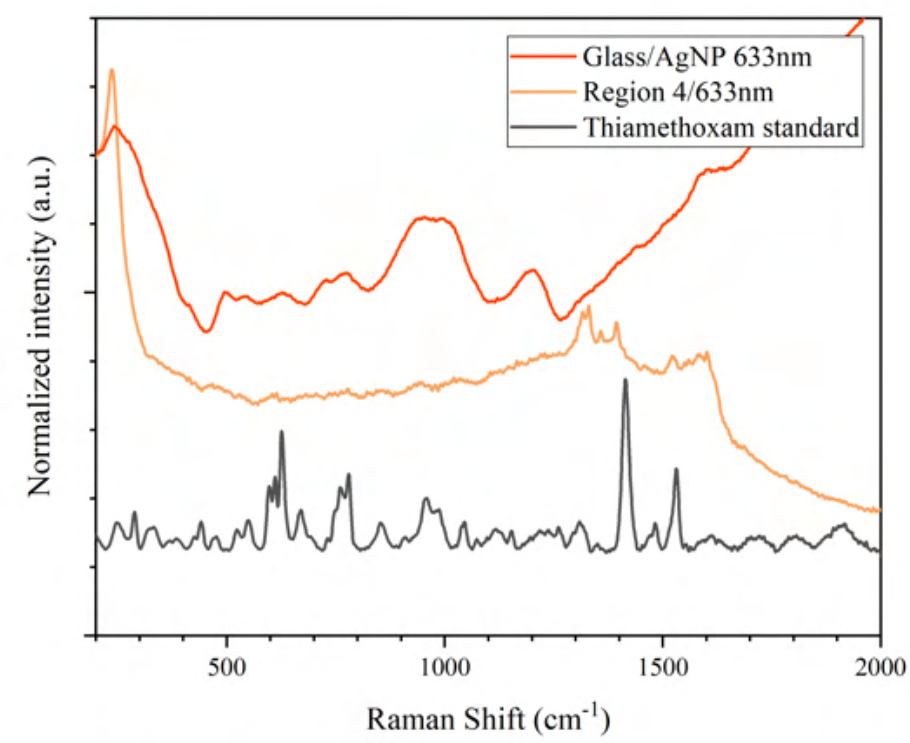

Figure 42 - Raman spectra of NBTN-Ag120 sample before and after contact with droplets of thiamethoxam 1000ppm in acetonitrile. The spectrum of thiamethoxam standard is shown as reference (in black).

Table 8 - Band assignment for solid thiamethoxam Raman spectrum [94]

\begin{tabular}{|c|c|}
\hline Raman shift $\left(\mathrm{cm}^{-1}\right)$ & ${ }^{a}$ Assignment \\
\hline 1531 & $\nu(\mathrm{O} 2 \mathrm{NN}=\mathrm{C})$ \\
\hline 1416 & $\nu(\mathrm{N}-\mathrm{O}$ nitro $)$ \\
\hline 1310 & $\nu(\mathrm{N}-\mathrm{N}($ nitro $))$ \\
\hline 1045 & $\nu(\mathrm{C}-\mathrm{O}(\mathrm{ring}))$ \\
\hline 982 & $\nu(\mathrm{O}-\mathrm{N}-\mathrm{O})+\nu(\mathrm{N}-\mathrm{N}($ nitro $))$ \\
\hline 858 & $\nu\left(\mathrm{H}_{3} \mathrm{C}-\mathrm{NCH}_{3}\right)+\delta(\mathrm{C}-\mathrm{N}-\mathrm{N}($ nitro $))$ \\
\hline 780 & $\delta(\mathrm{O}-\mathrm{N}-\mathrm{O})$ \\
\hline 626 & $\nu(\mathrm{S}-\mathrm{C}-\mathrm{Cl})$ \\
\hline
\end{tabular}

a Abbreviations: $\nu$, stretching, $\beta$, bending, $\delta$, scissoring in plane

These series of weak bands that appear between 1000 and $1600 \mathrm{~cm}^{-1}$ instead of the bands from the pesticide compounds are collectively called "cathedral bands". Their appearance is evidence of degradation of the analytes to some degree [78]. This fact can be attributed to the high intensity of the laser source.

To verify the effective SERS activity of the substrate, new trials were conducted using a 2,2'-bipyridine (bipy) $900 \mathrm{mg} \mathrm{L} \mathrm{L}^{-1}\left(5.76 \mathrm{~mol} \mathrm{~L}^{-1}\right)$ solution in ethanol. Again, spectra were collected from multiple regions within the glass sample, and only the results that show some information are shown in Figure 43 . The band assignment for bipy solid standard is presented in Table 9. 
Once again, several "cathedral bands" are present instead of amplified signals, this time with a much clearer pattern. The conclusion that can be drawn is that, even though the laser output intensity used during the experiments was between 2 and $25 \%$ of the nominal intensity, degradation of all the compounds tested was verified, probably due to the interaction with the glass samples and the nanoparticles (which is an initial clue that the synthesized material has photocatalytic properties).

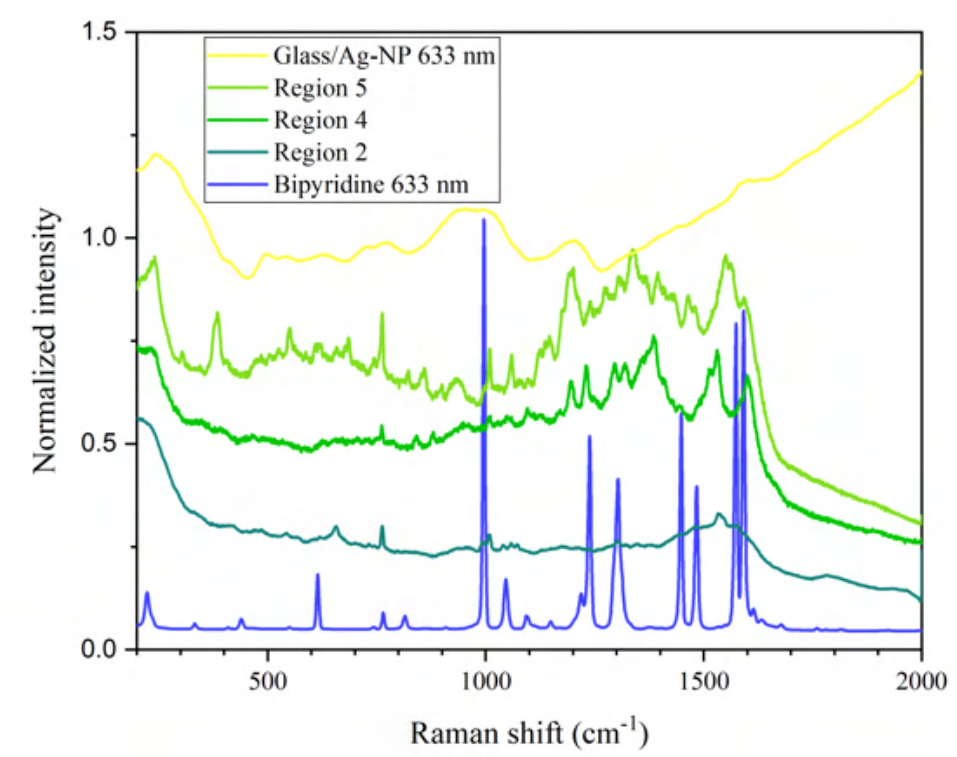

Figure 43 - Raman spectra of NBTN-Ag120 sample before and after contact with droplets of 2,2'-bipiridine $900 \mathrm{ppm}$ in ethanol. The spectrum of 2,2'-bipiridine standard is shown as reference (in blue).

Table 9 - Band assignment for solid 2,2'-bipyridine Raman spectrum [38]

\begin{tabular}{ll}
\hline Raman shift $\left(\mathbf{c m}^{-1}\right)$ & ${ }^{a}$ Assignment \\
\hline 1591 & $\nu(\mathrm{C}-\mathrm{C}$ aromatic $)+\nu(\mathrm{C} \equiv \mathrm{N})$ \\
1573 & $\nu(\mathrm{C}-\mathrm{C}$ aromatic $)+\nu(\mathrm{C} \equiv \mathrm{N})$ \\
1483 & $\nu(\mathrm{C}-\mathrm{C}$ aromatic $)+\nu(\mathrm{C} \equiv \mathrm{N})$ \\
1448 & $\nu(\mathrm{C}-\mathrm{C}$ aromatic $)+\nu(\mathrm{C} \equiv \mathrm{N})$ \\
1303 & $\nu(\mathrm{C}($ ring $A)-\mathrm{C}($ ring $\mathrm{B}))$ \\
1238 & $\nu(\mathrm{C}($ ring $\mathrm{A})-\mathrm{C}(\operatorname{ring} \mathrm{B}))$ \\
1095 & $\beta(\mathrm{C}-\mathrm{C}-\mathrm{H})$ \\
1045 & $\beta(\mathrm{C}-\mathrm{C}-\mathrm{H})$ \\
996 & $\nu(\mathrm{C}-\mathrm{C}$ aromatic $)$ breathing \\
815 & $\phi(\mathrm{C}-\mathrm{C}-\mathrm{H})$ \\
765 & $\beta(\mathrm{C}-\mathrm{C}-\mathrm{H})$ \\
614 & $\beta(\mathrm{C}-\mathrm{C}-\mathrm{H})$ \\
\hline
\end{tabular}

a Abbreviations: $\nu$, stretching, $\beta$, in-plane bending, $\phi$, out-of-plane bending 


\subsection{SERS detection of crystal violet}

Crystal violet (CV, Figure 44) was chosen as the analyte for another round of SERS trials using the synthesized glass samples because it is commonly utilized as probe molecule in other works [95, 96, 97, 98]. The laser source wavelength was altered to $473 \mathrm{~nm}$ to avoid resonance with CV, and to be closer to the Ag-NPs SPR maximum of absorption. The samples NBTN-Ag30, NBTN-Ag60, and NBTN-Ag120 were tested. $40 \mu \mathrm{L}$ of CV aqueous solution was added dropwise to the surface of the glass samples, and the analysis was performed after the solvent dried. The laser output intensity was $1 \%$ of the nominal intensity, and the accumulation time was 30s.

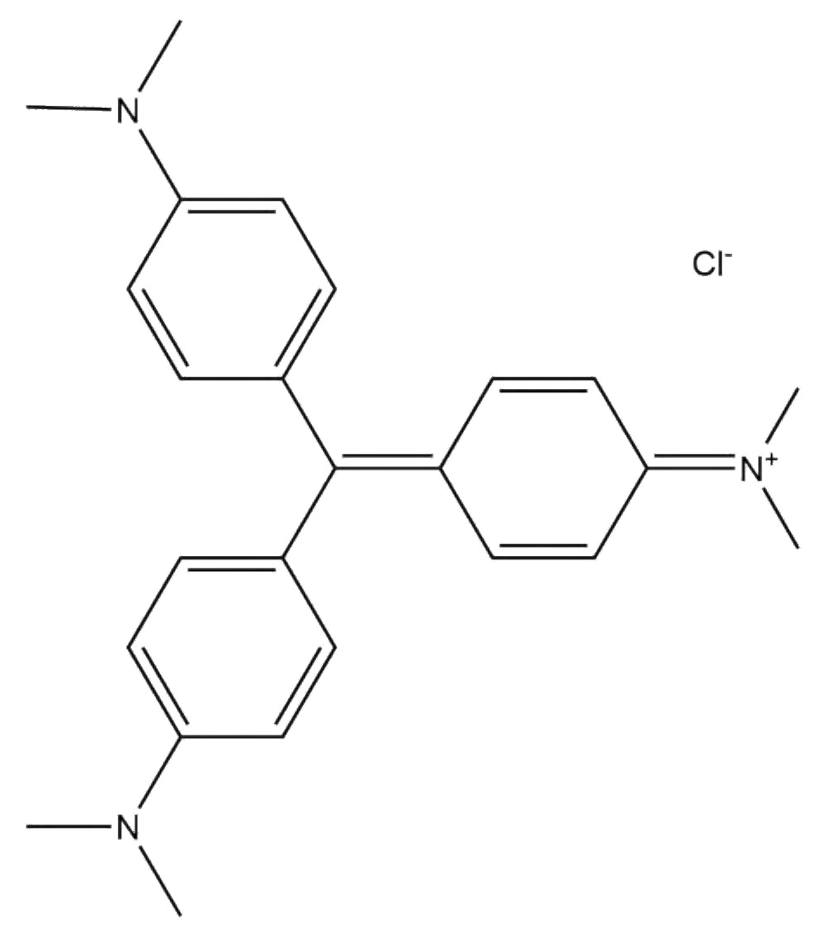

Figure 44 - Crystal violet structure.

SERS spectra could then be obtained. Figure 45 shows the normalized spectra, and Table 10 presents the band assignment for the solid CV. Appendix C contains the raw data of all samples and all concentrations of analyte, for a better comparison of the intensities. For the first two substrates, it was possible to detect the probe molecule up to a limit of $10^{-5} \mathrm{~mol} \mathrm{~L}{ }^{-1}$. NBTN-Ag120 could detect an ever lower concentration, $10^{-6} \mathrm{~mol}$ $\mathrm{L}^{-1}$ 

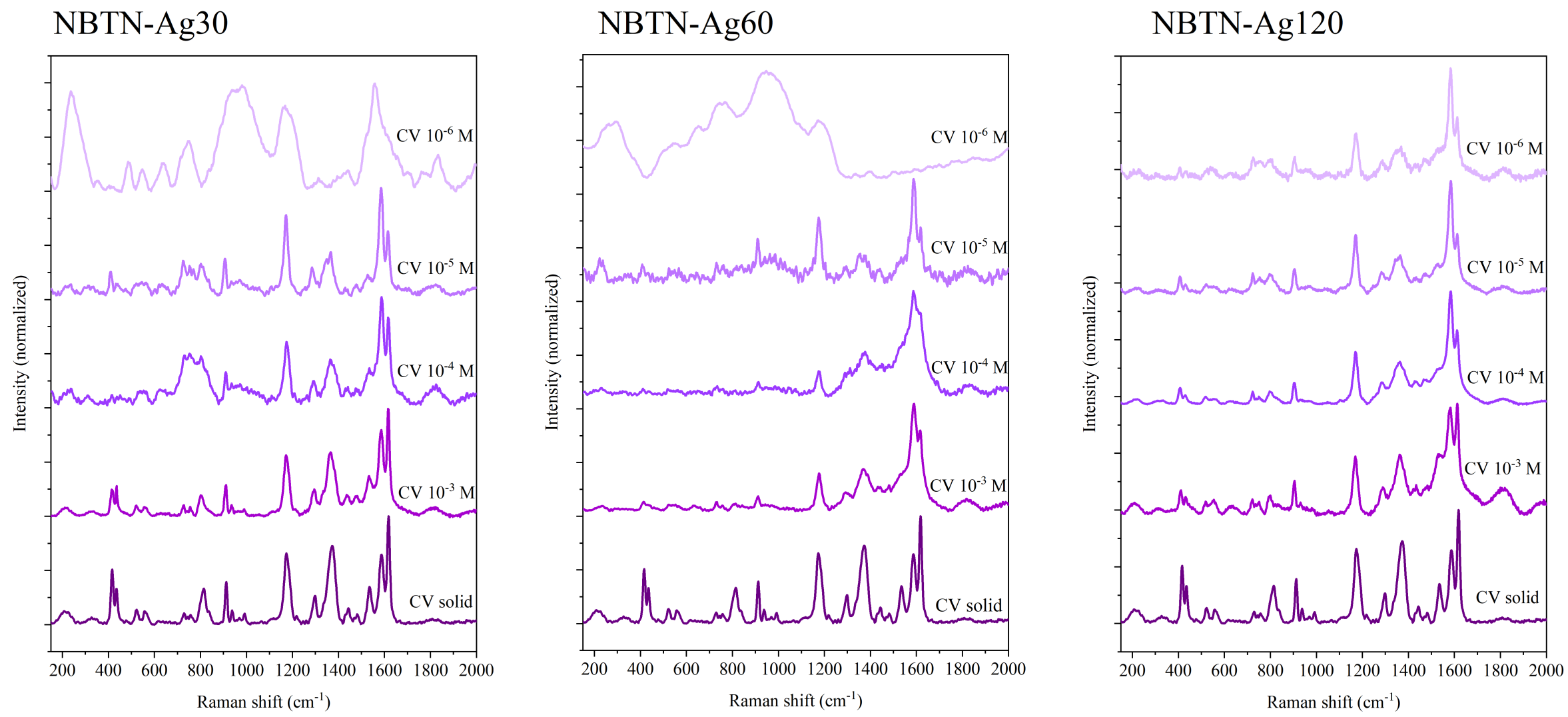

Figure 45 - SERS detection of crystal violet in concentrations $10^{-3}, 10^{-4}, 10^{-5}$, and $10^{-6}$ mol $\mathrm{L}^{-1}$ on the surface of glass samples decorated with Ag-NPs with ion exchange bath times of 30, 60, and 120min. 
Table 10 - Band assignment for solid crystal violet Raman spectrum [95]

\begin{tabular}{lll}
\hline Raman shift $\left.\mathbf{( c m}^{-1}\right)$ & ${ }^{a}$ Assignment & Irreducible representation \\
\hline 1617 & $\nu(\mathrm{C}-\mathrm{C})($ ring $)$ & $A_{1}$ \\
1588 & $\nu(\mathrm{C}-\mathrm{C})($ ring $)$ & $E$ \\
1534 & $\nu(\mathrm{C}(\mathrm{ring})-\mathrm{N})$ & $E$ \\
1373 & $\nu(\mathrm{C}($ center $)-\mathrm{C}(\mathrm{ring}))$ & $E$ \\
1173 & $\beta(\mathrm{C}-\mathrm{H})(\mathrm{ring})$ & $E$ \\
937 & $\nu(\mathrm{C}-\mathrm{C})(\mathrm{ring})$ & $A_{1}$ \\
912 & $\nu(\mathrm{C}-\mathrm{C})($ ring $)$ & $E$ \\
815 & $\phi(\mathrm{C}-\mathrm{H})($ ring $)$ & $E$ \\
435 & $\phi(\mathrm{C}-\mathrm{C})(\mathrm{ring})$ & $A_{1}$ \\
416 & $\beta(\mathrm{C}-\mathrm{N}-\mathrm{C})$ & $E$ \\
\hline
\end{tabular}

a Abbreviations: $\nu$, stretching, $\beta$, in-plane bending, $\phi$, out-of-plane bending

Figure 46 presents the non-scaled SERS/Raman spectra of CV for a comparison of the signal intensity using different substrates. Using Equation 5.9, the enhancement factor can be estimated from the displayed data. NBTN-Ag120 has an analytical enhancement factor of 5 when compared to spectrum taken on the glass without Ag-NPs. It is important to emphasize that this value is only an estimate. The materials being studied are solid substrates, and adsorption, as well as adhesion and cohesion, are important factors to be taken in consideration when comparing the glass samples. It was observed, for example, that when the solvent was drying, the analyte was concentrating in small spots on the surface of the untreated NBTN glass, while it was evenly spread out on the surface of the modified NBTN glass. Therefore, the silver nanoparticles that are present in the glass samples modify how CV interacts with their surface. That is the motive why, although CV could be detected using NBTN-Ag30 and NBTN-Ag60 substrates, the signals obtained using the untreated glass were more intense.

To have a better understanding on how this enhancement occurs, three pairs of signals are highlighted: $416(E)$ and $435\left(A_{1}\right), 912(E)$ and $937\left(A_{1}\right)$, and $1588(E)$ and $1617\left(A_{1}\right)$. With decreasing concentration of $\mathrm{CV}$, the intensity ratio $I_{E} / I_{A 1}$ increases, meaning that the non-totally symmetric signals ( $E$ representation) are more strongly enhanced than the totally symmetric ones ( $A_{1}$ representation).

Since charge transfer mechanisms are the main responsible for the enhancement of non-totally symmetric modes, such amplification of $E$ modes observed in the SERS spectra of crystal violet are evidence of chemical adsorption of CV on the surface of NBTN-Ag samples.

The inversion of intensity in the last pair of signals was not observed in other works ([95, 96, 97, 98]). Besides being an indicative of the SERS activity of the substrates, such behavior presents one clear advantage of solid substrates when compared to colloidal 
suspensions: there is no adsorption competition between the analyte and a stabilizing agent, which may hinder the interaction of the target molecule with the nanoparticles.

The Ag-NPs present on the surface of the glasses are free to interact with the analyte. The materials presented here are, therefore, good candidates for devices of organic molecules detection in small concentrations.

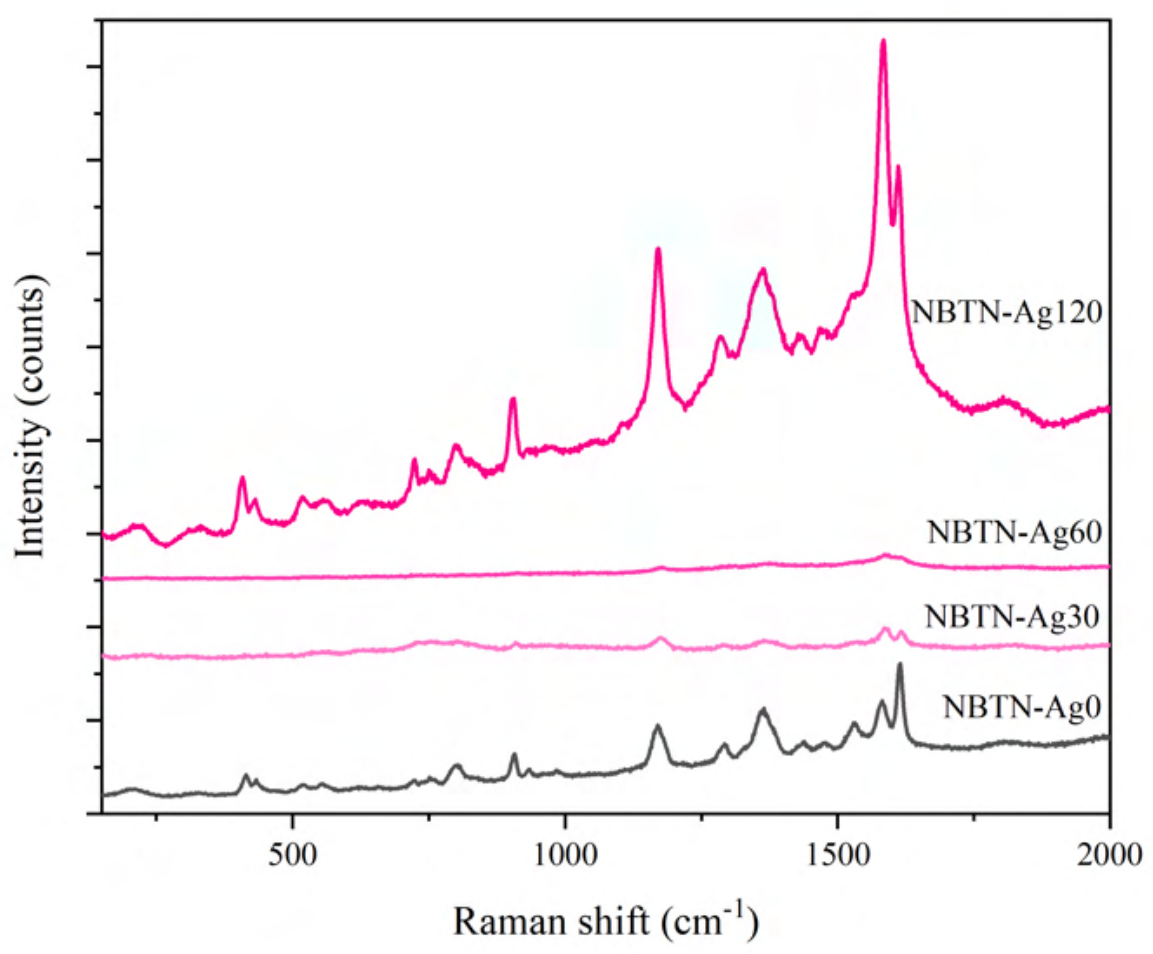

Figure 46 - Non-scaled spectra for comparison of the effect of surface interaction with the glass samples on the intensity of the signals of $\mathrm{CV} 10^{-4}$ mol L-1. Appendix $\mathrm{C}$ contains this comparison for the other concentrations of $\mathrm{CV}$.

\subsection{Photocatalysis essays}

The photocatalytic activity of the samples was evaluated in two forms: on the surface of bulk samples, and in suspensions of the powdered samples. The reason for that was each type of sample has one advantage in the photocatalysis experiment: bulk samples do not need to be milled, being more easily prepared; powdered samples, on the other hand, might have a greater photocatalytic activity, for possessing a larger surface area for the reaction to occur. 


\subsubsection{Optical band gap}

The band gap energy $\left(E_{g}\right)$ is the energy necessary to excite electrons from the valence band to the conduction band in solids. In 1966, J. Tauc proposed a method to calculate $E_{g}$ in amorphous solids using spectroscopic data [99]. The band gap energy calculated through this method is denominated optical band gap, and it can be derived from the following relationship:

$$
(\alpha \cdot h \nu)^{\frac{1}{\gamma}}=B\left(h \nu-E_{g}\right)
$$

where $\alpha$ is the absorption coefficient (which depends on the wavelength of the incoming photons), $h$ is the Planck constant, $\nu$ is the frequency of the incoming photons, $B$ is a constant, $E_{g}$ is the band gap energy, and $\gamma$ is a factor that depends on the nature of the electron transition ( $\frac{1}{2}$ for direct and 2 for indirect transition band gaps) [100].

The absorption coefficient $\alpha(\nu)$ is calculated via

$$
\alpha(\nu)=2.303\left(\frac{A(\nu)}{d}\right)
$$

where $A$ is the absorbance in the UV-Vis spectrum, and $d$ is the thickness of the solid sample [101].

In the case of bulk samples, where the absorbance is directly measured, the $E_{g}$ value is the extrapolation of the linear portion of the Tauc plot to the $x$ axis. However, in the case of powdered samples, where the diffuse reflectance spectra were taken instead, an additional treatment is necessary. Through the Kubelka-Munk transformation, presented in 1931, reflectance spectra can be converted to absorption spectra, using the equation

$$
F\left(R_{\infty}\right)=\frac{K}{S}=\frac{\left(1-R_{\infty}\right)^{2}}{2 R_{\infty}}
$$

where $R_{\infty}$ is the reflectance value of an infinitely thick sample, and $K$ and $S$ are the absorption and scattering coefficients, respectively [102].

The value $F\left(R_{\infty}\right)$ obtained from Equation 7.3 can then be directly applied to Equation 7.1 .

Tauc plots for the bulk samples, calculated from their absorption UV-Vis spectra, are presented in Figure 47, while the ones for the powder samples, calculated via KubelkaMunk treated spectra, are shown in Figure 48. The optical band gap energies were extracted from the extrapolation of the straight portion of these plots to the $x$ axis, and they are displayed in Tables 11 and 12 , respectively. 

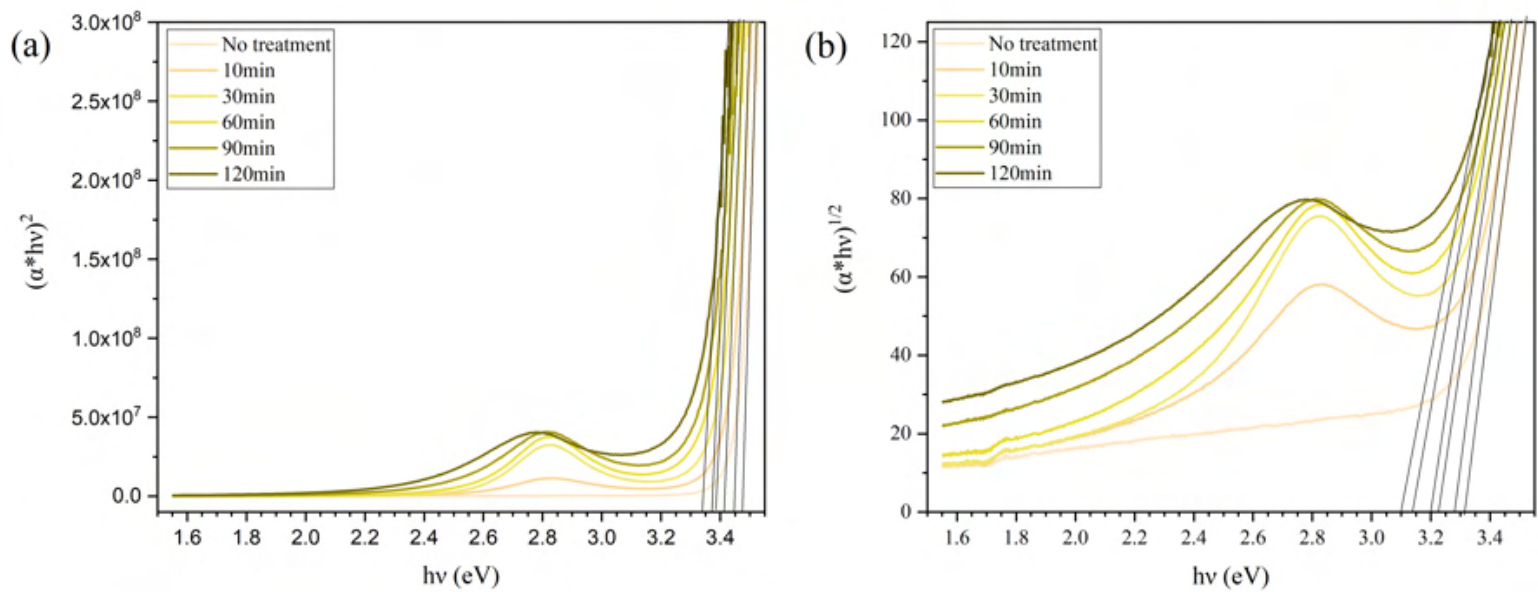

Figure 47 - Tauc plots for determination of (a) direct and (b) indirect band gap energies of NBTN-Ag bulk samples.

Table 11 - Optical band gap energies for NBTN-Ag bulk samples

\begin{tabular}{lll}
\hline Sample & Direct $E_{g}(\mathbf{e V})$ & Indirect $E_{g}(\mathbf{e V})$ \\
\hline NBTN (no treatment) & 3.47 & 3.32 \\
NBTN-Ag10 & 3.45 & 3.28 \\
NBTN-Ag30 & 3.41 & 3.23 \\
NBTN-Ag60 & 3.38 & 3.20 \\
NBTN-Ag90 & 3.37 & 3.14 \\
NBTN-Ag120 & 3.34 & 3.10 \\
\hline
\end{tabular}

In these tables, direct band gap energy refers to the energy value for an electronic transition to occur directly between the valence and conduction bands within the solid structure, while indirect band gap energy corresponds to the value for the transition to occur between these same states, but having a phonon (vibration of the structure) transition as intermediate. Since both of these types of transition may simultaneously occur, it is not simple to experimentally define which one is dominant [103].

Two behaviors can be noticed in the band gap tables: whilst in the bulk samples the direct transition values are larger than the indirect values, in the powdered samples it is the opposite. However, they should not be compared across tables, since they were obtained via different measurement modes (the former, directly from the absorbance spectra, and the latter, from the Kubelka-Munk treatment of the diffuse reflectance spectra).

Nevertheless, in both cases, the same trend is observed: the higher the content of Ag-NPs, the lower the $E_{g}$. This decrease is related to the red-shift in the UV-Vis spectra. 
This may be due to the raise of the upper limit of the valence band, which, in turn, is a consequence of a higher negative charge in non-bridging oxygen atoms [46].
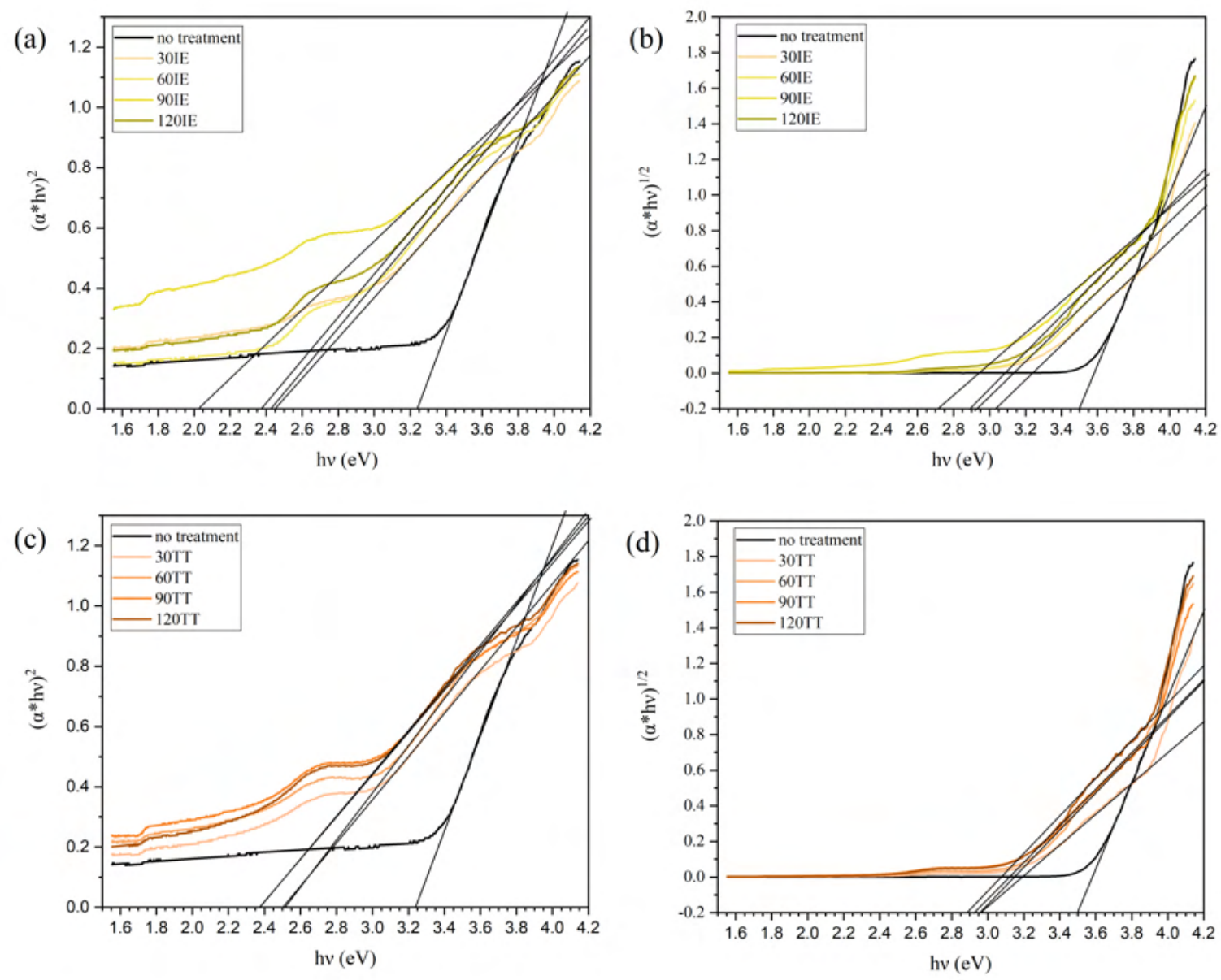

Figure 48 - Tauc plots for determination of direct (a and c) and indirect (b and d) band gap energies of powder glass samples after ion exchange only ( $a$ and b) and after ion exchange and thermal treatment (c and $\mathrm{d}$ ).

Table 12 - Optical band gap energies for NBTN-Ag powdered samples

\begin{tabular}{|c|c|c|c|c|}
\hline Sample & \multicolumn{2}{|c|}{ Direct $E_{g}(\mathrm{eV})$} & \multicolumn{2}{|c|}{ Indirect $E_{g}(\mathrm{eV})$} \\
\hline NBTN (no Ag-NPs) & 3.24 & & 3.50 & \\
\hline NBTN-Ag30 & 2.45 & 2.51 & 3.03 & 2.96 \\
\hline NBTN-Ag60 & 2.43 & 2.51 & 2.92 & 2.96 \\
\hline NBTN-Ag90 & 2.38 & 2.37 & 2.88 & 2.92 \\
\hline NBTN-Ag120 & 2.04 & 2.37 & 2.70 & 2.88 \\
\hline
\end{tabular}




\subsubsection{Photodegradation study of methylene blue: dispersion method}

The photocatalysis experiments were carried out using methylene blue (MB, Figure 49 as target molecule. The degradation was monitored using the decrease in the absorption band of MB in the electronic spectrum at $662 \mathrm{~nm}$. The light source used in all experiments was a Hamamatsu LightningCure LC8 Xe/Hg type 02A lamp.

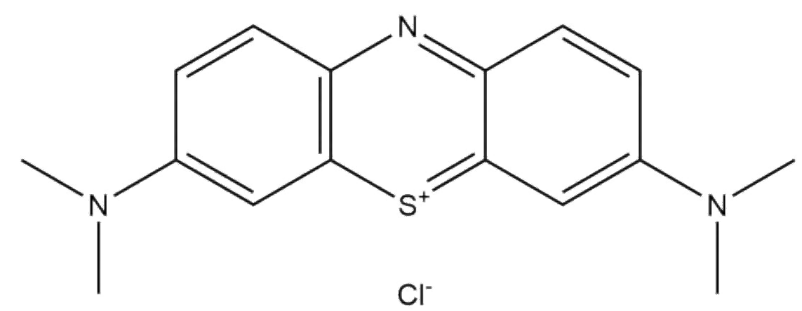

Figure 49 - Methylene blue structure.

For the photocatalytic tests in suspension, $30 \mathrm{mg}$ of each glass powder was weighed. That mass was added to $35 \mathrm{~mL}$ of water, which was then agitated using an ultrasound bath for $30 \mathrm{~min}$. The suspension was mixed with $35 \mathrm{~mL}$ of an $\mathrm{MB}$ aqueous solution to

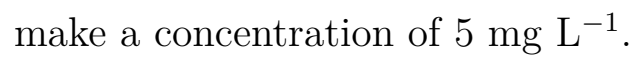

To assess the adsorption of MB to the glass powder surface, the MB solution containing the 60IE sample was left in the dark under agitation, and aliquots were taken every $10 \mathrm{~min}$ to measure the electronic absorption. Figure 50 shows the decay of the absorbance intensity of MB, $I$, in terms of its initial value $I_{0}$.

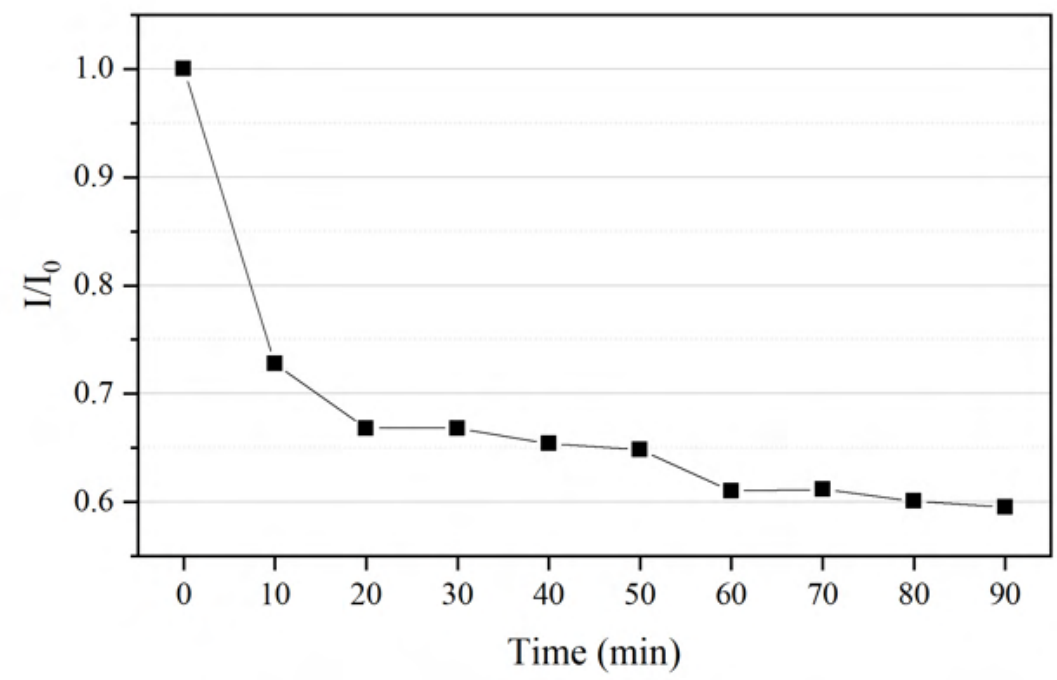

Figure 50 - Adsorption curve for 60IE sample suspended in an aqueous solution of methylene blue. 
After 10 min, there was a relative decay of $27 \%$ in the absorption of the dye, which can be correlated to its adsorption to the glass surface. After $30 \mathrm{~min}$, this value increased to $33 \%$ and, after $90 \mathrm{~min}$, to 40\%. That means that, between 30 and $90 \mathrm{~min}$, the adsorption was accounted for an intensity decrease of only $7 \%$, much smaller than in the first 30 min.

For that reason, to run the tests, the suspensions were kept in the dark for $30 \mathrm{~min}$. The lamp was positioned $7 \mathrm{~cm}$ away from the reactor (composed of borosilicate glass), and it was then turned on. This experimental setup is presented in Figure51. Aliquots were taken every $10 \mathrm{~min}$ in the next hour to verify the photocatalytic activity via electronic spectra of MB. The results of relative decays are displayed in Figure 52 .

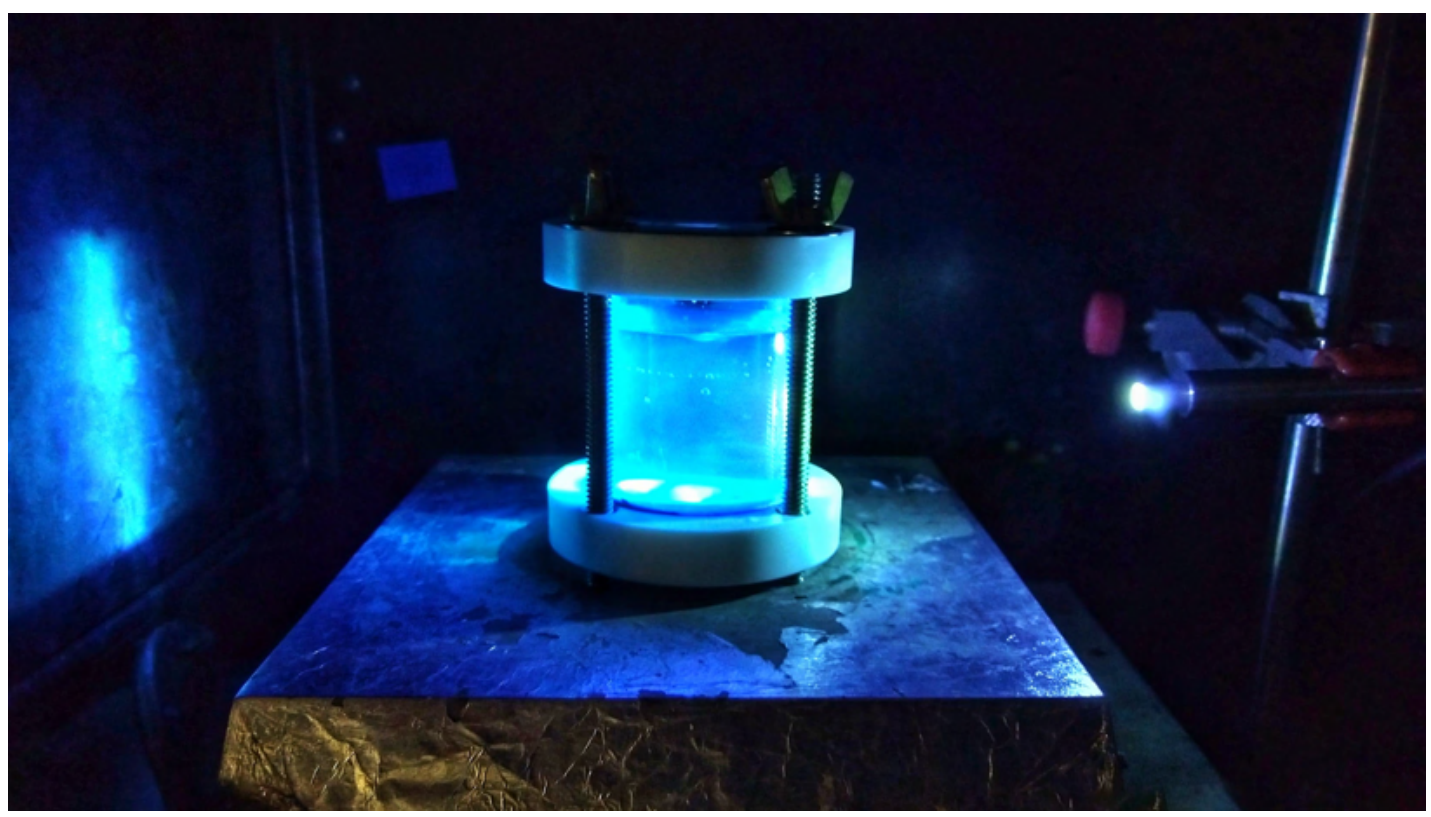

Figure 51 - Experimental setup of the photocatalysis tests in dispersion.

It was observed no significant degradation of MB by the light source, because the borosilicate glass walls of the reactor filters part of the UV radiation. The use of glass powder in all other experiments, however, promoted the degradation of the dye to some degree. Table 13 presents the percentage of degradation of each experiment after $60 \mathrm{~min}$. The values were obtained directly from the intensity ratios shown in Figure 52.

Some unusual behavior was observed in the results. The photodegradation curve for 30IE sample, for example, shows an increase in the intensity of the absorption band of MB after $40 \mathrm{~min}$. This is due to competition of the photocatalysis effect with adsorption and desorption of the analyte on and off the glass powder, which shows that the adsorption does not happen at the same rate for all samples. 


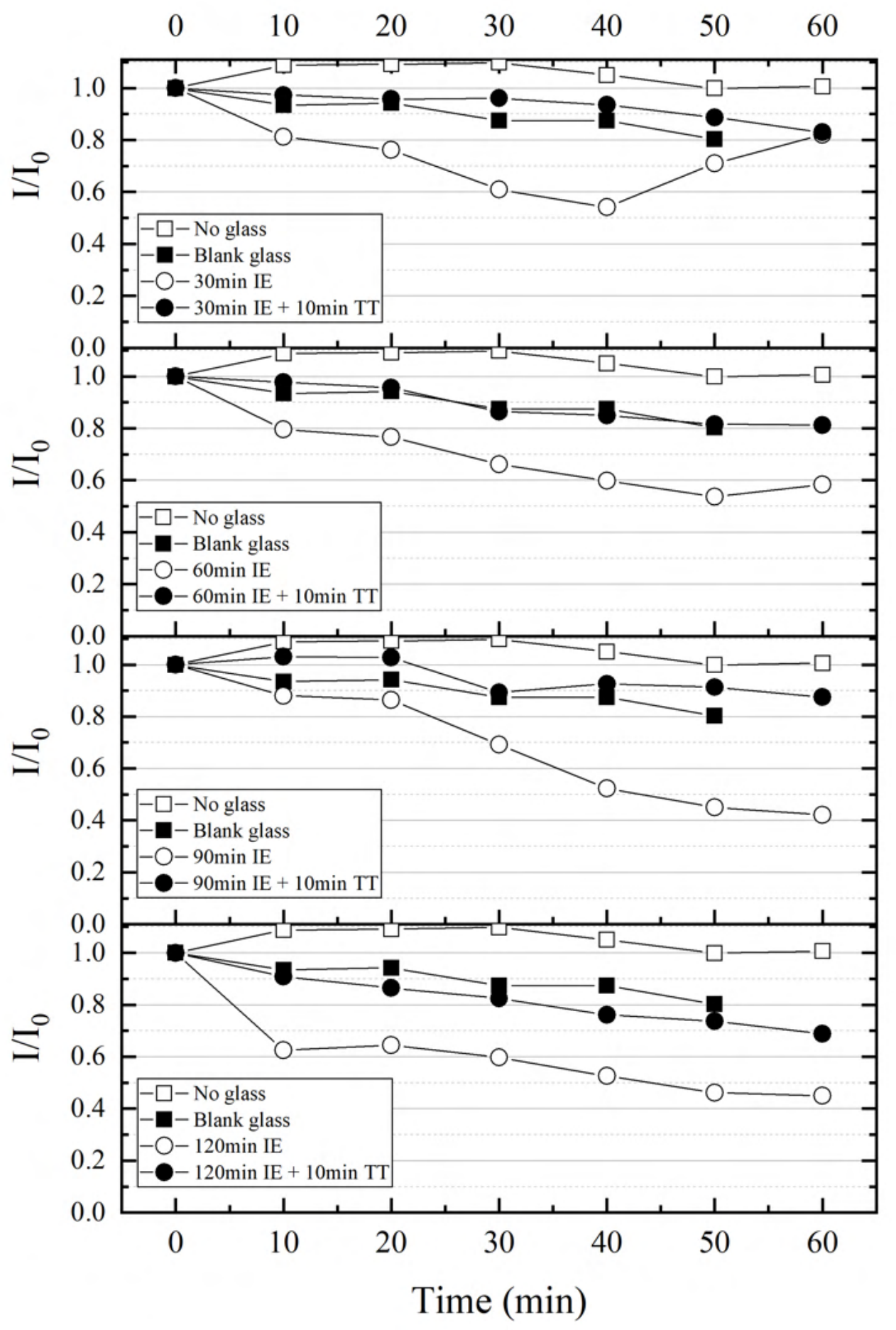

Figure 52 - Photodegradation curves of methylene blue. From top to bottom, each plot shows the experiments with the samples of 30,60,90, and 120 min ion exchange baths, with and without thermal treatment. The photodegradation curves using no glass and a blank sample (glass with no Ag-NPs) are showed as control. 
Table 13 - Percentage of degradation of methylene blue in solution using NBTN glass powders after $1 \mathrm{~h}$ of irradiation with light

\begin{tabular}{|c|c|c|}
\hline \multirow{2}{*}{ Sample } & \multicolumn{2}{|c|}{ Degradation \% } \\
\hline & IE & $\mathrm{TT}$ \\
\hline NBTN (no Ag-NPs) & 19.7 & \\
\hline NBTN-Ag30 & - & 17.0 \\
\hline NBTN-Ag60 & 41.5 & 18.8 \\
\hline NBTN-Ag90 & 57.8 & 12.6 \\
\hline NBTN-Ag120 & 55.1 & 31.2 \\
\hline
\end{tabular}

Nevertheless, degradation of up to $57.8 \%$ of the amount of MB present in solution was observed. A larger photocatalytic effect was acquired using the IE samples as opposed to the TT samples, even though the latter have a greater amount of NPs. The thermal treatment may have caused the NPs to aggregate, in a similar fashion to what was observed in Figure 35, where the SPR band of NBTN-Ag120 decreased due to the larger dimensions of the formed aggregates. Here, the photocatalysis enhancement provided by the nanoparticles was diminished because the LSPs were weaker.

When silver nanoparticles were not present in the glass, the photocatalytic activity was lesser than when they were incorporated in the substrates (considering the IE samples). This is a suggestion that Ag-NPs aided in degradation of MB.

Another trend that was observed is that the photocatalytic activity increases with increasing ion exchange bath time. This can be directly related to the band gap energy of the samples, which follows a decreasing trend. The lower the $E_{g}$ value, the lower the necessary energy to promote the electron from the valence to the conduction band, a required mechanism in the photocatalysis process. Therefore, the degradation yield was expected to increase.

However, the greatest activity was obtained with 90IE sample (57.8\%), not 120IE $(55.1 \%)$ as expected. One possible reason for that is, again, the aforementioned aggregation of NPs, which enlarge the dimensions of the overall particles, diminishing their LSPs.

\subsubsection{Photodegradation study of methylene blue: bulk method}

In addition to the suspension tests, photodegradation experiments using NBTNAg90 and NBTN-Ag120 bulk samples were conducted. The glass was used to cover the bottom of a $30 \mathrm{~mm} \times 23 \mathrm{~mm} \times 25 \mathrm{~mm}$ cuvette. $16 \mathrm{~mL}$ of MB aqueous solution with concentration $5 \mathrm{mg} \mathrm{L}^{-1}$ were added to the cuvette. After $30 \mathrm{~min}$ of agitation in the dark, the lamp, positioned $10 \mathrm{~cm}$ above, was turned on, directly illuminating the sample and the glass at the bottom. This setup is shown in Figure 53 Aliquots were taken every 10 min to 
measure the UV-Vis spectrum for $1 \mathrm{~h}$. Besides the glasses containing the nanoparticles, the experiment was repeated using NBTN15 without the Ag-NPs, and also with no glass sample in the cuvette. Figure 54 shows the results in terms of relative decay of absorbance intensity.

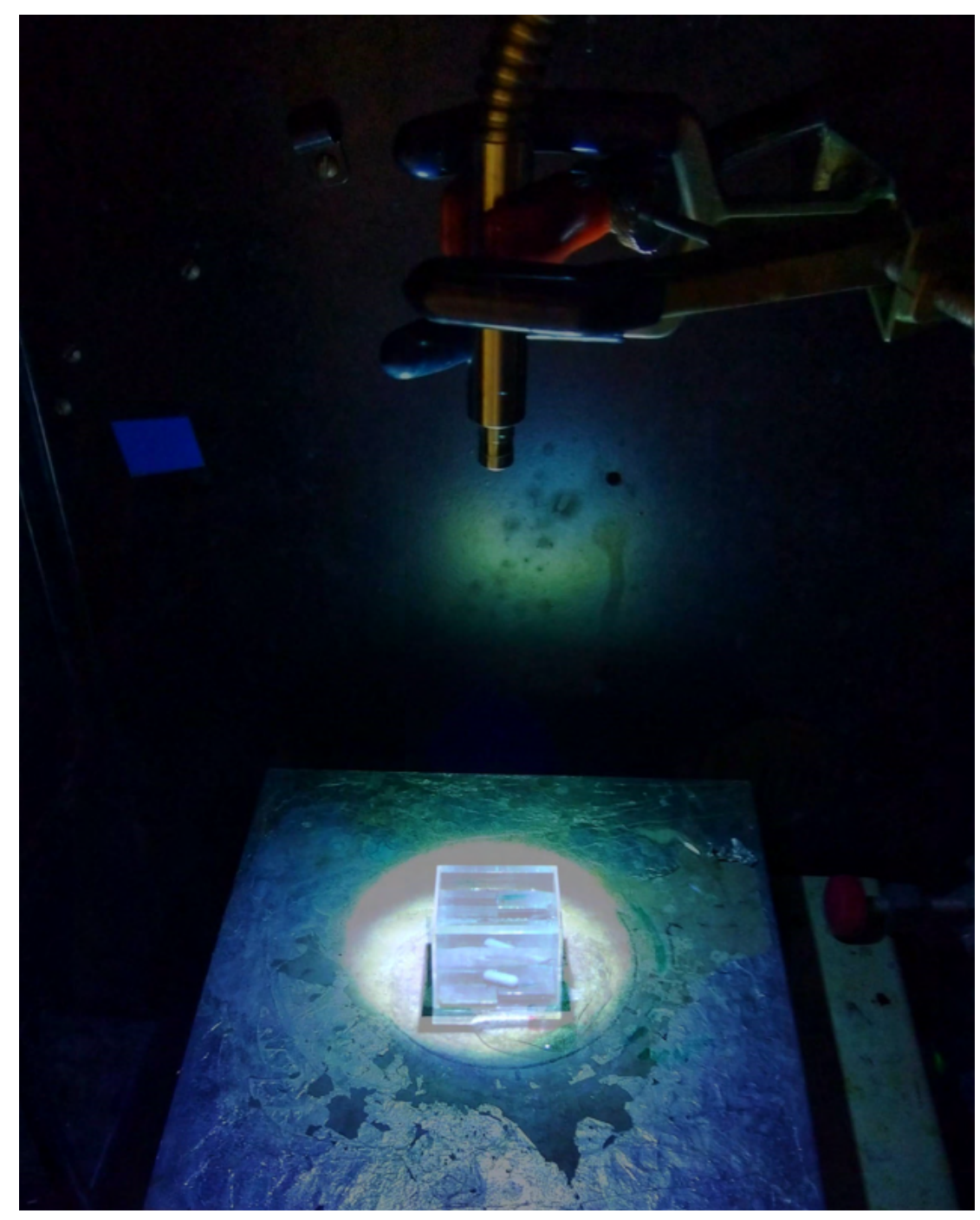

Figure 53 - Photodegradation curves of methylene blue. Each curve refers to the experiments using no glass sample (only the degradation by light is observed), using NBTN15 without Ag-NPs, and the NBTN-Ag120 sample.

Here, the light was being irradiated directly to the solution. Hence, the degradation of $37 \%$ of the initial amount of MB when no glass sample was used is solely due to the UV radiation. When NBTN15 sample was placed on the bottom of the cuvette, the intensity of the absorption band of the dye was reduced to $50 \%$ of its initial value. This means that the degradation of the dye doubled with the aid of the synthesized glass. When silver nanoparticles were present on the glass surface, $65 \%$ of degradation was observed for NBTN-Ag90, and $77 \%$ for NBTN-Ag120. 


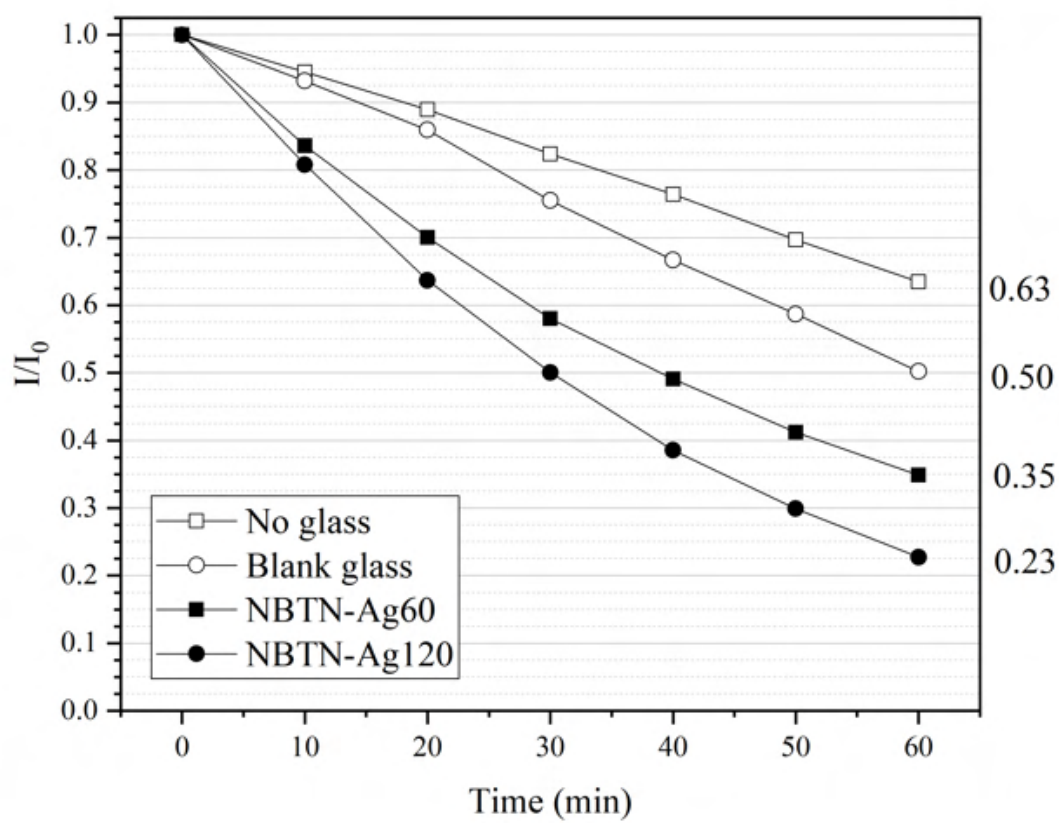

Figure 54 - Photodegradation curves of methylene blue. Each curve refers to the experiments using no glass sample (only the degradation by light is observed), using NBTN15 without Ag-NPs, NBTN-Ag90, and NBTN-Ag120.

The results presented above show that NBTN glass acts as a photocatalyst on its own. Furthermore, an effective contribution of the silver nanoparticles to the overall photocatalytic effect was observed, demonstrating that, in the synthesized vitreous materials, the proposed photodegradation aided by plasmonics effectively happened.

In a 60 min time window, more than half of the organic compound was degraded, and the silver nanoparticles were responsible for the enhancement of the photocatalytic activity. Hence, it was possible to obtain a vitreous material in which the plasmonic photocatalysis degradation of MB was performed. Such achievement is a great step towards the development of a solid device for removal of organic compounds from water sources and wastewater. 



\section{CHAPTER 8}

\section{Conclusion}

The main objective of this Master's research project was the development of a new vitreous substrate with applications in detection via SERS and photocatalysis, both aided by the SPR effect of silver nanoparticles synthesized on the surface of the glass. In face of this ambitious objective, four goals were set to be completed, and the results obtained led to the following conclusions:

- Two novel glass families, PBTN and NBTN, were synthesized containing $\mathrm{TiO}_{2}$, and their characterization showed that boron oxide, as a glass former, contributes with an increase in the characteristic temperatures of the samples. It was also verified that the presence of titanium in the glass network affects the thermal properties of the materials (also causing an increase in the observed glass transition temperatures). Also due to the inclusion of titanium, the synthesized glasses are both thermally and chemically stable, which makes the samples suitable for the proposed applications.

- Silver nanoparticles were synthesized on the surface of the glass samples, using the ion exchange-thermal treatment process. Their presence was proved by means of the SPR band analysis in UV/Vis spectra, EDX line scans in SEM, and TEM images. The Ag-NPs permeated into the samples to a depth up to $194 \mu \mathrm{m}$, being spherical, with a high diameter regularity, between 5 and $15 \mathrm{~nm}$.

- The samples were proven to be active SERS substrates towards the detection of crystal violet, up to a $10^{-6} \mathrm{~mol} \mathrm{~L}{ }^{-1}$ lower limit. Hence, the synthesized material can be further studied as a potential device for low-concentration organic molecules sensing.

- The photodegradation trials were performed both in bulk and powdered samples. The activity towards the degradation of methylene blue was verified in both cases, even though a combined effect of degradation and adsorption was found. Moreover, 
the addition of Ag-NPs to the substrates evidently enhances their photocatalytic potential.

The majority of the research experiments presented here was conducted during the COVID-19 pandemic. Because of many limitations this fact imposed, it was not possible to execute further SERS and photocatalysis essays, using the target pesticide molecules or the crystallized PBTN samples. The activity of the synthesized materials towards these two applications was demonstrated using common dyes as targets, therefore achieving the initial proposal.

In conclusion, this work presented the first step towards the creation of a vitreous device for detection and degradation of organic compounds dissolved in water. Glass is a versatile material that has an immense role in the development of humankind, in art and history, as well as in science and technology. Here, it was employed in applications that involve the use of nanoparticles and light, two other entities of great importance in the construction of the current world. As a perspective, LaMIV, the Inorganic and Vitreous Materials Lab, will keep studying these substrates and their applications to perfect them and make them ready for use as a real-world solution. 


\section{References}

1 PELTON, M.; AIZPURUA, J.; BRYANT, G. Metal-nanoparticle plasmonics. Laser \& Photonics Reviews, Weinheim, v. 2, n. 3, p. 136-159, 2008.

2 CATCHPOLE, K.; ; POLMAN, A. Plasmonic solar cells. Optics express, Washington, DC, v. 16, n. 26, p. 21793-21800, 2008.

3 MANDAL, P.; SHARMA, S. Progress in plasmonic solar cell efficiency improvement: A status review. Renewable and Sustainable Energy Reviews, Amsterdam, v. 65, p. 537-552, 2016.

4 GATHER, M. C.; MEERHOLZ, K.; DANZ, N.; LEOSSON, K. Net optical gain in a plasmonic waveguide embedded in a fluorescent polymer. Nature Photonics, London, v. 4, n. 7 , p. 457-461, 2010.

5 FU, Y.; ZHOU, X. Plasmonic lenses: a review. Plasmonics, New York, NY, v. 5, n. 3, p. 287-310, 2010.

6 LI, P.; XIE, W.; MAO, W.; TIAN, Y.; HUANG, F.; XU, S.; ZHANG, J. A new whole family perovskites quantum dots $\left(\mathrm{CsPbX}_{3}, \mathrm{X}=\mathrm{Cl}, \mathrm{Br}, \mathrm{I}\right)$ phosphate glasses with full spectral emissions. Journal of Alloys and Compounds, Amsterdam, v. 817, p. 153338, 2020 .

7 HE, M.; CHENG, Y.; SHEN, L.; ZHANG, H.; SHEN, C.; XIANG, W.; LIANG, X. Doping manganese into $\mathrm{CsPb}(\mathrm{Cl} / \mathrm{Br})_{3}$ quantum dots glasses: Dual-color emission and super thermal stability. Journal of the American Ceramic Society, Malden, MA, v. 102, n. 3, p. 1090-1100, 2019.

8 CAILlOSSE, E.; ZAIER, M.; MEZGHANI, M.; HAJJAR, S.; VIDAL, L.; LOUGNOT, D.; BALAN, L. Photo-induced self-assembly of silver nanoparticles for rapid generation of first and second surface mirrors. ACS Applied Nano Materials, Washington, DC, v. 3, n. 7 , p. $6510-6531,2020$.

9 VAllejO, M.; ROMERO-SERVIN, S.; AlvAREZ, M. I. C.; ANGEL, J. A. E.; GOMEZ-SOLIS, C.; ÁLVAREZ-VALTIERRA, L.; SOSA, M. Enhancing the nonlinear optical properties of lithium tetraborate glass using rare earth elements and silver nanoparticles. Nano, Singapore, v. 15, n. 05, p. 2050064, 2020.

10 WANG, Q.; DU, C.; KONG, L.; HU, H. High sensitivity fibre surface plasmon resonance sensor based on silver mirror reaction. Transactions of the Institute of Measurement and Control, London, v. 40, n. 2, p. 462-468, 2018. 
11 AHMADI, F.; EBRAHIMPOUR, Z.; ASGARI, A.; EL-MALLAWANY, R. Role of silver/titania nanoparticles on optical features of $\mathrm{Sm}^{3+}$ doped sulfophosphate glass. Optical Materials, Amsterdam, v. 105, p. 109922, 2020.

12 FreitAS, I. C. de; PARREIRA, L. S.; BARBOSA, E. C.; NOVAES, B. A.; MOU, T.; ALVES, T. V.; QUIROZ, J.; WANG, Y.-C.; SLATER, T. J.; THOMAS, A. et al. Design-controlled synthesis of $\mathrm{IrO}_{2}$ sub-monolayers on au nanoflowers: marrying plasmonic and electrocatalytic properties. Nanoscale, Cambridge, v. 12, p. 12281-12291, 2020.

13 BLETEAU, P.; BASTIDE, M.; GAM-DEROUICH, S.; MARTIN, P.; BONNET, R.; LACROIX, J.-C. Plasmon-induced grafting in the gap of gold nanoparticle dimers for plasmonic molecular junctions. ACS Applied Nano Materials, Washington, DC, v. 3, n. 8, p. 7789-7794, 2020.

14 ZHANG, Y.; HE, S.; GUO, W.; HU, Y.; HUANG, J.; MULCAHY, J. R.; WEI, W. D. Surface-plasmon-driven hot electron photochemistry. Chemical reviews, Washington, DC, v. 118, n. 6, p. 2927-2954, 2017.

15 SHELBY, J. E. Introduction to glass science and technology. Cambridge: Royal Society of Chemistry, 2005.

16 GUTZOW, I.; SCHMELZER, J. The vitreous state. Heidelberg: Springer, 2013.

17 VARSHNEYA, A. K. Fundamentals of inorganic glasses. Amsterdam: Elsevier, 2013.

18 ZARZYCKI, J. Glasses and the vitreous state. Cambridge: Cambridge university press, 1991.

19 ZANOTTO, E. D.; MAURO, J. C. The glassy state of matter: Its definition and ultimate fate. Journal of Non-Crystalline Solids, Amsterdam, v. 471, p. 490-495, 2017.

20 ATKINS, P.; OVERTON, T. Inorganic Chemistry. Oxford: Oxford University Press, 2010.

21 ATKInS, P. W.; PAUlA, J. D.; KEELER, J. Physical Chemistry. Oxford: Oxford University Press, 2018.

22 MUSGRAVES, J. D.; HU, J.; CALVEZ, L. Springer Handbook of Glass. [S.l.]: Springer, 2019.

23 ZACHARIASEN, W. H. The atomic arrangement in glass. Journal of the American Chemical Society, Washington, DC, v. 54, n. 10, p. 3841-3851, 1932.

24 STANWORTH, J. E. Physical properties of glass. Oxford: Clarendon Press, 1950. v. 6 .

25 SUN, K.-H. Fundamental condition of glass formation. Journal of the American Ceramic Society, Malden, MA, v. 30, n. 9, p. 277-281, 1947.

26 DIETZEL, A. Die kationenfeldstärken und ihre beziehungen zu entglasungsvorgängen, zur verbindungsbildung und zu den schmelzpunkten von silicaten. Zeitschrift für Elektrochemie und angewandte physikalische Chemie, Frankfurt, v. 48, n. 1, p. 9-23, 1942. 
27 IVASCU, C.; GABOR, A. T.; COZAR, O.; DARABAN, L.; ARDELEAN, I. Ft-ir, raman and thermoluminescence investigation of $\mathrm{P}_{2} \mathrm{O}_{5}-\mathrm{BaO}-\mathrm{Li}_{2} \mathrm{O}$ glass system. Journal of Molecular Structure, Amsterdam, v. 993, n. 1-3, p. 249-253, 2011.

28 FRANCO, D. F.; MANZANI, D.; CARVAJAL, E. E.; PRANDO, G. A.; DONOSO, J. P.; MAGON, C. J.; ANTONIO, S. G.; GOBATO, Y. G.; NALIN, M. Optical and epr studies of zinc phosphate glasses containing $\mathrm{Mn}^{2+}$ ions. Journal of Materials Science, New York, NY, v. 55, p. 9948-9961, 2020.

29 SHARMIN, N.; RUDD, C. D. Structure, thermal properties, dissolution behaviour and biomedical applications of phosphate glasses and fibres: a review. Journal of Materials Science, New York, NY, v. 52, n. 15, p. 8733-8760, 2017.

30 FARADAY, M. X. the bakerian lecture.- experimental relations of gold (and other metals) to light. Philosophical Transactions of the Royal Society of London, London, n. 147, p. 145-181, 1857.

31 FEYNMAN, R. P. There's plenty of room at the bottom. California Institute of Technology, Engineering and Science magazine, Pasadena, CA, 1960.

32 GEOnMOnOnD, R. S.; SILVA, A. G. D.; CAMARGO, P. H. Controlled synthesis of noble metal nanomaterials: Motivation, principles, and opportunities in nanocatalysis. Anais da Academia Brasileira de Ciências, Rio de Janeiro, v. 90, n. 1, p. 719-744, 2018.

33 RAFIQUE, M.; RAFIQUE, M. S.; KALSOOM, U.; AFZAL, A.; BUTT, S. H.; USMAN, A. Laser ablation synthesis of silver nanoparticles in water and dependence on laser nature. Optical and Quantum Electronics, New York, NY, v. 51, n. 6, p. 179, 2019 .

34 KULKARNI, S. K. Nanotechnology: principles and practices. New York, NY: Springer, 2014.

35 STILES, P. L.; DIERINGER, J. A.; SHAH, N. C.; DUYNE, R. P. V. Surface-enhanced raman spectroscopy. Annual Review of Analytical Chemistry, Palo Alto, CA, v. 1, p. 601-626, 2008.

36 SHEN, X.; ZHANG, Y.; XIA, L.; LI, J.; YANG, G.; ZHOU, Y. Broadband flat near-infrared emission from tellurite glass doped with $\mathrm{Tm}^{3+}, \mathrm{Er}^{3+}$ and $\mathrm{Ag}$ nps. Optics \& Laser Technology, London, v. 129, p. 106264, 2020.

37 SAAD, M.; ELHOUICHET, H. Good optical performances of $\mathrm{Eu}^{3+} / \mathrm{Dy}^{3+} / \mathrm{Ag}$ nanoparticles co-doped phosphate glasses induced by plasmonic effects. Journal of Alloys and Compounds, Amsterdam, v. 806, p. 1403-1409, 2019.

38 MANZANI, D.; FRANCO, D. F.; AFONSO, C. R.; SANT'ANA, A. C.; NALIN, M.; RIBEIRO, S. J. A new sers substrate based on niobium lead-pyrophosphate glasses obtained by $\mathrm{Ag}^{+} / \mathrm{Na}^{+}$ion exchange. Sensors and Actuators B: Chemical, Amsterdam, v. 277, p. 347-352, 2018.

39 DEJNEKA, M. J.; ELLISON, A. J.; GOMEZ, S. Ion exchanged, fast cooled glasses. US Patent 8,232,218. Assignee: Corning Incorporated, Corning, NY (US). Date of patent: Jul. 31, 2012. 
40 DEJNEKA, M. J.; ELLISON, A. J.; GOMEZ, S.; MORENA, R. M. Glasses having improved toughness and scratch resistance. US Patent 8,969,226. Assignee: Corning Incorporated, Corning, NY (US). Date of patent: Mar. 03, 2015.

41 WANG, P.; HUANG, B.; DAI, Y.; WHANGBO, M.-H. Plasmonic photocatalysts: harvesting visible light with noble metal nanoparticles. Physical Chemistry Chemical Physics, Cambridge, v. 14, n. 28, p. 9813-9825, 2012.

42 HOU, W.; CRONIN, S. B. A review of surface plasmon resonance-enhanced photocatalysis. Advanced Functional Materials, Weinheim, v. 23, n. 13, p. 1612-1619, 2013.

43 FAGAN, R.; MCCORMACK, D. E.; DIONYSIOU, D. D.; PILLAI, S. C. A review of solar and visible light active $\mathrm{TiO}_{2}$ photocatalysis for treating bacteria, cyanotoxins and contaminants of emerging concern. Materials Science in Semiconductor Processing, Oxford, v. 42, p. 2-14, 2016.

44 TEIXEIRA, I. F.; QUIROZ, J.; HOMSI, M. S.; CAMARGO, P. H. An overview of the photocatalytic $\mathrm{H}_{2}$ evolution by semiconductor-based materials for nonspecialists. Journal of the Brazilian Chemical Society, Sao Paulo, v. 31, n. 2, p. 211-229, 2020.

45 SHARMA, S. K.; SINGH, V.; CHAUHAN, V. S.; KUSHWAHA, H.; VAISH, R. Photocatalytic self-cleaning transparent $2 \mathrm{Bi}_{2} \mathrm{O}_{3}-\mathrm{B}_{2} \mathrm{O}_{3}$ glass ceramics. Journal of Applied Physics, Melville, NY, v. 122, n. 9, p. 094901, 2017.

46 THAKUR, V.; KUSHWAHA, H.; SINGH, A.; VAISH, R.; PUNIA, R.; SINGH, L. A study on the structural and photocatalytic degradation of ciprofloxacine using $\left(70 \mathrm{~B}_{2} \mathrm{O}_{3}-29 \mathrm{Bi}_{2} \mathrm{O}_{3}-1 \mathrm{Dy}_{2} \mathrm{O}_{3}\right)-\mathrm{x}\left(\mathrm{BaO}-\mathrm{TiO}_{2}\right)$ glass ceramics. Journal of Non-Crystalline Solids, Amsterdam, v. 428, p. 197-203, 2015.

47 SHARMA, S. K.; SINGH, V.; CHAUHAN, V. S.; KUSHWAHA, H.; VAISH, R. Photocatalytic active bismuth fluoride/oxyfluoride surface crystallized $2 \mathrm{Bi}_{2} \mathrm{O}_{3}-\mathrm{B}_{2} \mathrm{O}_{3}$ glass-ceramics. Journal of Electronic Materials, New York, NY, v. 47, n. 7, p. 3490-3496, 2018.

48 SINGH, V.; VAISH, R. Controlled crystallization of photocatalytic active bismuth oxyfluoride/bismuth fluoride on $\mathrm{SrO}-\mathrm{Bi}_{2} \mathrm{O}_{3}-\mathrm{B}_{2} \mathrm{O}_{3}$ transparent glass ceramic. Journal of the European Ceramic Society, London, v. 38, n. 10, p. 3635-3642, 2018.

49 FU, J. Photocatalytic properties of glass ceramics containing anatase-type $\mathrm{TiO}_{2}$. Materials Letters, Amsterdam, v. 68, p. 419-422, 2012.

50 MARGHA, F. H.; BADAWY, M. I.; GAD-ALLAH, T. A. ZnO enriched transparent glass-ceramics for wastewater decontamination. Environmental Progress \& Sustainable Energy, Hoboken, NJ, v. 36, n. 2, p. 442-447, 2017.

51 MARGHA, F. H.; ALI, M. E.; GAD-ALLAH, T. A. Transparent nanocrystalline glass-ceramic system for organic pollutants degradation. Silicon, Dordrecht, v. 10, n. 1, p. 123-129, 2018.

52 MARGHA, F. H.; RADWAN, E. K.; BADAWY, M. I.; GAD-ALlAH, T. A. $\mathrm{Bi}_{2} \mathrm{O}_{3}-\mathrm{BiFeO}_{3}$ glass-ceramic: Controllable $\beta-/ \gamma-\mathrm{Bi}_{2} \mathrm{O}_{3}$ transformation and application as magnetic solar-driven photocatalyst for water decontamination. ACS omega, Washington, DC, v. 5, n. 24, p. 14625-14634, 2020. 
53 PONRAJ, C.; VINITHA, G.; DANIEL, J. A review on the visible light active $\mathrm{BiFeO}_{3}$ nanostructures as suitable photocatalyst in the degradation of different textile dyes. Environmental Nanotechnology, Monitoring \& Management, Amsterdam, v. 7, p. 110-120, 2017.

54 WANG, K.; JANCZAREK, M.; WEI, Z.; RAJA-MOGAN, T.; ENDO-KIMURA, M.; KHEDR, T. M.; OHTANI, B.; KOWALSKA, E. Morphology-and crystalline composition-governed activity of titania-based photocatalysts: Overview and perspective. Catalysts, Basel, v. 9, n. 12, p. 1054, 2019.

55 BAFFOU, G.; QUIDANT, R. Nanoplasmonics for chemistry. Chemical Society Reviews, Cambridge, v. 43, n. 11, p. 3898-3907, 2014.

56 GEONMONOND, R. S.; SILVA, A. G. da; RODRIGUES, T. S.; FREITAS, I. C. de; ANDO, R. A.; ALVES, T. V.; CAMARGO, P. H. Addressing the effects of size-dependent absorption, scattering, and near-field enhancements in plasmonic catalysis. ChemCatChem, Weinheim, v. 10, n. 16, p. 3447-3452, 2018.

57 CHEN, M.; LI, X.; HUANG, Y.; YAO, J.; LI, Y.; LEE, S.-c.; HO, W.; HUANG, T.;

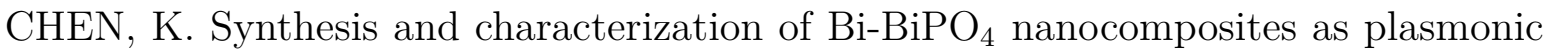
photocatalysts for oxidative no removal. Applied Surface Science, Amsterdam, v. 513, p. $145775,2020$.

58 DURÁN-ÁlvAREZ, J.; SANTIAGO, A.; RAMÍREZ-ORTEGA, D.; ACEVEDOPEÑA, P.; CASTILLÓN, F.; RAMÍREZ-ZAMORA, R.; ZANELLA, R. Surface modification of $\mathrm{b}-\mathrm{TiO}_{2}$ by deposition of $\mathrm{Au}$ nanoparticles to increase its photocatalytic activity under simulated sunlight irradiation. Journal of Sol-Gel Science and Technology, New York, NY, v. 88, n. 2, p. 474-487, 2018.

59 WU, D.-Y.; LIU, X.-M.; HUANG, Y.-F.; REN, B.; XU, X.; TIAN, Z.-Q. Surface catalytic coupling reaction of p-mercaptoaniline linking to silver nanostructures responsible for abnormal sers enhancement: a dft study. The Journal of Physical Chemistry C, Washington, DC, v. 113, n. 42, p. 18212-18222, 2009.

60 SUN, M.; XU, H. A novel application of plasmonics: plasmon-driven surface-catalyzed reactions. Small, Weinheim, v. 8, n. 18, p. 2777-2786, 2012.

61 WANG, C.; ASTRUC, D. Nanogold plasmonic photocatalysis for organic synthesis and clean energy conversion. Chemical Society Reviews, Cambridge, v. 43, n. 20, p. 7188-7216, 2014.

62 ENGELBREKT, C.; CRAMPTON, K. T.; FISHMAN, D. A.; LAW, M.; APKARIAN, V. A. Efficient plasmon-mediated energy funneling to the surface of Au@Pt core-shell nanocrystals. ACS nano, Washington, DC, v. 14, n. 4, p. 5061-5074, 2020.

63 GEISSEN, V.; MOL, H.; KLUMPP, E.; UMLAUF, G.; NADAL, M.; PLOEG, M. van der; ZEE, S. E. van de; RITSEMA, C. J. Emerging pollutants in the environment: a challenge for water resource management. International soil and water conservation research, Beijing, v. 3, n. 1, p. 57-65, 2015.

64 MUHAMMAD, M.; YAO, G.; ZHONG, J.; CHAO, K.; AZIZ, M. H.; HUANG, Q. A facile and label-free sers approach for inspection of fipronil in chicken eggs using $\mathrm{SiO}_{2} @ \mathrm{Au}$ core/shell nanoparticles. Talanta, Amsterdam, v. 207, p. 120324, 2020. 
65 LY, N. H.; NGUYEN, T. H.; NGHI, N. Đ.; KIM, Y.-H.; JOO, S.-W. Surface-enhanced raman scattering detection of fipronil pesticide adsorbed on silver nanoparticles. Sensors, Basel, v. 19, n. 6, p. 1355, 2019.

66 TOSI, S.; BURGIO, G.; NIEH, J. C. A common neonicotinoid pesticide,

thiamethoxam, impairs honey bee flight ability. Scientific reports, London, v. 7, n. 1, p. 1-8, 2017.

67 SINGH, A. K.; TALAT, M.; SINGH, D.; SRIVASTAVA, O. Biosynthesis of gold and silver nanoparticles by natural precursor clove and their functionalization with amine group. Journal of Nanoparticle Research, Dordrecht, v. 12, n. 5, p. 1667-1675, 2010.

68 SÖNNICHSEN, C.; REINHARD, B. M.; LIPHARDT, J.; ALIVISATOS, A. P. A molecular ruler based on plasmon coupling of single gold and silver nanoparticles. Nature biotechnology, New York, NY, v. 23, n. 6, p. 741-745, 2005.

69 JR, L. A. P.; JI, D.; WESTCOTT, S. L.; GRAUPE, M.; CZERNUSZEWICZ, R. S.; HALAS, N. J.; LEE, T. R. Gold and silver nanoparticles functionalized by the adsorption of dialkyl disulfides. Langmuir, Washington, DC, v. 14, n. 26, p. 7378-7386, 1998.

70 AMAYUELAS, E.; FIDALGO-MARIJUÁN, A.; BAZÁN, B.; URTIAGA, M.-K.; BARANDIKA, G.; ARRIORTUA, M.-I. Cu ii-based metal-organic nanoballs for very rapid adsorption of dyes and iodine. CrystEngComm, Cambridge, v. 18, n. 10, p. 1709-1712, 2016.

71 SKOOG, D. A.; HOLLER, F. J.; CROUCH, S. R. Principles of instrumental analysis. Boston, MA: Cengage learning, 2017.

72 MIESSLER, G. L.; TARR, D. Inorganic Chemistry. Upper Saddle River, NJ: Pearson Education, 2014.

73 HOLLAS, J. M. Modern spectroscopy. Chichester: John Wiley \& Sons, 2004.

74 KAUFMANN, E. N. Characterization of Materials, 2 Volume Set. Hoboken, NJ: John Wiley \& Sons, 2003.

75 KLEINMAN, S. L.; RINGE, E.; VALLEY, N.; WUSTHOLZ, K. L.; PHILLIPS, E.; SCHEIDT, K. A.; SCHATZ, G. C.; DUYNE, R. P. V. Single-molecule surface-enhanced raman spectroscopy of crystal violet isotopologues: theory and experiment. Journal of the American Chemical Society, Washington, DC, v. 133, n. 11, p. 4115-4122, 2011.

76 LUO, S.-C.; SIVASHANMUGAN, K.; LIAO, J.-D.; YAO, C.-K.; PENG, H.-C.

Nanofabricated sers-active substrates for single-molecule to virus detection in vitro: A review. Biosensors and Bioelectronics, Amsterdam, v. 61, p. 232-240, 2014.

77 ZHANG, L.; LIU, H.; CHEN, L.; GUAN, P.; CHEN, B.; FUJITA, T.; YAMAGUCHI, Y.; IWASAKI, H.; XUE, Q.-K.; CHEN, M. Large-scale growth of sharp gold nano-cones for single-molecule sers detection. RSC advances, Cambridge, v. 6, n. 4, p. 2882-2887, 2016.

78 AROCA, R. Surface-enhanced vibrational spectroscopy. Chichester: John Wiley \& Sons, 2006. 
79 RU, E. L.; ETCHEGOIN, P. Principles of Surface-Enhanced Raman Spectroscopy: and related plasmonic effects. Amsterdam: Elsevier, 2008.

80 ALBRECHT, A. C. On the theory of raman intensities. The Journal of chemical physics, Melville, NY, v. 34, n. 5, p. 1476-1484, 1961.

81 LOMBARDI, J. R.; BIRKE, R. L. A unified approach to surface-enhanced raman spectroscopy. The Journal of Physical Chemistry C, Washington, DC, v. 112, n. 14, p. 5605-5617, 2008.

82 MANZANI, D.; FERNANDES, R. G.; MESSADDEQ, Y.; RIBEIRO, S. J.; CASSANJES, F. C.; POIRIER, G. Thermal, structural and optical properties of new tungsten lead-pyrophosphate glasses. Optical Materials, Amsterdam, v. 33, n. 12, p. 1862-1866, 2011.

83 MEYERS, M. A.; CHAWLA, K. K. Mechanical behavior of materials. Cambridge: Cambridge University Press, 2008.

84 MANIU, D.; ILIESCU, T.; ARDELEAN, I.; CINTA-PINZARU, S.; TARCEA, N.; KIEFER, W. Raman study on $\mathrm{B}_{2} \mathrm{O}_{3}-\mathrm{CaO}$ glasses. Journal of Molecular Structure, Amsterdam, v. 651, p. 485-488, 2003.

85 MAnZANI, D.; GUAlBERTO, T.; AlmeidA, J. M.; MONTESSO, M.; MENDONÇA, C. R.; RIVERA, V. A.; BONI, L. D.; NALIN, M.; RIBEIRO, S. J. Highly nonlinear $\mathrm{Pb}_{2} \mathrm{P}_{2} \mathrm{O}_{7}-\mathrm{Nb}_{2} \mathrm{O}_{5}$ glasses for optical fiber production. Journal of Non-Crystalline Solids, Amsterdam, v. 443, p. 82-90, 2016.

86 YADAV, A. K.; SINGH, P. A review of the structures of oxide glasses by raman spectroscopy. RSC advances, Cambridge, v. 5, n. 83, p. 67583-67609, 2015.

87 LOPEZ-ISCOA, P.; PETIT, L.; MASSERA, J.; JANNER, D.; BOETTI, N. G.; PUGLIESE, D.; FIORILLI, S.; NOVARA, C.; GIORGIS, F.; MILANESE, D. Effect of the addition of $\mathrm{Al}_{2} \mathrm{O}_{3}, \mathrm{TiO}_{2}$ and $\mathrm{ZnO}$ on the thermal, structural and luminescence properties of $\mathrm{Er}^{3+}$-doped phosphate glasses. Journal of Non-Crystalline Solids, Amsterdam, v. 460, p. 161-168, 2017.

88 KIANI, A.; HANNA, J. V.; KING, S. P.; REES, G. J.; SMITH, M. E.; ROOHPOUR, N.; SALIH, V.; KNOWLES, J. C. Structural characterization and physical properties of $\mathrm{P}_{2} \mathrm{O}_{5}-\mathrm{CaO}-\mathrm{Na}_{2} \mathrm{O}-\mathrm{TiO}_{2}$ glasses by fourier transform infrared, raman and solid-state magic angle spinning nuclear magnetic resonance spectroscopies. Acta biomaterialia, Amsterdam, v. 8, n. 1, p. 333-340, 2012.

89 ANDRADE, L.; LIMA, S.; NOVATSKI, A.; NETO, A.; BENTO, A.; BAESSO, M.; GANDRA, F.; GUYOT, Y.; BOULON, G. Spectroscopic assignments of $\mathrm{Ti}^{3+}$ and $\mathrm{Ti}^{4+}$ in titanium-doped $\mathrm{OH}^{-}$free low-silica calcium aluminosilicate glass and role of structural defects on the observed long lifetime and high fluorescence of $\mathrm{Ti}^{3+}$ ions. Physical Review B, College Park, MD, v. 78, n. 22, p. 224202, 2008.

90 DIANOV, E. M.; LEBEDEV, V. F.; ZAVOROTNYI, Y. S. Luminescence of $\mathrm{Ti}^{3+}$ ions in silica glass. Quantum Electronics, London, v. 31, n. 2, p. 187, 2001. 
91 RAO, C. S.; SESHULATHA, K.; GURUPRIA, Y.; SAGAR, P.; VIJAYKUMAR, M.; SAIBABAVALI, S.; RAMANJANEYULU, D.; KOTIREDDY, S. Optical properties of $\mathrm{Na}_{2} \mathrm{SO}_{4}-\mathrm{B}_{2} \mathrm{O}_{3}-\mathrm{P}_{2} \mathrm{O}_{5}$ glasses doped with $\mathrm{TiO}_{2}$. Materials Today: Proceedings, Amsterdam, v. 5, n. 13, p. 26217-26222, 2018.

92 SEGAWA, H.; AKAGI, N.; YANO, T.; SHIBATA, S. Properties and structures of $\mathrm{TiO}_{2}-\mathrm{ZnO}-\mathrm{P}_{2} \mathrm{O}_{5}$ glasses. Journal of the Ceramic Society of Japan, Tokyo, v. 118, n. 1376 , p. $278-282,2010$.

93 MOCK, J.; BARBIC, M.; SMITH, D.; SCHULTZ, D.; SCHULTZ, S. Shape effects in plasmon resonance of individual colloidal silver nanoparticles. The Journal of Chemical Physics, Melville, NY, v. 116, n. 15, p. 6755-6759, 2002.

94 GAO, Y.; XU, M.-L.; XIONG, J. Raman and sers spectra of thiamethoxam and the $\mathrm{Ag}_{3}$-thiamethoxam complex: an experimental and theoretical investigation. Journal of Environmental Science and Health, Part B, New York, NY, v. 54, n. 8, p. 665-675, 2019.

95 MENG, W.; HU, F.; ZHANG, L.-Y.; JIANG, X.-H.; LU, L.-D.; WANG, X. Sers and dft study of crystal violet. Journal of Molecular Structure, Amsterdam, v. 1035, p. 326-331, 2013.

96 GEIMAN, I.; LEONA, M.; LOMBARDI, J. R. Application of raman spectroscopy and surface-enhanced raman scattering to the analysis of synthetic dyes found in ballpoint pen inks. Journal of Forensic Sciences, Hoboken, NJ, v. 54, n. 4, p. 947-952, 2009.

97 MENG, W.; HU, F.; JIANG, X.; LU, L. Preparation of silver colloids with improved uniformity and stable surface-enhanced raman scattering. Nanoscale research letters, Heidelberg, v. 10, n. 1, p. 1-8, 2015.

98 HATAB, N. A. A.; ORAN, J. M.; SEPANIAK, M. J. Surface-enhanced raman spectroscopy substrates created via electron beam lithography and nanotransfer printing. ACS nano, Washington, DC, v. 2, n. 2, p. 377-385, 2008.

99 TAUC, J.; GRIGOROVICI, R.; VANCU, A. Optical properties and electronic structure of amorphous germanium. physica status solidi (b), Weinheim, v. 15, n. 2, p. 627-637, 1966.

100 MAKUŁA, P.; PACIA, M.; MACYK, W. How to correctly determine the band gap energy of modified semiconductor photocatalysts based on UV-Vis spectra. Washington, DC: ACS Publications, 2018.

101 ABDELGHANY, A.; HAMMAD, A. H. The effect of $\mathrm{WO}_{3}$ dopant on the structural and optical properties of $\mathrm{ZnO}-\mathrm{P}_{2} \mathrm{O}_{5}$ glass and the effect of gamma irradiation. Journal of Molecular Structure, Amsterdam, v. 1081, p. 342-347, 2015.

102 KUBELKA, P.; MUNK, F. An article on optics of paint layers. Z. Tech. Phys, Heidelberg, v. 12, n. 593-601, p. 259-274, 1931.

103 LÓPEZ, R.; GÓMEZ, R. Band-gap energy estimation from diffuse reflectance measurements on sol-gel and commercial $\mathrm{TiO}_{2}$ : a comparative study. Journal of sol-gel science and technology, New York, NY, v. 61, n. 1, p. 1-7, 2012. 


\section{APPENDIX A}

\section{SEM images and EDX results}

This Appendix shows the images of NBTN-Ag samples obtained in SEM analysis with more detail and in other magnifications, as well as the EDX line scans for the other elements present in the samples.

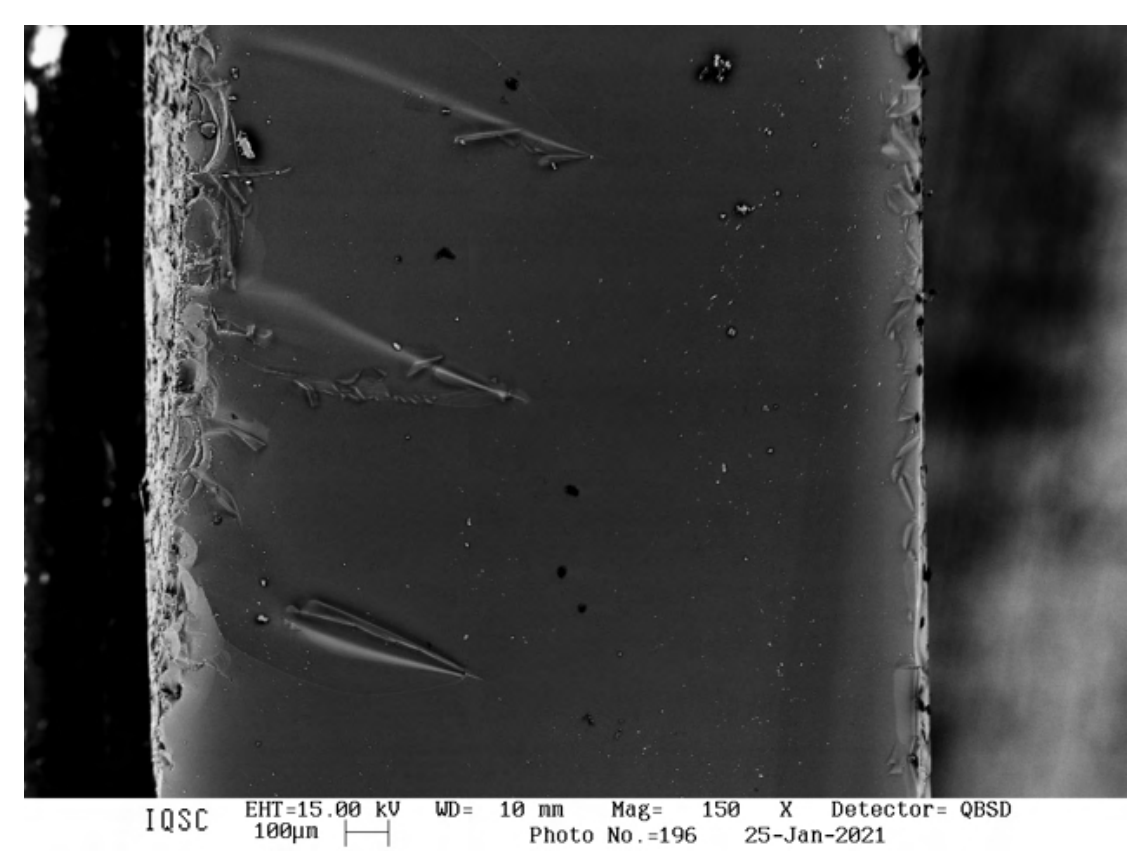

Figure 55 - 30 min ion exchanged sample back-scattered electrons image, 150x magnification. 


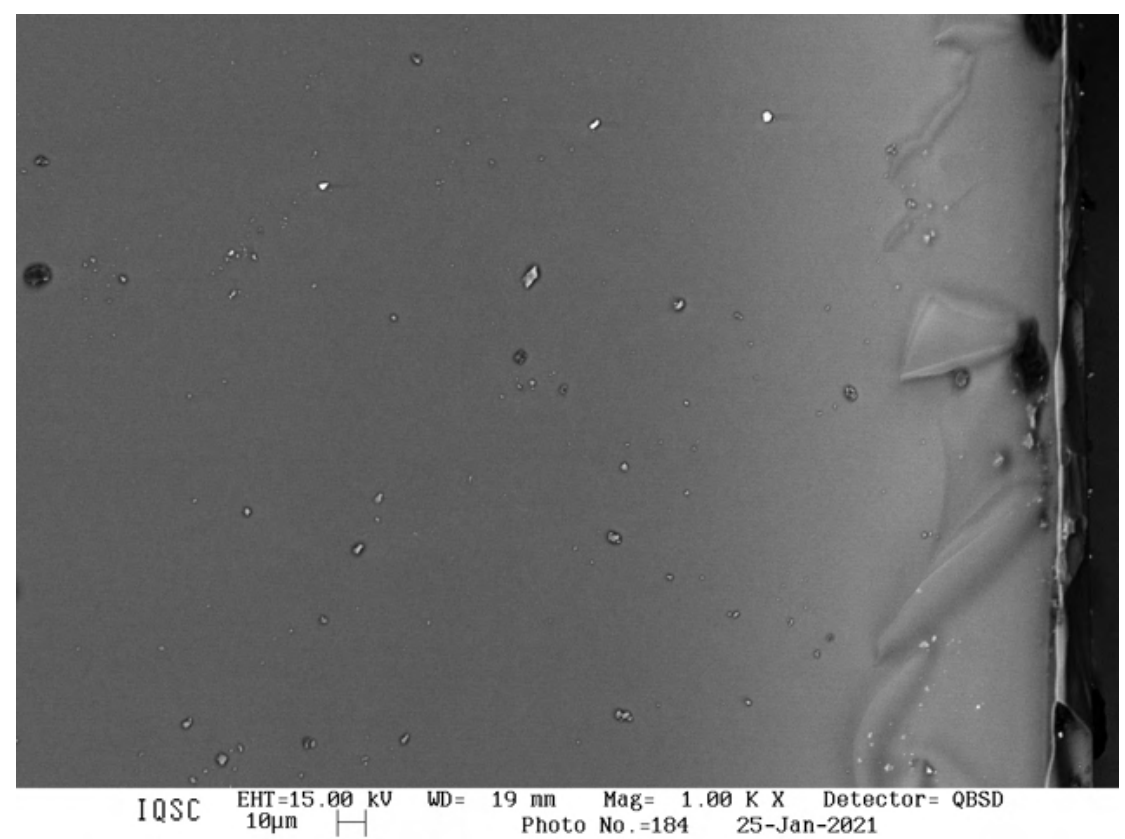

Figure 56 - 30 min ion exchanged sample back-scattered electrons image, 1000x magnification.

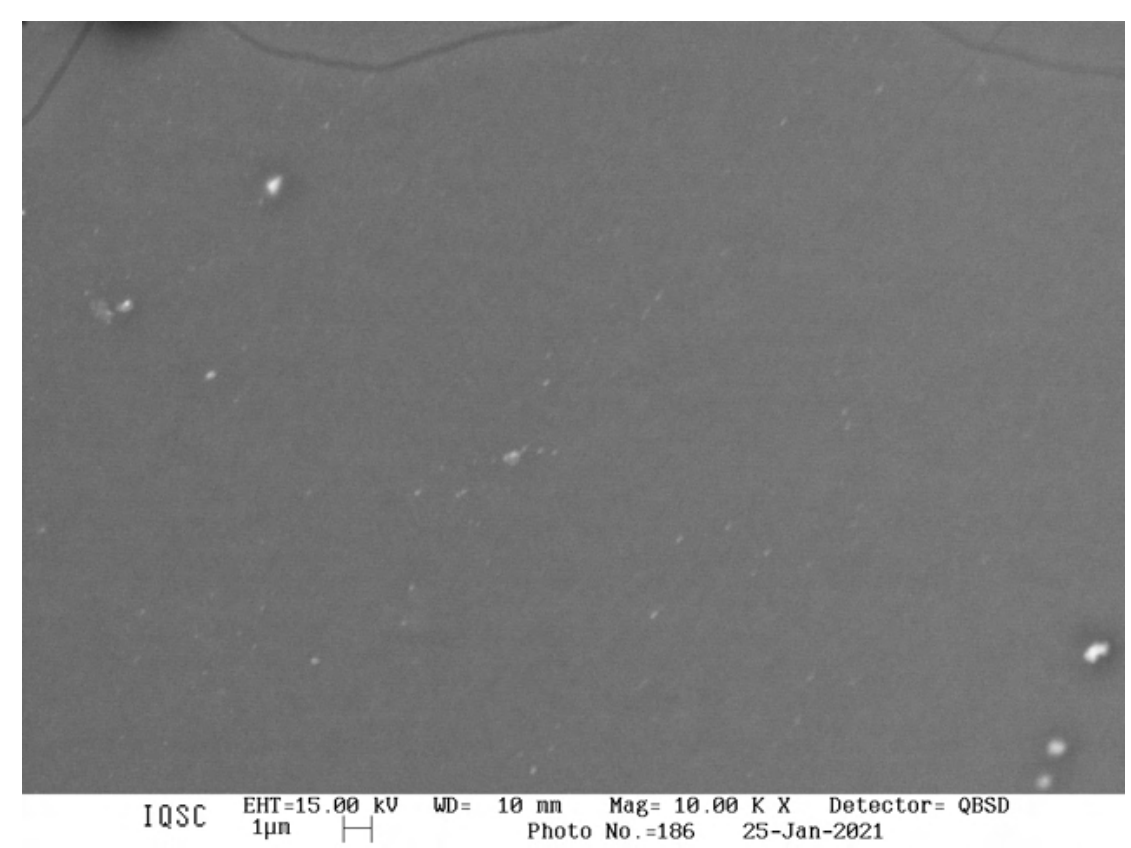

Figure 57 - 30 min ion exchanged sample back-scattered electrons image, 10000x magnification. 
DKa, 272

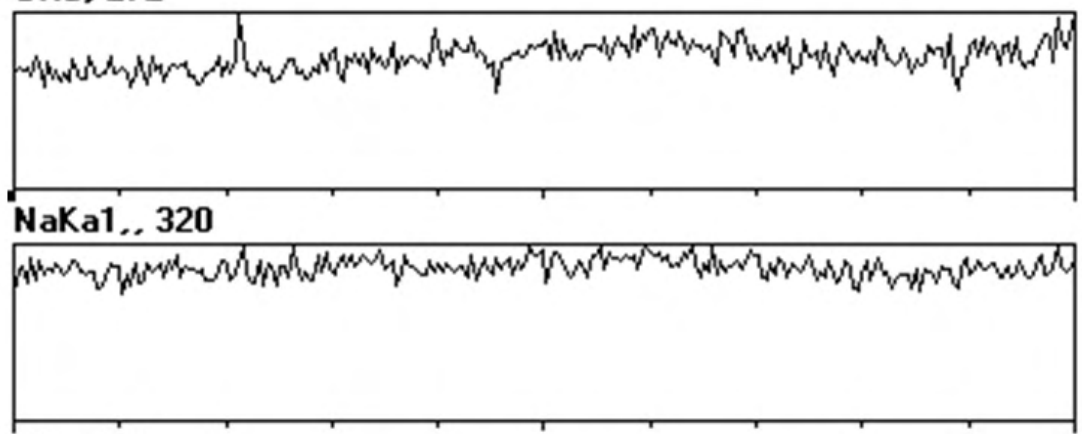

\section{PKa, 519}

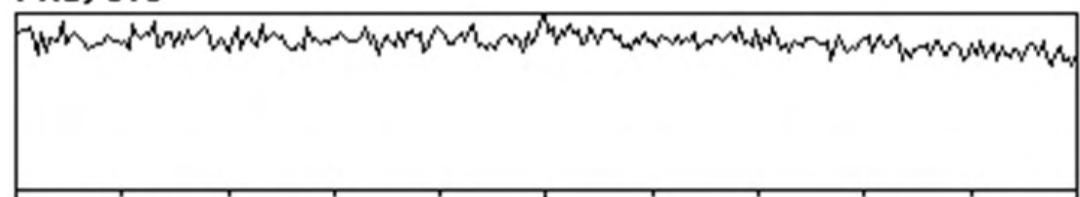

TiKa, 122

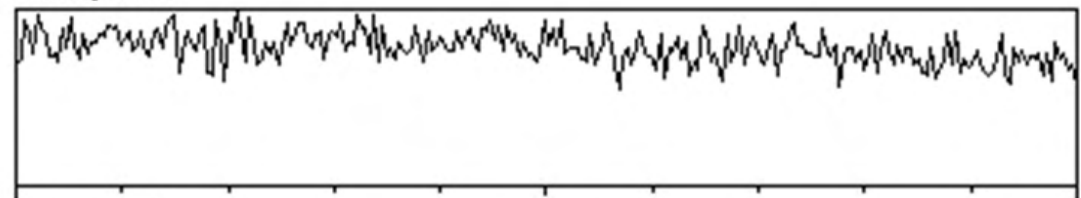

AgLa1, 97

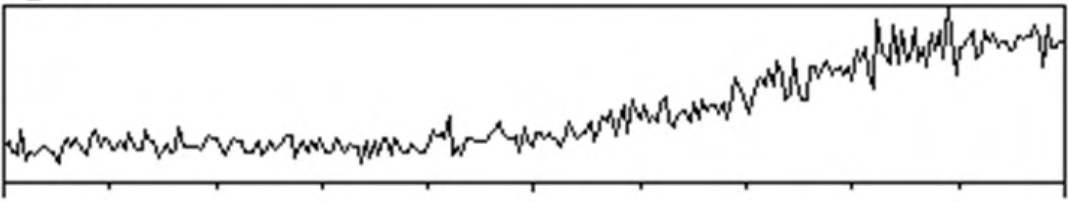

Figure 58 - EDX line scans for oxygen, sodium, phosphorus, titanium, and silver for the 30 min ion exchanged sample. Line width: $351 \mu \mathrm{m}$.

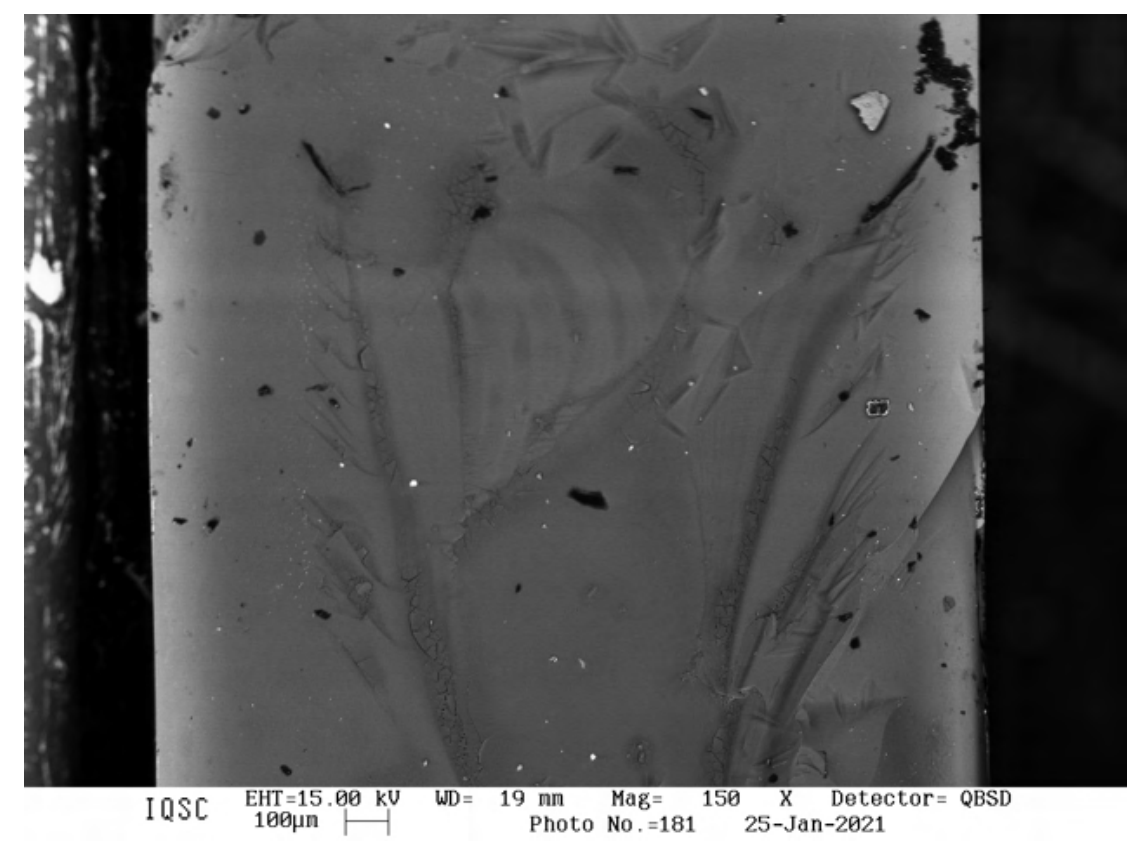

Figure 59 - 60 min ion exchanged sample back-scattered electrons image, 150x magnification. 


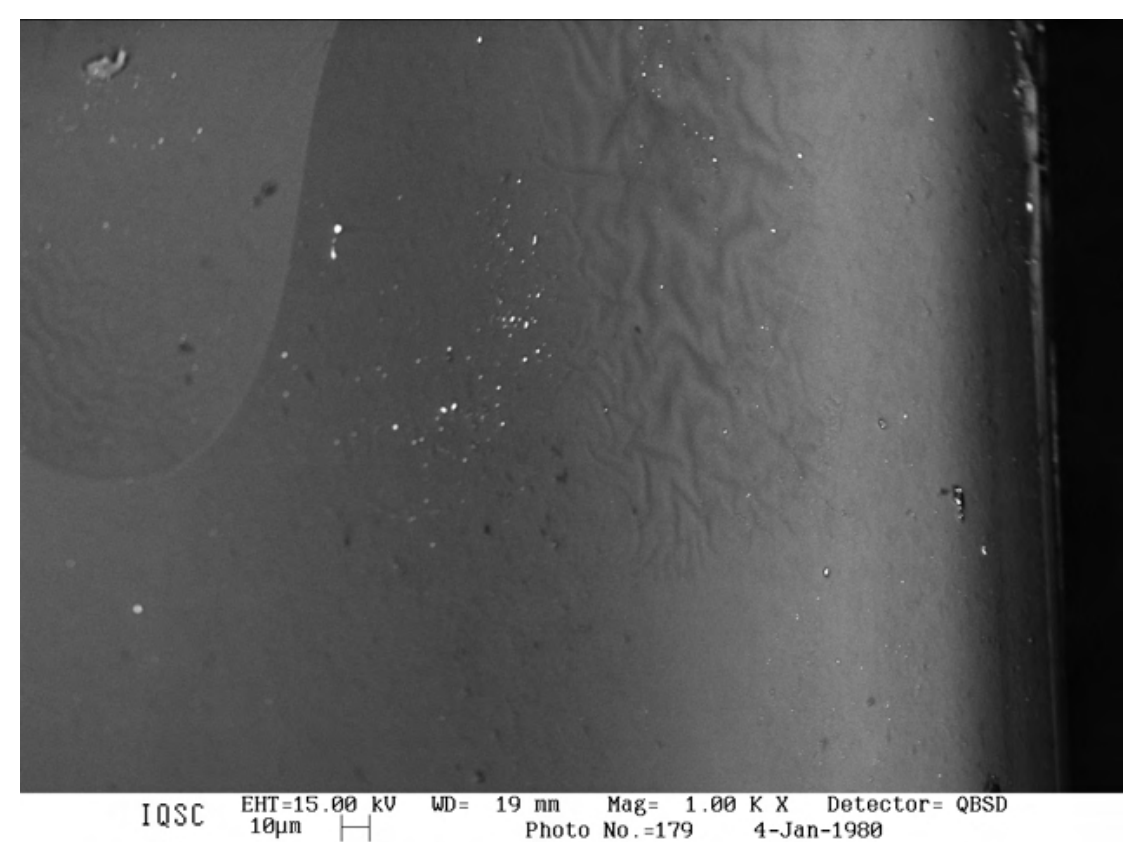

Figure 60 - 60 min ion exchanged sample back-scattered electrons image, 1000x magnification.

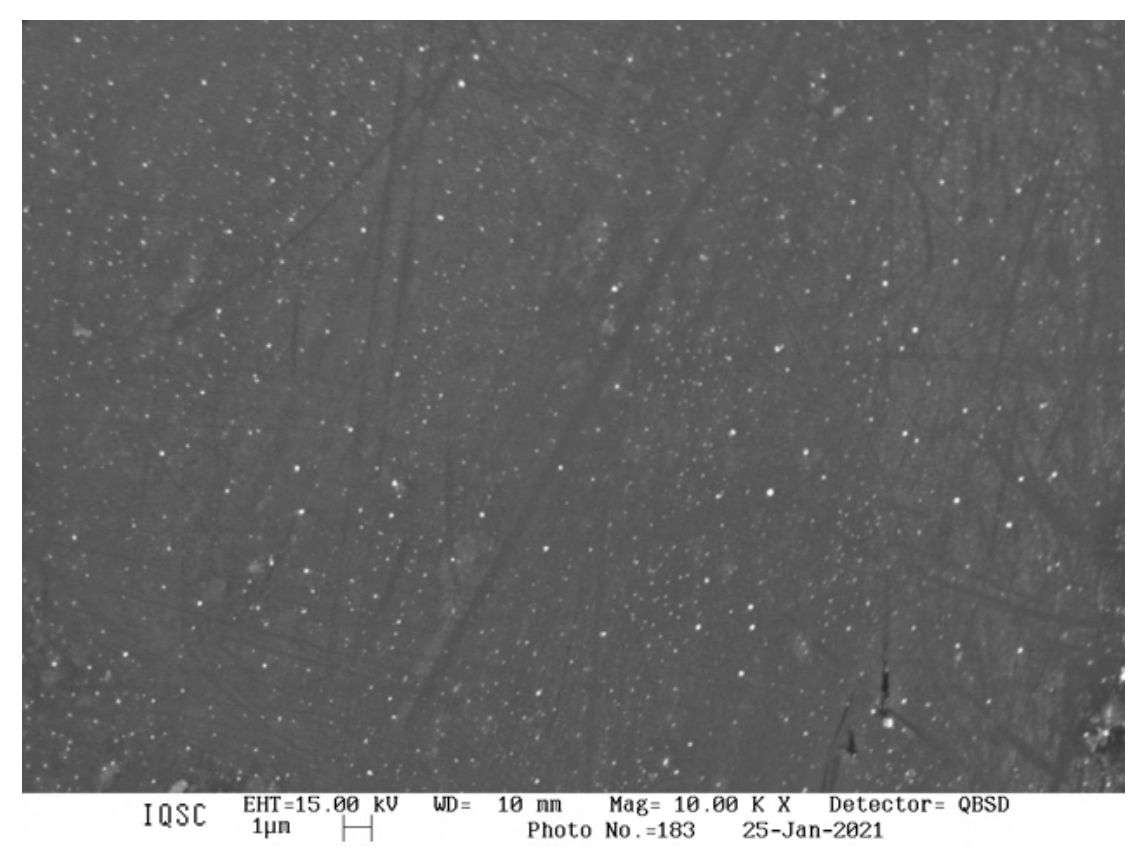

Figure 61 - 60 min ion exchanged sample back-scattered electrons image, 10000x magnification. 

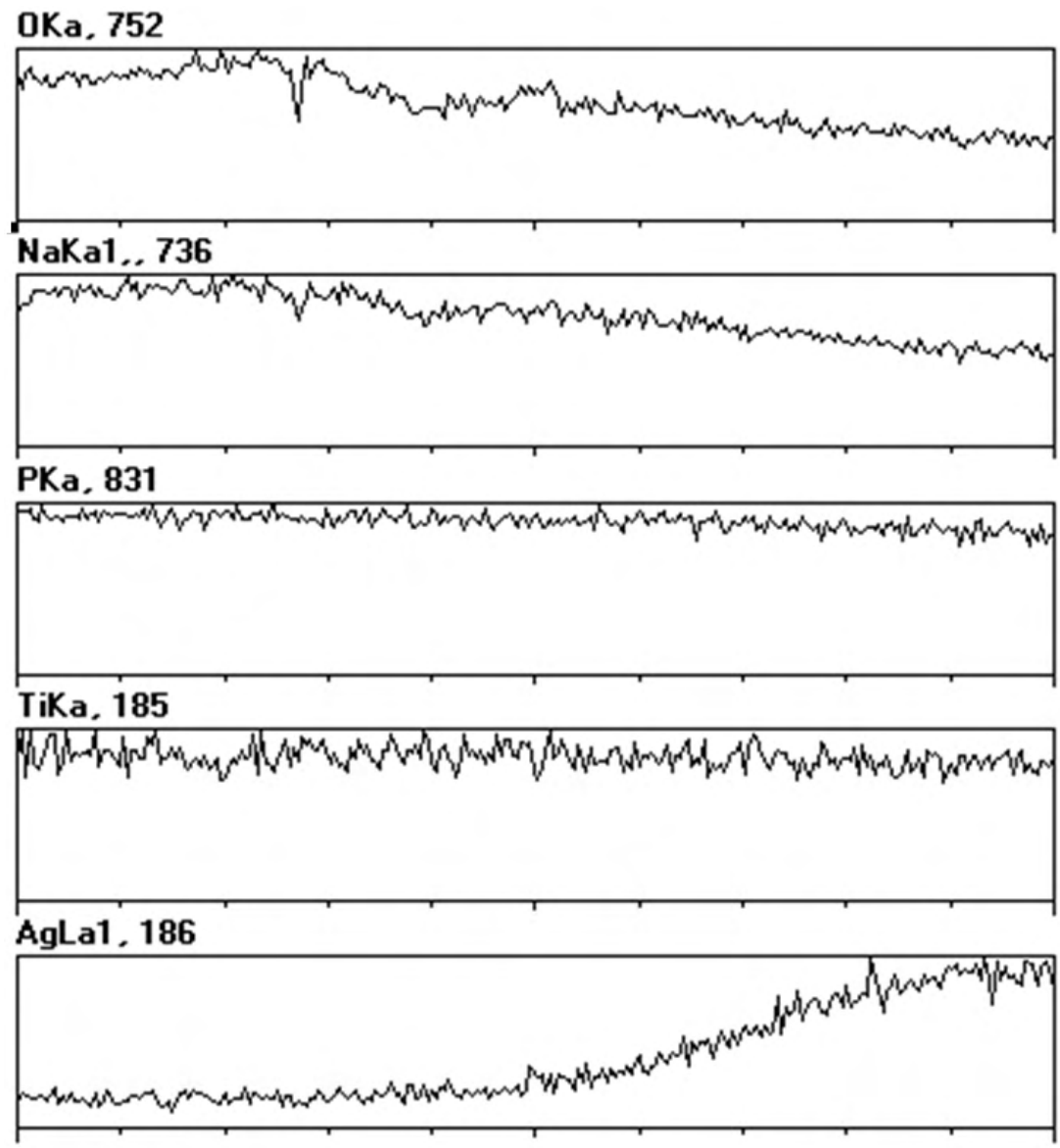

Figure 62 - EDX line scans for oxygen, sodium, phosphorus, titanium, and silver for the 60 min ion exchanged sample. Line width: $363 \mu \mathrm{m}$.

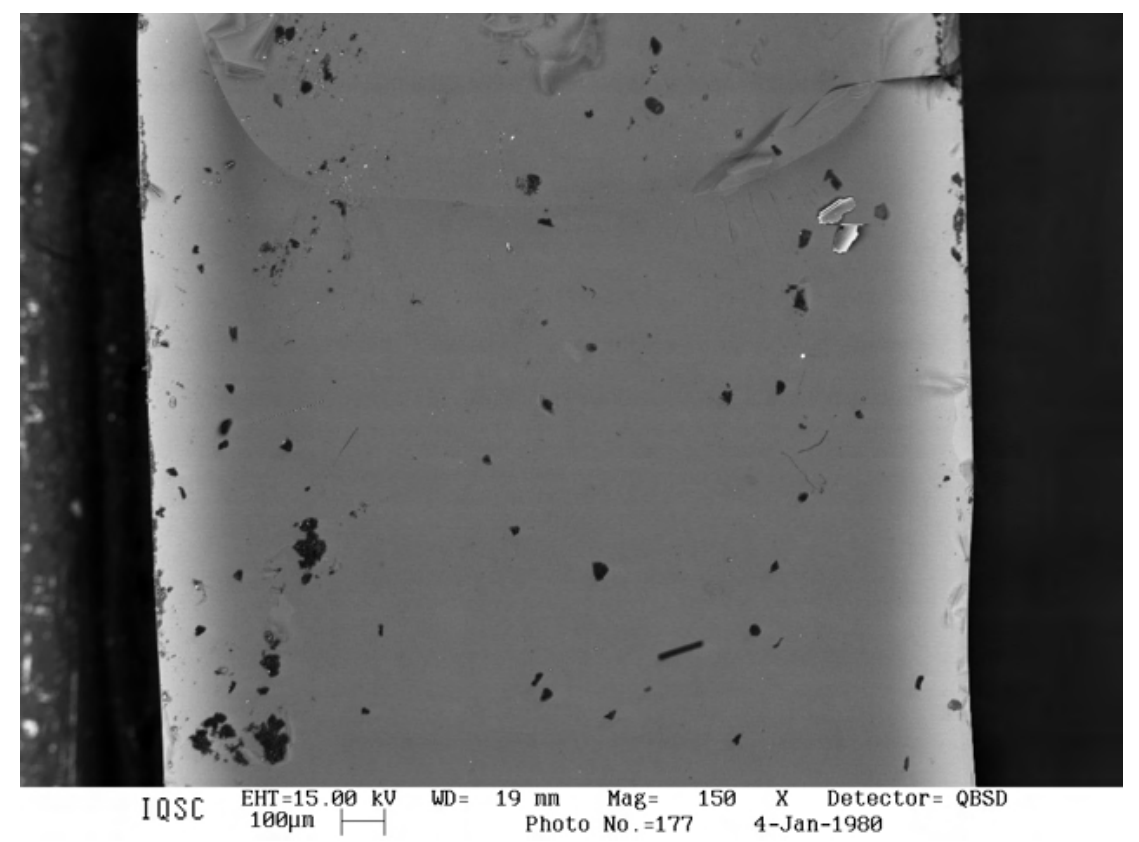

Figure 63 - 90 min ion exchanged sample back-scattered electrons image, 150x magnification. 


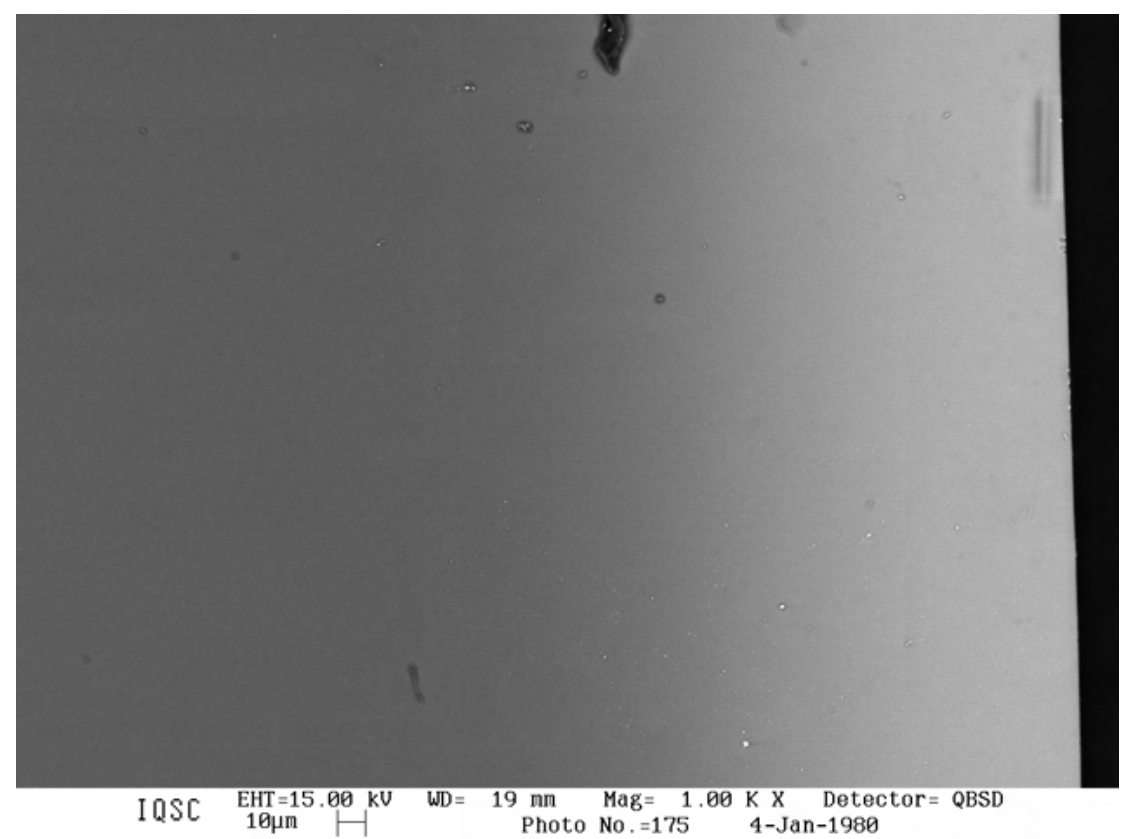

Figure 64 - 90 min ion exchanged sample back-scattered electrons image, 1000x magnification.

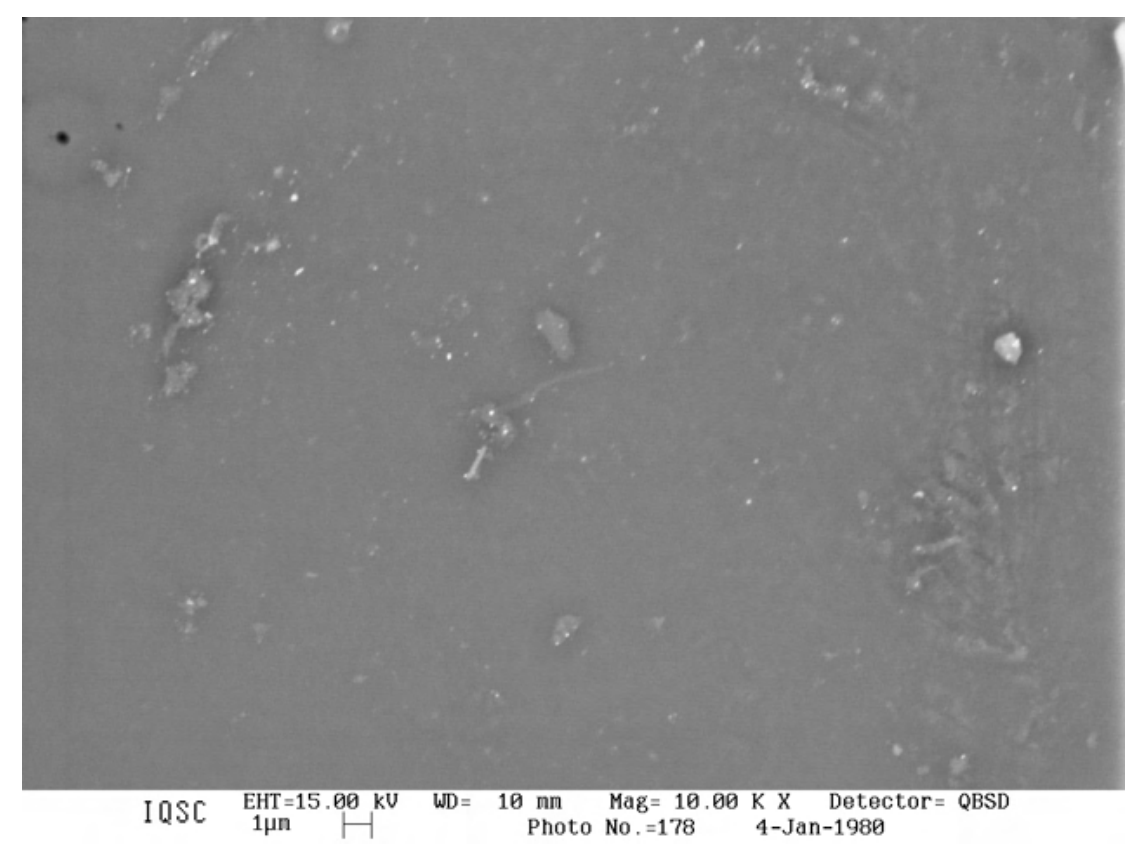

Figure 65 - 90 min ion exchanged sample back-scattered electrons image, 10000x magnification. 
OKa, 297

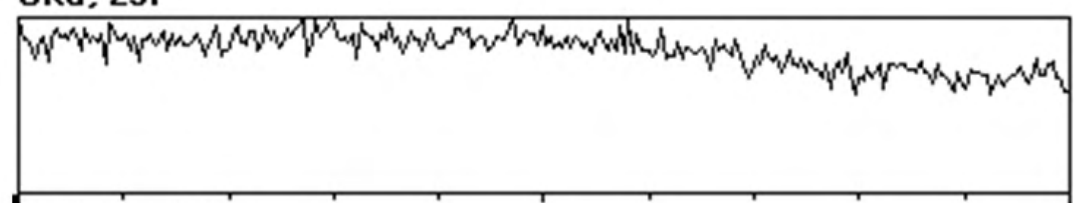

NaKa1,. 413

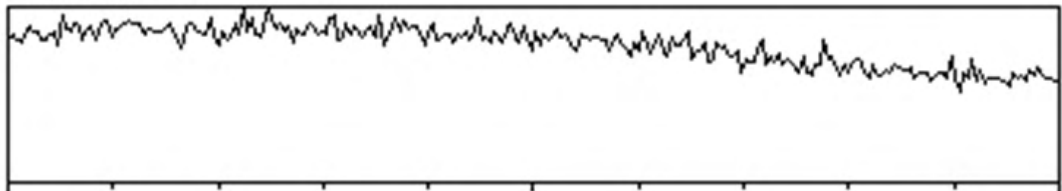

PKa, 679

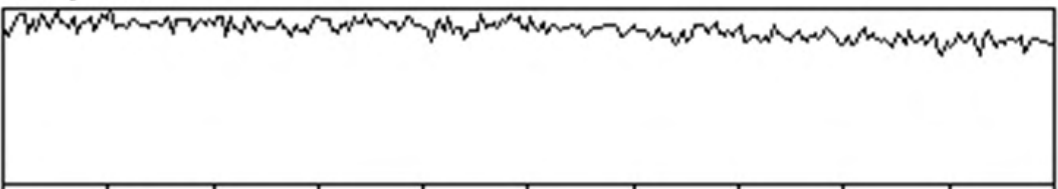

TiKa, 166

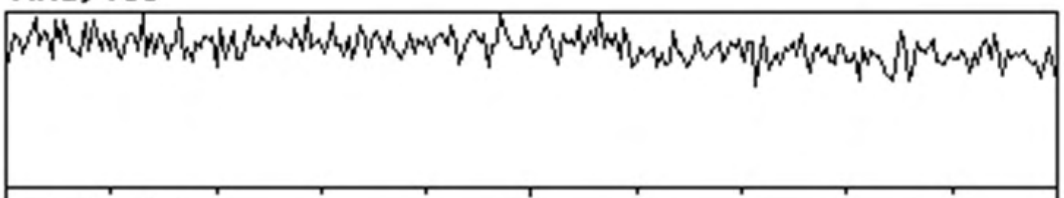

AgLa1, 218

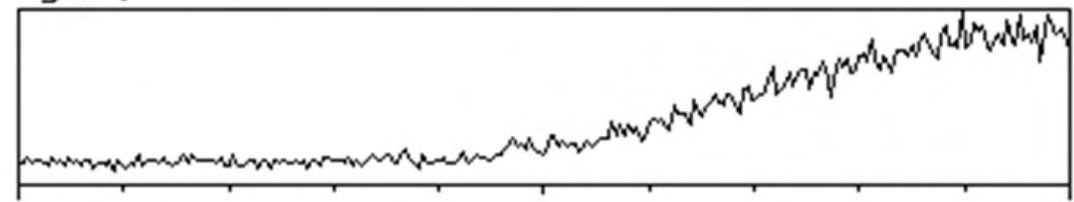

Figure 66 - EDX line scans for oxygen, sodium, phosphorus, titanium, and silver for the 90 min ion exchanged sample. Line width: $351 \mu \mathrm{m}$.

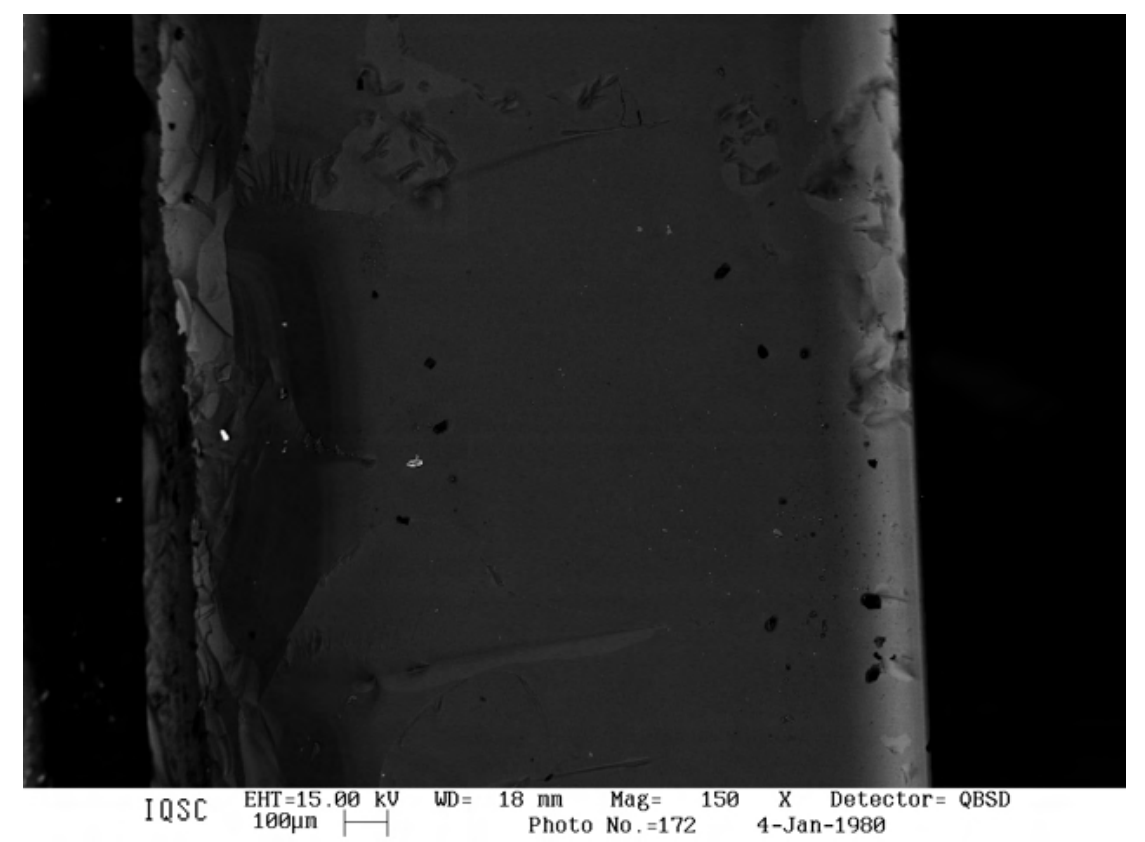

Figure 67 - 120 min ion exchanged sample back-scattered electrons image, 150x magnification. 


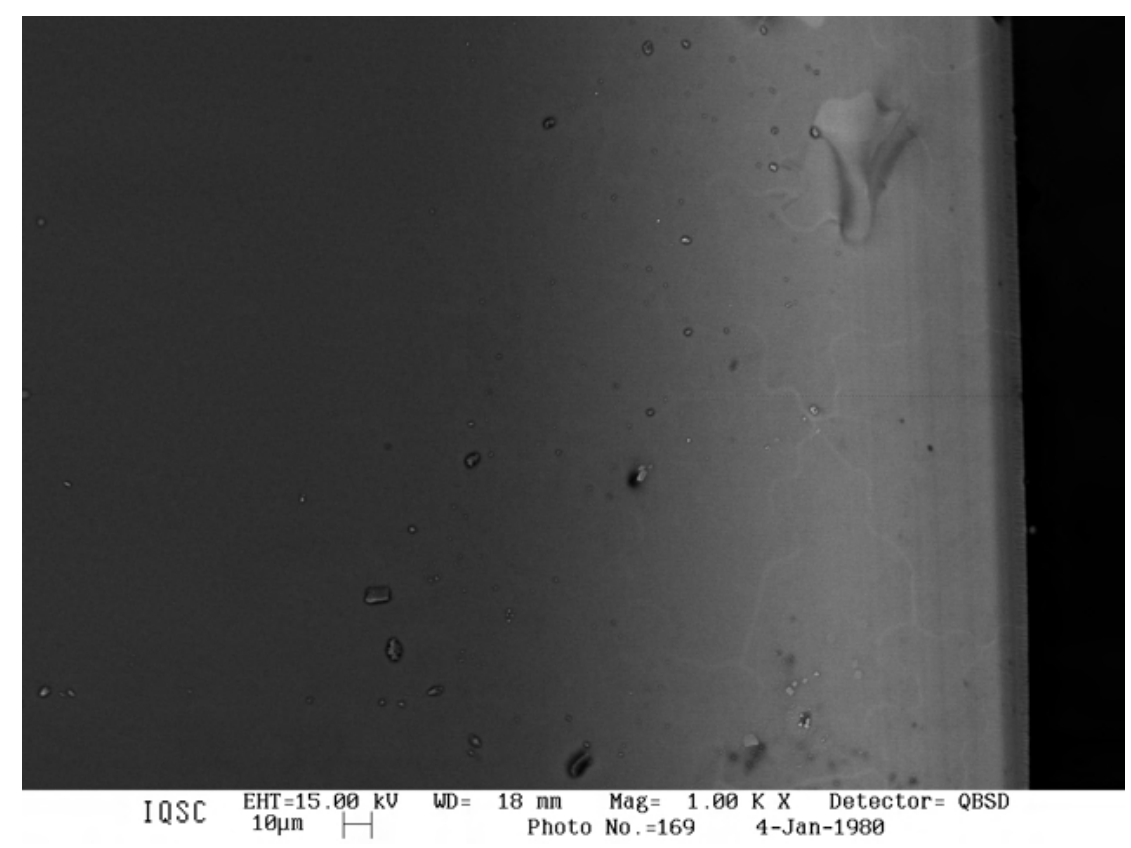

Figure 68 - 120 min ion exchanged sample back-scattered electrons image, 1000x magnification.

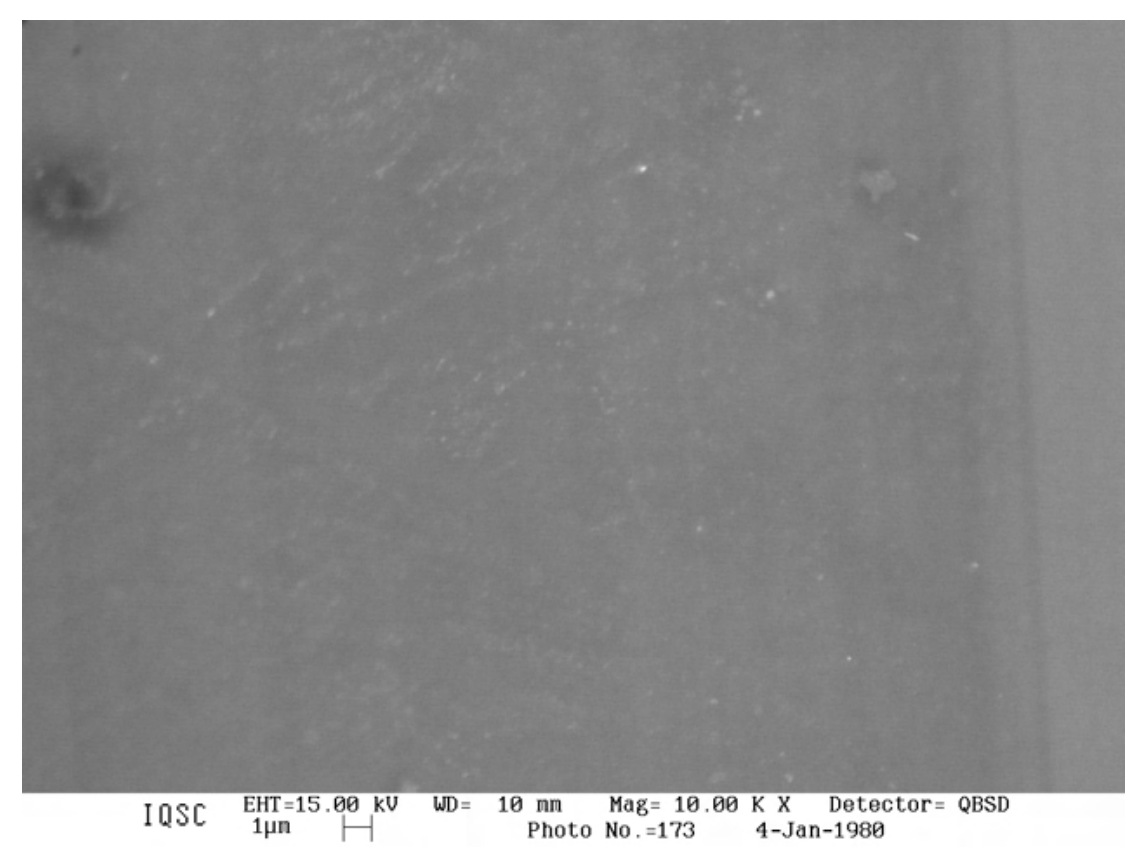

Figure 69 - 120 min ion exchanged sample back-scattered electrons image, 10000x magnification. 
$0 K a, 356$

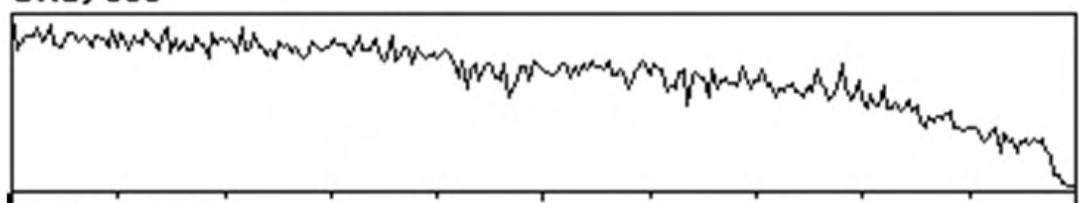

NaKa1,. 526

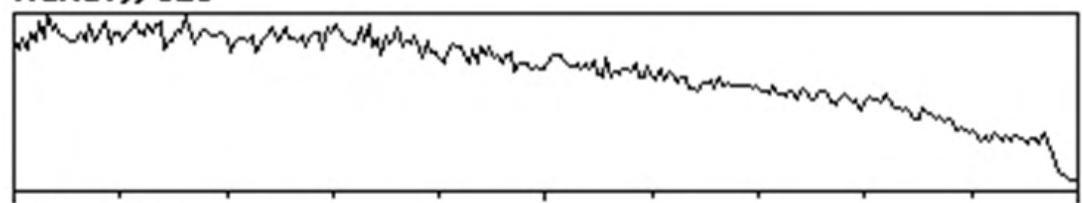

PKa, 820

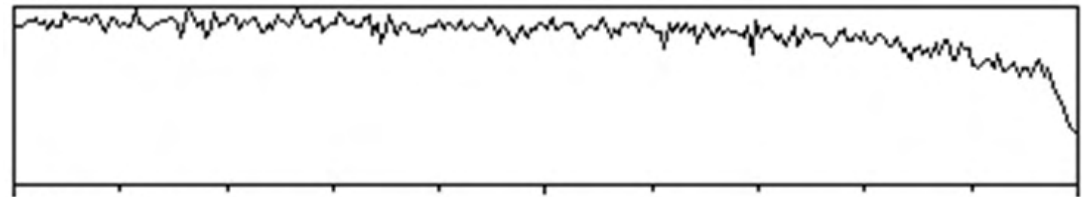

TiKa, 192

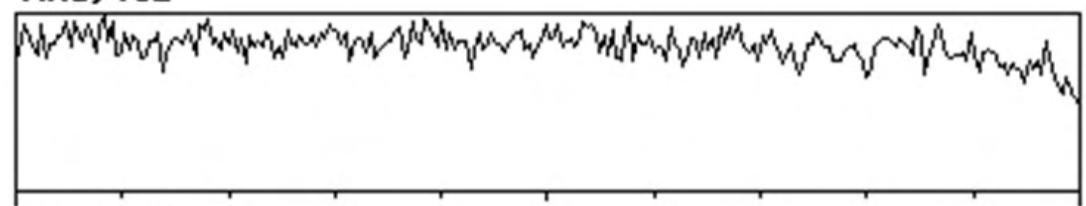

AgLa1, 259

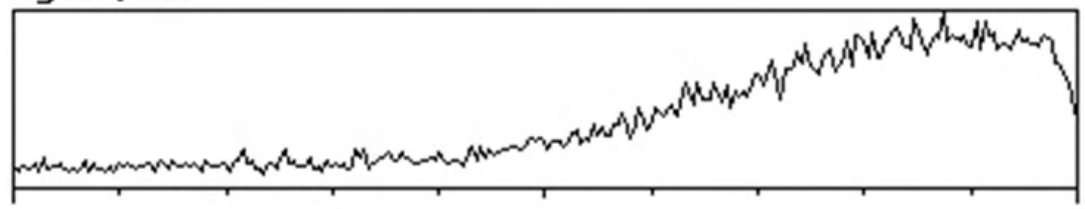

Figure 70 - EDX line scans for oxygen, sodium, phosphorus, titanium, and silver for the $120 \mathrm{~min}$ ion exchanged sample. Line width: $341 \mu \mathrm{m}$. 



\section{APPENDIX B}

\section{TEM images and EDX results}

The Appendix presents, with more detail, the images obtained in TEM analysis, as well as the EDX maps for all elements present in the NBTN-Ag samples.

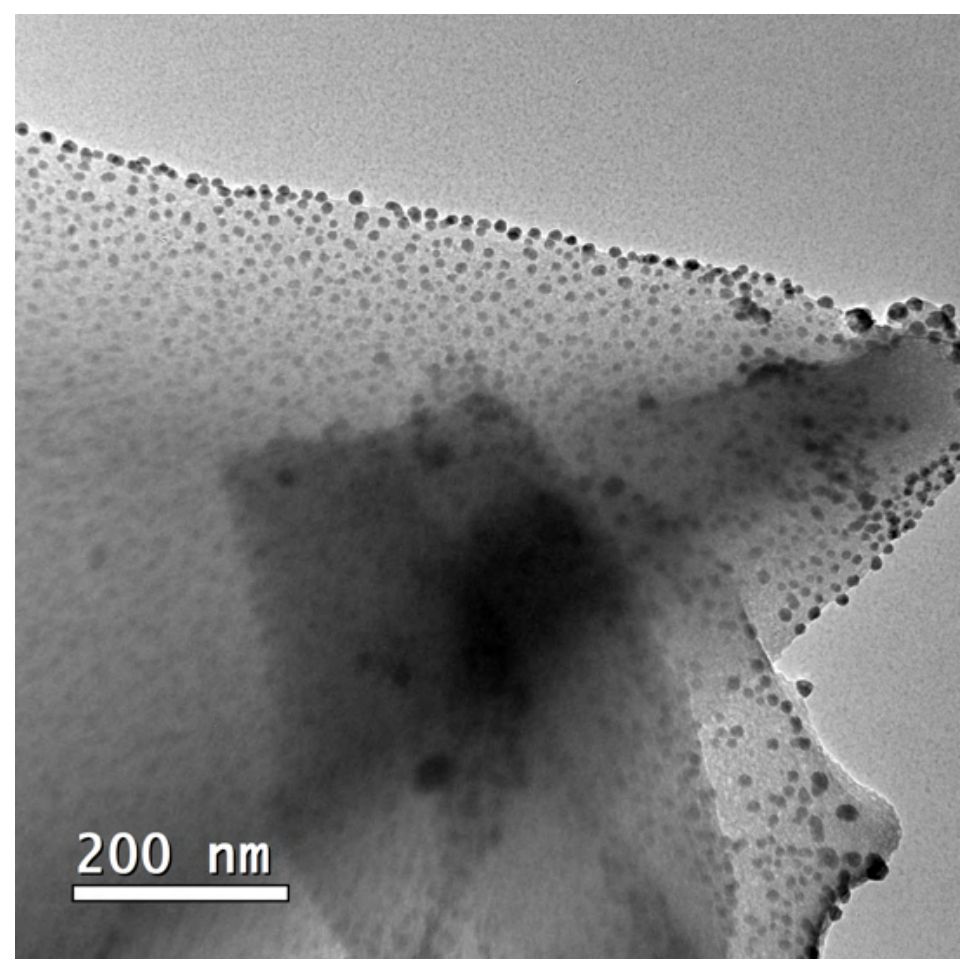

Figure 71 - 30 min ion exchanged sample transmitted electrons image. 


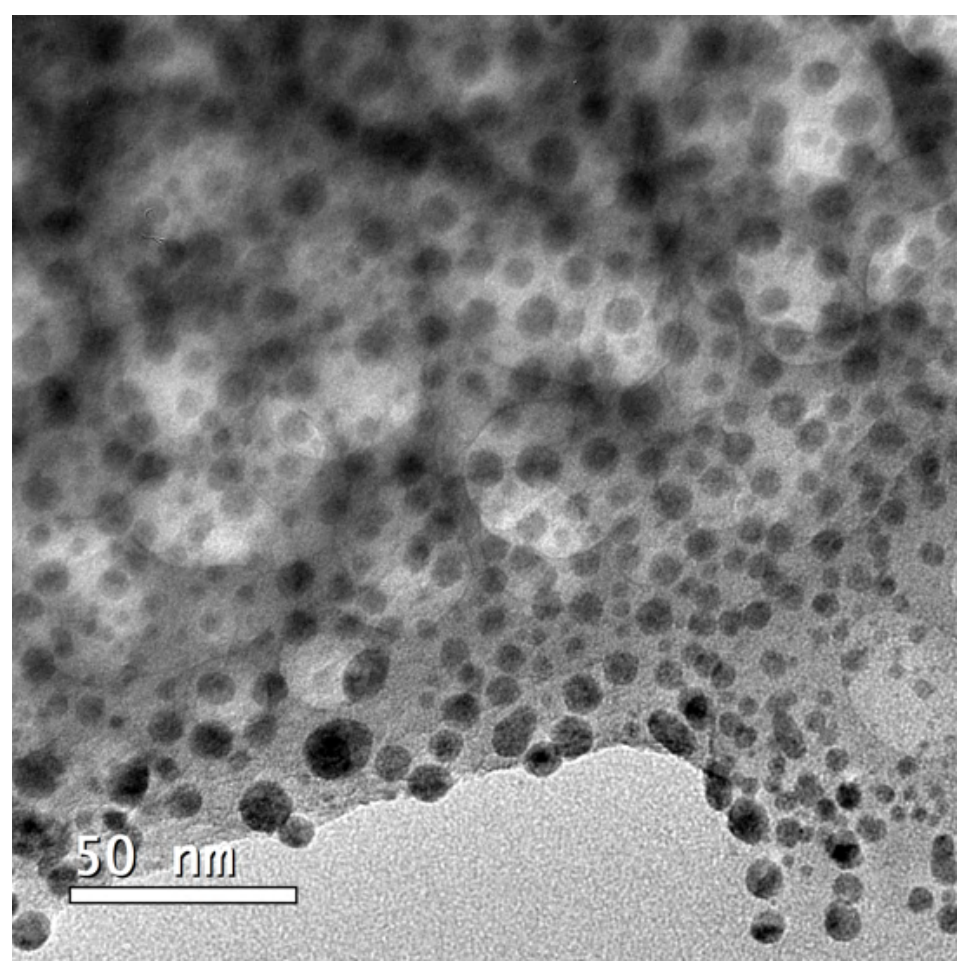

Figure 72 - 30 min ion exchanged sample transmitted electrons image.

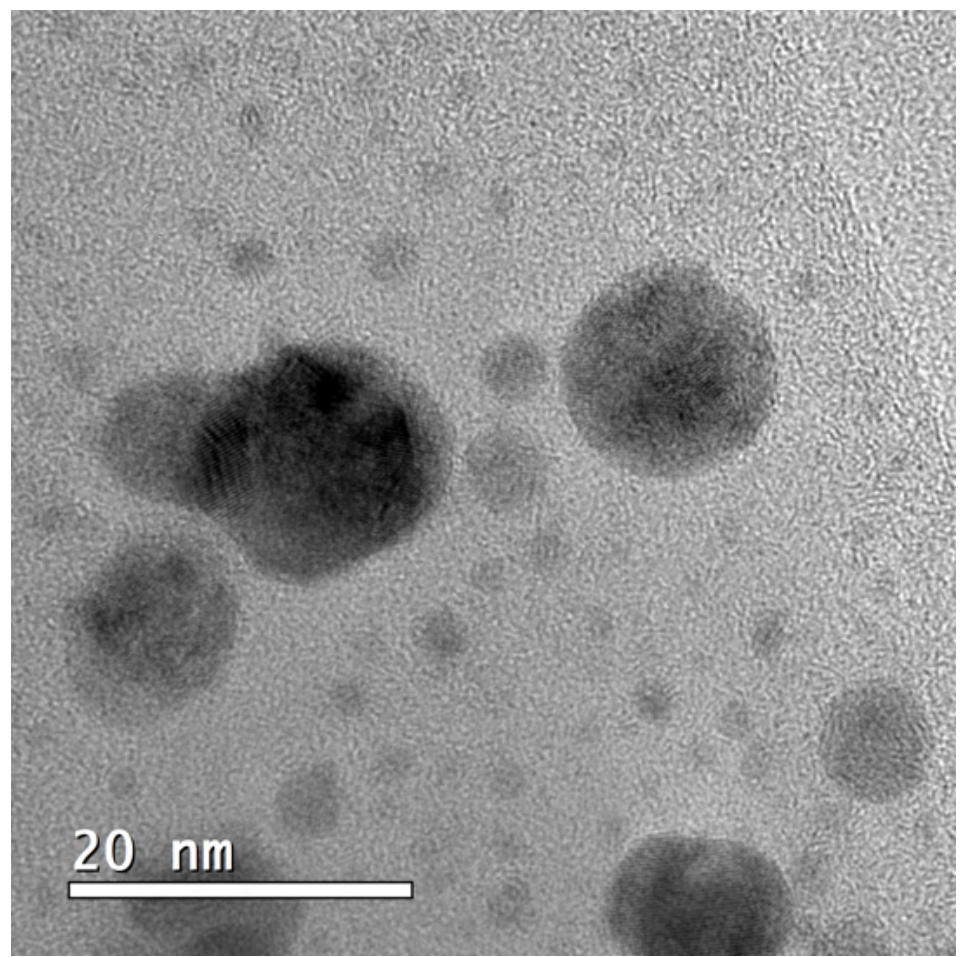

Figure 73 - 30 min ion exchanged sample transmitted electrons image. 


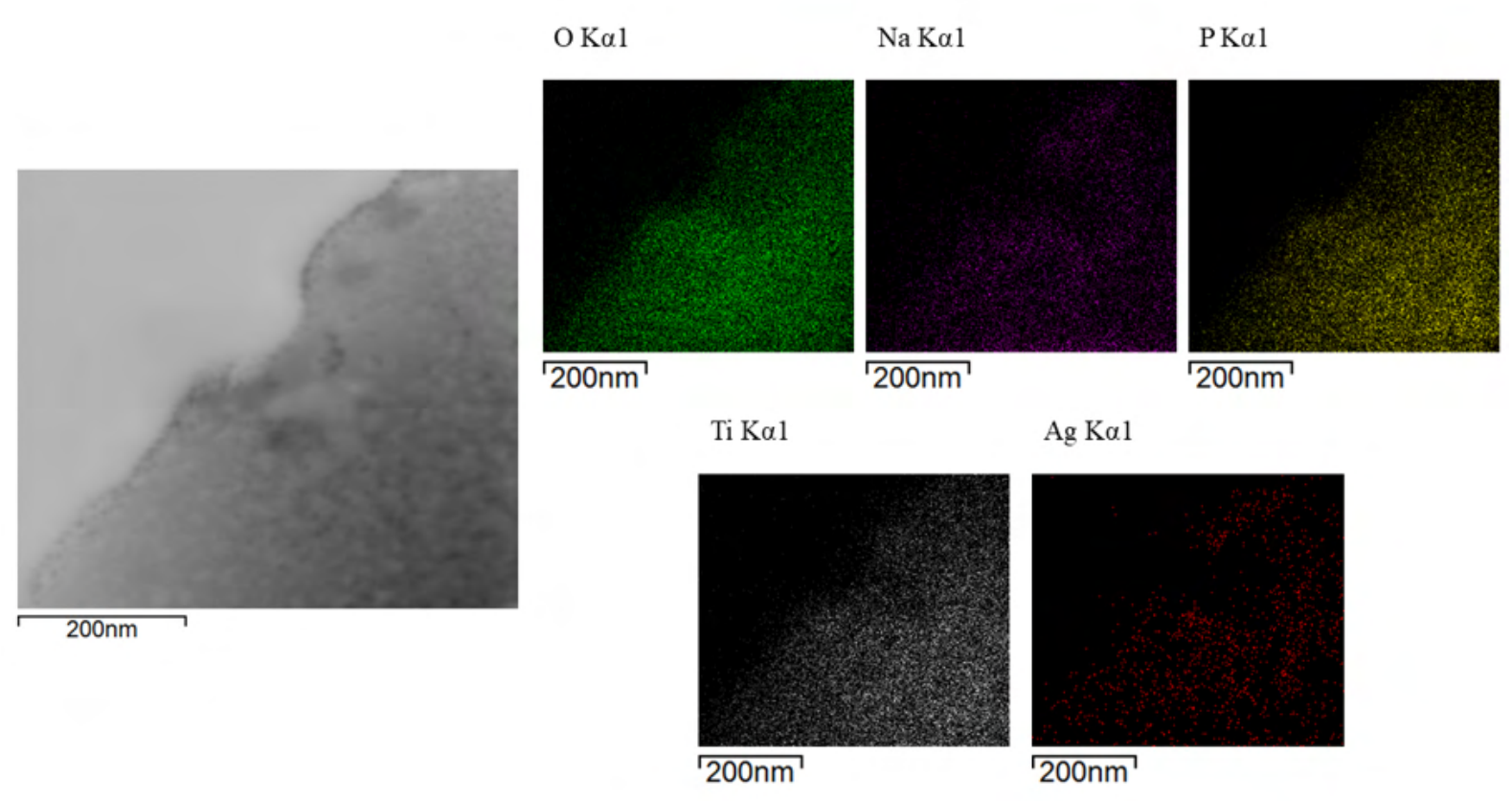

Figure 74 - EDX maps of NBTN-Ag30 sample for oxygen, sodium, phosphorus, titanium, and silver.

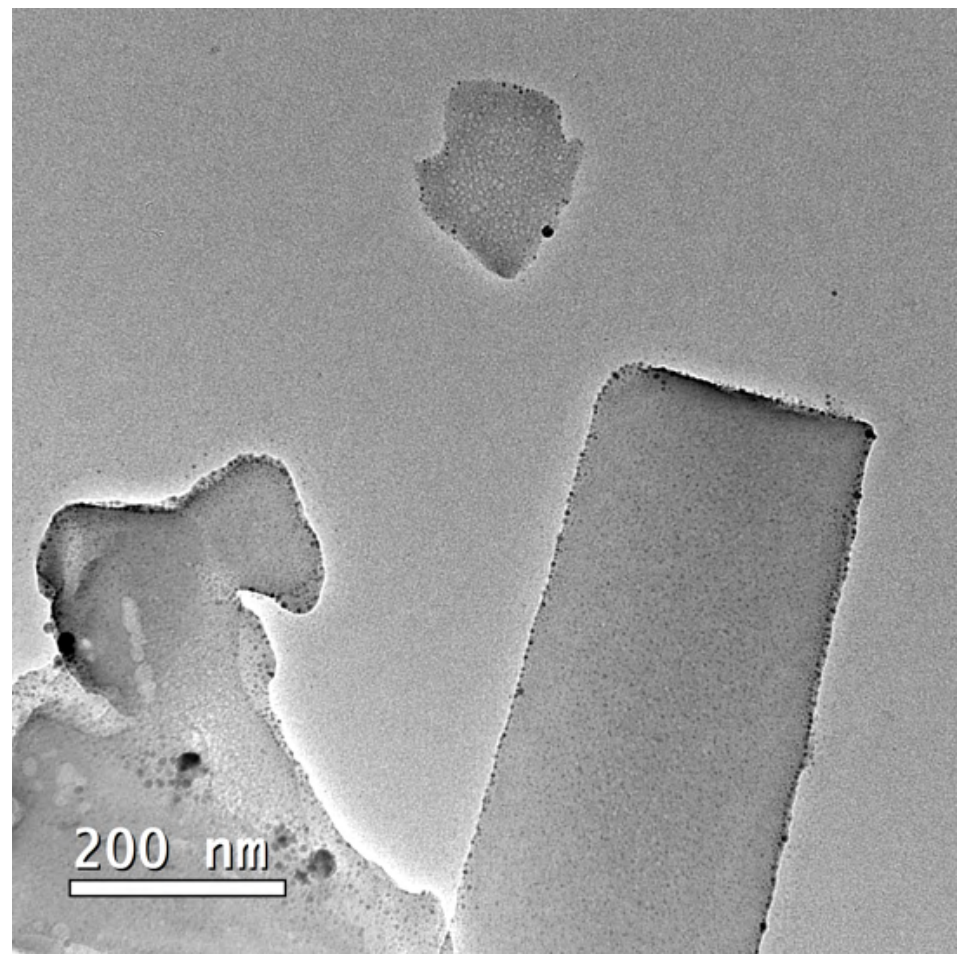

Figure 75 - 60 min ion exchanged sample transmitted electrons image. 


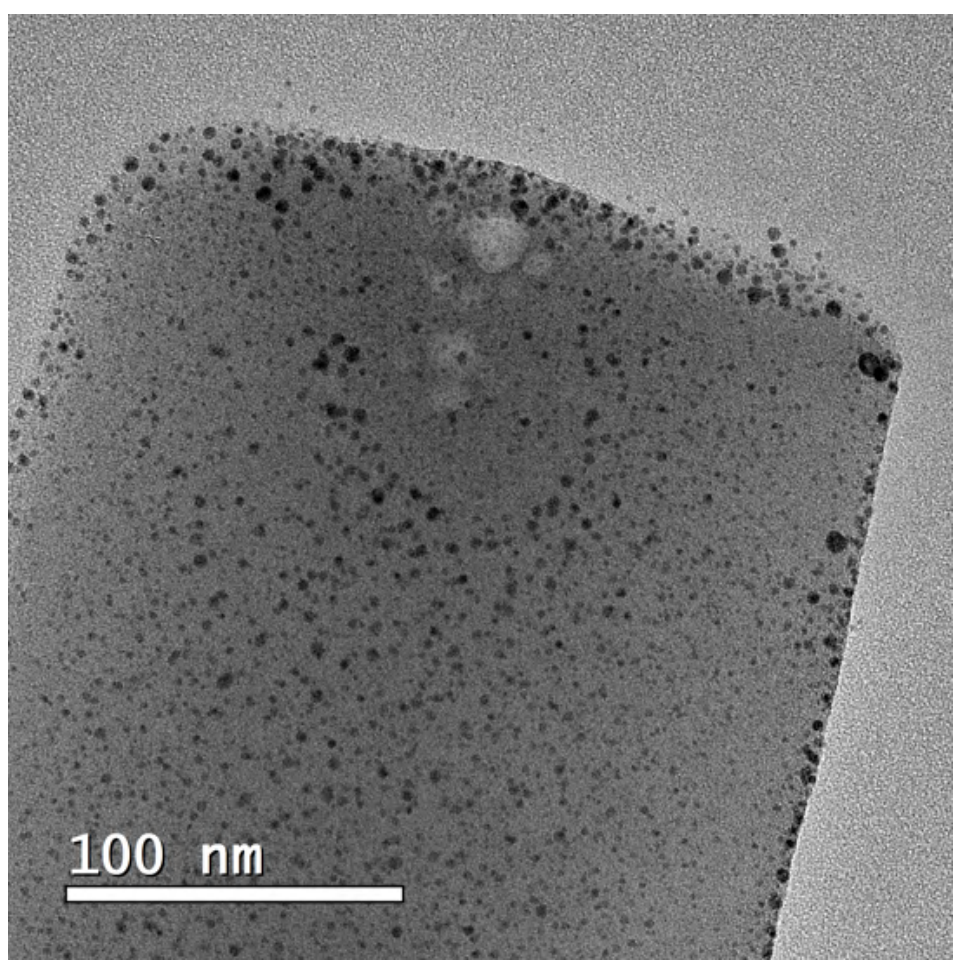

Figure $76-60$ min ion exchanged sample transmitted electrons image.

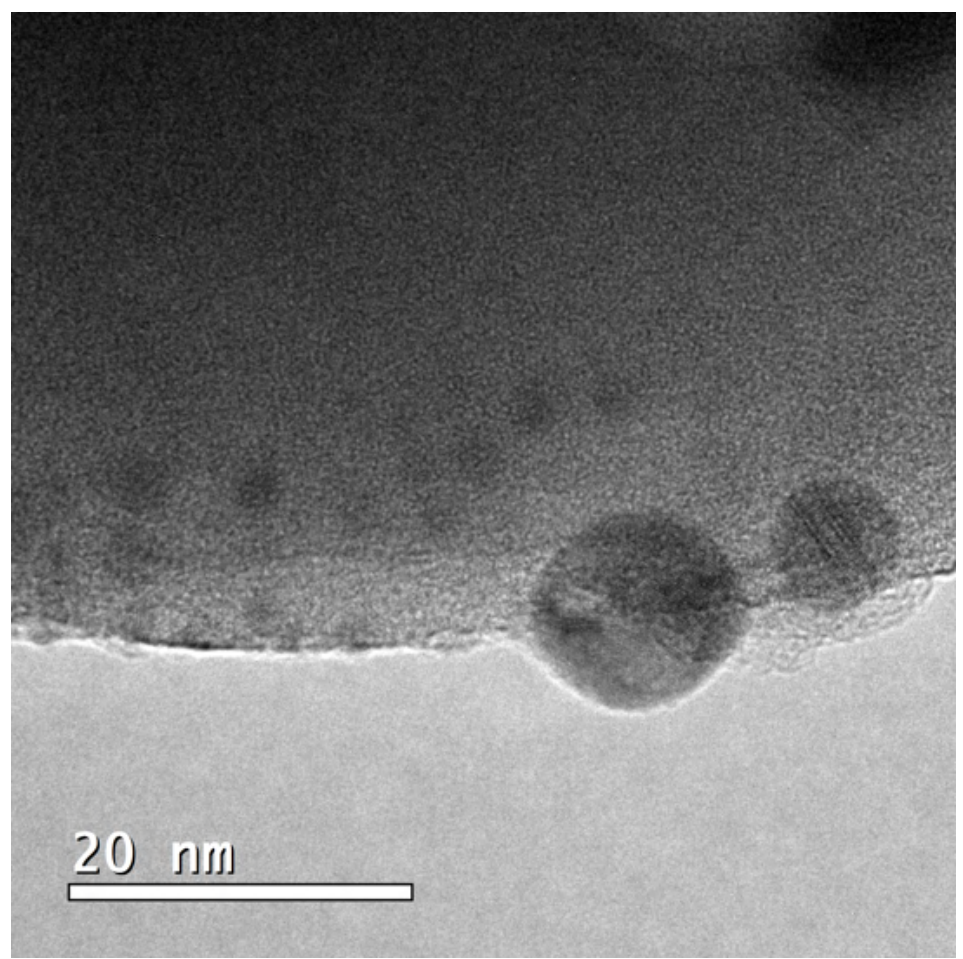

Figure $77-60$ min ion exchanged sample transmitted electrons image. 


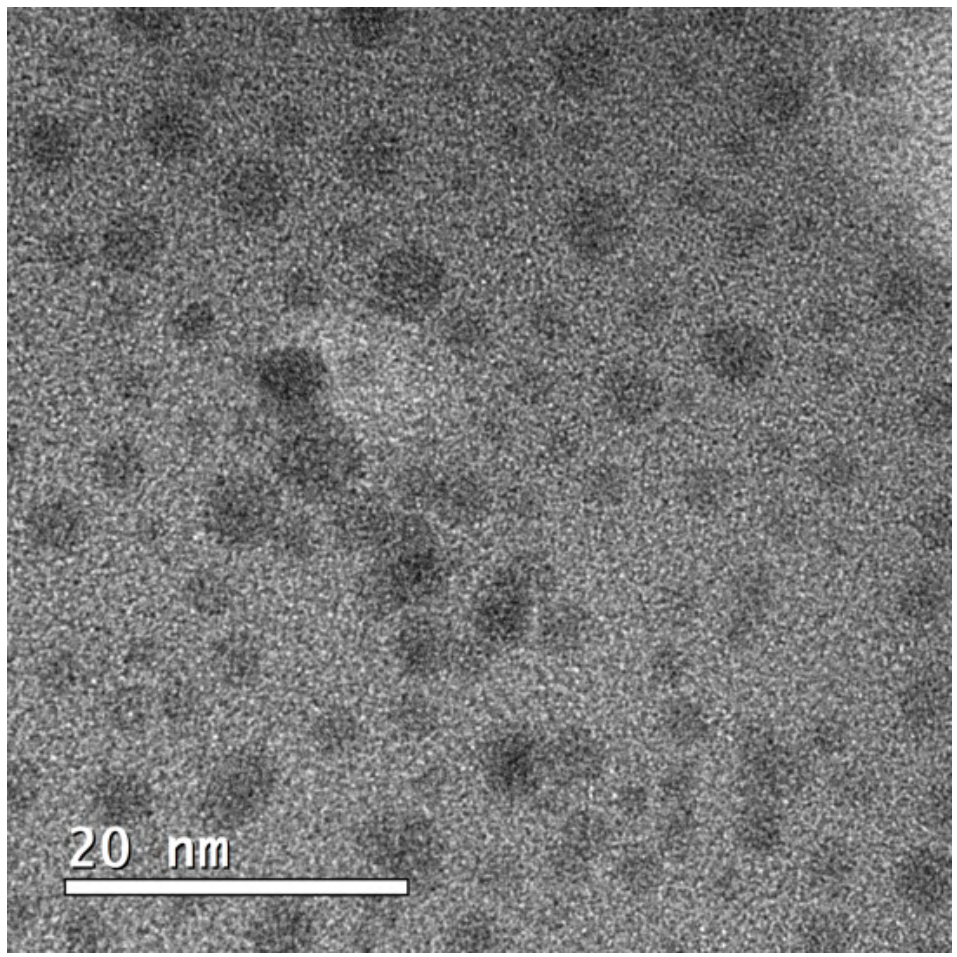

Figure 78 - 60 min ion exchanged sample transmitted electrons image.

$\mathrm{O} \mathrm{K} \alpha 1$

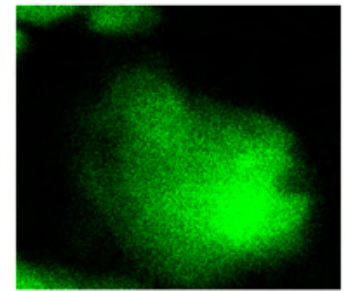

$\longdiv { 3 0 0 \mathrm { nm } }$
$\mathrm{Na} \mathrm{K} \alpha 1$

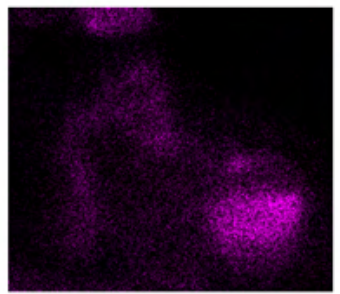

$\longdiv { 3 0 0 \mathrm { nm } }$

Ti $\mathrm{K} \alpha 1$

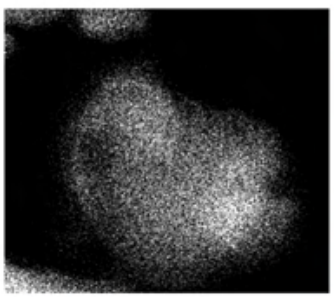

$300 \mathrm{~nm}$
$\mathrm{PK} \alpha 1$

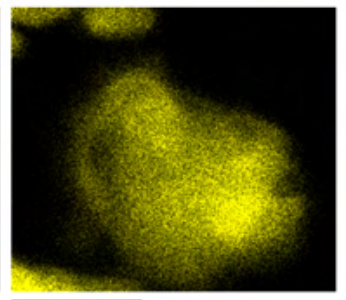

$\longdiv { 3 0 0 \mathrm { nm } }$

$\mathrm{Ag} \mathrm{K} \alpha 1$

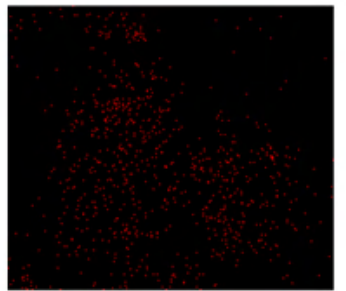

$\longdiv { 3 0 0 \mathrm { nm } }$

Figure 79 - EDX maps of NBTN-Ag60 sample for oxygen, sodium, phosphorus, titanium, and silver. 


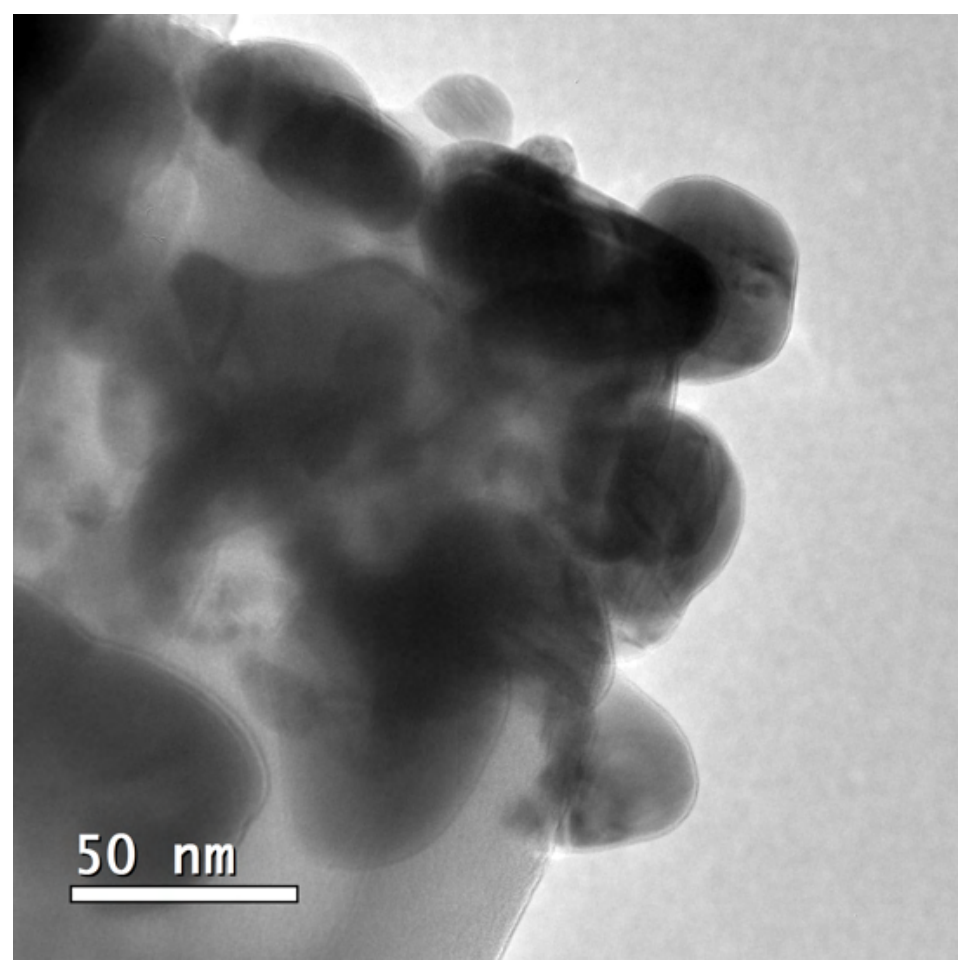

Figure 80 - 120 min ion exchanged sample transmitted electrons image.

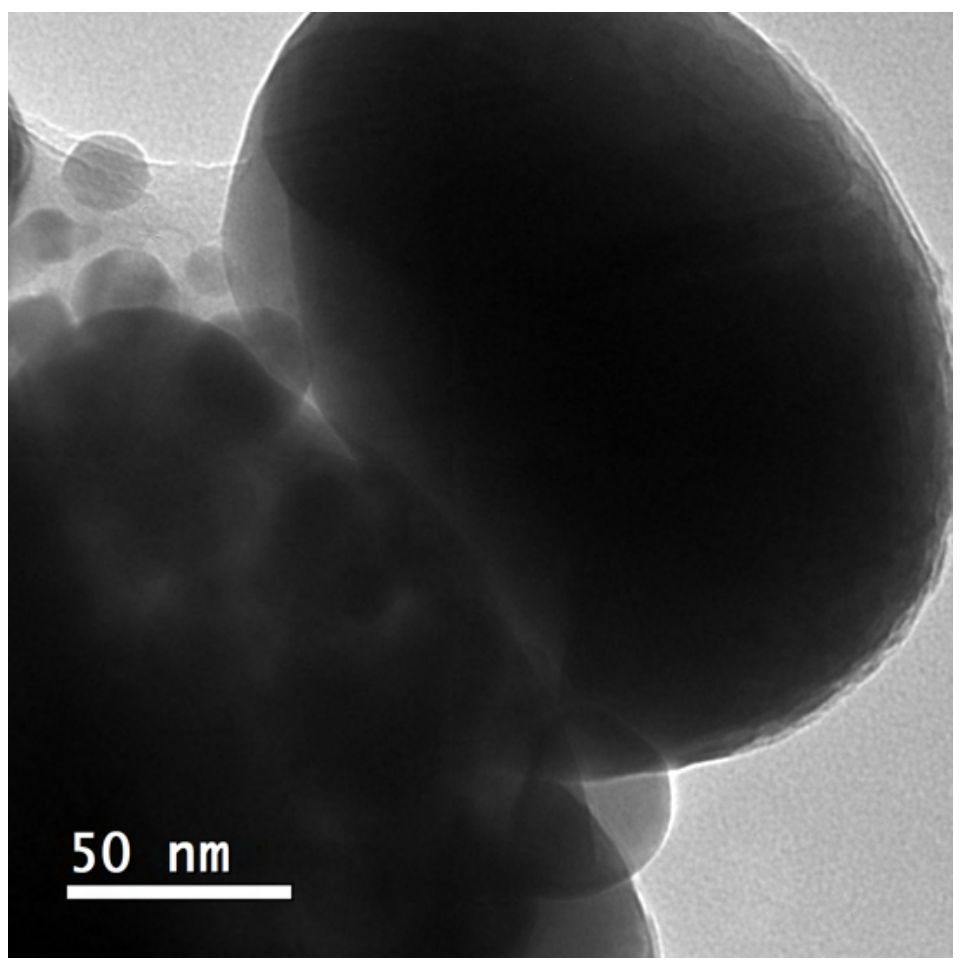

Figure 81 - 120 min ion exchanged sample transmitted electrons image. 


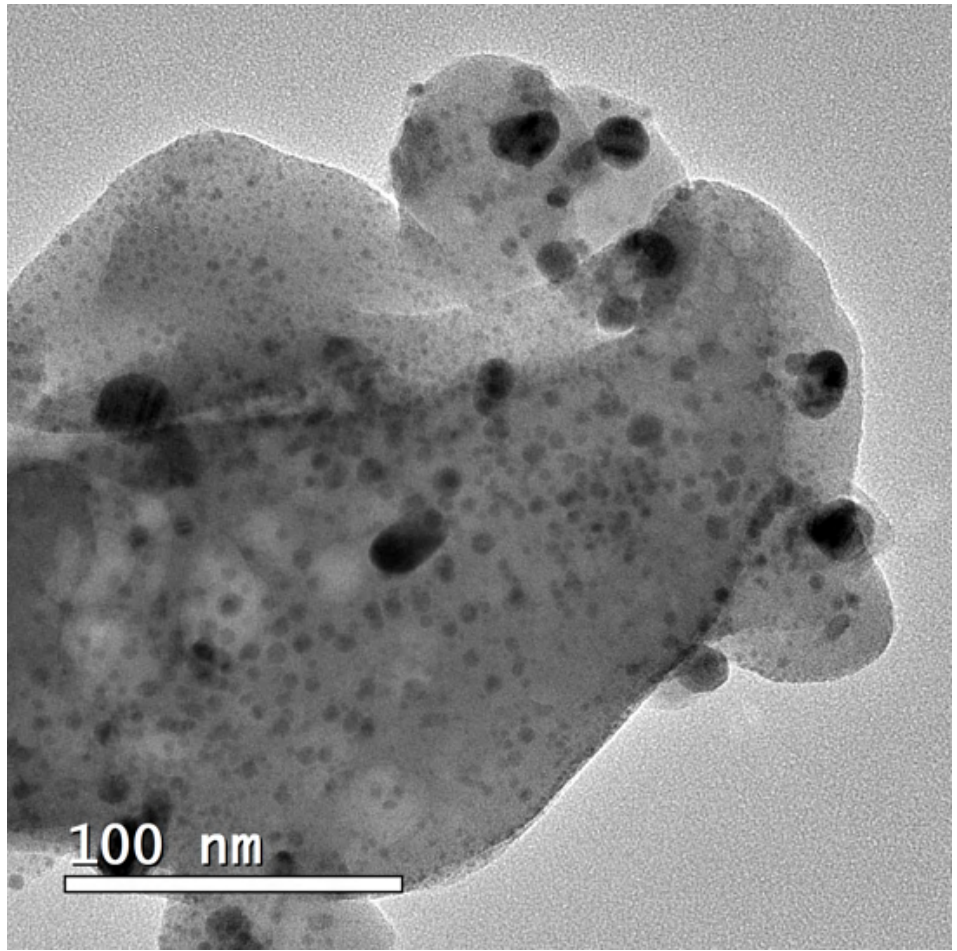

Figure 82 - 120 min ion exchanged sample transmitted electrons image.

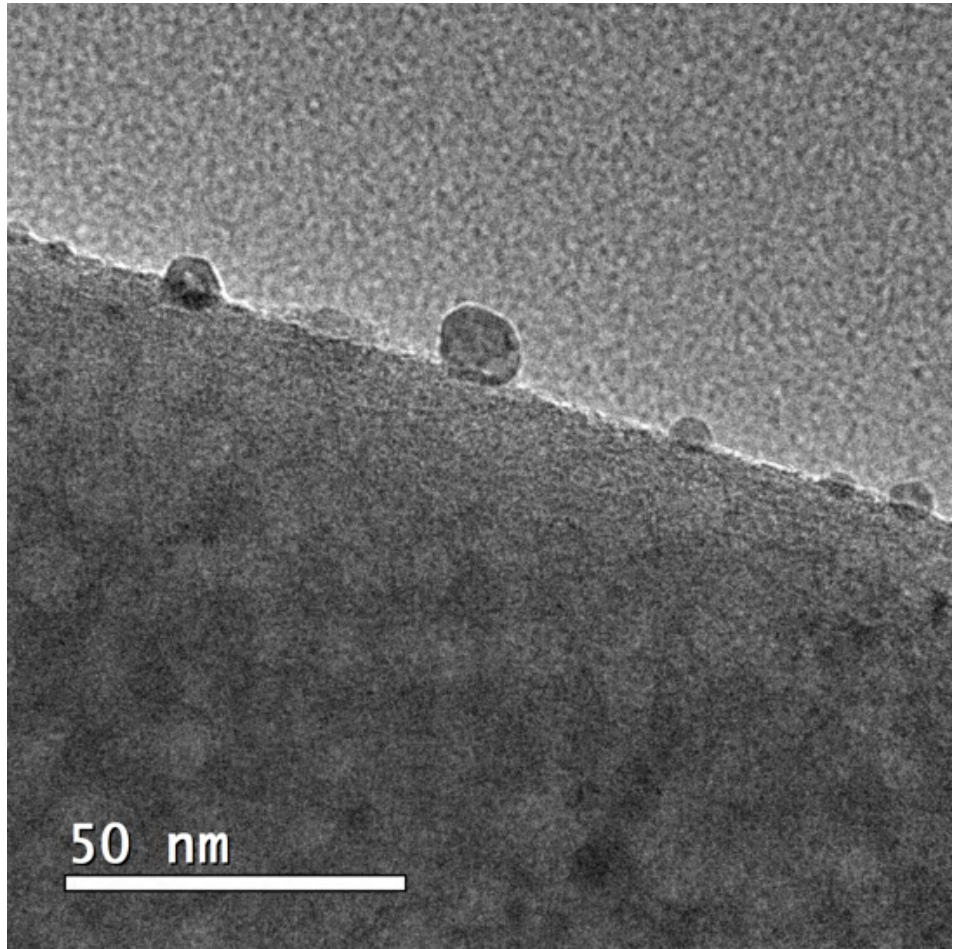

Figure 83 - 120 min ion exchanged sample transmitted electrons image. 


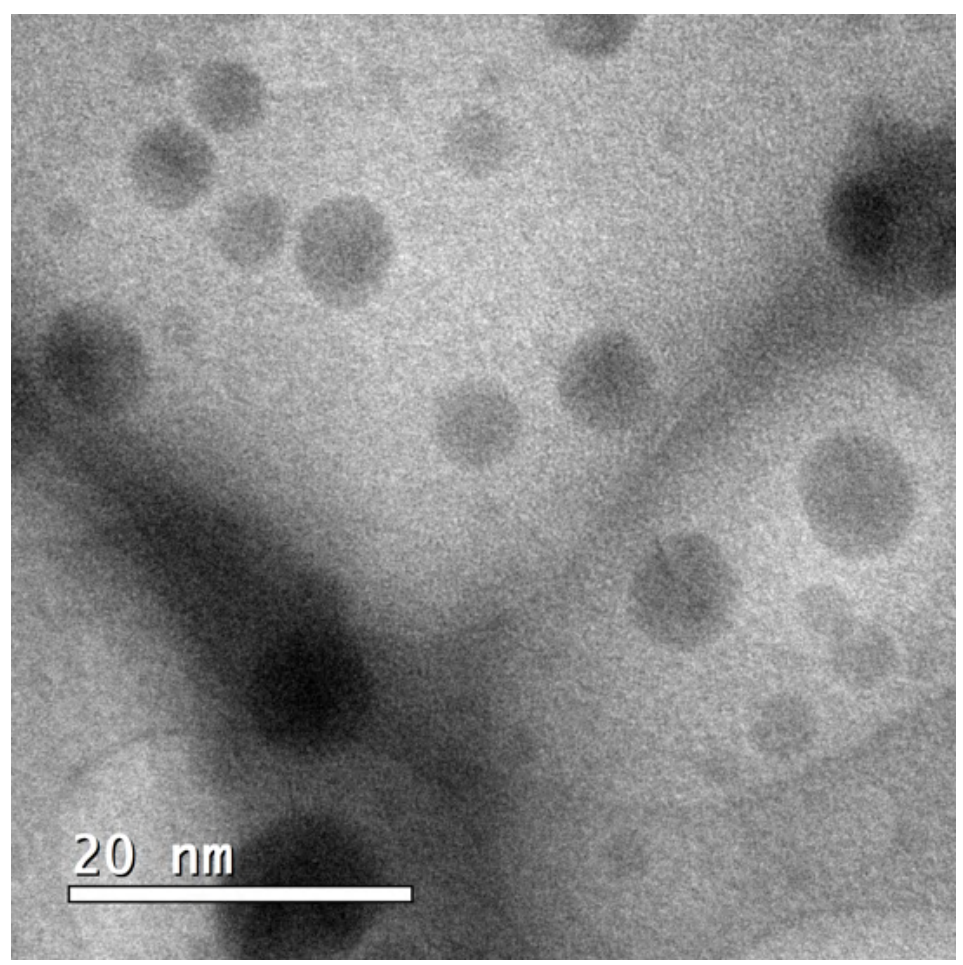

Figure 84 - 120 min ion exchanged sample transmitted electrons image.

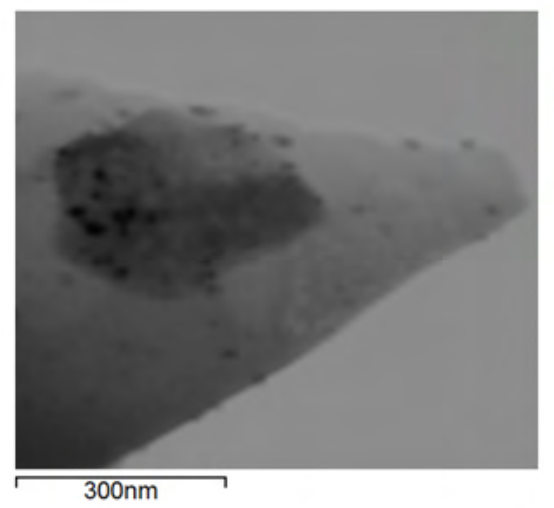

$\mathrm{OK} \alpha \mathrm{l}$

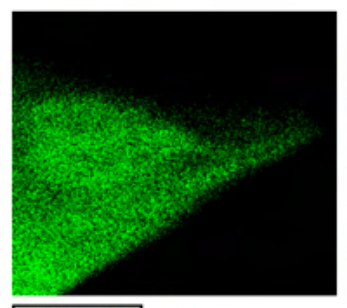

$\longdiv { 3 0 0 \mathrm { nm } }$
Na K $\alpha 1$

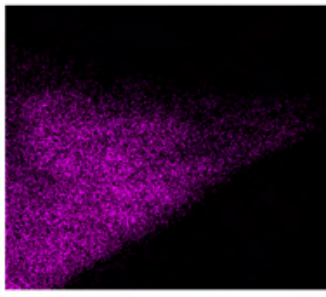

$\longdiv { 3 0 0 \mathrm { nm } }$
$\mathrm{PK} \alpha 1$

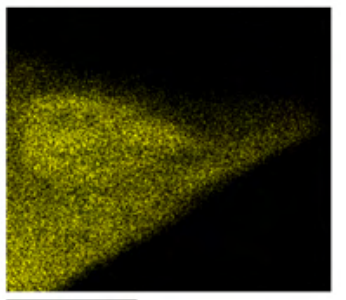

$\longdiv { 3 0 0 \mathrm { nm } }$
Ti $\mathrm{K} \alpha 1$

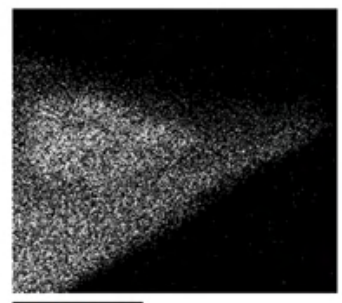

$\longdiv { 3 0 0 \mathrm { nm } }$
$\mathrm{Ag} \mathrm{K} \alpha 1$

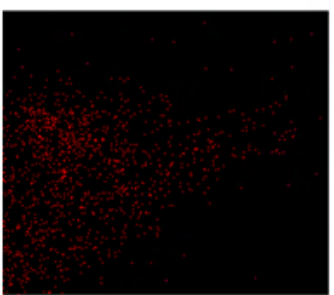

$\longdiv { 3 0 0 \mathrm { nm } }$

Figure 85 - EDX maps of NBTN-Ag120 sample for oxygen, sodium, phosphorus, titanium, and silver. 


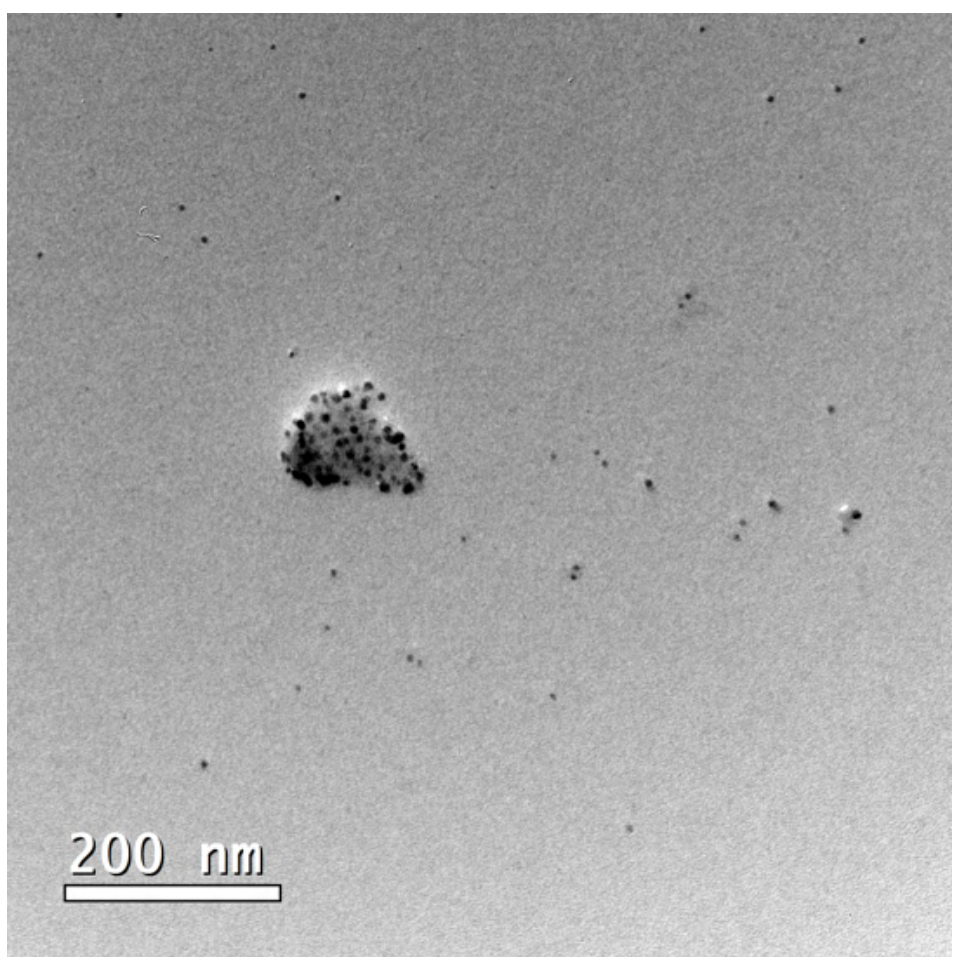

Figure 86 - Transmitted electrons image of powdered glass sample with 120 min of ion exchange bath.

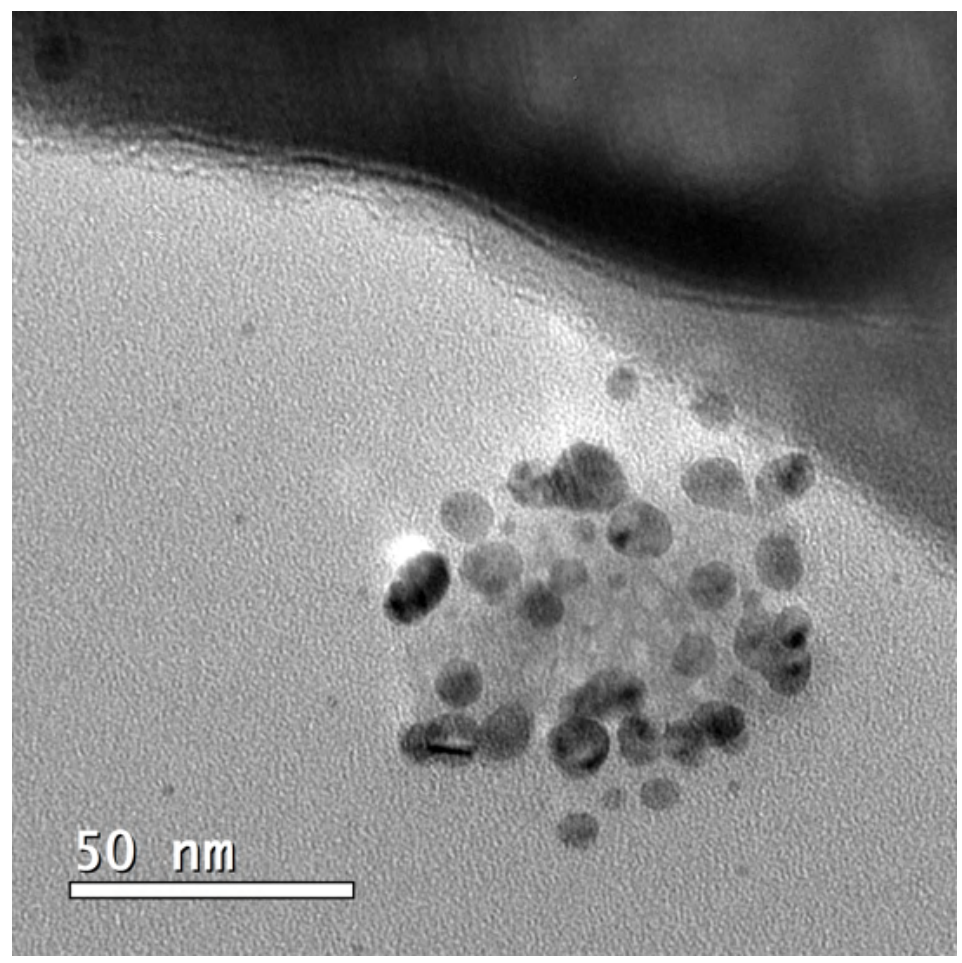

Figure 87 - Transmitted electrons image of powdered glass sample with 120 min of ion exchange bath. 


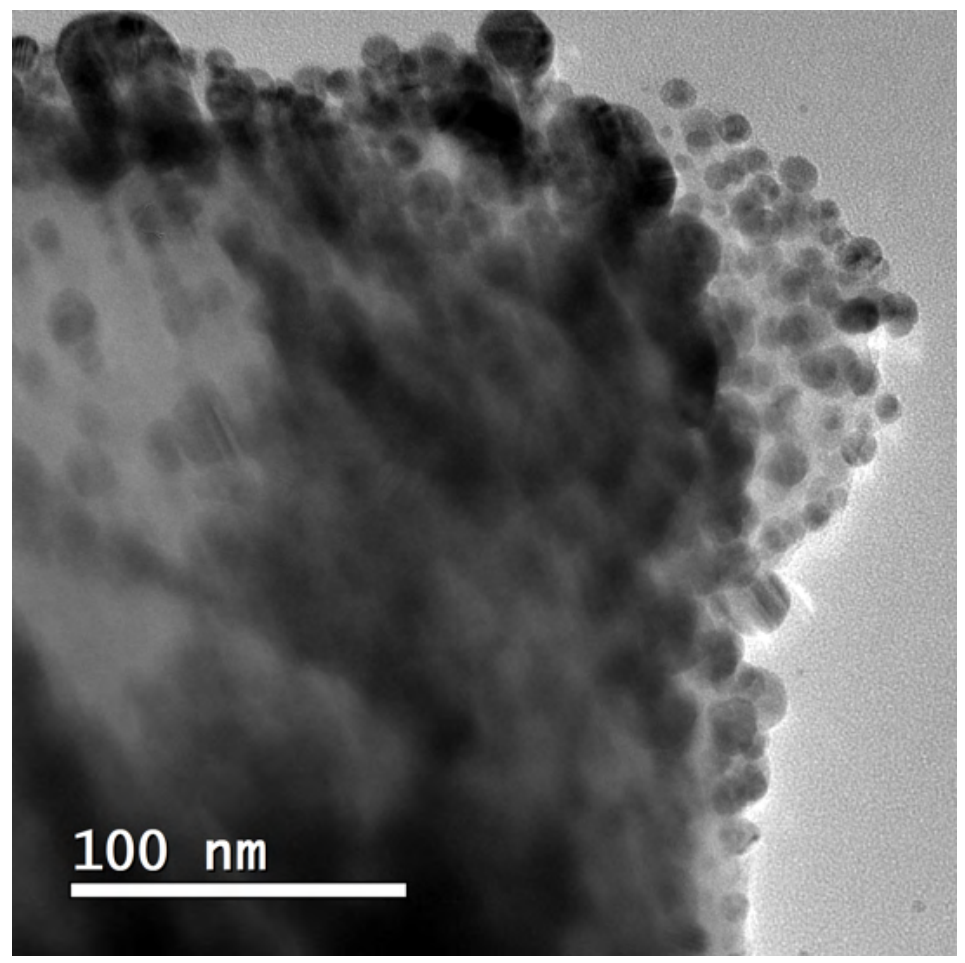

Figure 88 - Transmitted electrons image of powdered glass sample with 120 min of ion exchange bath.

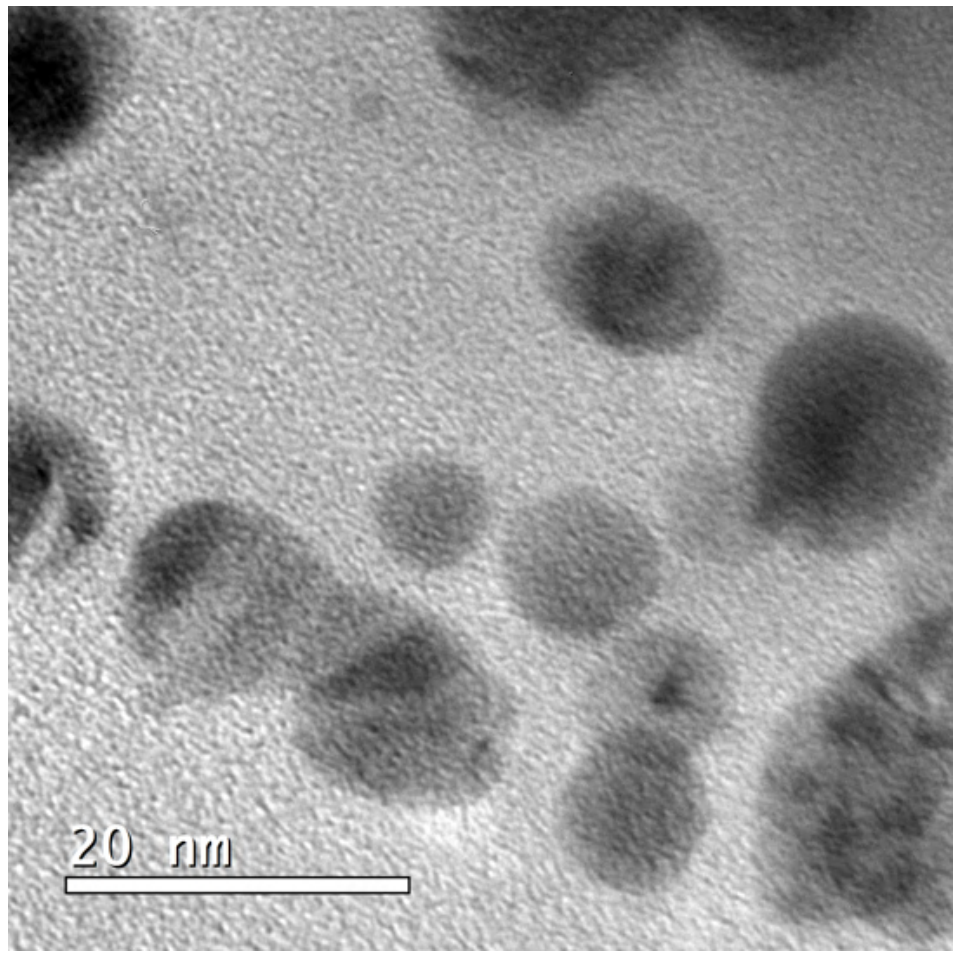

Figure 89 - Transmitted electrons image of powdered glass sample with 120 min of ion exchange bath. 


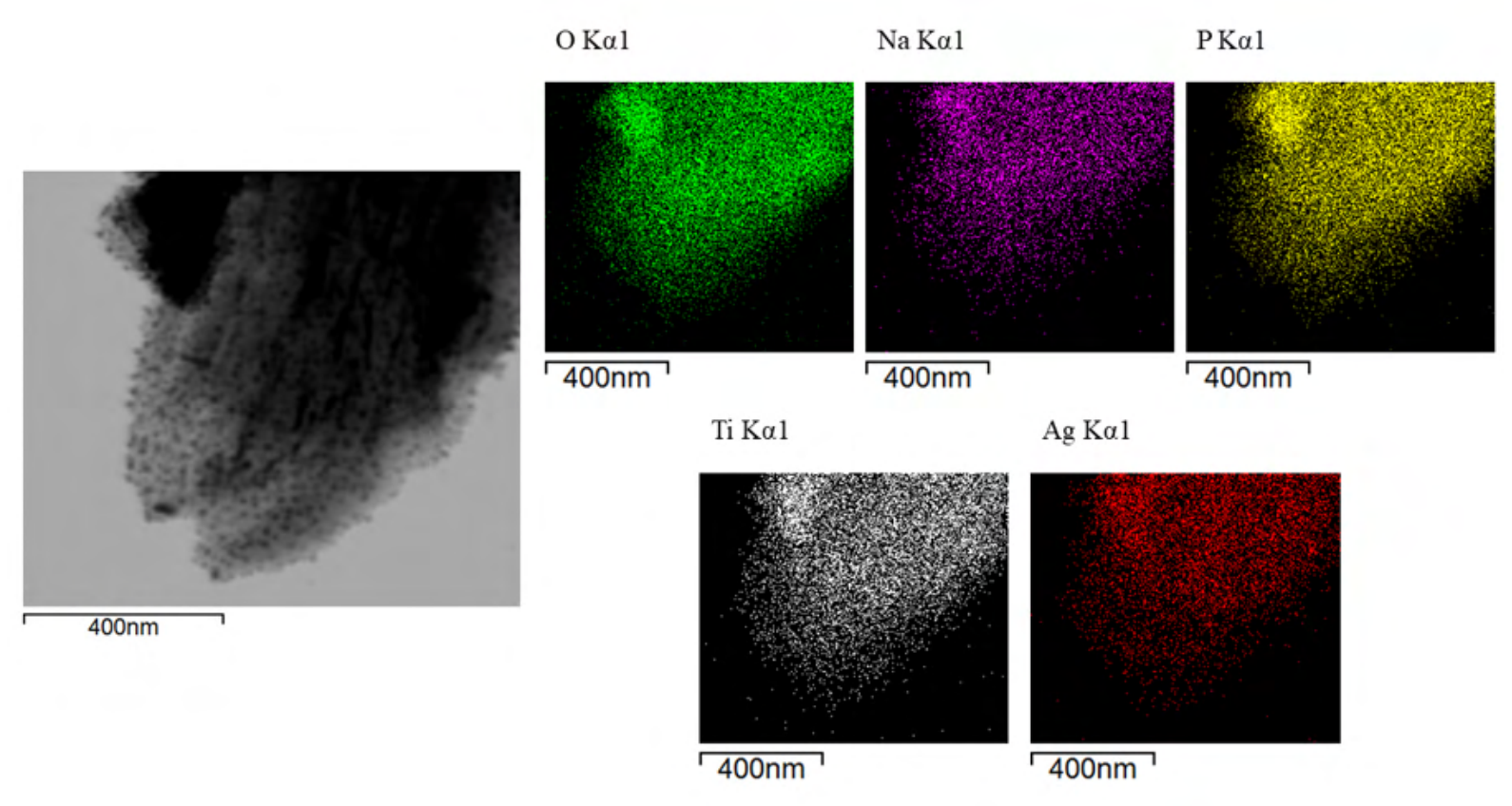

Figure 90 - EDX maps of powdered glass sample with 120 min of ion exchange bath for oxygen, sodium, phosphorus, titanium, and silver.

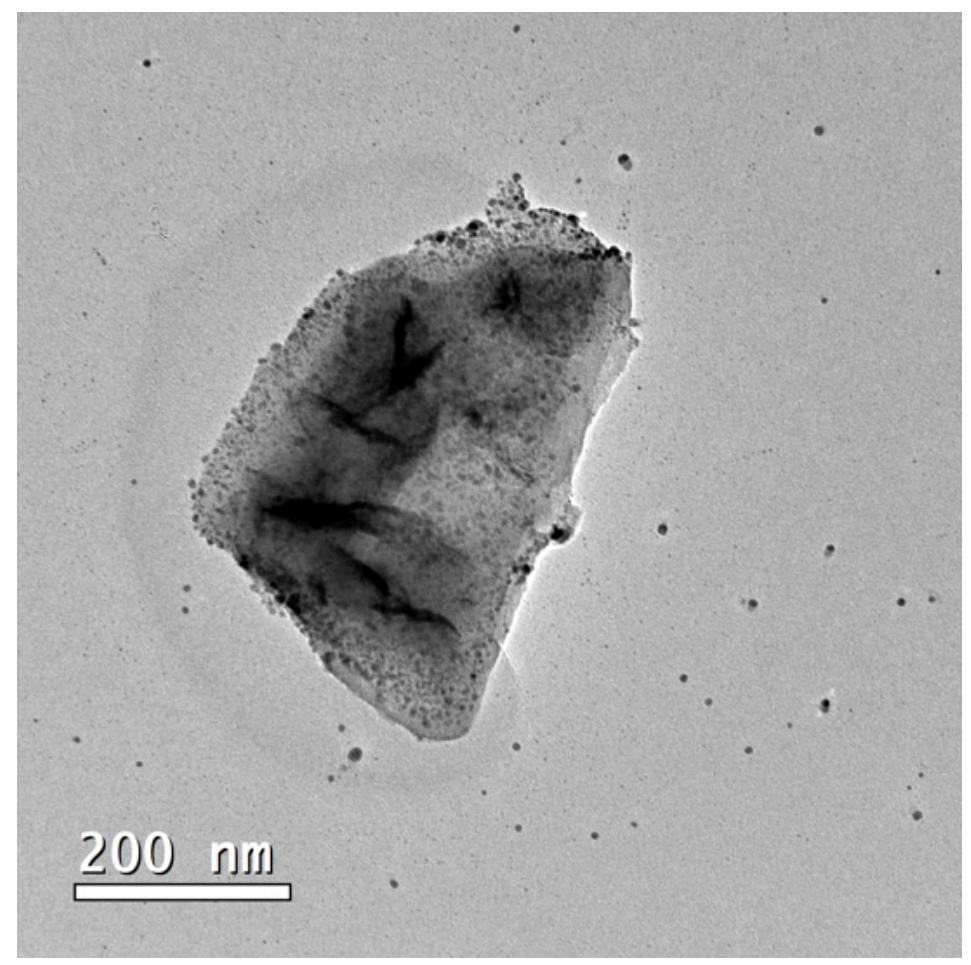

Figure 91 - Transmitted electrons image of powdered glass sample with 120 min of ion exchange bath and 10 min of thermal treatment at $T_{g}+10^{\circ} \mathrm{C}$. 


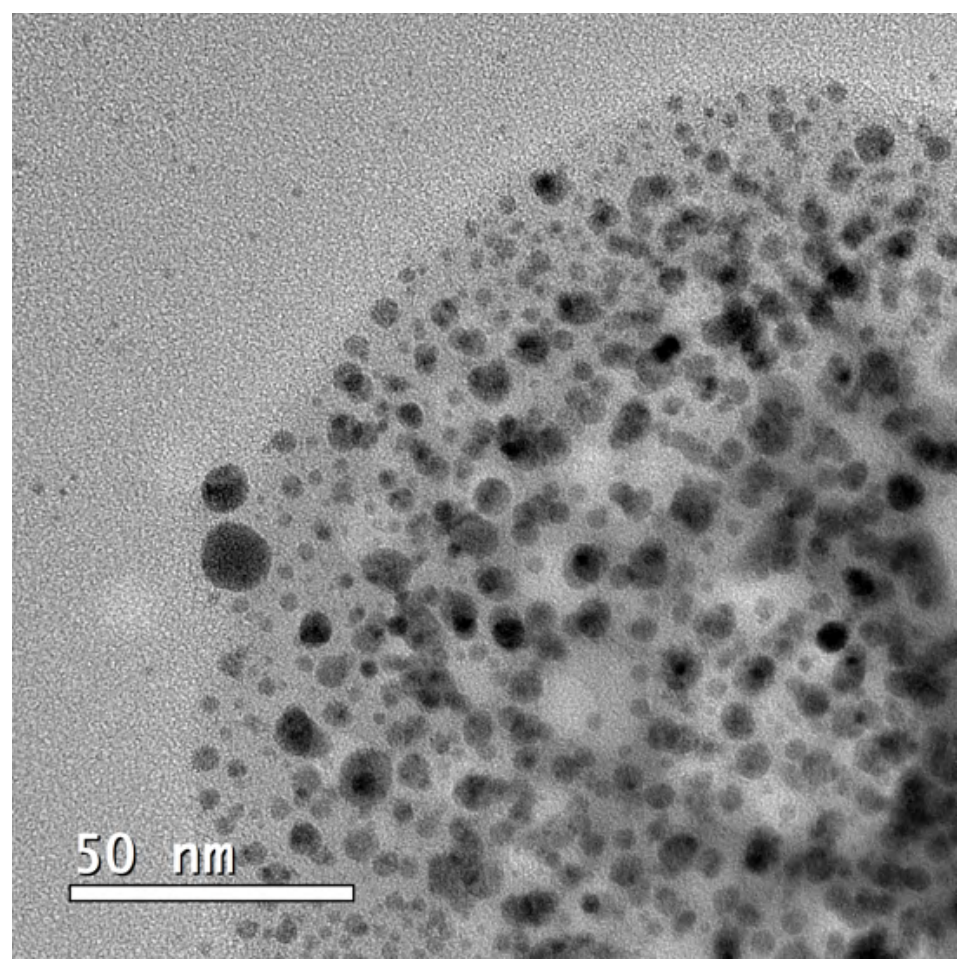

Figure 92 - Transmitted electrons image of powdered glass sample with 120 min of ion exchange bath and 10 min of thermal treatment at $T_{g}+10^{\circ} \mathrm{C}$.

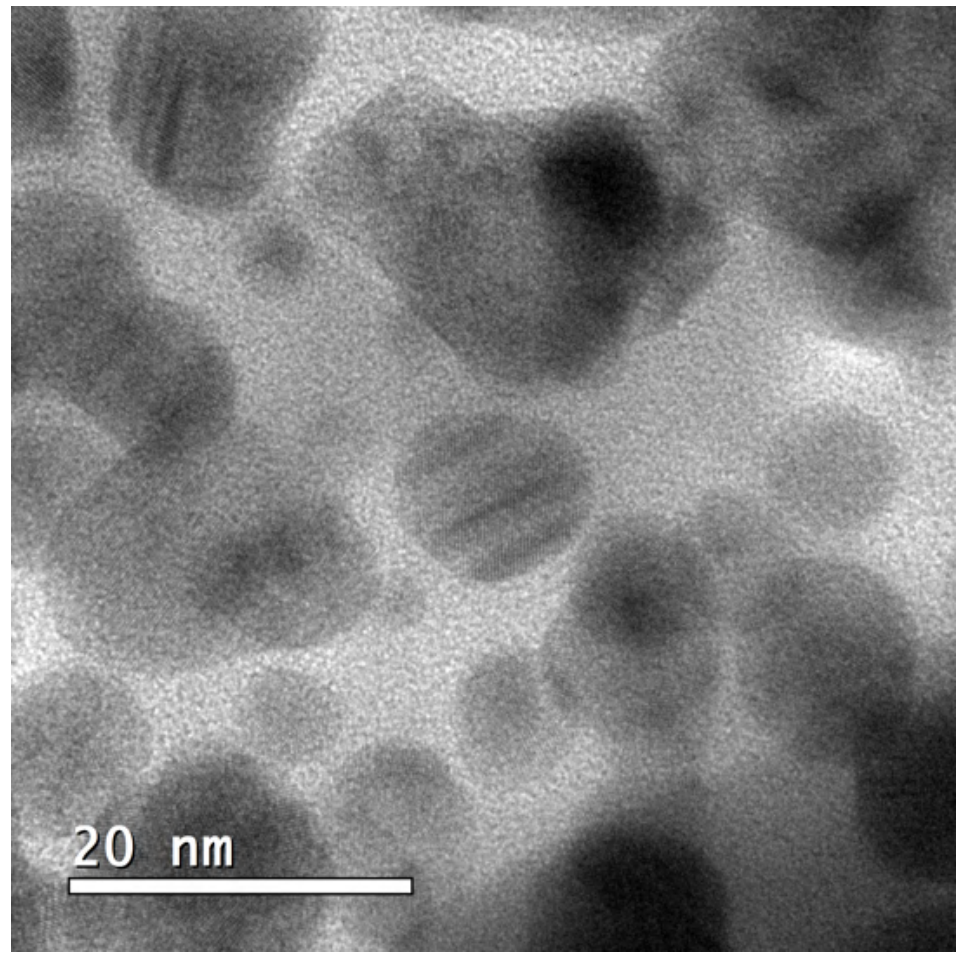

Figure 93 - Transmitted electrons image of powdered glass sample with 120 min of ion exchange bath and $10 \mathrm{~min}$ of thermal treatment at $T_{g}+10^{\circ} \mathrm{C}$. 


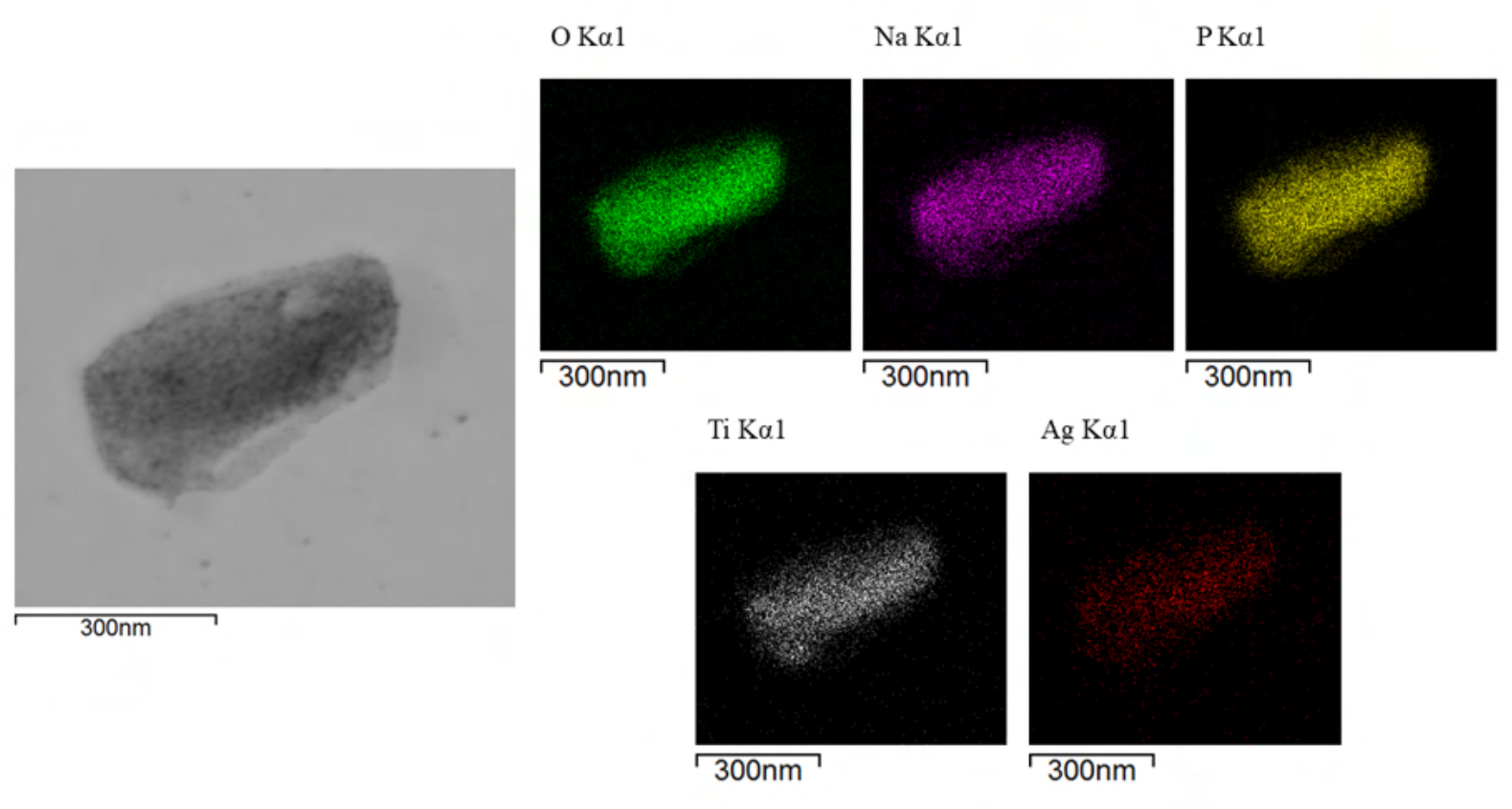

Figure 94 - EDX maps of powdered glass sample with 120 min of ion exchange bath and 10 min of thermal treatment at $T_{g}+10^{\circ} \mathrm{C}$ for oxygen, sodium, phosphorus, titanium, and silver. 



\section{APPENDIX $\mathbf{C}$}

\section{Crystal violet SERS raw data}

In this Appendix, raw data for the SERS experiments using crystal violet as molecule probe are presented for comparative purposes of the signal intensities.

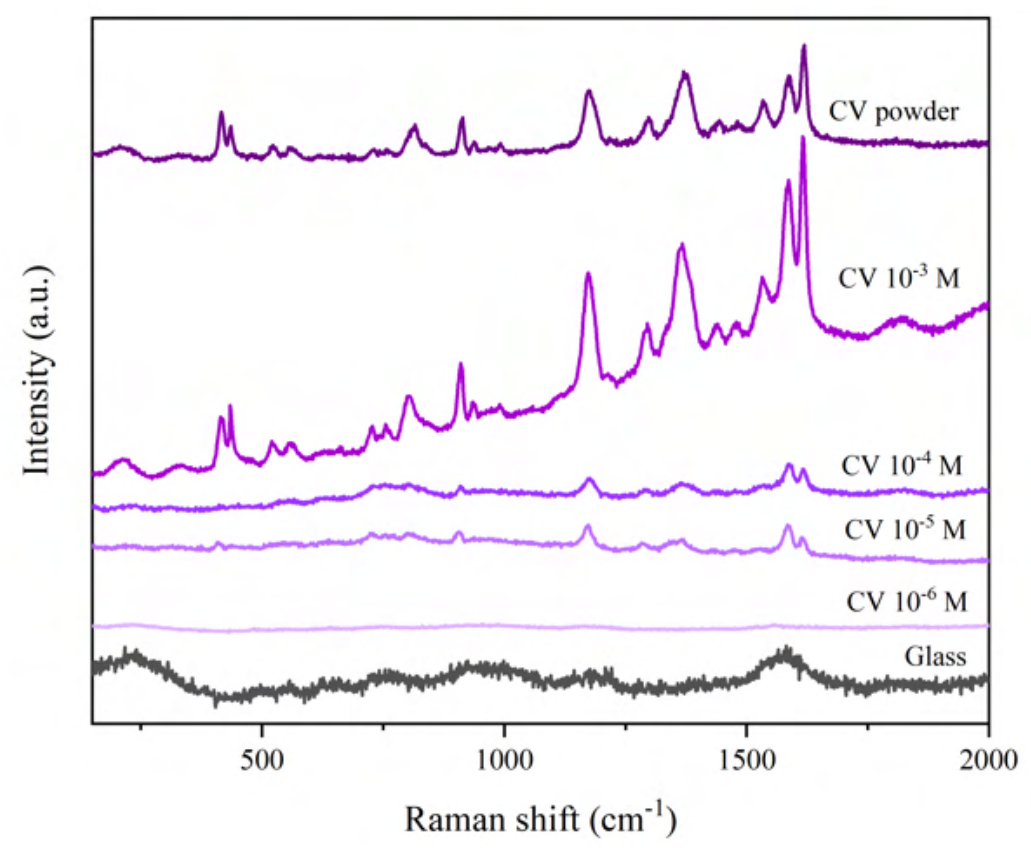

Figure 95 - Raw data of SERS experiments on NBTN-Ag30 sample. 


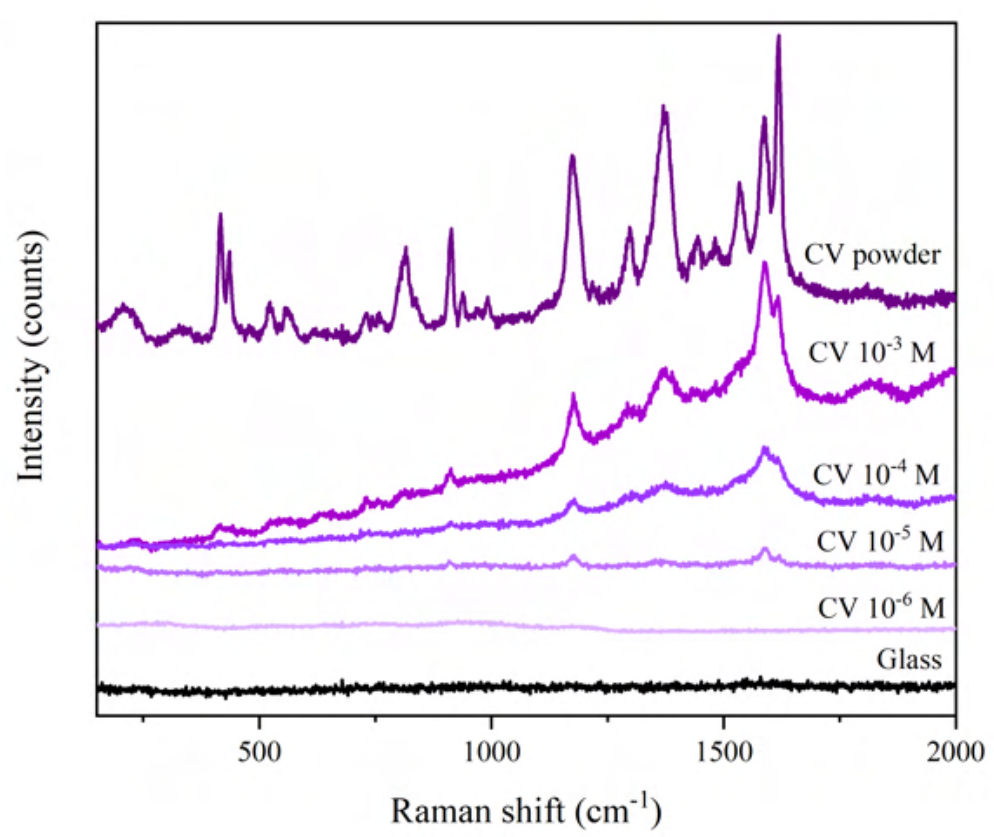

Figure 96 - Raw data of SERS experiments on NBTN-Ag60 sample.

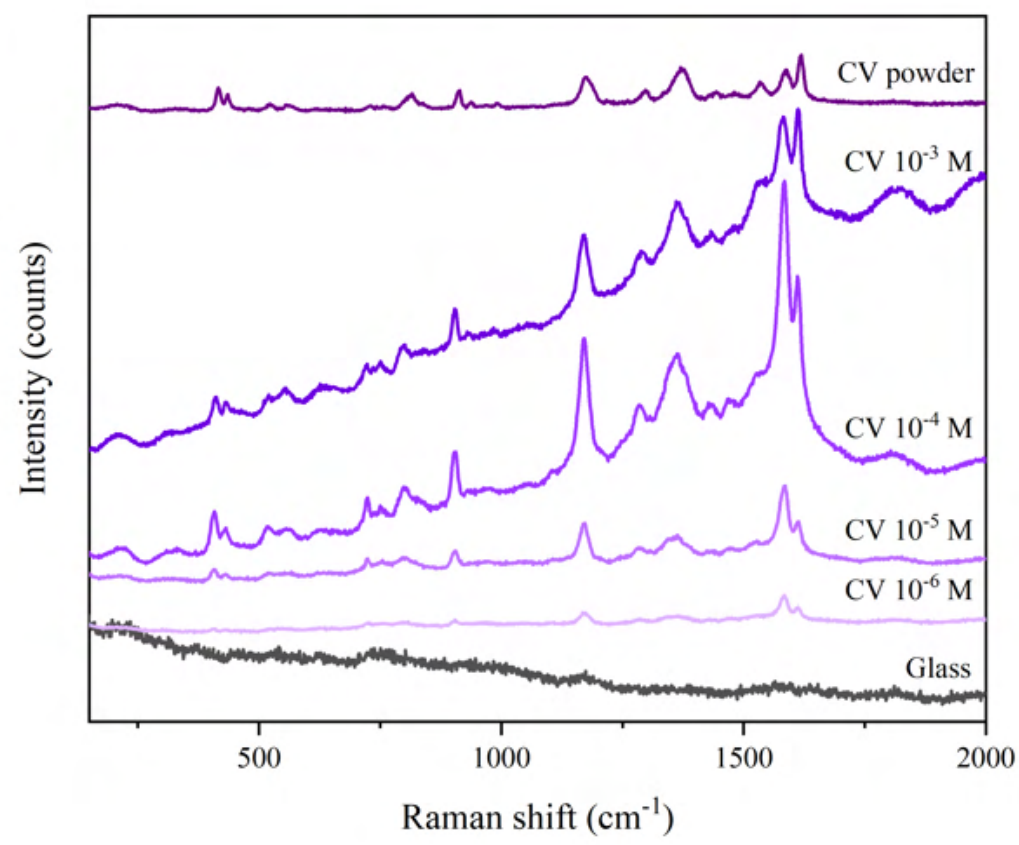

Figure 97 - Raw data of SERS experiments on NBTN-Ag120 sample. 


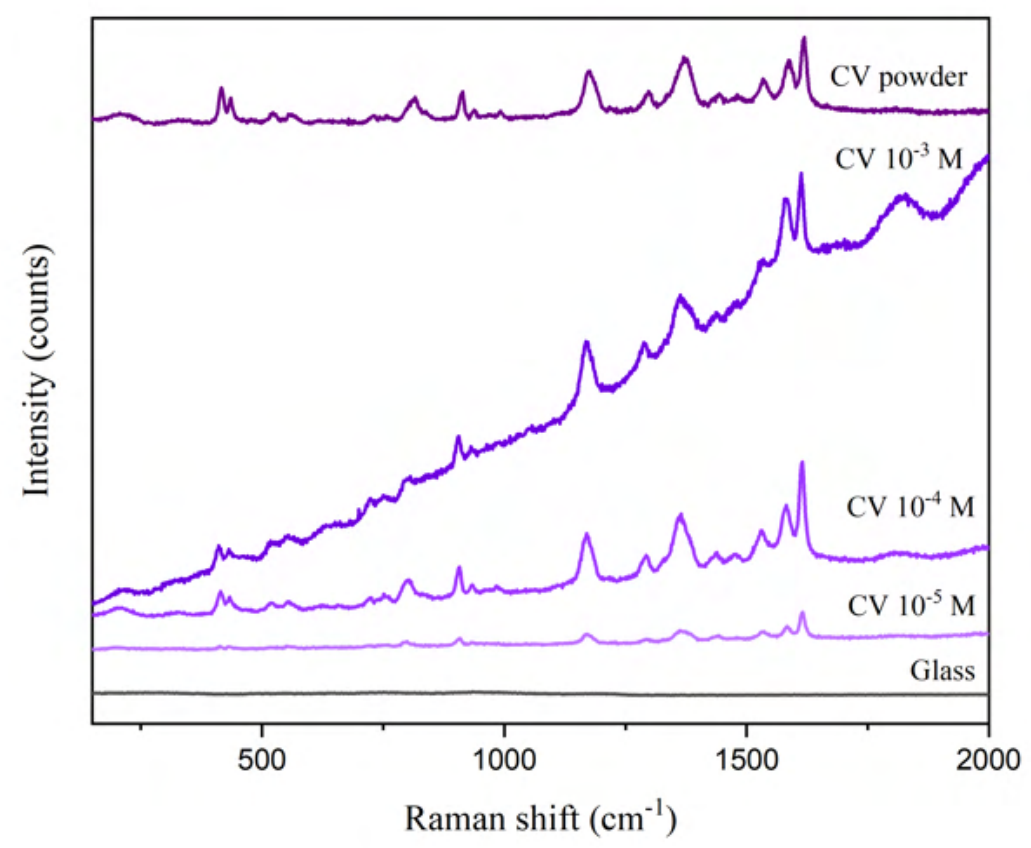

Figure 98 - Raw data of Raman experiments on NBTN sample that does not contain Ag-NPs.

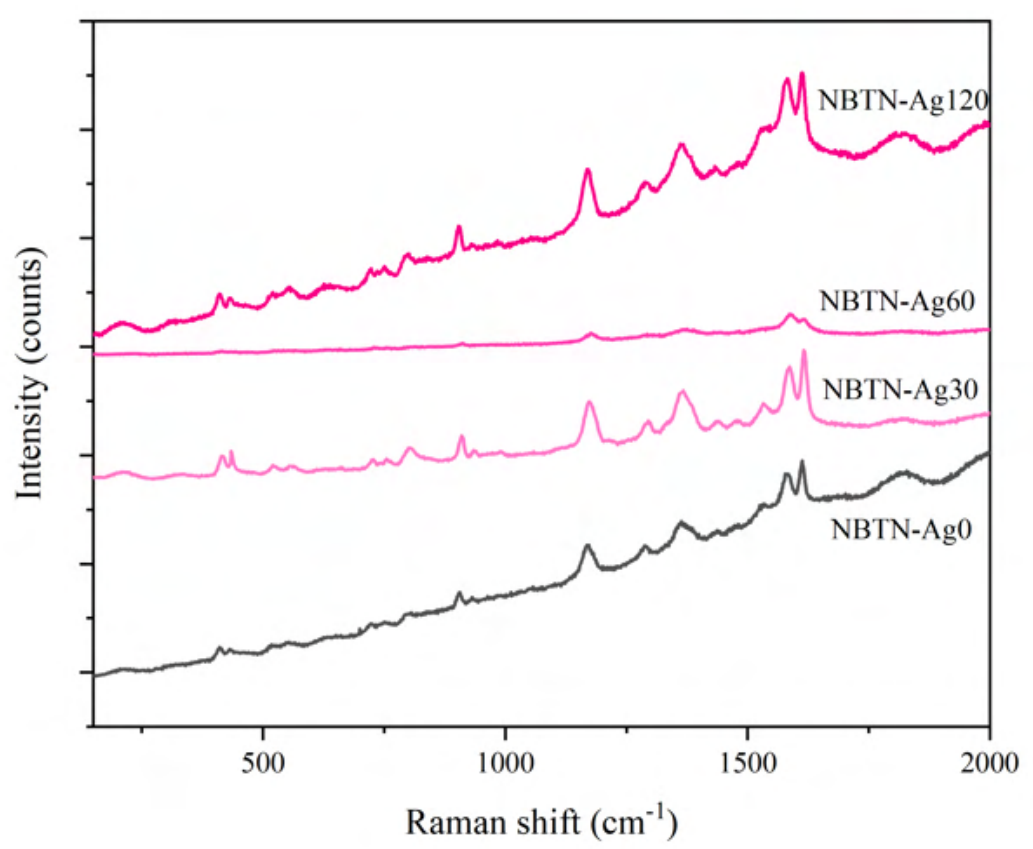

Figure 99 - Non-scaled spectra for comparison of the effect of surface interaction with the glass samples on the intensity of the signals of $\mathrm{CV} 10^{-3} \mathrm{~mol} \mathrm{~L}^{-1}$. 


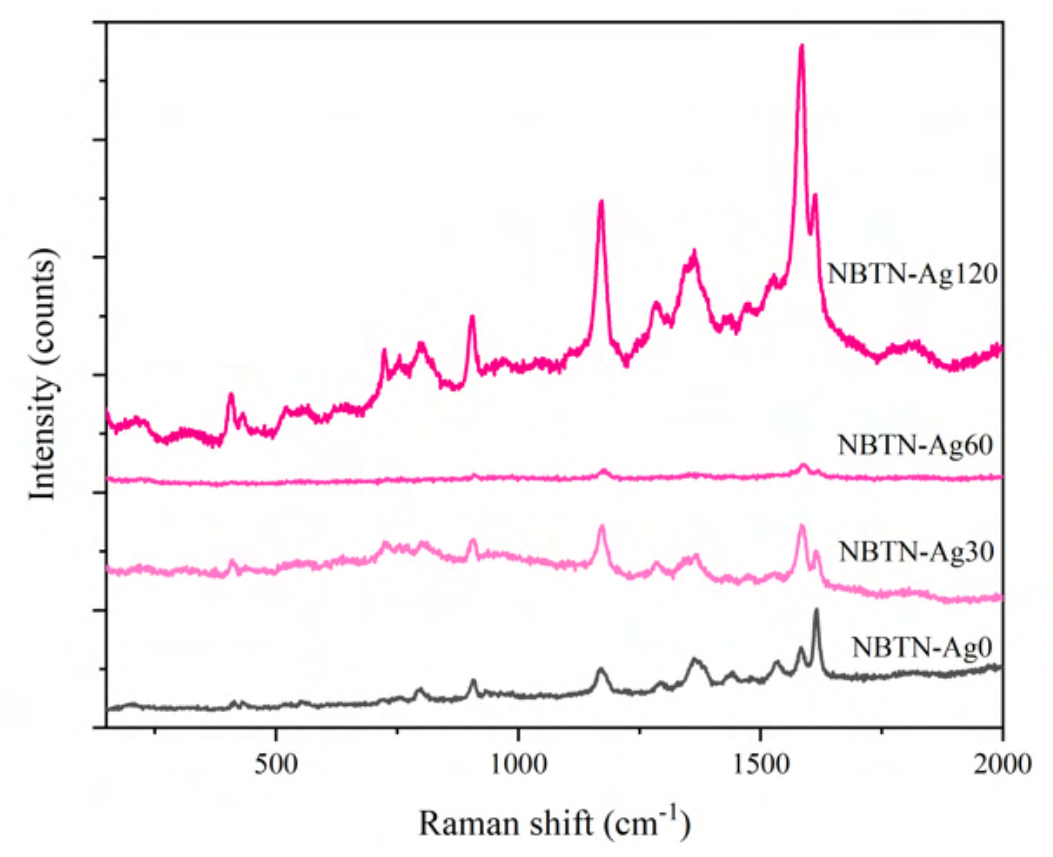

Figure 100 - Non-scaled spectra for comparison of the effect of surface interaction with the glass samples on the intensity of the signals of CV $10^{-5} \mathrm{~mol} \mathrm{~L}^{-1}$. 